\title{
Quantitative imaging of water flow in soil and roots using neutron radiography and deuterated water
}

\author{
to obtain the PhD. degree \\ in the Faculty of Agricultural Sciences, \\ Division of Soil Hydrology \\ Georg-August-University Göttingen, Germany \\ Presented by \\ Mohsen Zarebanadkouki, \\ 07. Sep. 1983, Iran
}

Accepted on recommendation of

Prof. Dr. Andrea Carminati.

Prof. Dr. Christoph Leuschner

Prof. Dr. Hans-Jörg Vogel 
Göttingen, 21 March 2013 
D7 )

Supervisor: Prof. Dr. Andrea Carminati.

Head of the Division of the Soil Hydrology

Georg-August University of Göttingen

Büsgenweg 2, 37077 Göttingen

Co-supervisor: Prof. Dr. Christoph Leuschner

Head of the Department Plant Ecology and Ecosystem Research

Georg-August University of Göttingen

Untere Karspüle 2, 37073 Göttingen

Examiner: Prof. Dr. Hans-Jörg Vogel

Head of the Department of Soil Physics

Helmholtz center for environmental science-UFZ

Theodor-Lieser-Straße 4, 06120 Halle (Saale)

Date of dissertation: 08 May 2013 



\section{Summary}

Where and how fast do roots take up water? Despite its importance in plant and soil sciences, there is limited experimental information on the location of water uptake along the roots of transpiring plants growing in soil. The answer to this question requires direct and in-situ measurement of the local flow of water into the roots. The aim of this study was to develop and apply a new method to quantify the local fluxes of water into different segments of the roots of intact plants. To this end, neutron radiography was used to trace the transport of deuterated water $\left(\mathrm{D}_{2} \mathrm{O}\right)$ into the roots of lupines.

Lupines were grown in aluminum containers filled with sandy soil. The soil was partitioned into different compartments using $1 \mathrm{~cm}$-thick layers of coarse sand as capillary barriers. These barriers limited the diffusion of $\mathrm{D}_{2} \mathrm{O}$ within the soil compartments. $\mathrm{D}_{2} \mathrm{O}$ was locally injected into the selected soil compartments during the day (transpiring plants) and night (nontranspiring plants). Transport of $\mathrm{D}_{2} \mathrm{O}$ into roots was then monitored by neutron radiography with spatial resolution of $100 \mu \mathrm{m}$ and time intervals of 10 seconds. Neutron radiographs showed that: i) transport of $\mathrm{D}_{2} \mathrm{O}$ into roots was faster during the day than during the night; 2) $\mathrm{D}_{2} \mathrm{O}$ quickly moved along the roots towards the shoots during the day, while at night this axial transport was negligible. The differences between day and night measurements were explained by convective transport of $\mathrm{D}_{2} \mathrm{O}$ into the roots. To quantify the net flow of water into roots, a simple convection-diffusion model was developed, where the increase rate of $\mathrm{D}_{2} \mathrm{O}$ concentration in roots depended on the convective transport (net root water uptake) and the diffusion of $\mathrm{D}_{2} \mathrm{O}$ into roots.

The results showed that water uptake was not uniform along the roots. Water uptake was higher in the upper soil layers than in the deeper ones. Along an individual roots, the water uptake rate was higher in the proximal segments than in the distal segments. In lupines most of the water uptake occurred in the lateral roots. The function of the taproot was to collect water from the laterals and transport it to the shoots. This function is ensured by a low radial conductivity and a high axial conductive.

We also applied the technique to measure how rhizosphere affects root water uptake. As was recently reported in the literature, in this study was also observed that the soil in the immediate vicinity of the roots, the so called rhizosphere, becomes hydrophobic as the soil dries. For the first time, it was shown that hydrophobicity of the rhizosphere decreased root water uptake after drying and subsequent irrigation. It was concluded that, after drying, the 
rhizosphere became a significant resistance to the local flow of water into the roots. This may change the pattern of the water uptake zone along the roots.

The significance of this study is the development of a new method to locally quantify water flow into roots of living plants. This method makes it possible to quantitatively measure where and how fast roots take up water in soils. This technique will allow understanding the function of roots in different plants, during root maturation and in response to varying external conditions, such as water content, transpiration demand, nutrient supply, and many other factors. The answer to these questions would open wide ranges of agronomy applications aimed at managing irrigation practice. 


\section{Zusammenfassung}

Wo und wie schnell nehmen Wurzeln Wasser auf? Obwohl diese Frage in Pflanzen- und Bodenwissenschaften von großer Bedeutung ist, gibt es nur wenige experimentelle Daten darüber, an welcher Stelle der Wurzeln eine transpirierende Pflanze das Wasser aus dem Boden erhält. Die Antwort auf diese Frage erfordert direkte und in-situ Messungen des lokalen Wasserflusses in die Wurzel hinein. Ziel dieser Arbeit war es, eine neue Methode zu entwickeln und anzuwenden, um den lokalen Wasserfluss in unterschiedliche Segmente der Pflanzenwurzeln zu quantifizieren.

Dabei wurde Neutronenradiographie eingesetzt um den Transport von deuteriertem Wasser $\left(\mathrm{D}_{2} \mathrm{O}\right)$ in die Wurzel von Lupinen zu untersuchen.

Die Lupinen wuchsen in Aluminium Containern, die mit sandigem Boden gefüllt waren. Der sandige Boden wurde mit Hilfe von $1 \mathrm{~cm}$-dicken Schichten groben Sandes in verschiedene Bereiche eingeteilt. Diese Schichten reduzierten die Diffusion von $\mathrm{D}_{2} \mathrm{O}$ zwischen den verschiedenen Bereichen. $\mathrm{D}_{2} \mathrm{O}$ wurde in ausgewählte Bereiche tagsüber (transpiriende Pflanzen) und nachts (nicht transpiriernde Pflanze) injiziert. Transport von $\mathrm{D}_{2} \mathrm{O}$ in die Wurzeln hinein wurde durch Neutronenradiographie mit einer räumlichen Auflösung von 100 $\mu \mathrm{m}$ in Intervallen von 10 Sekunden aufgezeichnet. Die Messungen zeigten: i) Transport von $\mathrm{D}_{2} \mathrm{O}$ in die Wurzel hinein war tagsüber schneller als nachst; ii) $\mathrm{D}_{2} \mathrm{O}$ wurde tagsüber schnell entlang der Wurzel in Richtung Spross transportiert, während dieser axiale Fluss nachts vernachlässigbar war. Die Unterschiede zwischen Tag- und Nachtmessungen wurden durch konvektiven Transport von $\mathrm{D}_{2} \mathrm{O}$ in den Wurzeln erklärt. Um den effektiven Wasserfluss in die Wurzeln hinein zu quantifizieren, wurde ein einfaches Konvektions-Diffusions Modell entwickelt, wobei die Zunahme der $\mathrm{D}_{2} \mathrm{O}$ Konzentration in Wurzeln vom konvektiven Transport abhängt und von the Diffusion des $\mathrm{D}_{2} \mathrm{O}$ in die Wurzeln.

Die Ergebnisse zeigten, dass die Wasseraufnahme nicht gleichmäßig entlang der Wurzel stattfindet. Die Wasseraufnahme war in den oberen Bodenschichten höher als in den tieferen. Entlang einzelner Wurzeln war der radiale Fluss in nahen Teilen der Wurzel höher als in den weiter entfernten Teilen der Wurzel. In Lupinen fand die Wasseraufnahme im Wesentlichen in den lateralen Wurzeln statt. Die Funktion der Pfahlwurzel war es, das Wasser der lateralen Wurzeln zu sammeln und zum Spross zu transportieren. Diese Funktion wird durch eine geringe radiale und eine hohe axiale Leitfähigkeit sichergestellt. 
Wir haben diese Technik auch angewandt um den Einfluss der Rhizosphäre auf die Wasseraufnahme zu untersuchen. Wie vor Kurzem auch in der Literatur berichtet wurde, wurde auch in dieser Arbeit beobachtet, dass der Boden in der unmittelbaren Nähe der Wurzeln, der sogenannten Rhizosphäre, hydrophob wird, wenn der Boden trocken wird. Zum ersten Mal konnte gezeigt werden, dass durch die Hydrophobizität der Rhizosphäre die Wasseraufnahme nach Trocknung und folgender Bewässerung reduziert wird. Es wurde die Schlussfolgerung gezogen, dass nach Trocknung die Rhizosphäre einen entscheidenden Wiederstand für den Wasserfluss zur Wurzel darstellt. Das beeinflusst vermutlich auch die Ausdehnung des Bereiches der Wurzeln, in dem Wasser aufgenommen wird.

Die Bedeutung dieser Arbeit ist die Entwicklung einer neuen Methode, um Wasseraufnahme durch Wurzeln lebender Pflanzen lokal zu quantifizieren. Diese Methode macht es möglich quantitativ zu messen, wo und wie schnell Wurzeln Wasser im Boden aufnehmen.

Diese Technik wird es erleichtern, die Funktionsweise der Wurzeln verschiedener Pflanzen zu verstehen und den Einfluss von Wurzelwachstum und wechselnder äußerer Bedingungen, wie Wassergehalt, Transpiration und Verfügbarkeit von Nährstoffen und vieler weiterer Faktoren zu untersuchen.

Die Antwort auf diese Fragen könnten einen weiten Bereich für landwirtschaftliche Anwendungen eröffnen, die darauf abzielen, Bewässerungsmethoden $\mathrm{zu}$ verbessern. 


\section{Acknowledgement}

Firstly, I would like to express my deep gratitude to Prof. Dr. Andrea Carminati, my supervisor, for his numerous supports and encouragements throughout my study. Above of all, I would like to thank for his great understanding and friendship. I feel very lucky to have had him as my supervisor.

I thank the members of my PhD committee, Prof. Dr. Christoph Leuschner and Prof. Dr. Hans-Jörg Vogel for agreeing to supervise and examine my PhD thesis.

I appreciate very much the scientific and friendly supports of Dr. Yangmin Kim during my study. I would like to thank her in particular for introducing me to the late Prof. Dr. Ernst Steudle who stands in my mind as a great icon in the scientific community.

My warmest gratitude and enormous thanks go to Dr. Ahmad Moradi for his scientific and friendly supports during my study. Above of all, I thank him for informing me about this position and supporting me to get this position. I also thank Prof. Dr. Majid Afyuni who introduced me to Dr Ahmad Moradi. Their great supports and encouragements throughout the study are highly appreciated.

My enormous thanks go to Prof. Dr. Sascha Ostwald and Prof. Dr. Hans-Jörge Vogel for hosting me at the Helmholtz Center for Environmental Research, Halle (Saale) in early stages of study.

My thanks also go to members of Paul Scherer Institute (PSI) of Switzerland for the precious technical supports during the measurements with neutron radiography.

I offer my deepest sense of acknowledgement to my beloved wife, Mina Moghani for her unconditional supports and encouragements during last years. I also thank my little girl, Ronia for blessing me with her birth during the writing of the thesis.

The financial support of the IPSWaT scholarship program (under stipendium IPS 11/Q04) from the German Federal Ministry of Education and Research (BMBF) is gratefully acknowledged.

\section{Mohsen Zarebanadkouki}

Göttingen, Germany, 21 March 2013 



\section{Table of Contents}

\section{Chapter 1}

Introduction.

Why we need to study root water uptake ................................................................ 1

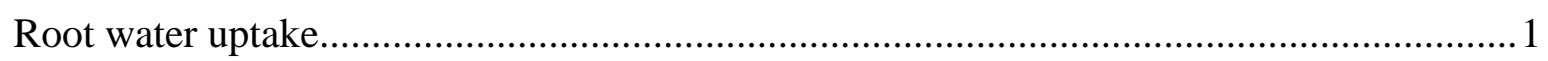

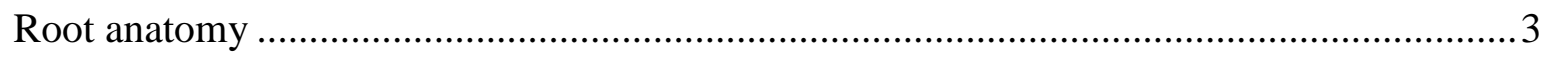

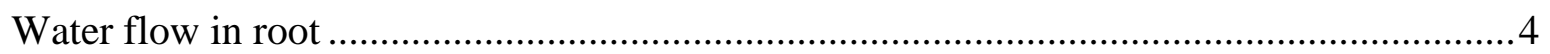

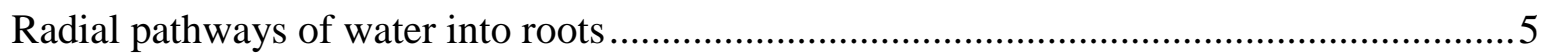

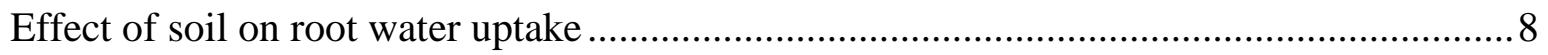

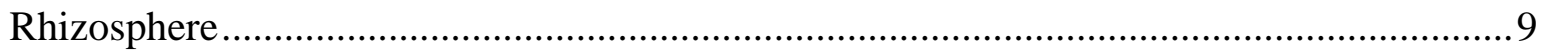

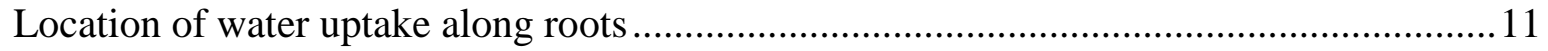

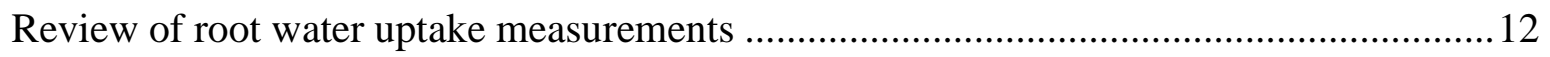

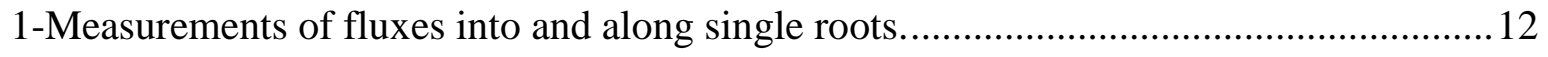

2-Measurement root water using potometer ......................................................... 14

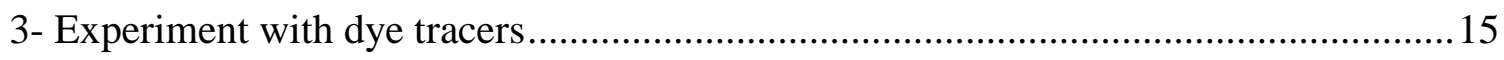

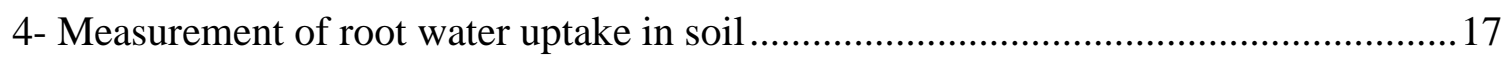

5- Measurement root water using heat-based sap flow gauges .................................... 18

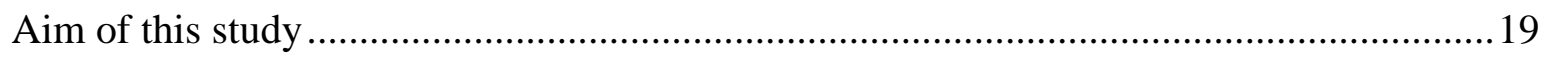

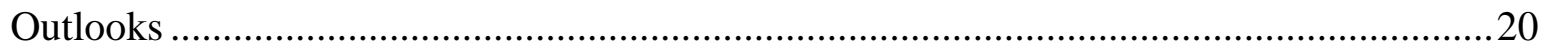

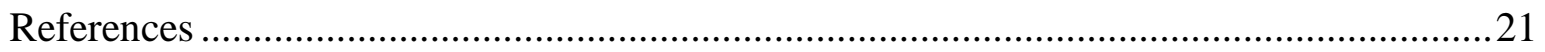

\section{Chapter 2}

Quantification and modeling of local root water uptake using neutron radiography and deuterated water ................................................................................................................................... 27

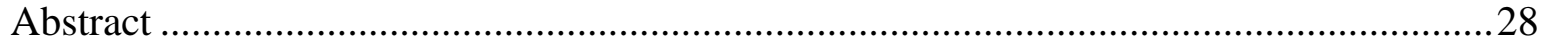

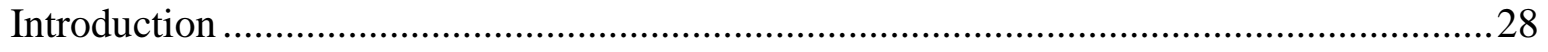

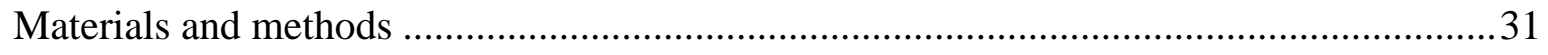




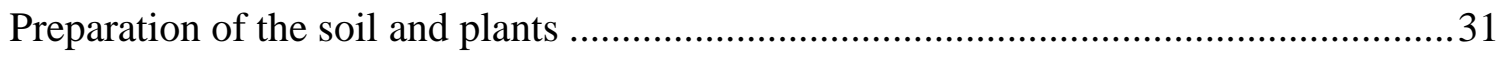

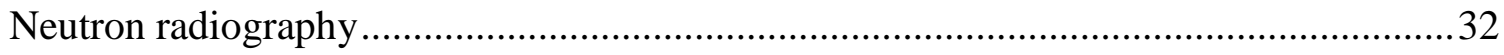

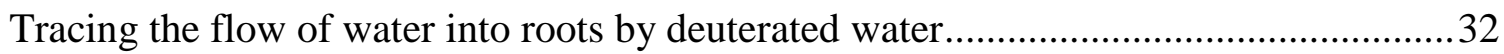

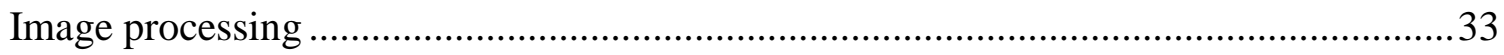

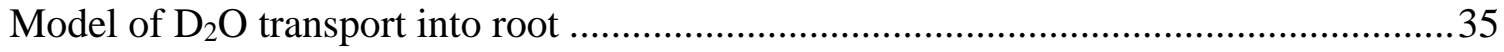

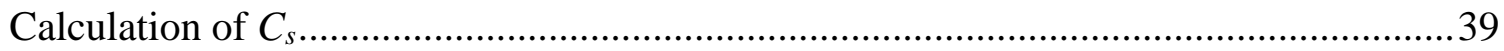

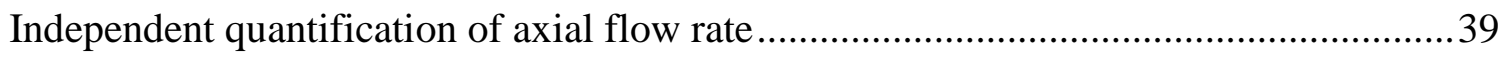

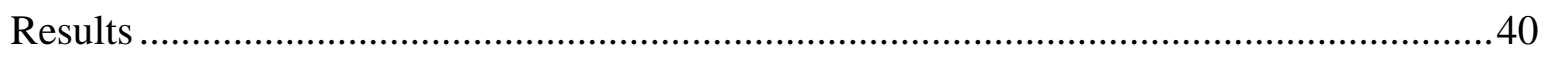

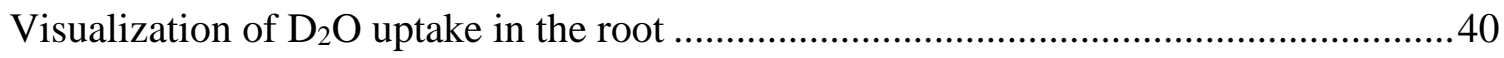

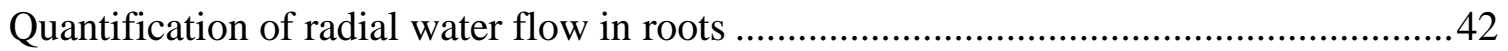

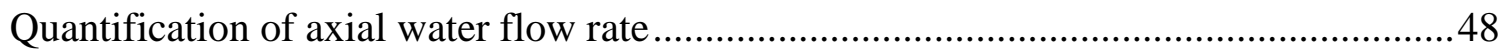

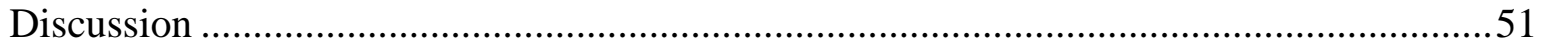

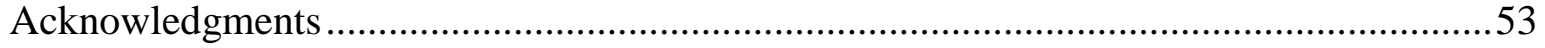

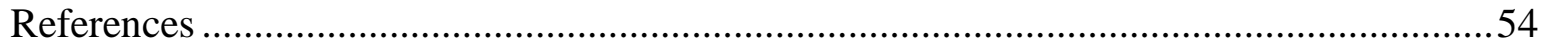

\section{Chapter 3}

Where do roots take up water? Neutron radiography of water flow into roots of transpiring plants growing in soil.....................................................................................................59

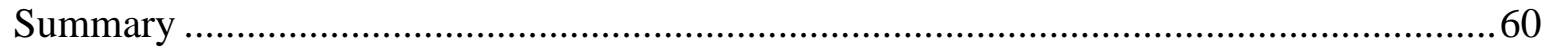

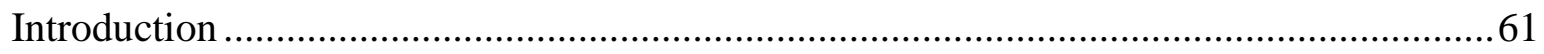

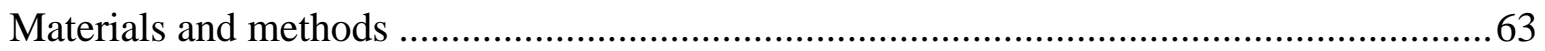

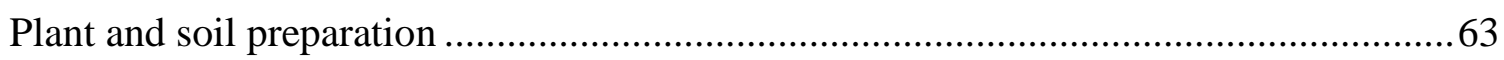

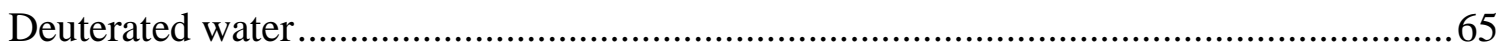

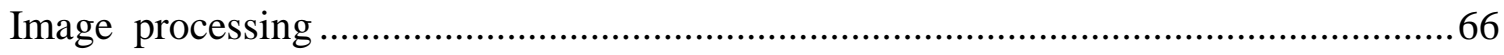

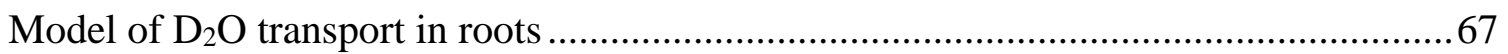

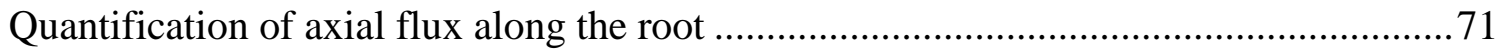

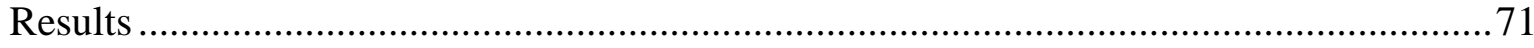

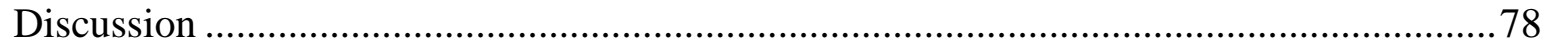


Appendix A: Derivation of the model of $\mathrm{D}_{2} \mathrm{O}$ transport into roots

Appendix B: $\mathrm{D}_{2} \mathrm{O}$ concentration in the roots: experimental results and best fits with single

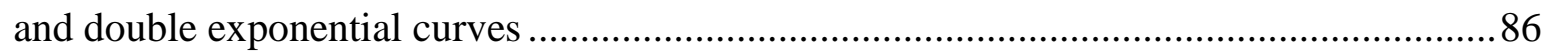

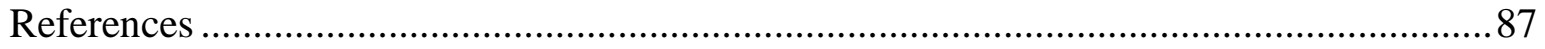

\section{Chapter 4}

Reduced root water uptake after drying and rewetting ................................................. 91

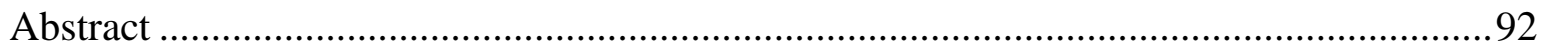

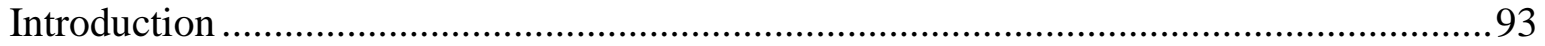

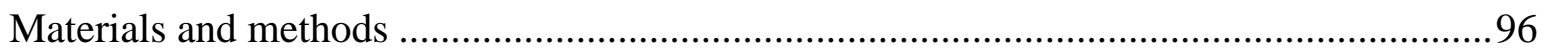

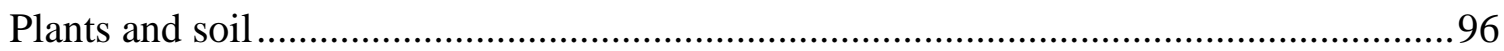

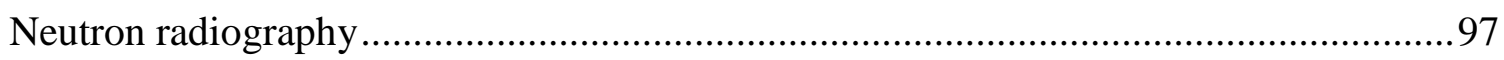

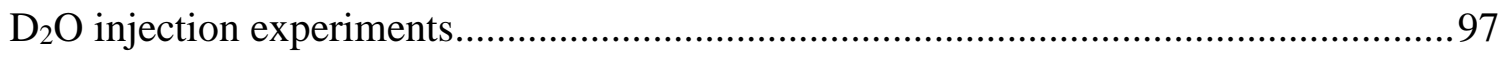

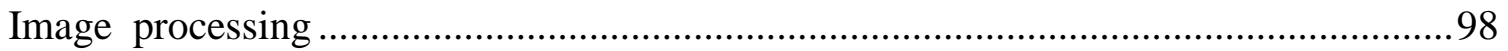

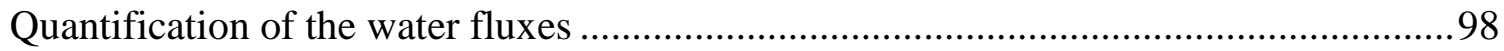

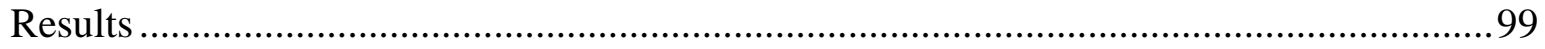

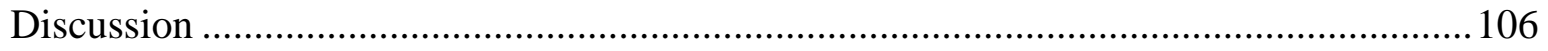

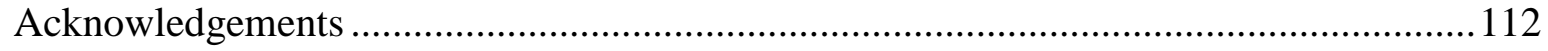

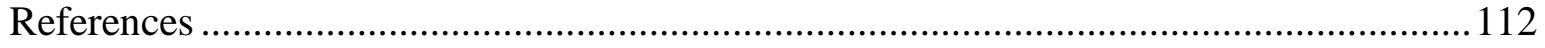

\section{Chapter 5}

A method to measure hydraulic conductivity of the rhizosphere after drying

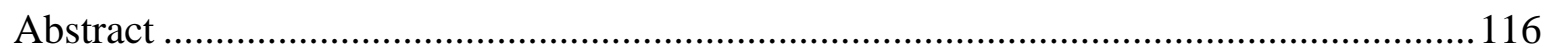

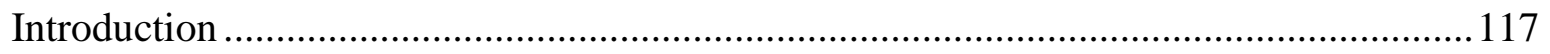

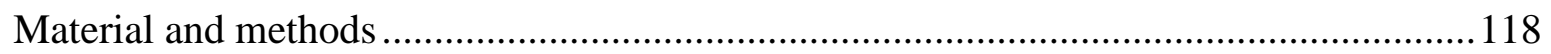

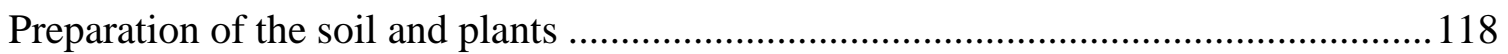

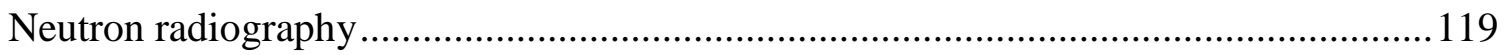

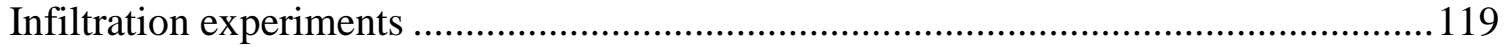

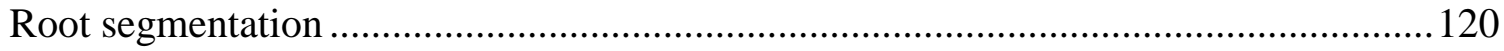


Quantification of water content in the bulk soil ...................................................... 120

Quantification of water content in the rhizosphere …................................................ 121

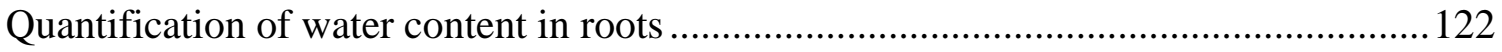

Effective hydraulic conductivity of the rhizosphere.................................................. 122

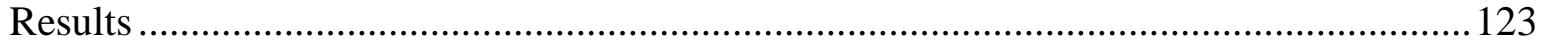

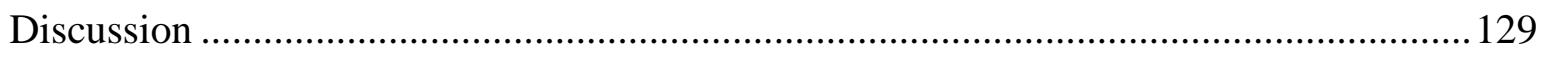

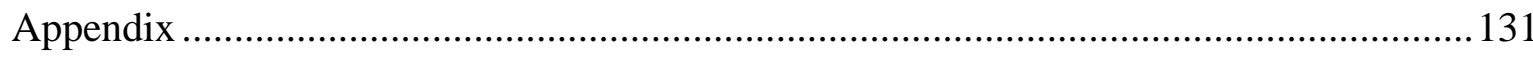

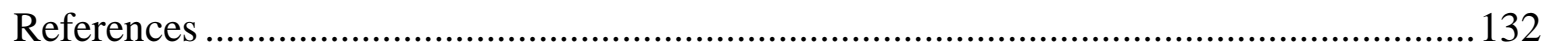

\section{Chapter 6}

Final conclusions

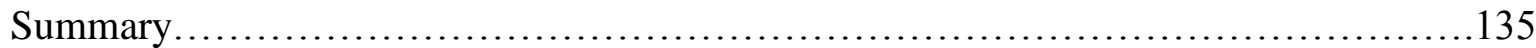

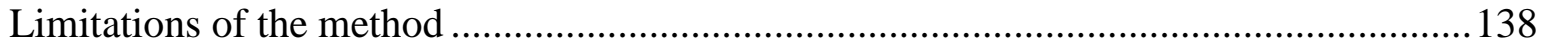

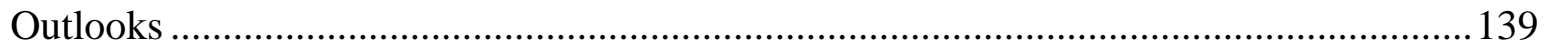

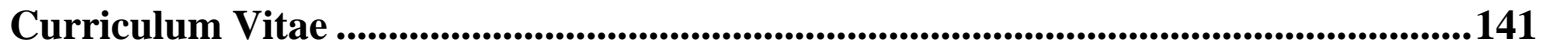




\section{List of Figures}

\section{Chapter 1}

Figure 1: radial pathways of water into roots.

Figure 2: Measured and calculated value of water uptake along a $20 \mathrm{~cm}$ excised root of Maize.

Figure 3: Water uptake of different location of roots along the seminal axes of barley, at two air humidity regimes, in relation to the development of the endodermis. .15

Figure 4: Water flux into different locations of roots along the axes and branches of mature maize grown in aeroponic culture. .17

\section{Chapter 2}

Figure 1: Illustration of $\mathrm{D}_{2} \mathrm{O}$ transport in root. .38

Figure 2: Neutron radiographs of the samples at night and day..... 41

Figure 3: Neutron radiographs of the samples before $\mathrm{D}_{2} \mathrm{O}$ injection and after injection 42

Figure 4: Average $\mathrm{D}_{2} \mathrm{O}$ concentration in the soil near the roots after injecting $3 \mathrm{ml}$ of $\mathrm{D}_{2} \mathrm{O}$ during night and day measurement. .44

Figure 5: Average $\mathrm{D}_{2} \mathrm{O}$ concentration in roots after $\mathrm{D}_{2} \mathrm{O}$ injection during the night and day in the root tip, and in stele after excluding cortex contribution during the night and day......

Figure 6: Total volume of $\mathrm{D}_{2} \mathrm{O}$ passing the barrier as a function of time after $\mathrm{D}_{2} \mathrm{O}$ injection and total volume of $\mathrm{D}_{2} \mathrm{O}$ passing the barrier divided by the concentration in the root at the barrier . Linear regression of the data in the right figure yielded the axial water flow rate. ...50

\section{Chapter 3}

Figure 1: Illustration of $\mathrm{D}_{2} \mathrm{O}$ transport into a root that is partially immersed in $\mathrm{D}_{2} \mathrm{O}$

Figure 2: Neutron radiographs of one sample before and after injection of $4 \mathrm{ml} \mathrm{D}_{2} \mathrm{O}$ during daytime

Figure 3: Neutron radiographs of one sample before $\mathrm{D}_{2} \mathrm{O}$ injection and after injection at nighttime.

Figure 4: Increase of $\mathrm{D}_{2} \mathrm{O}$ concentration inside roots (a), and volume of $\mathrm{D}_{2} \mathrm{O}$ passing beyond the barrier (b) .76

Figure 5: Scheme of the root system showing the distribution of the radial fluxes, $\mathrm{j}_{\mathrm{r}},\left[\mathrm{m} \mathrm{s}^{-1}\right]$ calculated with Eq. (3.5). 
Figure 6: Axial fluxes, $\left[\mathrm{m} \mathrm{s}^{-1}\right]$, in long and medium roots calculated from the model (Eq. 3.5, solid arrows above roots) and directly obtained from radiographs (Eq. 3.7, dashed thin arrows below roots).

Figure 7: Measured $\mathrm{D}_{2} \mathrm{O}$ concentration inside the roots and the best-fit lines using a single and double exponential equation. .86

\section{Chapter 4}

Figure 1: Hypothetical water distribution in the rhizosphere during drying and wetting including mucilage dynamics .94

Figure 1: Neutron radiograph of a sample one hour after irrigation with normal water.. .95

Figure 1: Schematic cross-section of root (black), rhizosphere (dark gray) and bulk soil (light gray).

Figure 2: Neutron radiographs of sample after a drying period and after rewetting at time $t$ during nighttime

Figure 3: The profile of water content as a function of distance to roots after irrigation in different roots.

Figure 4: Average water content in the rhizosphere and in the bulk soil after infiltration....127

Figure 5: a) Change in volume of roots after irrigation. (b) Volume-pressure curve of the Lupine roots parameterized according to Eq. (5.7)

Figure 6: Effective hydraulic conductivity of the rhizosphere as a function of time after irrigation (a), and as a function of water content in the rhizosphere (b). 128

Figure 7: Neutron radiographs of a sample after rewetting at time $t$ 131 


\section{List of Tables}

\section{Chapter 2}

Table 1: Properties of the segmented roots and $\mathrm{D}_{2} \mathrm{O}$ transport parameters fitted by an exponential function for night measurement. ................................................................... 47

Table 2: Properties of the segmented roots and $\mathrm{D}_{2} \mathrm{O}$ transport parameters fitted for day measurement.

\section{Chapter 3}

Table 1: Diffusional permeability of cortical cells, $\mathrm{P}_{\mathrm{D}, \mathrm{c}},\left[\mathrm{m} \mathrm{s}^{-1}\right]$, and endodermis, $\mathrm{P}_{\mathrm{D}, \mathrm{e}},\left[\mathrm{m} \mathrm{s}^{-1}\right]$, along lateral roots

\section{Chapter 5}

Table 1: Mualem-van Genuchten parameters for the bulk soil. 

Introduction 



\section{Why we need to study root water uptake}

All organisms, including plants, require water for their survival. Water has numerous vital functions in plant life such as major constituent of living cells, maintaining cell turgidity, providing a transport medium, serving as a raw material for various chemical processes, heat dissipater through transpiration, and buffering plants against temperature changes (Kudrev, 1988; Kirkham, 2005). Plants as a big water mover on the earth return approximately, $40 \%$ of the terrestrial precipitation to atmosphere via transpiration (Bengough, 2012). Root water uptake is the gateway to replace water lost by transpiration.

Inadequate supply of water from soil is a worldwide constraint to plant yield and food production. Increasing population and periodic droughts due to reduced rainfall frequency (Gallagher et al., 1976; Laraus, 2004; Oki \& Kanae, 2006; Miraglia et al., 2009) are expected to increase the alarm of water scarcity. Due to the high water consumption in agriculture, improved water use efficiency has been recommended as a needed management practice (Laraus, 2004; Oki \& Kanae, 2006). Water use efficiency is the ability of plants to convert water into biomass (Stanhill, 1986; Howell, 2001). Besides improving the productivity of plant species, an irrigation practice that is capable of increasing the soil water content in the regions where roots are more active in root water uptake, while reducing water loss by evaporation and deep infiltration, will improve the water use efficiency in agriculture. To this end, we need to know where roots take up water in soil.

\section{Root water uptake}

Water moves from soil to plants and then to the atmosphere following an increasingly negative water potential in the process called transpiration. Water moves into and within plants in liquid form and it leaves the plant as vapor through the leaf stomata. Stomata are cavities open to atmosphere during the daytime to facilitate the entry of $\mathrm{CO}_{2}$ for photosynthesis. When stomata are open, water evaporates from the leaf tissue to the atmosphere. According to the cohesion-tension theory, water lost from leaves generates a tension in water that is transmitted along the xylem down to the roots. The resulting gradient in water potential between roots and soil drives water into the roots. Water supply to leaves depends on maintenance of a continuing column of water in the xylem from roots to shoots (Holbrook et al., 1995; Walker et al., 2003; Koch et al., 2004). When transpiration is low, 
osmotic adjustment in plants by accumulation or removal of solutes in the xylem can move water into and within the roots (Steudle \& Peterson, 1998). Water flow from the soil into the roots must continuously compensate the water lost from leaves. A non-sufficient root water uptake will gradually decrease water potential in the xylem. An imbalance between root water uptake and water lost from the leaves may cause dehydration of the root tissues (Zimmermann et al., 1992; Holbrook et al., 1995; Koch et al., 2004). To avoid dehydration, plants may reduce the rate of water loss from leaves by regulation of the stomata conductance (Schulze, 1986; Saliendra et al., 1995; Chaves et al., 2003) and/or increase water uptake from the roots. The increase of water uptake may occur by increasing the permeability of roots (Moshelion et al., 2004; Knipfer et al., 2011), and/or enhancing the growth rate of the roots to explore new sources of water (Dale \& Causton, 1992; Dias-Filho, 1995).

The concept of water movement in plants is often described analogous to electricity flux (Ohm's and Kirchhoff's laws). Applying these laws to plants, the flux of water into plants depends on the difference in water potential between soil and roots as driving force and the resistivity of the soil-root-atmosphere continuum. The hydraulic resistance is a parameter that describes how difficult it is for water to pass a certain cross section. It is the inverse of conductance. The flow of water from the soil into plants and then to the atmosphere occurs through different pathways in series with different resistances. When the pathways are in the series, the resistances of the pathways are additive, while when they are in parallel the inverse of their resistances is additive. In whole plant level, flow of water from soil to plant and then atmosphere, $J_{t},\left(\mathrm{~cm}^{3} \mathrm{~s}^{-1}\right)$, can be written as

$$
j_{t}=\frac{1}{\left(R_{\text {soil }}+R_{\text {root }}+R_{\text {shoot }}+R_{\text {leaf }}+R_{\text {stomata }}\right)}\left(\psi_{\text {soil }}-\psi_{\text {atmosphere }}\right)
$$

when $\Psi$ denotes water potential (MPa) and $\mathrm{R}$ is resistance $\left(\mathrm{cm}^{3} \mathrm{MPa}^{-1} \mathrm{~s}^{-1}\right)$. Typically, the hydraulic resistance in the leaves is the biggest resistance. Then the resistance occurring in the roots is the second biggest resistance to flow of water.

In the case of roots grown in the soil, the process of root water uptake is more complex than what it may appear in Eq. (1.1). Draye et al. (2010) summarized typical values of soil and root hydraulic conductivities as a function of water potentials. Their review shows that when the soil is wet, its hydraulic conductivity is typically sufficient to sustain the transpirational demand and the root resistance controls the flow of water. As the soil dries, its hydraulic conductivity decreases of several orders of magnitudes and the soil becomes the limiting 
factor in the water flow into roots (Gardner, 1960; Passioura, 1988; Garrigues et al., 2006; Draye et al., 2010).

Acquiring a proper knowledge on root water uptake requires good understanding of the root structure, the pathways of water into the roots, and functioning of roots in response to their environments. In the following sections, we briefly review the basic structure of roots with regard to water transport, the pathways of water into the roots, and the effects of soil on root water uptake.

\section{Root anatomy}

The hydraulic properties of roots are related to the anatomy of roots, and there is no way to understand the transport of water into roots and root functioning in response to external factors without sufficient knowledge of their structure and its dynamics (Huang \& Eissenstat, 2000; Steudle, 2000). Water taken up from soil has to cross a series of cell layers before reaching the xylem vessels where it is transported towards the shoots. These cell layers (from outside to inside) are epidermis, cortex, endodermis and the root stele (Enstone et al., 2003). In many plants if not all, the root endodermis is considered as a major resistance to flow of water and solute into the roots (Perumalla \& Peterson, 1986; Peterson et al., 1993; Steudle, 2000). The endodermis separates the root cross section into two compartments: the root cortex and the root stele. The outermost compartment is the root cortex and consists of many parenchyma cells called cortical cells. The innermost compartment is the root stele and consists of conducting vessels (xylem and phloem) surrounded by parenchyma cells.

The outermost layer of the cortex is the epidermis, which is a single layer of elongated and tightly packed cells from which originates root hairs and cluster roots. The overall quantity and longevity of root hairs and cluster roots varies among plant species and depends also on the interaction with the soil environment. In some plants, a second layer of cells may originate from the epidermal cells called the hypodermis. The exodermis is a special type of hypodermic cells that are subjected to different cell modifications such as formation of casparian bands in the anticlinal walls or deposition of suberin lamella at the surface of cells. These modifications usually occur in the late developmental stages of roots. External adverse conditions such as water stress may stimulate these modifications (Perumalla \& Peterson, 1986; Reinhardt \& Rost, 1995; Enstone et al., 2003). 
The innermost layer of the cortex enclosing the stele is called endodermis. Endodermis is a single layer of elongated and tightly packed cells that develop casparian bands in the anticlinal walls and suberin lamella (deposition of hydrophobic covering around the cell as a secondary wall). In most plants, casparian bands form within $1 \mathrm{~cm}$ from the root tip. The effectiveness of casparian bands in the water flow is highly variable among different plants and depends on the growth conditions. Enstone et al. (2003), speculated that casparian bands block the passive transport of ions from soil into the roots and prevent the back diffusion of ions and water into the soil. In addition to formation of casparian bands, the surface of the endodermis is characterized by deposition of hydrophobic components (suberin lamellae). Unlike casparian bands, suberin lamellae only reduce permeability of cell-to-cell pathways of roots.

Strong modification of the endodermis cells, formation of casparian bands and suberin lamellae have been often observed when roots suffered of harsh external conditions such as water stress. These evidences confirmed positive adaptive functions of these formations in improving the water status of the plant. Water and nutrient shortage, salinity stress and pathogenic attack cause an earlier and denser formation of casparian band and suberin lamella (Nobel \& Cui, 1992; McCully, 1995; Enstone et al., 2003; Hu et al., 2011). However, both casparian bands and suberin lamella do not occupy the endodermal and exodermal cells completely. Casparian bands rarely occupy more than 1/3-1/2 of the anticlinal walls (Enstone et al., 2003). Lack of presence of casparian bands even in some portion of the root endodermis may be enough to facilitate the flow of water through apoplastic pathways. Although, presence of casparian bands and suberin lamella are easily detectable by microscopic investigation of root cross section, the quantitative effect of them on the flow of water into roots is not resolvable.

\section{Water flow in root}

Root water uptake is often described in terms of radial and/or axial flow. The axial flow refers to the movement of water along the xylem. The axial flow, $J_{x},\left(\mathrm{~cm}^{3} \mathrm{~s}^{-1}\right)$, can be described as

$$
J_{x}(x)=-\frac{1}{R_{x}} \cdot \frac{d \psi_{x}(x)}{d x}
$$


where $R_{x}$ is the xylem axial resistance $\left(\right.$ bar s $\mathrm{cm}^{-4}$ ), $\Psi_{x}$ is water potential in the xylem (bar) and $x$ is location along the xylem. Axial flow of water can be calculated by Poiseuille's law where the xylem vessels of roots are considered as continuous conduits. According to this law, the size and abundance of the xylem vessels determine the axial resistance of root (Frensch \& Steudle, 1989; McCully, 1995; Bramley et al., 2009). However, the measurement of the axial resistance showed that actual axial resistance (flow rate) occurring along roots differed from the one calculated by Poiseuille's law (Frensch \& Steudle, 1989). The axial resistances along roots are commonly measured by root pressure probe and high-pressure flow meter technique.

Typically, axial resistance in the apical parts of the root is high, resulting in hydraulic isolation of the root apex. As root matures, the axial resistance in xylem decreases due to the increasing size and abundance of the xylem vessels (Frensch \& Steudle, 1989; McCully, 1995; Bramley et al., 2009). Additionally, as root elongates the axial resistance increases due to a longer pathway of water (Landsberg \& Fowkes, 1978; Zwieniecki et al., 2003).

The radial flow, $J_{r},\left(\mathrm{~cm}^{3} \mathrm{~s}^{-1}\right)$ is defined as flow of water from soil into the xylem crossing a set of concentric layers in the root tissue. The water potential difference between xylem and root is the driving force of water. The radial flow can be written as

$J_{r}=\frac{\left(\psi_{s}-\psi_{x}\right)}{R_{x}}$

where $R_{r}$ is the radial resistance (bar s cm${ }^{-3}$ ), $\Psi_{x}$ is water potential in the xylem (bar) and $\Psi_{x}$ is water potential in soil (bar). The radial resistance of roots varies along root system during root development and responses to external conditions such as drought stress. The measure of radial resistance and radial flow of water into root depends on the pathways of water into the roots (Frensch \& Steudle, 1989; Steudle \& Peterson, 1998; Knipfer \& Fricke, 2010b).

\section{Radial pathways of water into roots}

Water has to cross root tissue before reaching the xylem vessels. The structure of root tissue results in composite pathways of water flow into the roots (McCully \& Canny, 1988; Steudle, 2000). The main pathways of water into roots are apoplastic pathway, symplastic pathway and transcellular pathway (Fig. 1). The apoplastic pathway occurs through the cell walls and the extracellular spaces. Apoplast is a free diffusional space. The symplastic pathway occurs 
across the cytoplasm interconnected by plasmodesmata. Plasmodesmata are narrow strands of cytoplasm that interconnect the protoplasts of neighboring plant cells. In the transcellular pathway, water crosses the cell membrane by diffusing through cell membranes. In the symplastic pathway, water flow between cells is facilitated by the presence of plasmodesmata, whereas in the transcellular pathway water has to cross the cellular membranes. To date, it has been difficult to separate symplastic and transcellular pathways experimentally and therefore they are commonly referred to as cell-to cell pathway.

Besides difficulties in separating two components of cell-to-cell pathway, the relative importance of the apoplastic pathway and cell-to-cell pathway in transport of water into roots has also been matter of big debates for decades (McCully \& Canny, 1988; Canny, 1995; Magnani et al., 1996; Steudle, 2000; Fritz \& Ehwald, 2011). The relative importance of these two pathways depends on plant species, developmental stage of the plant, growth condition, and nature of water flow (osmotic or hydrostatic). Casparian bands in the endodermis and the exodermis influence the contribution of the apoplastic pathway in transport of water. These structures play an important role in reducing the hydraulic conductance of apoplastic pathways and, depending on the relative importance of apoplastic pathway in transport of water, on the hydraulic conductance of te root system (Peterson et al., 1981, 1993; Enstone et al., 2003). The contribution of the cell-to-cell path to the overall hydraulic conductivity of the root is influenced by changes in the hydraulic conductivity of cell membranes. Suberization of the cell membranes following root maturation and/or in response to external conditions reduces the permeability of the root tissue (Peterson et al., 1981; McCully \& Canny, 1988; Knipfer \& Fricke, 2010a). Aquaporins in cell membrane also actively controls permeability of the cell-to-cell pathways and their regulation may reduce or increase the root permeability (Henzler \& Steudle, 1995; Maurel \& Chrispeels, 2001; Knipfer et al., 2011; McLean et al., 2011).

In the cell-to-cell transport, water has to cross several cell layers and two plasma membranes per cell layer, which results in a high hydraulic resistance. The transport of water can occur in a combination of pathways, in which water may travel through the apoplast for some distance and then cross the cell membrane and flow via the cell-to-cell pathway. Typically, apoplast is interrupted at the root endodermis. In the purely apoplastic pathway, water flows into the roots without involvement of any cell membranes. The possibility of a purely apoplastic pathway along root tissue up to the xylem is questionable. The fact that the roots can build up 
turgor pressure in the xylem indicates that at least one cellular membrane is interrupting the apoplastic pathway (Knipfer \& Fricke, 2010b).

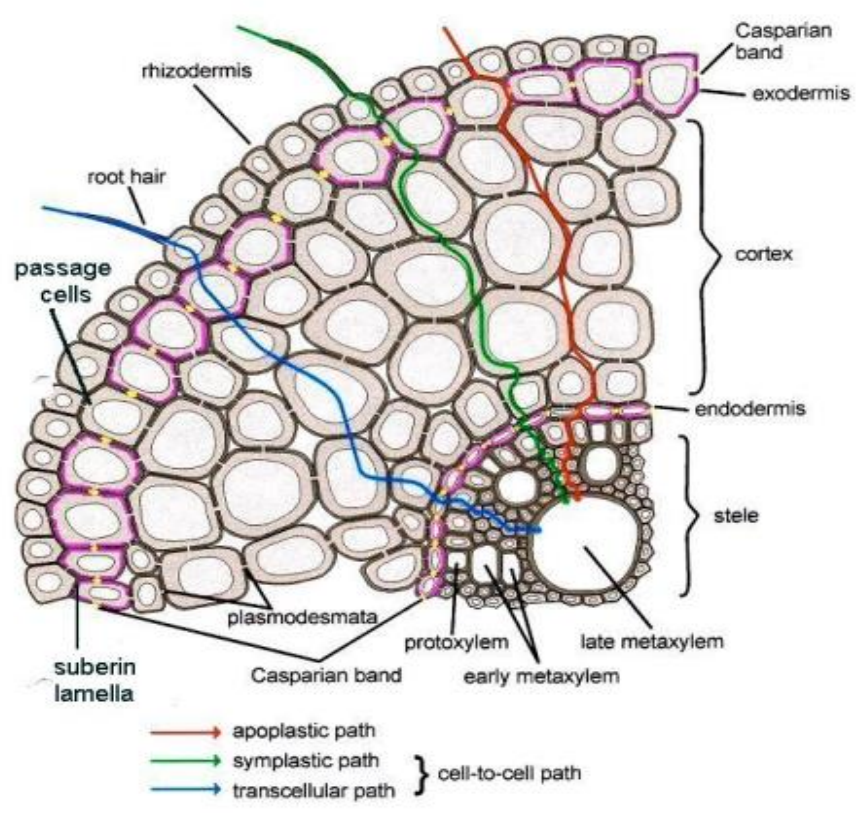

Figure 1: radial pathways of water into roots. The apoplast provide a diffusion free space to water flow through the cell walls and the extracellular spaces. Casparian bands in the endodermis and the exodermis may interrupt the apoplastic pathway. Symplastic pathway is the continuum of cytoplasm interconnected by plasmodesmata. In symplastic pathway, water flow into the cells occurs through the plasmodesmata. Plasmodesmata are narrow strands of cytoplasm that interconnect the protoplasts of neighboring plant cells. In transcellular pathway, water should cross the cell membrane by diffusing through cell membranes. Both symplastic and transcellular pathways may be interrupted by deposition of suberin lamella in the endodermis and the exodermis (from Ranathunge, 2005).

The transport of water along the apoplast is passive and it is driven by a gradient in hydrostatic potential. The transport of water through cell-to-cell pathway has also an osmotic component. In the absence of hydrostatic gradient between root and soil, water transport is occurring through the cell-to-cell pathway. During the night when transpiration is low, roots are in equilibrium with their surroundings (in well moist soil). In this condition, due to accumulation of solutes in the roots (transport of solute from leaves to roots trough phloem) water potential in the roots drops down and leads building up of gradient in water potential 
between roots and soil. This gradient pulls water into the roots via cell-to-cell pathway. This results in a high turgor pressure. The relative contribution of the apoplastic pathway to cellto-cell pathway may depend on the transpiration demand of plants. Switching between pathways is well described by Steudle (2000) who introduced a composite transport model to describe the transport of water into roots based on composite structure of roots. The volume of the apoplast is reported to contribute to $3-7 \%$ and the cell-to-cell pathway to more than $90 \%$ of the total root volume.

\section{Effect of soil on root water uptake}

The transport of water into roots is highly influenced by the radial permeability of the root tissue. Besides root maturation, plants may regulate their radial permeability in response to adverse external conditions such as water and nutrient shortage, salinity stress, physical stress, and extreme temperature in the soil (Peterson et al., 1981; Reinhardt \& Rost, 1995; Zimmermann \& Steudle, 1998; Enstone et al., 2003). It is well known that formation and density of casparian bands, suberin lamellae, and aquaporins are influenced by soil water content (Perumalla \& Peterson, 1986; Reinhardt \& Rost, 1995; Enstone et al., 2003).

Besides the effect of soil water content on the permeability of roots, supply of water to roots becomes limited when soil dries and its hydraulic conductivity decreases (Gardner, 1960; Landsberg \& Fowkes, 1978; Dousssan et al., 1998; Draye et al., 2010). Model calculations showed that as the soil becomes dry, significant gradients in water potential and water content develop near the root surface. The drop in water potential near the roots in the soil occurs because of the radial geometry of the flow to the roots and the nonlinearity of the unsaturated soil conductivity (Gardner, 1960; Dousssan et al., 1998; Carminati et al., 2011). Under this condition, the hydraulic conductivity of the soil near roots becomes the main resistance to flow of water into the roots. Model calculations showed that the reduction in hydraulic conductivity of soil occurs in the immediate vicinity of soil. Plants may regulate their resistance in response to the low water potential developed at their surface. To date, it has been very difficult to measure the water potential gradients near roots and most of the high temporal and spatial measurements relied on monitoring water content in soil. Under drying condition, a big drop in water potential may occur with only a tiny change in water content, which is not detectable with our devices. This is particularly true in sandy soil. 
In addition, the physical and biochemical properties of the immediate soil near the root, the so called rhizosphere is influenced by root exudation (Or et al., 2007b; Carminati et al., 2010; Moradi et al., 2012a). Recent observations on redistribution of water during the drying cycle of transpiring plant grown in soil showed that the rhizosphere was wetter than the bulk soil. During the rewetting phase, the rhizosphere stayed temporarily dry (Carminati et al., 2010). The first observation was explained by modification of the soil hydraulic properties by root exudation. The second observation was explained by the presence of lipid components in the root exudates. Lipids reduce wettability of the soil. How a hydrophobic rhizosphere may affect the flow of water into roots is still an open question. Answering to this question requires in situ measurement of water flux into roots.

\section{Rhizosphere}

Rhizosphere is defined as the soil in the immediate vicinity of the roots. Its physical and biochemical properties are actively modified by roots as well as by microorganisms living in symbiosis with the roots. Plants actively and constantly release various photosynthetic compounds into the soil. (Chenu \& Roberson, 1996; Gregory \& Hinsinger, 1999; Hinsinger et al., 2005; Gregory, 2006). One of the substances exuded from the roots is mucilage. Mucilage released by the peripheral cells of the root cap (both root tip and cluster roots) and is left behind following root maturation (Iijima et al., 2003; Nakaji et al., 2007).

There have been many speculations on the role of mucilage in relation to water status of plants. Mucilage exuded by the roots, with its high water holding capacity, may increase the water holding capacity of the rhizosphere (McCully \& Boyer, 2006). Mucilage contains many organic components in particular polysaccharides that stabilize soil aggregates. In addition to improving soil aggregation, the polysaccharides in mucilage form a continuous network that acts as a sponge and has a considerable capacity to absorb water. Water is absorbed and maintained in the network by osmotic, and capillary forces resulting in swelling of the matrix and increasing the water content (Gessa \& Deiana, 1990; Chenu, 1993; Chenu \& Roberson, 1996; Or et al., 2007). On the other hand, mucilage also contains lipids that can act as surfactants and alter the surface tension of water in soil. Change in surface tension will affect on water holding capacity of the soil, unsaturated hydraulic conductivities, and solute diffusion near to the root surface at any given soil matric potential. (Read \& Gregory, 1997; Czarnes et al., 2000; Hallett et al., 2003; Read et al., 2003; Whalley et al., 2005; Carminati et al., 2010; Moradi et al., 2012). The significance of rhizosphere hydrophobicity upon 
rewetting may vary with plant species, root age, growth conditions, soil water content, and number of wetting/drying cycles (Watt et al., 1994; Moradi et al., 2012).

Taking the advantage of new imaging techniques, experimental evidence of distribution of water content in the rhizosphere became recently more available. Currently, there are two different views on redistribution of water content around transpiring roots. MacFall et al. (1990) observed lower water content occurring first in the rhizosphere of the taproot and then extended to the laterals. Segal et al. (2008) also reported that the rhizosphere of two-week-old barley had lower water content than the bulk soil. In contrast to these findings, a higher water content in the rhizosphere has also been observed (Nakashi, 2005; Tumlinson et al., 2007; Carminati et al., 2010; Moradi et al., 2011). Carminati et al. (2010) investigated the redistribution of water in rhizosphere and bulk soil during a drying and wetting cycles. They observed higher water content in the rhizosphere than in the bulk soil during drying. They also observed a temporarily hydrophobic behavior of rhizosphere after rewetting. Hydrophobicity of rhizosphere recovered during the following days and water content of the rhizosphere increased and finally exceeded that of the bulk. However, literature information on profile of water content in the rhizosphere of roots is puzzling. Carminati, (2012) believed that two different views on the distribution of water around roots are not in contradiction and they rather reflect the dynamic and hysteretic hydraulic behavior of the rhizosphere. Depending on the history of the rhizosphere (state of hydration) and chemical composition of the mucilage exuded into soil, the rhizosphere may turn hydrophobic or hydrophilic.

At first glance, the effect of mucilage on increasing water holding capacity of the rhizosphere may seem insignificant due to the small size of rhizosphere (around 1-2 $\mathrm{mm}$ ) and the high water demand of plants. However, mucilage may have an important role in controlling the flux of water into the roots, in particular as soil dries. Increase the water-holding capacity of the rhizosphere may increase the hydraulic conductivity by avoiding the formation of deepwater depletion in the immediate vicinity of the roots as soil dries. Modeling calculations by Carminati et al. (2011) showed that the presence of mucilage in the rhizosphere reduced the water potential gradients around the roots, helping plants to extract more water from the soil. Although hydrophobicity of the rhizosphere has been reported by direct observation of water redistribution in the soil (Carminati et al., 2010), measurements of contact angle between water and soil particles in the rhizosphere (Moradi et al., 2012), and measurement of water infiltration into the rhizosphere (Hallett et al., 2003; Read et al., 2003), its significance in root water uptake is still unclear. The important questions to be answered are: what water 
potential does plants feel when the rhizosphere becomes hydrophobic? How may distribution of water uptake zone along roots change when the rhizosphere becomes hydrophobic?

One may see hydrophobicity of the rhizosphere as a negative factor due to limitation of water flow into roots, or a positive factor by preventing the back flow of water from the roots into the dry soil. This may be important for root system with deep roots in contact with wet soil and upper roots in a dry soil. These speculations should be tested in systematic experiments. The lack of answer to these questions is due to lack of a technique that allows us to measure the local flux of water into the roots.

\section{Location of water uptake along roots}

Where and how fast do roots take up water from soil is an important question in both soil and plant science. Many efforts have been made to answer these questions. There are two different views on the location of water uptake along the roots. Studies on root anatomy variations along root have lead scientists to conclude that young parts of roots (apical parts) are more involved in water uptake. Primarily measurements of radial hydraulic conductivity of roots also confirmed this view. This view is still commonly cited in textbooks.

Recently, our understanding of water uptake and its transport in roots has been substantially improved by new experimental techniques. Advanced modeling approaches combined with detailed measurements of root hydraulic conductivities showed that depending on the relative importance of radial and axial hydraulic conductivities the water uptake zone could be variable along the root system (Landsberg \& Fowkes, 1978; Frensch \& Steudle, 1989; Zwieniecki et al., 2003). These studies showed that the proximal parts of roots were more involved in delivering water into roots than the distal parts. These studies also pointed out the dynamic variation of the water uptake zone along root following root maturation and/or the reduction of hydraulic conductance at the root surface in the soil. However, these results were obtained from excised roots grown in hydroponic culture. The properties of these roots may largely differ from those grown in soils.

Taking the advantage of new imaging techniques, researchers have been able to study water uptake by roots grown in soil. Imaging techniques were used to monitor the distribution of root and water content in soil. These observations revealed that greater changes in soil water content appeared in the regions where root density was higher(Garrigues et al., 2006; Pohlmeier et al., 2008). They also found that the location of root water uptake moved 
downwards along the soil profile starting from the upper soil layers when soil was initially wet. Although these techniques allowed us to in situ observations of root growth in soil, they could not reveal directly the fluxes of water into roots and need to be coupled with models of root water uptake in soils. A review of the methods to measure root water uptake is given in the following paragraphs.

\section{Review of root water uptake measurements}

Locations of water uptake along roots can be determined by measuring radial flux or axial flux of water into and along roots, respectively. The radial flux of water into roots is defined as the local speed of water crossing the root tissue [cm s-1]. The axial flux of water is defined as the average velocity of water along the xylem vessels. The radial flux is a local measure of the speed of water into roots and its distribution along roots tells us about the relative importance of each segment of the root in water uptake. While the axial flux, its measure is cumulative along roots toward the proximal parts and it does directly give information about the location of water uptake.In the following section the main method of measuring fluxes are reviewed:

\section{1-Measurements of fluxes into and along single roots.}

In these methods, the distribution of the fluxes is derived by measuring the radial and axial resistances along the root. The main methods are: pressure probe, pressure chamber, and high-pressure flow meter (Passioura, 1980; Frensch \& Steudle, 1989; Tyree et al., 1995; Zwieniecki et al., 2003; Knipfer \& Fricke, 2010b). The principle of these techniques is rather similar. An excised root is sealed into devices and then water flow in or out of the root is measured as a function of the pressure gradient applied. The water flow can be induced by a hydrostatic and/or somatic pressure gradient. The water flow is given by (House, 1974)

$$
J=2 \pi r L \frac{1}{R}\left(\psi_{e x t}-\psi_{x}\right)
$$

Where $\mathrm{J}$ is the volumetric flow rate $\left(\mathrm{cm}^{3} \mathrm{~s}^{-1}\right), \mathrm{r}$ is the radius $(\mathrm{cm}), L$ is the length of root, $R$ is the root resistance $\left(\mathrm{cm} \mathrm{s}^{-1} \mathrm{MPa}^{-1}\right), \Psi_{\text {ext }}$ is thewater potential in the surrounding medium of the root $(\mathrm{MPa})$, and $\Psi_{x}$ is the water potential at the cut end of the root. The calculated resistance is the total resistance that water should overcome to flow in or out of the cut end of a root with a length of $L$. The total resistance depends on the local radial and axial resistances. To 
assess the distribution of radial and axial resistance along the root, the root should be successively cut into smaller segments from the apical parts toward the basal end of the root. Due to the porous nature of roots, the pressure gradient applied to the cut end of the root may dissipate along the root and, consequently, the apical parts of root are less involved in water uptake (Frensch \& Steudle, 1989; Zwieniecki et al., 2003). To assess the distribution of radial and axial resistances along roots, the results have to be coupled with a model of water flow in the root (Landsberg \& Fowkes, 1978).

However, most of the measurement data available in literatures have not undertaken the efforts to calculate the distribution of resistances along the root and they just reported the total resistance. Frensch \& Steudle (1989) using a root pressure probe apparatus measured hydraulic resistance along a $14 \mathrm{~cm}$ excised root of maize. They showed that the flow of water into the root was mainly restricted by the radial resistance of the root, except in the apical parts $(1-2 \mathrm{~cm})$ that were hydraulically isolated from the rest of the root due to high axial resistance. They showed that axial resistance was high at the distal parts of the roots and it decreased towards the more proximal parts of the roots. They showed that the radial resistance depended on the nature of pressure gradient applied to move water: the measured radial resistance by inducing hydrostatic flow was approximately 4 times bigger than that of the osmotic flow. Zwieniecki et al. ( 2003) measured water flow into a $20 \mathrm{~cm}$ long maize root grown in hydroponic. They measured the flow of water into roots using a pressure chamber in which the root was immersed in water and subjected to a given pressure. The apical segment of roots $(3-6 \mathrm{~cm})$ was successively removed starting from both the basal end, in a second approach, from the apical parts. The first approach showed that water uptake from $70 \%$ of the apical parts of the initial root was not detectable. In other words, as they removed the 10-15 $\mathrm{cm}$ of the apical parts, water uptake stayed constant. The second approach showed that by removing $50 \%$ of the basal segment of root water uptake stayed constant. They concluded that profile of water uptake zone varies along root depending on the relative importance of radial to axial resistances (Fig. 2). However, the measure of radial and axial resistance along root may differ depending on the plant species, the developmental stage of the plant and the growth condition. To date, most of our available data on the local resistances of roots are obtained from plants grown in hydroponic cultures. The hydraulic properties of roots grown in hydroponic cultures may differ from those grown in soil. 


\section{2-Measurement root water using potometer}

A potometer directly measures the rate of water into different locations of the root of an intake plant grown in hydroponic. Different locations of the roots are sealed into a tube filled with water and then the rate of water uptake is monitored by the change in volume of water in each tube. The potometer and roots should be immersed in water during the measurements. There have been many different potometer designed to measure the water uptake rate by roots.

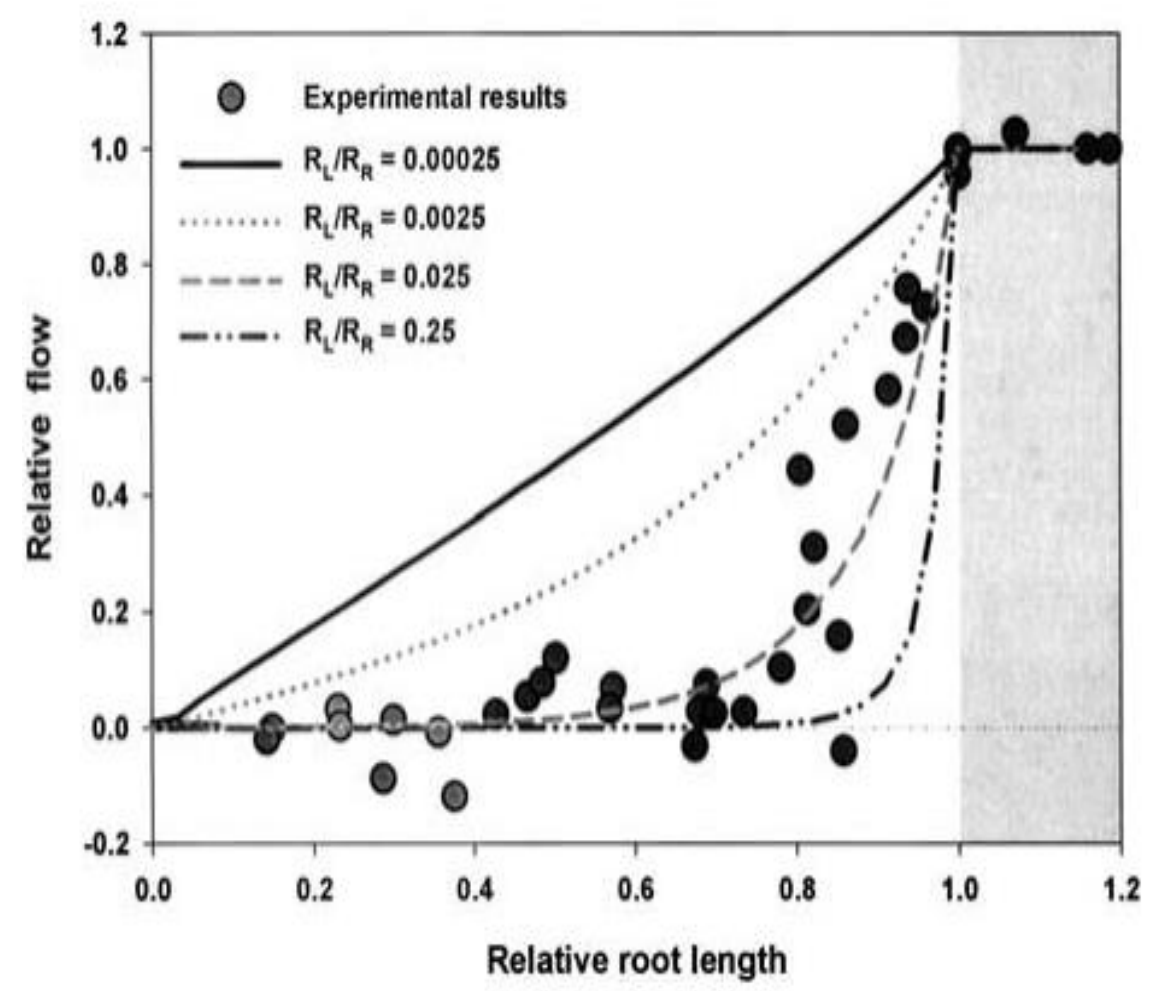

Figure 2: Measured (point) and calculated (lines) value of water uptake along a $20 \mathrm{~cm}$ excised root of Maize. Length of root is percent of unsuberized root length and water uptake is percent of total root water uptake. The shaded area represents the suberized portion of the root. Lines represent the profile of water uptake along root modeled for different ratios between axial and radial resistance (from Zwieniecki et al., 2003).

Sanderson (1983) measured water uptake at different locations of seminal axes of barley. Water uptake was measured in potometer with the shoot in the air with two different humidities. Maximum water uptake occurred in the root segment with $10 \mathrm{~cm}$ distance from 
the root tip and it decreased towards the distal and the proximal parts (Fig. 3). He found that the increasing transpiration rate was accompanied by a more marked increase in the water uptake rate at the proximal parts of roots.

Although application of this technique to answer the question which parts of roots are more involved in water uptake is straightforward, its application is limited to roots grown in a hydroponic system.

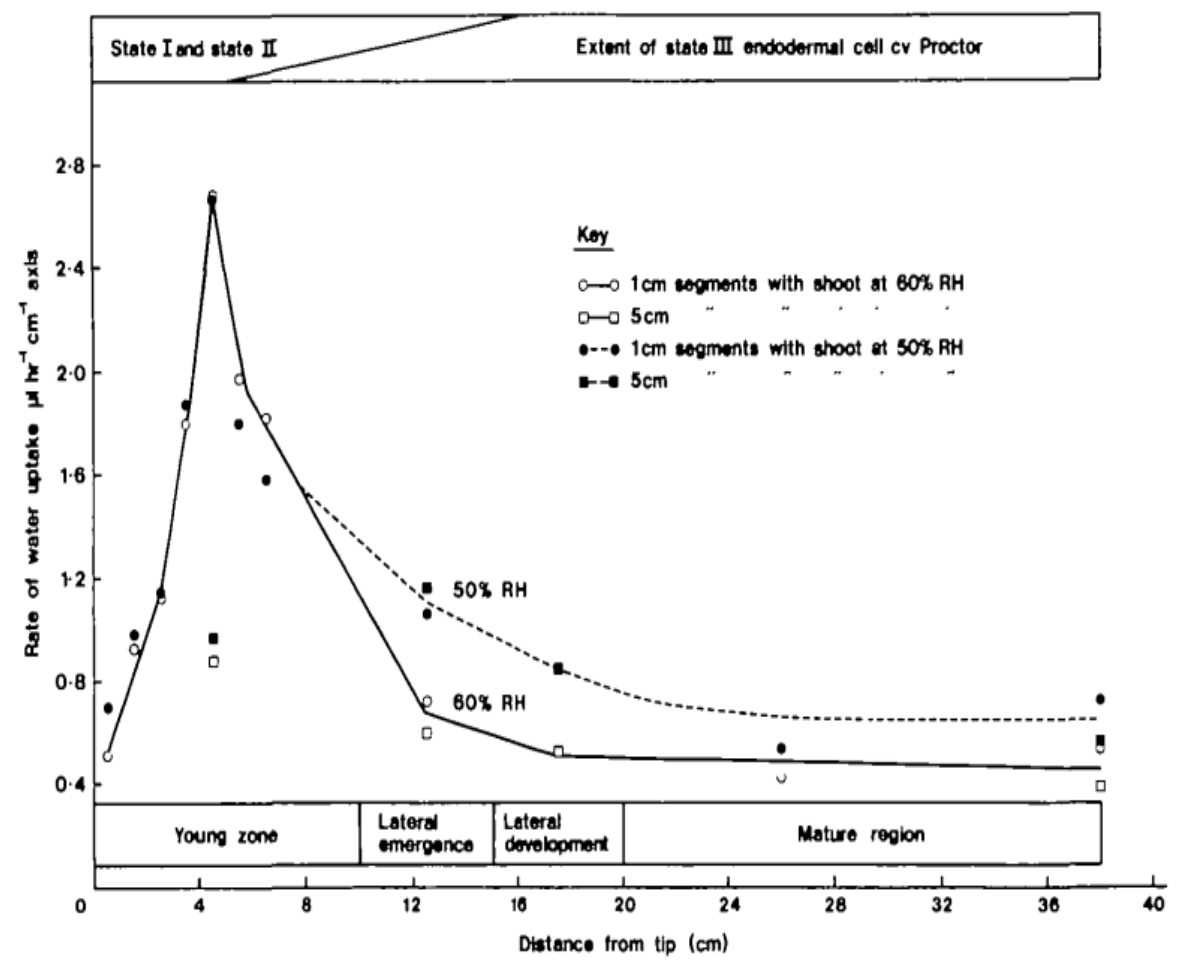

Figure 3: Water uptake of different location of roots along the seminal axes of barley, at two air humidity regimes, in relation to the development of the endodermis (. From Sanderson 1983).

\section{3- Experiment with dye tracers}

In these techniques, water uptake is quantified based on accumulation rate of a dye inside the root tissue or at the root surface. The concept is that when a dye is added to the solution in the root medium, it accumulates faster in the parts where the water uptake rate is higher. The dye may accumulate in the apoplast where water passes the cell membrane or at the root surface if transport of water is purely cell to cell.

The dye accumulation inside the root tissue depends on the critical assumption that the apoplastic pathway is fully interrupted at the root endodermis. However, when the apoplastic pathway is not fully interrupted at the root endodermis, there will some apoplastic transport 
of the dye into the root stele followed by an axial flow along xylem, which results in a uniform distribution of the dye or in the accumulation of dye at the more proximal parts of roots near to shoots. In this case, radial flux cannot be derived from the dye concentration solely.

In the case of monitoring the accumulation rate of the dye at the root surface, the critical assumption is that the dye does not diffuse through the membrane of root cells, and the transport of water into roots is purely cell-to-cell. If the solute penetrates the membrane of the root cell or it is transported through apoplastic pathway, the rate of water uptake is underestimated. Varney \& Canny (1993) introduced a new dye based method of measuring water uptake by roots, which was applied to whole root systems of large maize plants growing in aeroponic culture. The method depends on the buildup of concentration of dye (sulphorhodamine $\mathrm{G}$ ) on the root surface. The local rate of accumulation of dye was related to flux of water into the roots. They observed that maximum uptake from laterals occurred at $30-60 \mathrm{~cm}$ from the root tip of the main axes, and it decreased towards the tip and the proximal parts (Fig. 4). Although this technique could be used to measure the rate of water uptake along mature roots and branch roots, its application is limited to roots grown in aeroponic system.

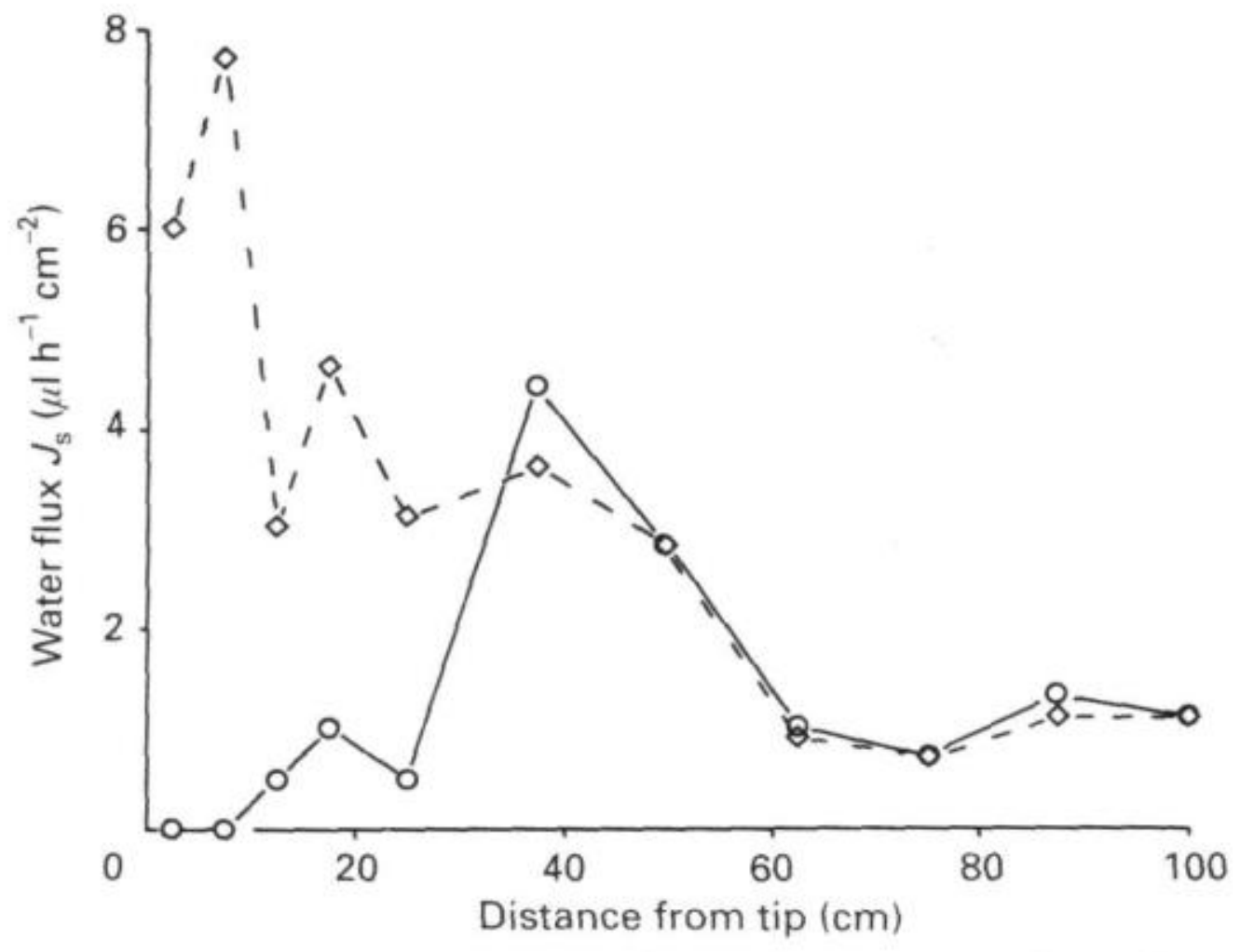


Figure 4: Water flux into different locations of roots along the axes and branches of mature maize grown in aeroponic culture (from Varney \& Canny, 1993).

\section{4- Measurement of root water uptake in soil}

Recently, advanced imaging methods like x-ray computed tomography, light transmission imaging, magnetic resonance imaging, and neutron radiography have been applied to monitor the spatial distribution of root and soil water contents (Pierret et al., 2003; Garrigues et al., 2006; Pohlmeier et al., 2008; Moradi et al., 2011). Garrigues et al. (2006) used light transmission imaging to observe root and water content distributions in an artificial soil. They found that water uptake zone was initially at the upper layer of soil and it moved downwards as the upper soil dried. Pohlmeier et al. (2008) used magnetic resonance imaging (MRI) to study water content changes in soil caused by root water uptake. They found that greater changes in soil water content appeared in the regions where root density was higher.

These imaging techniques qualitatively showed the location of water uptake along the roots. To quantify the water uptake, in particular along each individual roots, the changes in soil water content should be coupled with simulation of water redistribution in the soil profile. This requires accurate knowledge of the soil hydraulic properties in the root zone, which are difficult to experimentally characterize. For instance, Carminati et al. (2010) reported that the hydraulic properties of the rhizosphere were different from those of the bulk soil. Such heterogeneity of soil properties in the root zone may complicate the interpretation of soil water content changes in relation to root water uptake.

Besides that, the application of these techniques is often limited to dry soil. In wet soil, in the soil hydraulic conductivity is much higher than that of the roots resulting in a very fast redistribution of water in the soil. Additionally, these methods are not able to differentiate the water uptake of two or more neighboring roots due to the redistribution of water in the soil. 


\section{5- Measurement root water using heat-based sap flow gauges}

Heat-based sap flow gauges were initially developed for plant stems and have been recently modified for application to roots (Coners \& Leuschner, 2002). The principle of this measurement is that a heat pulse is released either on the surface of root through a probe attached to the surface or inside the root tissue through an implanted probe into the xylem tissue. The probes and the root tissues at the place of measurement are carefully isolated from the sounding soil to reduce heat dissipation. The intensity and/or redistribution of the applied pulse at a certain distance are recorded and related to the rate of sap flow in xylem. Different types of these devices have been developed and tested (Howard et al., 1996; Lott et al., 1996; Smith \& Allen, 1996; Coners \& Leuschner, 2002). These techniques quantify root water uptake by measuring the axial flux of water in xylem. Axial flux of water in the xylem is a local measure of the speed of water along root and it is a cumulative parameter along the roots. Application of this technique is limited to roots with diameters larger than $3 \mathrm{~mm}$. 


\section{Aim of this study}

In the last decades, fundamental advances have been made in the conceptual understanding and modeling of root water uptake. Despite the modeling advances, there is still a lack of experimental data on basic questions such as: where do roots take up water from soil? Are taproot and laterals equally involved in water uptake? What segments of individual roots are more active in water uptake, the proximal or the distal segments? Experiments with roots grown in a hydroponic system showed that 10 to $30 \%$ of the total root length are sufficient to fulfill the transpirational demand (Frensch \& Steudle, 1989; Zwieniecki et al., 2003). This finding was also confirmed by monitoring and modeling water uptake by roots growing in soil (Passioura, 1980; Doussan et al., 2006; Garrigues et al., 2006). However, an important question is which of the $10-30 \%$ of the roots are actively involved in water uptake. Answering all of these questions need in situ measurement of local flow of water into the roots of transpiring plants grown in soil.

The aims of this study were to develop, and apply a new technique to measure local fluxes of water into the roots of plants growing in soil and investigate on the effects of rhizosphere on root water uptake. The specific objectives were:

- To develop a new method to measure the local flux of water into the roots of plants growing in soil.

- To apply the technique to different locations of roots and to map the flux of water along the roots. The finding will answer the questions about what parts of the roots are more involved in water uptake.

- To assess the effect of rhizosphere on flow of water into the roots. 


\section{Outlooks}

The study proceeded in four steps, each of which is described in one of the main chapters of this dissertation:

1-We introduce a new technique to measure the local flux of water into the roots of plants growing in soil by combining neutron radiography with local injection of deuterated water $\left(\mathrm{D}_{2} \mathrm{O}\right)$ into the soil next to roots. The spatial and temporal distribution of $\mathrm{D}_{2} \mathrm{O}$ in both soil and plants was monitored using time series neutron radiography. The transport of water into roots was quantified using a convection-diffusion model of $\mathrm{D}_{2} \mathrm{O}$ transport into roots. As the first attempt, the model was developed to describe the transport of $\mathrm{D}_{2} \mathrm{O}$ into root segments that were entirely immersed in $\mathrm{D}_{2} \mathrm{O}$.

2- We further modified the description of the proposed model to describe the transport of $\mathrm{D}_{2} \mathrm{O}$ into roots that were partly immersed in $\mathrm{D}_{2} \mathrm{O}$. We have also generalized the description of the model to allow a varying importance of apoplastic and cell-to-cell flow across the root tissue. We measured and modeled $\mathrm{D}_{2} \mathrm{O}$ transport into different locations of the roots.

3- We applied the technique to determine the water fluxes across dry and wet rhizosphere. Our goal was to verify whether and to what extent the rhizosphere conductivity limits the water fluxes to roots during rewetting.

4- We investigated a new method to estimate the effective hydraulic conductivity of the rhizosphere following of a rewetting cycle. We used a time series neutron radiography to monitor redistribution of water in soil and roots after a rewatting cycle. We used the swelling rate of roots as an indication of water flow into the roots to estimate the effective hydraulic conductivity of the rhizoshere. 


\section{References}

Bengough, A.G. 2012. Water Dynamics of the Root Zone: Rhizosphere Biophysics and Its Control on Soil Hydrology. Vadose Zone Journal 11, 0.

Bramley, H., Turner, N.C., Turner, D.W., \& Tyerman, S.D. 2009. Roles of morphology, anatomy, and aquaporins in determining contrasting hydraulic behavior of roots. Plant Physiol. 150, 348-364.

Canny, M.J. 1995. Apoplastic water and solute movement: new rules for an old space. Annu. Rev. Plant Biol. 46, 215-236.

Carminati, A. 2012. A Model of Root Water Uptake Coupled with Rhizosphere Dynamics. Vadose Zone J. 11

Carminati, A., Moradi, A.B., Vetterlein, D., Vontobel, P., Lehmann, E., Weller, U., Vogel, H.-J., \& Oswald, S.E. 2010. Dynamics of soil water content in the rhizosphere. Plant Soil 332, 163-176.

Carminati, A., Schneider, C.L., Moradi, A.B., Zarebanadkouki, M., Vetterlein, D., Vogel, H.J., Hildebrandt, A., Weller, U., Schüler, L., \& Oswald, S.E. 2011. How the Rhizosphere May Favor Water Availability to Roots. Vadose Zone J. 10, 988-998.

Chaves, M.M., Maroco, J.P., \& Pereira, J.S. 2003. Understanding plant responses to drought — from genes to the whole plant. Functional Plant Biol. 30, 239-264.

Chenu, C. 1993. Clay-or sand-polysaccharide associations as models for the interface between micro-organisms and soil: water related properties and microstructure. Geoderma 56, 143-156.

Chenu, C., \& Roberson, E.B. 1996. Diffusion of glucose in microbial extracellular polysaccharide as affected by water potential. Soil Biol. Biochem. 28, 877-884.

Coners, H., \& Leuschner, C. 2002. In situ water absorption by tree fine roots measured in real time using miniature sap-flow gauges. Funct. Ecol. 16, 696-703.

Czarnes, S., Hallett, P.D., Bengough, A.G., \& Young, I.M. 2000. Root-and microbial-derived mucilages affect soil structure and water transport. Eur. J. Soil. Sci. 51, 435-443.

Dale, M.P., \& Causton, D.R. 1992. The ecophysiology of Veronica chamaedrys, V. montana and V. officinalis. I. Light quality and light quantity. J. Ecol., 483-492.

Dias-Filho, M.B. 1995. Root and shoot growth in response to soil drying in four Amazonian weedy species. Revista Brasileira de Fisiologia Vegetal 7, 53-59.

Doussan, C., Pierret, A., Garrigues, E., \& Pagès, L. 2006. Water Uptake by Plant Roots: II Modelling of Water Transfer in the Soil Root-system with Explicit Account of Flow within the Root System - Comparison with Experiments. Plant Soil 283, 99-117. 
Dousssan, C., Vercambre, G., \& Page, L. 1998. Modelling of the hydraulic architecture of root systems: An integrated approach to water absorption-distribution of axial and radial conductances in maize. Ann. Bot-London 81, 225-232.

Draye, X., Kim, Y., Lobet, G., \& Javaux, M. 2010. Model-assisted integration of physiological and environmental constraints affecting the dynamic and spatial patterns of root water uptake from soils. J. Exp. Bot. 61, 2145-2155.

Enstone, D.E., Peterson, C.A., \& Ma, F. 2003. Root Endodermis and Exodermis: Structure, Function, and Responses to the Environment. J. Plant Growth Regul. 21, 335-351.

Frensch, J., \& Steudle, E. 1989. Axial and radial hydraulic resistance to roots of maize (Zea mays L.). Plant Physiol. 91, 719-726.

Fritz, M., \& Ehwald, R. 2011. Mannitol permeation and radial flow of water in maize roots. New Phytol. 189, 210-217.

Gallagher, J.N., Biscoe, P.V., \& Hunter, B. 1976. Effects of drought on grain growth. Nature 264, 541-542.

Gardner, W.R. 1960. Dynamic aspects of water availability to plants. Soil Sci. 89, 63-73.

Garrigues, E., Doussan, C., \& Pierret, A. 2006. Water Uptake by Plant Roots: I - Formation and Propagation of a Water Extraction Front in Mature Root Systems as Evidenced by 2D Light Transmission Imaging. Plant Soil 283, 83-98.

Gessa, C., \& Deiana, S. 1990. Fibrillar structure of Ca polygalacturonate as a model for a soil-root interface. Plant Soil 129, 211-217.

Gregory, P.J. 2006. Roots, rhizosphere and soil: the route to a better understanding of soil science? Eur. J. Soil. Sci. 57, 2-12.

Gregory, P.J., \& Hinsinger, P. 1999. New approaches to studying chemical and physical changes in the rhizosphere: an overview. Plant Soil 211, 1-9.

Hallett, P.D., Gordon, D.C., \& Bengough, A.G. 2003. Plant influence on rhizosphere hydraulic properties: direct measurements using a miniaturized infiltrometer. New Phytol. 157, 597-603.

Henzler, T., \& Steudle, E. 1995. Reversible closing of water channels in Chara internodes provides evidence for a composite transport model of the plasma membrane. J. Exp. Bot. 46, 199-209.

Hinsinger, P., Gobran, G.R., Gregory, P.J., \& Wenzel, W.W. 2005. Rhizosphere geometry and heterogeneity arising from root-mediated physical and chemical processes. New Phytol. 168, 293-303.

Holbrook, N.M., Burns, M.J., \& Field, B. 1995. Negative xylem pressures in plants: a test of the balancing pressure technique. Science v. 270(5239), 1193-1194

House, C.R. 1974. Water transport in cells and tissues. London, E. Arnold. 
Howard, S.B., Ong, C.K., Black, C.R., \& Khan, A.A. 1996. Using sap flow gauges to quantify water uptake by tree roots from beneath the crop rooting zone in agroforestry systems. Agroforestry Systems 35, 15-29.

Howell, T.A. 2001. Enhancing Water Use Efficiency in Irrigated Agriculture. Agronomy Journal 93, 281.

Hu, T., Kang, S., Li, F., \& Zhang, J. 2011. Effects of partial root-zone irrigation on hydraulic conductivity in the soil-root system of maize plants. J. Exp. Bot. 62, 4163-4172.

Huang, B., \& Eissenstat, D.M. 2000. Linking hydraulic conductivity to anatomy in plants that vary in specific root length. J. Am. Soc. Hortic. Sci. 125, 260-264.

Iijima, M., Sako, Y., \& Rao, T.P. 2003. A new approach for the quantification of root-cap mucilage exudation in the soil. Plant Soil 255, 399-407.

Kirkham, M.B. 2005. Principles of soil and plant water relations. Academic Press.

Knipfer, T., Besse, M., Verdeil, J.-L., \& Fricke, W. 2011. Aquaporin-facilitated water uptake in barley (Hordeum vulgare L.) roots. J. Exp. Bot. 62, 4115-4126.

Knipfer, T., \& Fricke, W. 2010a. Root pressure and a solute reflection coefficient close to unity exclude a purely apoplastic pathway of radial water transport in barley (Hordeum vulgare). New Phytol. 187, 159-170.

Knipfer, T., \& Fricke, W. 2010b. Water uptake by seminal and adventitious roots in relation to whole-plant water flow in barley (Hordeum vulgare L.). J. Exp. Bot. 62, 717-733.

Koch, G.W., Sillett, S.C., Jennings, G.M., \& Davis, S.D. 2004. The limits to tree height. Nature 428, 851-854.

Kudrev, T.G. 1988. Water and plant productivity. , 190 pp.

Landsberg, J.J., \& Fowkes, N.D. 1978. Water movement through plant roots. Ann. BotLondon 42, 493-508.

Laraus, J. 2004. The problems of sustainable water use in the Mediterranean and research requirements for agriculture. Ann. Bot-London 144, 259-272.

Lott, J.E., Khan, A.A.H., Ong, C.K., \& Black, C.R. 1996. Sap flow measurements of lateral tree roots in agroforestry systems. Tree Physiol. 16, 995-1001.

MacFall, J.S., Johnson, G.A., \& Kramer, P.J. 1990. Observation of a water-depletion region surrounding loblolly pine roots by magnetic resonance imaging. Proc. Natl. Acad. Sci. USA 87, 1203.

Magnani, F., Centritto, M., \& Grace, J. 1996. Measurement of apoplasmic and cell-to-cell components of root hydraulic conductance by a pressure-clamp technique. Planta 199, 296-306.

Maurel, C., \& Chrispeels, M.J. 2001. Aquaporins. A molecular entry into plant water relations. Plant Physiol. 125, 135-138. 
McCully, M. 1995. How Do Real Roots Work?(Some New Views of Root Structure). Plant Physiol. 109, 1-6.

McCully, M.E., \& Boyer, J.S. 2006. The expansion of maize root-cap mucilage during hydration. 3. Changes in water potential and water content. Physiol. Plantarum 99, $169-177$.

McCully, M.E., \& Canny, M.J. 1988. Pathways and processes of water and nutrient movement in roots. Plant Soil 111, 159-170.

McLean, E.H., Ludwig, M., \& Grierson, P.F. 2011. Root hydraulic conductance and aquaporin abundance respond rapidly to partial root-zone drying events in a riparian Melaleuca species. New Phytol. 192, 664-675.

Miraglia, M., Marvin, H.J.P., Kleter, G.A., Battilani, P., Brera, C., Coni, E., Cubadda, F., Croci, L., De Santis, B., Dekkers, S., Filippi, L., Hutjes, R.W.A., Noordam, M.Y., Pisante, M., Piva, G., Prandini, A., Toti, L., Van den Born, G.J., \& Vespermann, A. 2009. Climate change and food safety: An emerging issue with special focus on Europe. Food Chem. Toxicol. 47, 1009-1021.

Moradi, A.B., Carminati, A., Lamparter, A., Woche, S.K., Bachmann, J., Vetterlein, D., Vogel, H.J., \& Oswald, S.E. 2012. Is the rhizosphere temporarily water repellent? Vadose Zone J. 11.

Moradi, A.B., Carminati, A., Vetterlein, D., Vontobel, P., Lehmann, E., Weller, U., Hopmans, J.W., Vogel, H.-J., \& Oswald, S.E. 2011. Three-dimensional visualization and quantification of water content in the rhizosphere. New Phytol. 192, 653-663.

Moshelion, M., Moran, N., \& Chaumont, F. 2004. Dynamic changes in the osmotic water permeability of protoplast plasma membrane. Plant Physiol. 135, 2301-2317.

Nakaji, T., Noguchi, K., \& Oguma, H. 2007. Classification of rhizosphere components using visible-near infrared spectral images. Plant Soil 310, 245-261.

Nakashi, T.M. 2005. Water gradient profiles at bean plant roots determined by neutron beam analysis. J. Radioanal. Nucl. Chem. 264, 313-317.

Nobel, P.S., \& Cui, M. 1992. Hydraulic conductances of the soil, the root-soil air gap, and the root: changes for desert succulents in drying soil. J. Exp. Bot. 43, 319-326.

Oki, T., \& Kanae, S. 2006. Global hydrological cycles and world water resources. Science 313, 1068-1072.

Or, D., Phutane, S., \& Dechesne, A. 2007. Extracellular polymeric substances affecting porescale hydrologic conditions for bacterial activity in unsaturated soils. Vadose Zone J. 6, 298-305.

Passioura, J.B. 1980. The Transport of Water from Soil to Shoot in Wheat Seedlings. J. Exp. Bot. 31, 333-345.

Passioura, J.B. 1988. Water transport in and to roots. 39, 245-265. 
Perumalla, C.J., \& Peterson, C.A. 1986. Deposition of Casparian bands and suberin lamellae in the exodermis and endodermis of young corn and onion roots. Botany 64, 18731878.

Peterson, C.A., Emanuel, M.E., \& Humphreys, G.B. 1981. Pathway of movement of apoplastic fluorescent dye tracers through the endodermis at the site of secondary root formation in corn (Zea mays) and broad bean (Vicia faba). Can. J. Bot 59, 618-625.

Peterson, C.A., Murrmann, M., \& Steudle, E. 1993. Location of the major barriers to water and ion movement in young roots of Zea mays L. Planta 190, 127-136.

Pohlmeier, A., Oros-Peusquens, A., Javaux, M., Menzel, M.I., Vanderborght, J., Kaffanke, J., Romanzetti, S., Lindenmair, J., Vereecken, H., \& Shah, N.J. 2008. Changes in soil water content resulting from Ricinus root uptake monitored by magnetic resonance imaging. Vadose Zone J. 7, 1010-1017.

Ranathunge, K.M. 2005. The role of the apoplastic transport barriers for radial water and ion uptake in rice (Oryza sativa L.) and corn (Zea mays L.) roots.

Read, D.B., Bengough, A.G., Gregory, P.J., Crawford, J.W., Robinson, D., Scrimgeour, C.M., Young, I.M., Zhang, K., \& Zhang, X. 2003. Plant roots release phospholipid surfactants that modify the physical and chemical properties of soil. New Phytol. 157, 315-326.

Read, D.B., \& Gregory, P.J. 1997. Surface tension and viscosity of axenic maize and Lupine root mucilages. New Phytol., 623-628.

Reinhardt, D.H., \& Rost, T.L. 1995. Salinity accelerates endodermal development and induces an exodermis in cotton seedling roots. Environ.Exp. Bot. 35, 563-574.

Saliendra, N.Z., Sperry, J.S., \& Comstock, J.P. 1995. Influence of leaf water status on stomatal response to humidity, hydraulic conductance, and soil drought in Betula occidentalis. Planta 196, 357-366.

Sanderson, J. 1983. Water uptake by different regions of the barley root. Pathways of radial flow in relation to development of the endodermis. J. Exp. Bot. 34, 240-253.

Schulze, E. 1986. Whole-Plant Responses to Drought. Functional Plant Biol. 13, 127-141.

Segal, E., Kushnir, T., Mualem, Y., \& Shani, U. 2008. Microsensing of water dynamics and root distributions in sandy soils. Vadose Zone J. 7, 1018-1026.

Smith, D.M., \& Allen, S.J. 1996. Measurement of sap flow in plant stems. J. Exp. Bot. 47, $1833-1844$.

Stanhill, G. 1986. Water Use Efficiency. p. 53-85. In N.C. Brady (ed.), Advan. Agron. Academic Press.

Steudle, E. 2000. Water uptake by plant roots: an integration of views. Plant Soil 226, 45-56.

Steudle, E., \& Peterson, C.A. 1998. How does water get through roots? J. Exp. Bot. 49, 775788. 
Tumlinson, L.G., Liu, H., Silk, W.K., \& Hopmans, J.W. 2007. Thermal Neutron Computed Tomography of Soil Water and Plant Roots. Soil Sci. Soc. Am. J. 72, 1234-1242.

Tyree, M.T., Patiño, S., Bennink, J., \& Alexander, J. 1995. Dynamic measurements of roots hydraulic conductance using a high-pressure flowmeter in the laboratory and field. $J$. Exp. Bot. 46, 83-94.

Varney, G.T., \& Canny, M.J. 1993. Rates of water uptake into the mature root system of maize plants. New Phytol. 123, 775-786.

Walker, T.S., Bais, H.P., Grotewold, E., \& Vivanco, J.M. 2003. Root exudation and rhizosphere biology. Plant Physiol. 132, 44-51.

Watt, M., McCully, M.E., \& Canny, M.J. 1994. Formation and stabilization of rhizosheaths of Zea mays L.(Effect of soil water content). Plant Physiol. 106, 179-186.

Whalley, W.R., Riseley, B., Leeds-Harrison, P.B., Bird, N.R.A., Leech, P.K., \& Adderley, W.P. 2005. Structural differences between bulk and rhizosphere soil. Eur. J. Soil. Sci. 56, 353-360.

Zimmermann, U., Rygol, J., Balling, A., Klöck, G., Metzler, A., \& Haase, A. 1992. Radial turgor and osmotic pressure profiles in intact and excised roots of Aster tripolium: pressure probe measurements and nuclear magnetic resonance-imaging analysis. Plant Physiol. 99, 186-196.

Zimmermann, H.M., \& Steudle, E. 1998. Apoplastic transport across young maize roots: effect of the exodermis. Planta 206, 7-19.

Zwieniecki, M.A., Thompson, M.V., \& Holbrook, N.M. 2003. Understanding the Hydraulics of Porous Pipes: Tradeoffs Between Water Uptake and Root Length Utilization. $J$. Plant Growth Regul. 21, 315-323. 


\section{Quantification and modeling of local root water uptake using neutron radiography and deuterated water}

M. Zarebanadkouki, Y.X. Kim, A. B. Moradi, H-J. Vogel, A. Kaestner, A. Carminati Published in Vadose Zone Journal (2012), Vol. 11 No. 3 


\begin{abstract}
Knowledge of local water fluxes across the soil-root interface is essential to understand and model root water uptake. Despite its importance, there is a lack of direct methods to measure the location of water uptake along the roots. The aim of this study is to develop a technique to quantify local fluxe of water from the soil to the roots of living plants. To this end, we used neutron radiography to trace the transport of deuterated water $\left(\mathrm{D}_{2} \mathrm{O}\right)$ into individual roots. We grew Lupines in $30 \times 25 \times 1 \mathrm{~cm}$ containers filled with a sandy soil, which was partitioned into different compartments using $1 \mathrm{~cm}$-thick layers of coarse sand. We locally injected $\mathrm{D}_{2} \mathrm{O}$ in a selected soil compartment near the roots of eighteen-day old Lupines during the day (transpiring) and night (non-transpiring). The transport of $\mathrm{D}_{2} \mathrm{O}$ into roots was then monitored using time-series neutron radiography. The results show that: 1) The transport of $\mathrm{D}_{2} \mathrm{O}$ into roots was faster during the day than during the night; 2) during day $\mathrm{D}_{2} \mathrm{O}$ was quickly transported along the roots towards the shoots, while at night this transport was insignificant. The differences between day and night measurements were explained by convective transport of $\mathrm{D}_{2} \mathrm{O}$ into the roots driven by transpiration. To quantify the local transport of $\mathrm{D}_{2} \mathrm{O}$ into roots, we developed a simple convection-diffusion model that assumed the endodermis as the main resistance to water transport. The $\mathrm{D}_{2} \mathrm{O}$ uptake predicted by the model was in agreement with the axial flow within the roots as derived from the transport of $\mathrm{D}_{2} \mathrm{O}$ behind the capillary barrier. This new method allows for quantification of local water uptake in different parts of the root system.
\end{abstract}

\title{
Introduction
}

In the last decades, fundamental advances have been made in the conceptual understanding and modeling of root water uptake. Many models of root water uptake are available with various degrees of complexity (Landsberg and Fowkes, 1978; Somma et al., 1998; Roose and Fowler, 2004; Doussan et al., 2006; De Jong Van Lier et al., 2006; Javaux et al., 2008). Although recent architectural models are capable of taking into account local root water uptake and can predict the water uptake pattern across the root length, there is a lack of experimental data on their parameterizations and validations.

Root water uptake is a dynamic process that involves complex interactions between roots and the surrounding soil (Passioura, 1980; Steudle, 2000; Draye et al., 2010). It is assumed that 
root resistance controls water uptake in relatively wet soils. As soil dries, soil hydraulic resistance increases and may restrict the flow of water to roots. Detailed measurements of root hydraulic properties along individual roots have mainly been performed on excised roots growing in hydroponic culture (Frensch and Steudle, 1989; Huang and Nobel, 1993; Frensch et al., 1996; Barrowclough et al., 2000; Zwieniecki et al., 2003; McLean et al., 2011). Frensch and Steudle, (1989) and Zwieniecki et al. (2003) demonstrated experimentally and theoretically that the distributed nature of water uptake zone depends on the relative importance of radial and axial resistance. These two resistances change with root maturation and soil water content.

So far, it has been difficult to experimentally measure local water uptake along an individual soil-grown root and most of existing data are obtained from excised root grown in hydroponic systems. However, dynamics of root water uptake in the soil may be more complex than in hydroponic cultures. A complexity is that roots growing in the soil may have different hydraulic properties than those in hydroponics (Peterson et al., 1993; Enstone et al., 2002; Meyer et al., 2009). Additionally, root water uptake is influenced by the heterogeneous distribution of water in the soil and the presence of rhizosphere with distinct hydraulic properties (Carminati et al., 2010; Moradi et al., 2011).

Recently, advanced experimental methods including X-ray computer tomography, light transmission imaging, magnetic resonance imaging and neutron tomography have been applied to monitor the spatial distribution of root and soil water content (Pierret et al., 2003; Garrigues et al., 2006; Pohlmeier et al., 2008; Moradi et al., 2011). Pierret et al. (2003) used $\mathrm{X}$-ray transmission to monitor root distribution and soil water content around living roots in two dimensions. Pohlmeier et al. (2008) used magnetic resonace imaging (MRI) to study water content change in the soil caused by root water uptake. They found that greater changes in soil water content appeared in the regions where root density was higher. Changes in soil water content were also observed in regions where no root was observed in MRI images. Therefore, they called for a higher spatially-resolved observation of fine roots, and coupling the experimental measurements with an advanced modeling approach for better understanding of water flow along the distance in the soil. Using neutron tomography, Moradi et al. (2011) demonstrated that there was more water in the rhizosphere of lupins, maizes and chick peas than in the bulk soil during a drying cycle caused by root water uptake. Garrigues et al. (2006) used light transmission imaging to observe root and water content distribution in thin samples filled with an artificial translucent medium (mixture of 
98.5\% Fontainebleau sand and $1.5 \%$ Hectorite clay). In a follow up study, Doussan et al. (2006) modelled the observed water content distribution by coupling the water flow in soils and roots. They found that the location of root water uptake moved downwards along the soil profile starting from the upper soil layers when soil was initially wet. The above mentioned studies indirectly estimated root water uptake from the changes in soil water content after stimulation of the water redistribution in the soil profile. The method requires accurate knowledge of the soil hydraulic properties in the root zone, which is difficult to experimentally characterize. For instance, Carminati et al. (2010) reported that the hydraulic properties of the rhizosphere were different than those of the bulk soil. Such heterogeneity of soil properties in the root zone may complicate the interpretation of the soil water content changes in relation to root water uptake. Additionally, these methods are not able to differentiate the water uptake of two or more neighboring roots due to the redistribution of water in soil. An alternative method is miniature sap-flow gauges (Coners and Leuschner, 2002). They measured water flow along fine roots of trees. This technique can be applied to the roots with diameters down to $3 \mathrm{~mm}$, but it does not explicitly measure the radial flow across the root-soil interface and it only measures the axial flow of water in xylem after a certain length of root without giving information on the location of the uptake.

A direct measurement of local water uptake along individual roots growing in soil is highly desirable for better understanding of root function, particularly in response to various environmental conditions. The objective of this study was to introduce an in-situ technique for quantification of radial and axial flow of water into and within the roots. The method consists of monitoring the transport of deuterated water $\left(\mathrm{D}_{2} \mathrm{O}\right)$ into roots by means of neutron radiography. Neutron radiography was chosen because of the high sensitivity to water, which makes roots more visible than in X-ray radiography, and because of the high contrast between $\mathrm{D}_{2} \mathrm{O}$ and $\mathrm{H}_{2} \mathrm{O}$. The use of neutron radiography and $\mathrm{D}_{2} \mathrm{O}$ was first proposed by Matsushima et al. (2008). They used $\mathrm{D}_{2} \mathrm{O}$ to image water fluxes in roots and shoot of living plants. However, they did not localize and quantify the flow of water into the roots. Our intention was to derive the quantitative the local water flow to the roots from the observed $\mathrm{D}_{2} \mathrm{O}$ transport. The results are expected to provide a better understanding of root water uptake and provide a database to evaluate and improve existing models. 


\section{Materials and methods}

\section{Preparation of the soil and plants}

Experiments were carried out on 18-day-old Lupines (Lupine Albus) grown in aluminum containers (25 cm wide, $30 \mathrm{~cm}$ high and $1 \mathrm{~cm}$ thick) filled with a sandy soil. The sandy soil was collected from the artificial catchment Chicken Creek located near Cottbus, Germany. The soil (sieved to $<2 \mathrm{~mm}$ ) consisted of approximately $92 \%$ sand, $5 \%$ silt, $3 \%$ clay and had a bulk density of $1.4 \mathrm{~g} \mathrm{~cm}^{-3}$. The soil hydraulic properties are given in Carminati et al. (2010). The containers were filled with soil while they were laid horizontally. A grid was placed into the containers to separate the sample into 16 compartments ( 4 rows $\times 4$ columns). The sandy soil was poured into each compartment through one sieve to favor a homogeneous soil deposition and to reduce soil layering. The space between the compartments was $1 \mathrm{~cm}$ wide and was filled with a coarse sand (grain diameter of 1.2-1.7 $\mathrm{mm}$ ), which acted as capillary barriers to hydraulically disconnect the adjacent compartments. The containers were then closed and the samples were gently placed vertically. The average bulk density of the packed soil in each compartment was $1.4 \mathrm{~g} \mathrm{~cm}^{-3}$. One face of each container was perforated using a 1-mm thick drill forming a network of holes each $3 \mathrm{~cm}$ apart. A fine-needle syringe was used for injecting $\mathrm{D}_{2} \mathrm{O}$ into the desired regions through the holes.

Lupine seeds (Lupine Albus) were soaked in $10 \% \mathrm{H}_{2} \mathrm{O}_{2}$ solution for 10 min and subsequently in $10 \mathrm{mM} \mathrm{CaSO} 4$ solution for another $10 \mathrm{~min}$. Then they were germinated for one day on moist filter paper in the dark. Germinated seeds were then sown on the soil at the center of the containers. The samples were kept under controlled conditions in a growth chamber with a photoperiod of 14 hours, light intensity of $300 \mu \mathrm{mol} \mathrm{m} \mathrm{m}^{2} \mathrm{~s}^{-1}$, day/night temperature of $25^{\circ} \mathrm{C} / 19^{\circ} \mathrm{C}$, and relative humidity of $60 \%$. Plants were irrigated with nutrient solution every third day by slowly immersing the samples in water until the water table reached the bottom of the upper compartments. Then the water table was sequentially lowered to the top of the lower compartment letting each compartment to drain freely. This resulted in an average water content of $0.2 \mathrm{~cm}^{3} \mathrm{~cm}^{-3}$ with a gradient in water potential due to gravity. The plants were eighteen days old when the neutron radiography experiment started. At this stage plants had six leaves with a total leaf area of approximately $63 \pm 4.7 \mathrm{~cm}^{2}(\mathrm{n}=3)$. During the daily photoperiod, the transpiration rate of individual plants averaged $1.20 \pm 0.23 \mathrm{~g} \mathrm{~h}^{-1}(\mathrm{n}=6)$, as measured gravimetrically. The night transpiration was insignificant. 


\section{Neutron radiography}

Neutron radiography is a noninvasive imaging technique with high sensitivity to water. This makes it suitable to monitor soil water dynamics and root distributions (Moradi et al., 2009). The Beer-Lambert law describes the attenuation of neutrons across a sample

$$
\frac{I}{I_{0}}=\exp ^{-\sum_{i=1}^{i=n}\left(\mu_{i} d_{i}\right)}
$$

where $I$ is the intensity of the attenuated neutron beam $\left(\mathrm{cm}^{-2} \mathrm{~s}^{-1}\right), I_{0}$ is the intensity of the incident neutron beam, $d_{i}(\mathrm{~cm})$ is the thickness of the sample, and $\mu_{i}\left(\mathrm{~cm}^{-1}\right)$ is the macroscopic neutron attenuation coefficient of material $i$ composing the sample. The neutron attenuation coefficient defines the probability of neutron interaction per unit thickness of material. The attenuated neutron flux is converted to visible light by a scintillator plate and digital images are acquired by a cooled CCD camera.

The experiments were carried out at the ICON beam-line at Paul Scherrer Institute (PSI), Switzerland (Kaestner et al. 2011). We used a CCD camera detector with an array of $1260 \times 1260$ pixels, a field of view of $15.75 \times 15.75 \mathrm{~cm}$, and effective spatial resolution of 0.2 $\mathrm{mm}$. In this field of view, four radiographs with marginal overlaps were needed to scan one sample. For measurements during the day, a lamp identical to those in the growth chamber was installed in the imaging station above the plant. The transpiration rates in the imaging station stayed the same as in the climate chamber.

\section{Tracing the flow of water into roots by deuterated water}

Because of its similarity to water, deuterated water $\left(\mathrm{D}_{2} \mathrm{O}\right)$ has been used to study the water flow processes in plants (Bacic and Ratkovic, 1987; Matsushima et al, 2008). Deuterated water has a much lower neutron attenuation coefficient compared to $\mathrm{H}_{2} \mathrm{O}$, which makes it an ideal tracer for neutron radiography experiments. We locally injected $3 \mathrm{ml} \mathrm{D}_{2} \mathrm{O}$ (purity of $99.97 \%$ ) in a selected soil compartment using a syringe. $\mathrm{D}_{2} \mathrm{O}$ redistribution in soil and its transport into roots were monitored with a time interval of 10 seconds for a period of 1 hour. The measurements were performed during the day and night on 10 replicates. The objective of this study is to introduce this new method, therefore we focus on the results obtained from two samples; one measured during the day and one at night, where $\mathrm{D}_{2} \mathrm{O}$ was injected at the same location. 


\section{Image processing}

The radiographs were corrected for the flat field and dark current according to

$$
I_{n o r m}(x, y)=\frac{I(x, y)-I_{D C}(x, y)}{I_{F F}(x, y)-I_{D C}(x, y)}
$$

where $I_{\text {norm }}(x, y)$ is the corrected image, $I(x, y)$ is the recorded image on camera, $I_{F F}(x, y)$ is the flat field (radiography without sample), and $I_{D C}(x, y)$ is the dark current (signal recorded by the camera when there was no beam). The Beer-Lambert law for our samples is

$$
-\log I_{\text {norm }}(x, y)=+\mu_{A l} d_{A l}+\mu_{S}(1-\phi) d_{t o t}+\mu_{H 2 O} d_{H 2 O}+\mu_{D 2 O} d_{D 2 O}
$$

where the subscripts $\mathrm{Al}, \mathrm{S}, \mathrm{H}_{2} \mathrm{O}$ and $\mathrm{D}_{2} \mathrm{O}$ refer to aluminium container, solid phase of the soil, normal and deuterated water, respectively, $\emptyset$ is the soil porosity $\left(\mathrm{cm}^{3} \mathrm{~cm}^{-3}\right)$, and $d_{\text {tot }}$ is the inner thickness of the container $(1 \mathrm{~cm})$. The contribution of container and soil were derived from the radiograph of a dry sample, $I_{d r y}(x, y)$. The attenuation of dry soil and aluminium were $\mu_{\mathrm{s}}=0.13 \mathrm{~cm}^{-1}$ and $\mu_{\mathrm{Al}}=0.02 \mathrm{~cm}^{-1}$, respectively. The attenuation coefficients of water $\left(\mu_{\mathrm{H} 2 \mathrm{O}}=3.65 \mathrm{~cm}^{-1}\right)$ and $\mathrm{D}_{2} \mathrm{O}\left(\mu_{\mathrm{D} 2 \mathrm{O}}=0.61 \mathrm{~cm}^{-1}\right)$ were measured using control samples with known normal and deuterated water content. Assuming that the contribution of the container and soil was uniform across the sample, the contribution of $\mathrm{H}_{2} \mathrm{O}$ and $\mathrm{D}_{2} \mathrm{O}$ is given by

$$
-\log \left(\frac{I_{n o r m}(x, y)}{I_{d r y}(x, y)}\right)=\mu_{H 2 O} d_{H 2 O}+\mu_{D 2 O} d_{D 2 O}
$$

Eq. (2.4) gives the average neutron attenuations across the sample thickness $(1 \mathrm{~cm})$. For our convenience, we define

$$
\mu_{\text {soil }}=\frac{\left(\mu_{H 2 O} d_{H 2 O}+\mu_{D 2 O} d_{D 2 O}\right)}{d_{t o t}}
$$

which gives the neutron attenuation coefficient of the liquid phase over the total sample cross section $\left(d_{t o t}\right)$. In soil where the liquid phase consists of pure $\mathrm{H}_{2} \mathrm{O}, \mu_{\text {soil }}=\mu_{\mathrm{H} 2 \mathrm{O}} \theta$, where $\theta$ is the soil volumetric water content. In the pixels containing roots at a $2 \mathrm{D}$ projection through the $1 \mathrm{~cm}$ thick sample, the signal is composed of the attenuation coefficients of the root and of the soil in front of and behind the root in the beam direction. The actual contributions of $\mathrm{H}_{2} \mathrm{O}$ and $\mathrm{D}_{2} \mathrm{O}$ in root can be calculated assuming that the contributions of $\mathrm{H}_{2} \mathrm{O}$ and $\mathrm{D}_{2} \mathrm{O}$ in the soil in front of and behind the root are equal to those of the soil at the sides of the roots as quantified by Eq. (2.5). The sharp contrast between the roots and the surrounding soil, due to 
their difference in water contents, allowed us to segment roots from the soil. Roots were segmented using the algorithm roottracker2D as described in Menon et al. (2007). The segmented roots were skeletonized and their length and diameter were calculated using the Euclidean distance mapping functions in MATLAB. The pixel-wise neutron attenuation coefficient in roots $\mu_{\text {root }}$ is calculated as

$$
\mu_{\text {root }}=\frac{-\log \left(\frac{I_{\text {root }}}{I_{\text {soil }}}\right)+\mu_{s}(1-\phi) d_{\text {root }}-\mu_{\text {soil }} d_{\text {root }}}{d_{\text {root }}}
$$

where $I_{\text {root }}$ is the value of $I_{\text {norm }}$ in the most center pixel in the roots, $I_{\text {soil }}$ is the average values of $I_{\text {norm }}$ in soil near to the roots and $d_{\text {root }}$ is the root diameter. The attenuation coefficient of root $\left(\mu_{\text {root }}\right)$ depends on the volumetric content of $\mathrm{H}_{2} \mathrm{O}$ and $\mathrm{D}_{2} \mathrm{O}$ in the root.

To calculate the $\mathrm{D}_{2} \mathrm{O}$ content in roots we assumed that root swelling after $\mathrm{D}_{2} \mathrm{O}$ injection was negligible. This means that the total liquid content $\left(\mathrm{H}_{2} \mathrm{O}\right.$ plus $\left.\mathrm{D}_{2} \mathrm{O}\right)$ in roots were constant over time. It follows that

$$
d_{\text {root }}^{D 2 O}=\frac{\mu_{\text {root }}(t)-\mu_{\text {root }}(t=0)}{\mu_{D 2 O}-\mu_{H 2 O}} d_{\text {root }}
$$

Where $\left(d_{\text {root }}^{D 2 O}\right)$ is the thickness of $\mathrm{D}_{2} \mathrm{O}$ in roots, and $t=0$ refers to the radiograph before $\mathrm{D}_{2} \mathrm{O}$ injection. The thickness of $\mathrm{D}_{2} \mathrm{O}$ in soil $\left(d_{\text {soil }}^{D 2 O}\right)$ is given by

$$
d_{\text {soil }}^{D 2 O}=\frac{\mu_{\text {soil }}-\mu_{H 2 O}}{\mu_{D 2 O}-\mu_{H 2 O}} d_{\text {soil }}^{i q}
$$

where $\left(d_{\text {soil }}^{\text {liq }}\right)$ is the total liquid content in soil. To calculate $\left(d_{\text {soil }}^{\text {liq }}\right)$, we assumed that liquid content $\left(\mathrm{H}_{2} \mathrm{O}+\mathrm{D}_{2} \mathrm{O}\right)$ inside the compartment quickly reaches to a uniform distribution after injection. It follows that

$d_{\text {soil }}^{\text {liq }}=\frac{V_{D 2 O}+V_{H 2 O}}{A}$

where $V_{D 2 O}$ and $V_{H 2 O}$ are respectively the total volume of $\mathrm{D}_{2} \mathrm{O}$ and $\mathrm{H}_{2} \mathrm{O}$ in each compartment, and $A$ is the total area of the isolated compartment $\left(\mathrm{cm}^{2}\right)$. To calculate $V_{D 2 O}$ and $V_{H 2 O}$ we assumed that $V_{H 2 O}$ in the compartment was constant over time and it could be calculated from the first radiograph before injection $(\mathrm{t}=0)$ 


$$
V_{H 2 O}=\frac{\left(\sum_{i=1}^{i=n} \sum_{j=1}^{j=n} \mu_{\text {soil }}(t=0)\right) d_{\text {tot }} \lambda^{2}}{\mu_{H 2 O}}
$$

$V_{D 2 O}(t)=\frac{\left(\sum_{i=1}^{i=n} \sum_{j=1}^{j=n} \mu_{\text {soil }}(t)-\sum_{i=1}^{i=n} \sum_{j=1}^{j=n} \mu_{\text {soil }}(t=0)\right) d_{t o t} \lambda^{2}}{\mu_{D 2 O}}$

where $i$ and $j$ are the $x$ and $y$ coordinates of the compartment, $\lambda$ is the pixel size and $t$ is the time after injection. We used the volumetric definition of $\mathrm{D}_{2} \mathrm{O}$ concentration in the root $\left(\mathrm{C}_{\text {root }}\right)$ and soil $\left(C_{\text {soil }}\right)$ as the thickness of $\mathrm{D}_{2} \mathrm{O}$ divided by the total liquid thickness in root and soil, respectively:

$$
\begin{gathered}
C_{\text {root }}=\frac{d_{\text {root }}^{D 2 O}}{d_{\text {root }}^{\text {liq }}} \\
C_{\text {soil }}=\frac{d_{\text {soil }}^{D 2 O}}{d_{\text {soil }}^{\text {liq }}}
\end{gathered}
$$

The total liquid thickness in root $\left(d_{\text {root }}^{\text {liq }}\right)$ is calculated as $\mathrm{H}_{2} \mathrm{O}$ thickness in the first radiograph before $\mathrm{D}_{2} \mathrm{O}$ was injected.

\section{Model of $\mathrm{D}_{2} \mathrm{O}$ transport into root}

To quantify the transport of $\mathrm{D}_{2} \mathrm{O}$ into roots, a simple mathematical model was developed. The model calculated the local radial water flux from the penetration rate of $\mathrm{D}_{2} \mathrm{O}$ into roots. Deuterated water enters the roots by diffusion and convection. Thus, transport of $\mathrm{D}_{2} \mathrm{O}$ is described by a diffusion-convection equation, where the rate of $\mathrm{D}_{2} \mathrm{O}$ entering the root depends on: 1) the convective flow resulting from transpiration (net water uptake), and 2) the diffusional permeability of roots to $\mathrm{D}_{2} \mathrm{O}$. It is known that root resistance is composite; it has an apoplastic pathway around the protoplasts, and a cell-to-cell pathway crossing cell membranes and plasmodesmata (Steudle, 2000). The relative importance of the pathways is still a matter of debate. To simplify the process, we assumed that endodermis is the main resistance to $\mathrm{D}_{2} \mathrm{O}$ transport with a reflection coefficient of close to zero (Henzler and Steudle, 1995; Dainty and Ginzburg, 1964), and $\mathrm{D}_{2} \mathrm{O}$ transport in the apoplast is much quicker than in the cell-to-cell pathway. This means that $\mathrm{D}_{2} \mathrm{O}$ quickly passed through apoplast and reached the endodermis shortly after it was injected at the root surface. Subsequently $\mathrm{D}_{2} \mathrm{O}$ passes the 
endodermis and the cell membrane of cortical cells in the cortex (Fig. 1). From the assumption of quick apoplastic transport in the cortex, the concentration of $\mathrm{D}_{2} \mathrm{O}$ in the apoplast of cortex was assumed to be identical to that at the root surface in soil. Additionally, we assumed that there is no considerable resistance to $\mathrm{D}_{2} \mathrm{O}$ transport inside the root stele and concentration of $\mathrm{D}_{2} \mathrm{O}$ inside the root stele is uniform. According to House (1974) the transport rate of $\mathrm{D}_{2} \mathrm{O}\left(\mathrm{cm}^{3} \mathrm{~s}^{-1}\right)$ across the endodermis is the sum of the convective part $\left(J_{r}^{S, C}\right)$

$$
J_{r}^{S, C}=2 \pi R_{s} L_{r} C_{o}
$$

and a diffusive part $\left(J_{r}^{S, D}\right)$

$$
J_{r}^{S, D}=2 \pi R_{s} L P_{D}\left(C_{0}-C_{s}\right)
$$

where $j_{r}\left(\mathrm{~cm}^{3} \mathrm{~cm}^{-2} \mathrm{~s}^{-1}\right)$ is the radial flux of liquid driven by convection into the root stele, $P_{D}$ is the diffusional permeability coefficient of the root endodermis $\left(\mathrm{cm} \mathrm{s}^{-1}\right), R_{S}$ is the radius of root stele including the endodermis $(\mathrm{cm}), L$ is the length of root immersed in $\mathrm{D}_{2} \mathrm{O}(\mathrm{cm}), C_{o}$ is $\mathrm{D}_{2} \mathrm{O}$ concentration in the apoplast of root cortex $\left(\mathrm{cm}^{3} \mathrm{~cm}^{-3}\right)$, where according to our assumption, quick apoplastic transport, it is equal to the that of the soil at root surface and $C_{s}$ is $\mathrm{D}_{2} \mathrm{O}$ concentration in the root stele $\left(\mathrm{cm}^{3} \mathrm{~cm}^{-3}\right)$. Here, the flux of $\mathrm{D}_{2} \mathrm{O}$ from the soil into the root across the membrane is taken as positive. In our equations, superscripts $r$ and $x$ refer to radial and axial flow, respectively, and superscripts $D$ and $C$ refer to diffusion and convection, respectively.

Besides the radial component of $\mathrm{D}_{2} \mathrm{O}$ transport, there is also an axial component inside the root. Once $\mathrm{D}_{2} \mathrm{O}$ passed the endodermis, it moves up inside the xylem axially (Fig. 1). Such axial transport is dominated by the hydrostatic gradient along xylem set by transpiration. The volumetric solute transport in the xylem, $J_{x}^{S, C}\left(\mathrm{~cm}^{3} \mathrm{~s}^{-1}\right)$, is

$J_{x}^{S, C}=\pi R_{s}^{2} j_{x} C_{s}$

where $j_{x}$ is the axial flux $\left(\mathrm{cm}^{3} \mathrm{~cm}^{-2} \mathrm{~s}^{-1}\right)$ and $R_{s}$ is the radius of the root stele including endodermis. Note, we defined the axial flux $\left(j_{x}\right)$ referring to the stele cross section $\left(\pi R_{s}^{2}\right)$. Therefore, the actual water velocity in the xylem referring to the xylem cross section will be higher than defined axial flux. From a mass conservation, it follows that

$$
\pi R_{s}^{2} j_{x}=2 \pi R_{s} L j_{r}
$$


The right hand side of Eq. (2.17) is the radial volumetric flow of $\mathrm{H}_{2} \mathrm{O}$ entering the root segment in the injected compartment and the left hand side is the axial volumetric flow leaving the root segment towards the shoot. Assuming that entire root including the root tip is immersed in $\mathrm{D}_{2} \mathrm{O}$; Eq. (2.17) can be rewritten for $\mathrm{D}_{2} \mathrm{O}$ transport as

$J_{x}^{S, C}=\pi R_{s}^{2} j_{x} C_{s}=2 \pi R_{s} L j_{r} C_{s}$

Finally, the increase of $\mathrm{D}_{2} \mathrm{O}$ concentration inside the root stele can be described as:

$$
\begin{gathered}
\pi R_{s}^{2} L \frac{\partial C_{s}}{\partial t}=2 \pi R_{s} L P_{D}\left(C_{0}-C_{s}\right) \\
+2 \pi R_{s} L j_{r}\left(C_{0}-C_{s}\right)
\end{gathered}
$$

Under the following boundary conditions

$$
\begin{aligned}
& C_{s}(t=0)=0 \\
& C_{0}(t)=C_{0} \quad \text { for } \quad t \geq 0
\end{aligned}
$$

the solution of Eq. (2.19) is

$C_{s}=C_{0}\left(1-\exp ^{-\left(2 \cdot \frac{P_{D}+j_{r}}{R_{s}}\right) t}\right)$

Eq. (2.21) shows that the $\mathrm{D}_{2} \mathrm{O}$ concentration in the root stele $\left(\mathrm{C}_{\mathrm{S}}\right)$ increases exponentially to the $\mathrm{D}_{2} \mathrm{O}$ concentration in the root surface $\left(C_{o}\right)$. The rate constant $\left(2\left(P_{D}+j_{r},\right) / R_{s}\right)$ contains the contribution of convection $\left(j_{r}\right)$ and diffusion $\left(P_{D}\right)$. We assumed that $\mathrm{D}_{2} \mathrm{O}$ enters the root only by diffusion at night when transpiration is nearly zero and by both convection and diffusion during the day. Assuming that $P_{D}$ does not change with transpiration rate, it is possible to calculate the local flux of $\mathrm{D}_{2} \mathrm{O}$ into root $\left(j_{r}\right)$ during the day. The latter assumption needs further experimental evidence (see Discussion). 

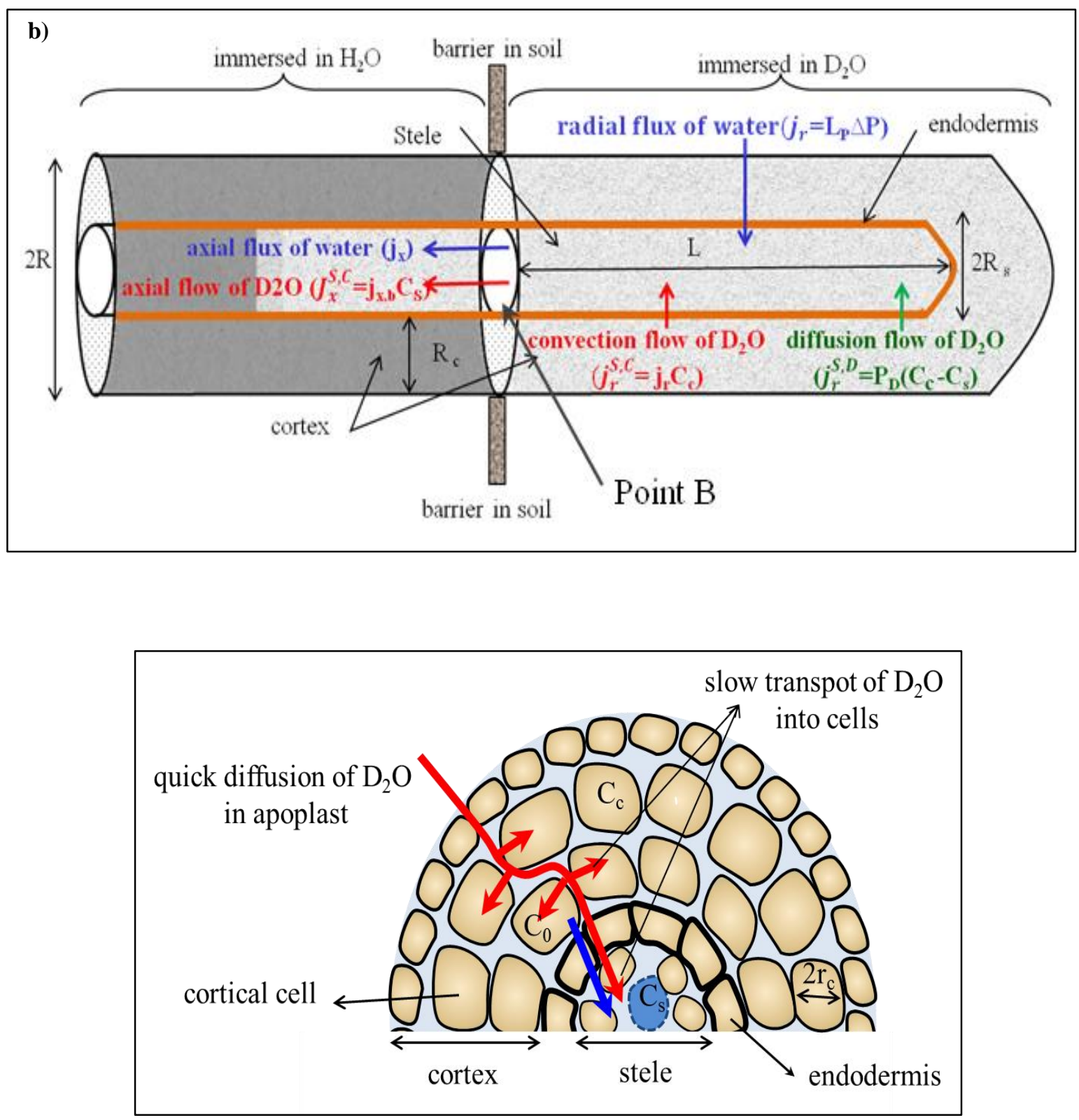

Figure 1: Illustration of $\mathrm{D}_{2} \mathrm{O}$ transport in root $(\mathrm{A})$. Endodermis is assumed the major resistance to water and $\mathrm{D}_{2} \mathrm{O}$ transport. Deuterated water moves into the root stele by convection and diffusion, respectively driven by pressure and the concentration gradient between cortex and xylem (Eq.2.21). We assumed quick $\mathrm{D}_{2} \mathrm{O}$ transport through the apoplast and a slower transport across cell membranes and endodermis (B). Note the capillary barrier to stop $\mathrm{D}_{2} \mathrm{O}$ diffusion in soil. 


\section{Calculation of $C_{s}$}

The calculated neutron attenuation coefficient for the roots represents the average of $C_{D 2 O}$ across the root cortex and the root stele.

$$
C_{\text {root }}=\frac{C_{c} R_{c}+C_{s} R_{s}}{R}
$$

where $C_{\text {root }}$ is the average of $\mathrm{D}_{2} \mathrm{O}$ concentration in the root, $C_{c}$ is $\mathrm{D}_{2} \mathrm{O}$ concentration in the cortex, $C_{s}$ is $\mathrm{D}_{2} \mathrm{O}$ concentration in the root stele, $R$ is the root radius, $R_{c}$ is the cortex thickness, and $R_{s}$ is the stele radius. To obtain $C_{\mathrm{s}}$ we need to know the contribution of cortex $C_{c}$. This value was estimated as follows; the cortex is formed by a series of cortical cells which are hydraulically in local equilibrium with the apoplast. Assuming a quick transport of $\mathrm{D}_{2} \mathrm{O}$ in apoplast, all the cortical cell membranes are uniformly immersed in an identical concentration as that of the root surface in soil. The increase of $\mathrm{D}_{2} \mathrm{O}$ concentration inside the cortical cells, neglecting the volume of apoplastic pathway, is then described as

$C_{c}=C_{0}\left(1-\exp ^{-\left(2 \cdot \frac{P_{D . C}}{r_{c}}\right) t}\right)$

where $P_{D . C}$ is diffusional permeability across the membrane of cortical cells and $r_{c}$ is the radius of a single cortical cell. Assuming that endodermis and xylem are not yet developed in the root tip and it consists of only cortical cells, we took the increase of $\mathrm{D}_{2} \mathrm{O}$ concentration in the root tip to represent that of the cortex.

\section{Independent quantification of axial flow rate}

Mass conservation imposes that axial flow rate of liquid at the capillary barrier is:

$$
J_{x, b}=\pi R_{s, b}^{2} j_{x, b}=2 \pi \bar{R}_{s} L j_{r}
$$

where $R_{s, b}$ is the radius of root stele including endodermis at the location of the coarse sand barrier (point B in Fig. 3), $J_{\mathrm{x}, \mathrm{b}}$ is the axial flow rate at point B $\left(\mathrm{cm}^{3} \mathrm{~s}^{-1}\right), j_{x, b}$ is the axial flux at point $\mathrm{B}\left(\mathrm{cm} \mathrm{s}^{-1}\right)$ and $\overline{R_{S}}$ is the average radius of stele along the root length up to barrier $(L)$. 
In addition to Eq. (2.24), the axial flow rate $\left(J_{x, b}\right)$ can be calculated from the cumulative volume of $\mathrm{D}_{2} \mathrm{O}$ passing the barrier. The cumulative volume of $\mathrm{D}_{2} \mathrm{O}$ moving across the barrier $\left(\mathrm{V}_{\mathrm{D} 2 \mathrm{O}}\right)$ can be quantified from the time-series neutron images:

$$
V_{D_{2} O}=J_{x, b} C_{s, b} t
$$

where $\mathrm{C}_{\mathrm{s}, \mathrm{b}}$ is the $\mathrm{D}_{2} \mathrm{O}$ concentration in the root stele at point $\mathrm{B}$ in fig 3 . The axial flow rate calculated by Eq. (2.25) is independent from our modeling approach. Therefore, comparison of $J_{x, b}$ calculated with Eq. (2.24) (modeling approach) and Eq. (2.25) (quantified neutron images) provides a first test of the proposed model to describe the radial flow of $\mathrm{D}_{2} \mathrm{O}$ into roots.

\section{Results}

Figure 2 shows radiography of the two samples measured at night (left) and day (right). The images show the root distribution and soil water content before $\mathrm{D}_{2} \mathrm{O}$ injection - i.e. the darker the image, the higher the soil water content. The signal in soil varies due to soil heterogeneity and variations in the soil water content. The top compartments of both samples were initially drier than the lower compartments. This resulted from the higher root density, and therefore higher water uptake in these compartments as well as from gravity drainage when the soil was initially wet.

From the segmented images, the total root length and root surface were calculated to be $446.81 \mathrm{~cm}$ and $78.06 \mathrm{~cm}^{2}$ for the day sample and $489.19 \mathrm{~cm}$ and $91.36 \mathrm{~cm}^{2}$ for the night sample, respectively. $\mathrm{D}_{2} \mathrm{O}$ was injected in both samples at the same location (Fig. 2), where the average water content was 0.07 in the night sample and $0.06 \mathrm{~cm}^{3} \mathrm{~cm}^{-3}$ in the day sample. These water content values correspond to matric potential of $-35 \mathrm{hPa}$ and $-47 \mathrm{hPa}$, based on the water retention curve of the soil.

\section{Visualization of $\mathrm{D}_{2} \mathrm{O}$ uptake in the root}

Figure 3 shows the distribution of $\mathrm{H}_{2} \mathrm{O}$ and $\mathrm{D}_{2} \mathrm{O}$ in the soil and roots before and after injection. The color-marked roots in the rectangular area in image A were used for the flow calculations in both samples according to Eq. (2.21). In this rectangular area, the $\mathrm{D}_{2} \mathrm{O}$ concentration in the soil near roots reached a relatively constant value shortly after injection in both samples. The marked roots had a length of 11.75-12.80 cm (night sample), and 10.81- 
$11.25 \mathrm{~cm}$ (day sample). The rectangular area was chosen so that it contained a root tip in both day and night samples (Root3). $\mathrm{D}_{2} \mathrm{O}$ concentration in the root tip of this root was used to represent the concentration of $\mathrm{D}_{2} \mathrm{O}$ in the cortex. The first $2 \mathrm{~mm}$ of root 3 after excluding 5 $\mathrm{mm}$ of the apical part was used for this calculation in both samples. Images B, C and D in Figure 3 show the difference between the actual radiographs (at various times) and the radiograph before the $\mathrm{D}_{2} \mathrm{O}$ injection (at $\mathrm{t}=0$ ). Bright gray values indicate reduced neutron attenuation due to increasing the $\mathrm{D}_{2} \mathrm{O} / \mathrm{H}_{2} \mathrm{O}$ ratio. In contrary, the dark areas show $\mathrm{H}_{2} \mathrm{O}$ accumulation after $\mathrm{D}_{2} \mathrm{O}$ injection. Deuterated water first redistributed in the soil quickly due to fast pressure dissipation (bulk flow of $\mathrm{H}_{2} \mathrm{O}+\mathrm{D}_{2} \mathrm{O}$ ), and then slowed down as the diffusive mixing of $\mathrm{D}_{2} \mathrm{O}$ and $\mathrm{H}_{2} \mathrm{O}$ dominated. Roots turned white relatively fast in both night and day samples, indicating a significant diffusion of $\mathrm{D}_{2} \mathrm{O}$ into the roots (Fig. 3B). During the day, $\mathrm{D}_{2} \mathrm{O}$ moved up inside the root beyond the capillary barrier while this was insignificant during night.
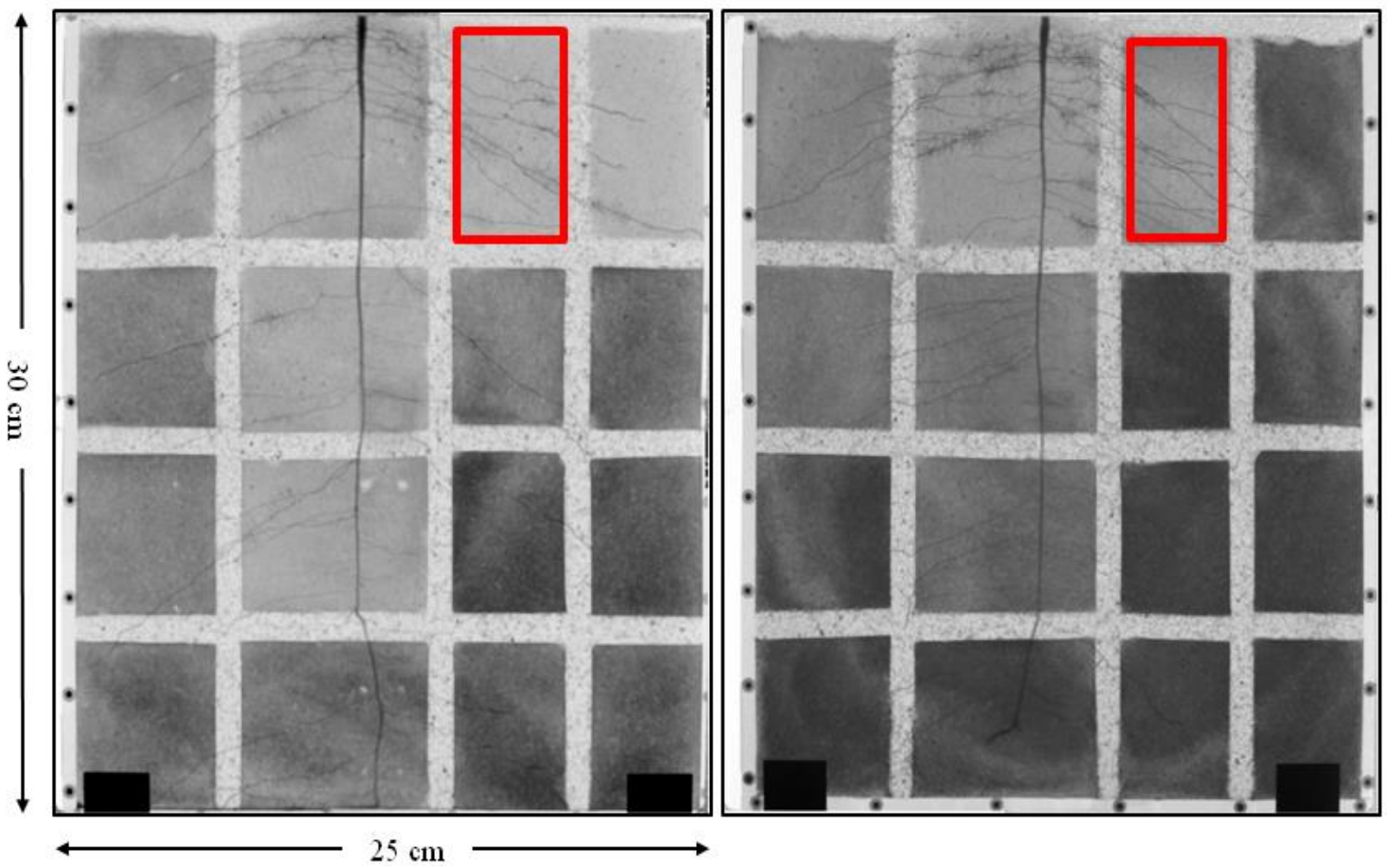

Figure 2: Neutron radiographs of the samples at night (left) and day (right). The gray scales are proportional to water content: the darker, the wetter. The red rectangles show the compartment where $\mathrm{D}_{2} \mathrm{O}$ was injected in each sample. The bright horizontal and vertical layers are the capillary barriers made of coarse sand. 


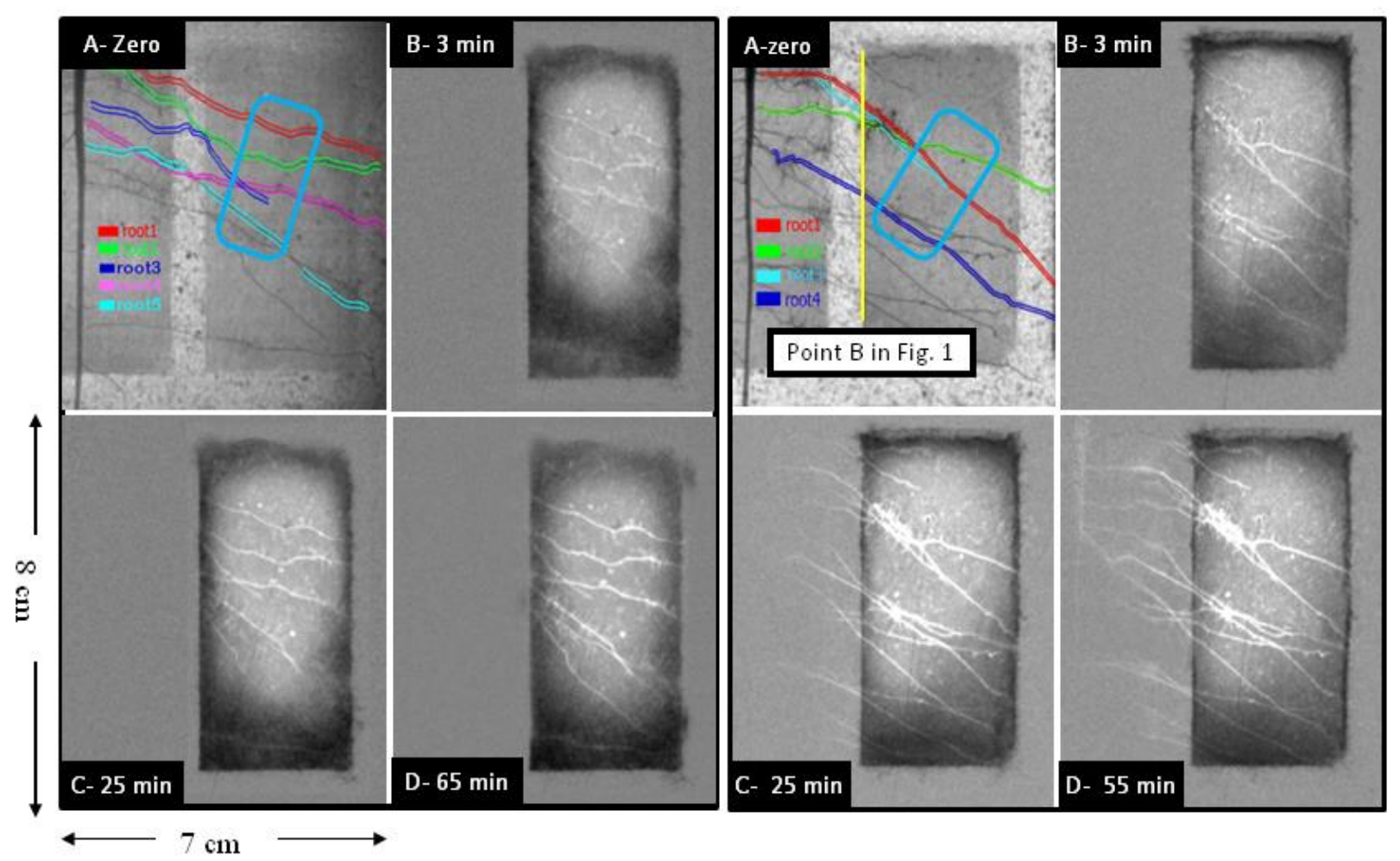

Figure 3: Neutron radiographs of the samples before $\mathrm{D}_{2} \mathrm{O}$ injection (A) and after injection (B, C and $\left.\mathrm{D}\right)$. Left: measurements performed during the night. Right: measurements performed during the day. In Figure A we marked the segmented roots used for the flow analysis. Figures B, C and D images are the difference between the actual radiograph at various times and the one before injection (at $t=0$ ). Brighter color indicates less neutron attenuation and higher $\mathrm{D}_{2} \mathrm{O} / \mathrm{H}_{2} \mathrm{O}$ ratio. The blue rectangles show the location of roots, where we used for calculation of the radial flux ( $\left.j_{r}\right)$ according to Eq. (2.21). The yellow line indicates the location of roots, where we calculated the axial flow rate $\left(J_{x, b}\right)$ according to Eq. (2.24) and (2.25).

\section{Quantification of radial water flow in roots}

After segmenting the roots, we calculated the $\mathrm{D}_{2} \mathrm{O}$ concentration in soil and roots by Eq. (2.12) and Eq. (2.13). Figure 4 shows the average $\mathrm{D}_{2} \mathrm{O}$ concentration in the soil near the roots $\left(\mathrm{C}_{0}\right)$ at night (Fig. 4A) and day (Fig. 4B). The $\mathrm{D}_{2} \mathrm{O}$ concentrations were averaged for the soil 
within $3 \mathrm{~mm}$ distance from the roots inside the rectangular area shown in Fig. 3. The $\mathrm{D}_{2} \mathrm{O}$ concentration sharply increased and then stayed relatively constant over the course of the next hour. The volumetric liquid content $\left(\mathrm{H}_{2} \mathrm{O}+\mathrm{D}_{2} \mathrm{O}\right)$ increased in both samples to $0.18 \mathrm{~cm}^{3}$ $\mathrm{cm}^{-3}$ after $\mathrm{D}_{2} \mathrm{O}$ injection. Based on the soil water retention curve, we expect the soil matric potential to increase from -35 to $-12 \mathrm{hPa}$ for night sample, and from -47 to $-12 \mathrm{hPa}$ for day sample. Therefore, the changes in the soil matric potentials before and after $\mathrm{D}_{2} \mathrm{O}$ injection, compared to the typical gradients in water potential between soil and roots, were insignificant to induce a flow into the roots.

The increase of $\mathrm{D}_{2} \mathrm{O}$ concentration in the roots $\left(C_{\text {root }}\right)$ is shown in Fig. $5 \mathrm{~A}$ and $5 \mathrm{~B}$ for night and day sample, respectively. This increase was faster in the day sample than in the night sample with a half time of approximately 150 seconds for the day, and 280 seconds for the night. The calculated $\mathrm{D}_{2} \mathrm{O}$ concentration in the root $\left(C_{\text {root }}\right)$ is the average concentration across the cortex and stele (Eq. 2.22). To quantify the radial water flux into roots by Eq. (2.21), we need to calculate the concentration of $\mathrm{D}_{2} \mathrm{O}$ in stele $\left(C_{s}\right)$. We used the increase of $\mathrm{D}_{2} \mathrm{O}$ concentration in the root tip of root 3 in both samples, to represent $\mathrm{D}_{2} \mathrm{O}$ concentration in cortical cells. Figure 5C shows that $\mathrm{D}_{2} \mathrm{O}$ concentration in the root tip increased similarly in both day and night sample; suggesting that $\mathrm{D}_{2} \mathrm{O}$ transport into the root tip was driven only by diffusion. The curves were fitted by Eq. (2.23) and the half time of the concentration increase in cortical cells was approximately 120 seconds in day and night. Microscopic observation of the root cross sections (data not shown here) revealed that the radius of the stele was $46 \%$ of the root radius. The cross-sections also showed that the area of 5-6 cm from the root tip had developed an endodermis with casparian bands. The concentration of $\mathrm{D}_{2} \mathrm{O}$ in the root stele $\left(C_{s}\right)$ was calculated according to Eq. (2.22). $\mathrm{D}_{2} \mathrm{O}$ concentration in the root stele increased exponentially with time in both day and night samples (Fig. $5 \mathrm{D}$ and $\mathrm{E}$ ). $\mathrm{D}_{2} \mathrm{O}$ concentration in the root stele increased much faster at day than at night, with a half time of approximately $160 \mathrm{~s}$ at day and $430 \mathrm{~s}$ at night (Eq. 2.21). 

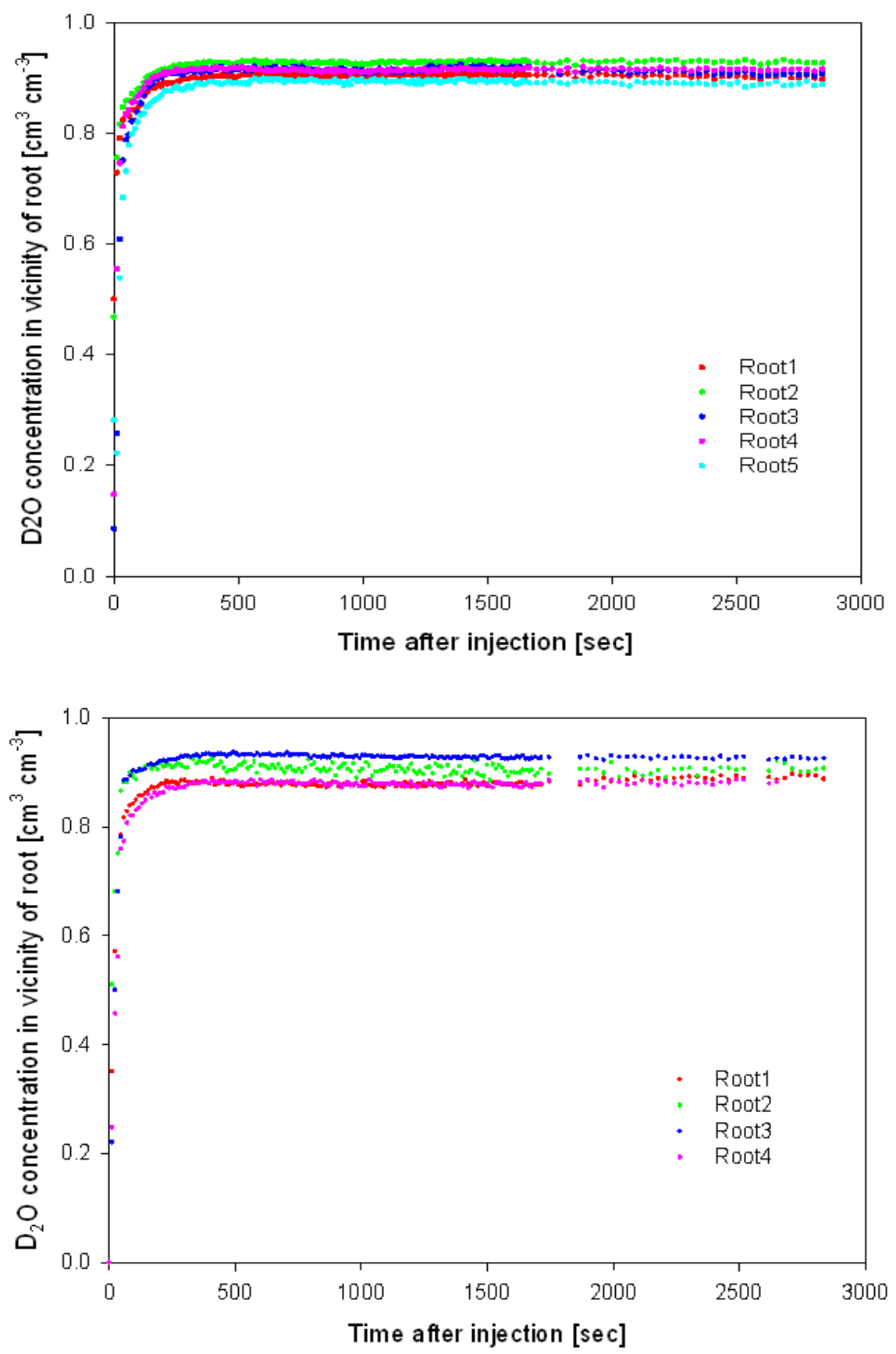

Figure 4: Average $\mathrm{D}_{2} \mathrm{O}$ concentration in the soil near the roots after injecting $3 \mathrm{ml}$ of $\mathrm{D}_{2} \mathrm{O}$ during night (A) and day (B) measurement. The $\mathrm{D}_{2} \mathrm{O}$ concentration is average within $2 \mathrm{~mm}$ region in soil near to root surface in the blue rectangle marked in fig. 3. 

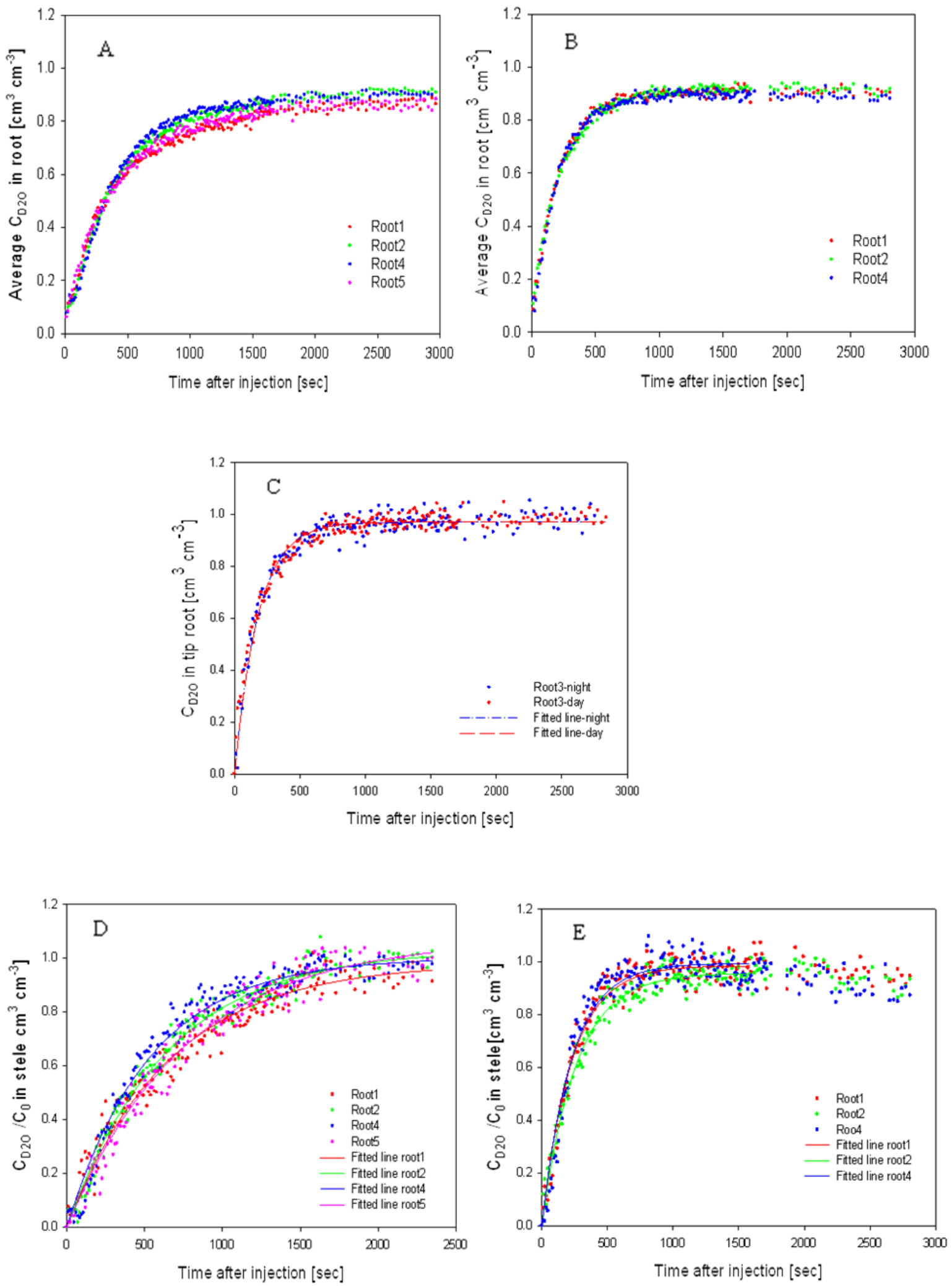

Figure 5: Average $\mathrm{D}_{2} \mathrm{O}$ concentration in roots after $\mathrm{D}_{2} \mathrm{O}$ injection during the night $(\mathrm{A})$ and day $(\mathrm{B})$, in the root tip (C), and in stele after excluding cortex contribution during the night (D) and day (E). In Fig. A, 
B, D and E, the average is calculated along the segmented roots in the blue rectangle marked in Fig. 3. In Fig. $\mathrm{C}$, the data shows the average $\mathrm{D}_{2} \mathrm{O}$ concentration along $2 \mathrm{~mm}$ length of root after excluding $5 \mathrm{~mm}$ apical part of the root tip. 
Table 1 summarized the results obtained from fitting Eq. (2.21) to the $\mathrm{D}_{2} \mathrm{O}$ concentration in the root stele of the night sample. The calculated diffusional permeability of different roots with the same length was similar. The average concentration of $\mathrm{D}_{2} \mathrm{O}$ in soil and root in the final minutes of measurement is presented as equilibrium concentration. We observed slightly smaller $\mathrm{D}_{2} \mathrm{O}$ concentration in the roots than in the soil. The small differences may be originated from the estimation of $\mathrm{D}_{2} \mathrm{O}$ concentration in root, where we neglected the neutron attenuation of solid parts of root. In other words, we assumed that neutron attenuation of root represented the thickness of liquid in the root. Additionally, the differences may be due to the presence of non-exchangeable water inside the root as reported by Bacic and Ratkovic (1987) for maize roots with NMR technique.

Table 1: Properties of the segmented roots and $\mathrm{D}_{2} \mathrm{O}$ transport parameters fitted by an exponential function for night measurement (Eq. (2.21)).

\begin{tabular}{|c|c|c|c|c|c|}
\hline & Unit & Root1 & Root2 & Root4 & Root5 \\
\hline Diffusional permeability, $P_{D}$ & {$\left[\mathrm{~cm} \mathrm{~s}^{-1}\right]$} & $8.52 \mathrm{e}-6$ & $8.69 \mathrm{e}-6$ & $1.04 \mathrm{e}-5$ & $8.13 e-6$ \\
\hline $\begin{array}{l}\text { Equilibrium concentration of } \\
\mathrm{D}_{2} \mathrm{O} \text { at root surface, } \mathrm{C}_{0}\end{array}$ & {$[-]$} & 0.89 & 0.93 & 0.91 & 0.88 \\
\hline $\begin{array}{l}\text { Equilibrium concentration of } \\
\mathrm{D}_{2} \mathrm{O} \text { in root stele, } \mathrm{C}_{\mathrm{s}}\end{array}$ & {$[-]$} & 0.86 & 0.90 & 0.85 & 0.84 \\
\hline Total length & {$[\mathrm{cm}]$} & 12.80 & 11.75 & 11.88 & 11.75 \\
\hline Length after barrier, $L$ & {$[\mathrm{~cm}]$} & 8.58 & 7.79 & 8.38 & 7.72 \\
\hline Root radius, $R$ & {$[\mathrm{~cm}]$} & 0.024 & 0.024 & 0.024 & 0.024 \\
\hline
\end{tabular}




\section{Quantification of axial water flow rate}

We used the calculated value of radial flux $\left(j_{r}\right)$ from Eq. (2.24) to calculate the axial flow of water crossing the barrier (Table 2). For this calculation, we assumed that apical parts of the root tip (length of $1.5 \mathrm{~cm}$ ) were hydraulically isolated from the rest of the roots (Frensch and Steudle, 1989). Therefore, we excluded $1.5 \mathrm{~cm}$ of each root length and assumed that the radial flux $\left(j_{r}\right)$ is uniform along the rest of the root up to the barrier.

To test our model, we quantified the total volume of $\mathrm{D}_{2} \mathrm{O}$ passing the barrier from the neutron radiographs and independently calculated the axial flow rate according to Eq. (2.24). Figure 6A shows the total volume of $\mathrm{D}_{2} \mathrm{O}$ passing the barrier as a function of time during the day. $\mathrm{A}$ few seconds after $\mathrm{D}_{2} \mathrm{O}$ injection, $\mathrm{D}_{2} \mathrm{O}$ was detected beyond the barrier. The volume of $\mathrm{D}_{2} \mathrm{O}$ passing the barrier increased gradually at the beginning, because $\mathrm{D}_{2} \mathrm{O}$ concentration in the root xylem was increasing. After $900 \mathrm{~s}$, when $\mathrm{D}_{2} \mathrm{O}$ concentration in the root at the barrier reached a constant value, the $V_{D 2 O}$ beyond the barrier increased linearly with time. This linear behavior was observed until approximately $2400 \mathrm{~s}$, when $\mathrm{D}_{2} \mathrm{O}$ in the xylem reached the taproot, where it was not monitored anymore. To estimate the axial transport rate at the place of the barrier $\left(J_{x, b}\right)$ according to Eq.(2.25), we used only the linear parts of data. The calculated value of $J_{x, b}$ for each roots is presented in Table 2. The independent calculated values of $J_{x, b}$ using Eq.(2.25) were in a good agreement with the calculated value of $J_{x}$, by using our model according to Eq.(2.24) (Table 2). 
Table 2: Properties of the segmented roots and $\mathrm{D}_{2} \mathrm{O}$ transport parameters fitted by Eq. (2.21), (2.24) and (2.25) for day measurement.

\begin{tabular}{lcccc}
\hline & Unit & Root1 & Root2 & Root4 \\
\hline Radial flux, $j_{r}$, Eq.(2.21) & {$\left[\mathrm{cm} \mathrm{s}^{-1}\right]$} & $1.72 \mathrm{e}-5$ & $1.42 \mathrm{e}-5$ & $1.75 \mathrm{e}-5$ \\
Axial flow rate, $J_{x, b}$, Eq.(2.24) & {$\left[\mathrm{cm}^{3} \mathrm{~s}^{-1}\right]$} & $8.35 \mathrm{e}-6$ & $7.33 \mathrm{e}-6$ & $8.44 \mathrm{e}-6$ \\
Axial flow rate, $J_{x, b}$, Eq.(2.25) & {$\left[\mathrm{cm}^{3} \mathrm{~s}^{-1}\right]$} & $8.00 \mathrm{e}-6$ & $6.00 \mathrm{e}-6$ & $7.00 \mathrm{e}-6$ \\
Equilibrium concentration of $\mathrm{D}_{2} \mathrm{O}$ at & & & & \\
root surface, $\mathrm{C}_{0}$ & {$[-]$} & 0.88 & 0.91 & 0.88 \\
Equilibrium concentration of $\mathrm{D}_{2} \mathrm{O}$ in & & & & \\
root stele, $\mathrm{C}_{\mathrm{s}}$ & {$[-]$} & 0.85 & 0.88 & 0.84 \\
Total length & {$[\mathrm{cm}]$} & 10.81 & 11.25 & 10.91 \\
Length after barrier, $L$ & {$[\mathrm{~cm}]$} & 8.00 & 8.42 & 7.95 \\
Root radius, $R$ & {$[\mathrm{~cm}]$} & 0.025 & 0.025 & 0.025 \\
\hline
\end{tabular}



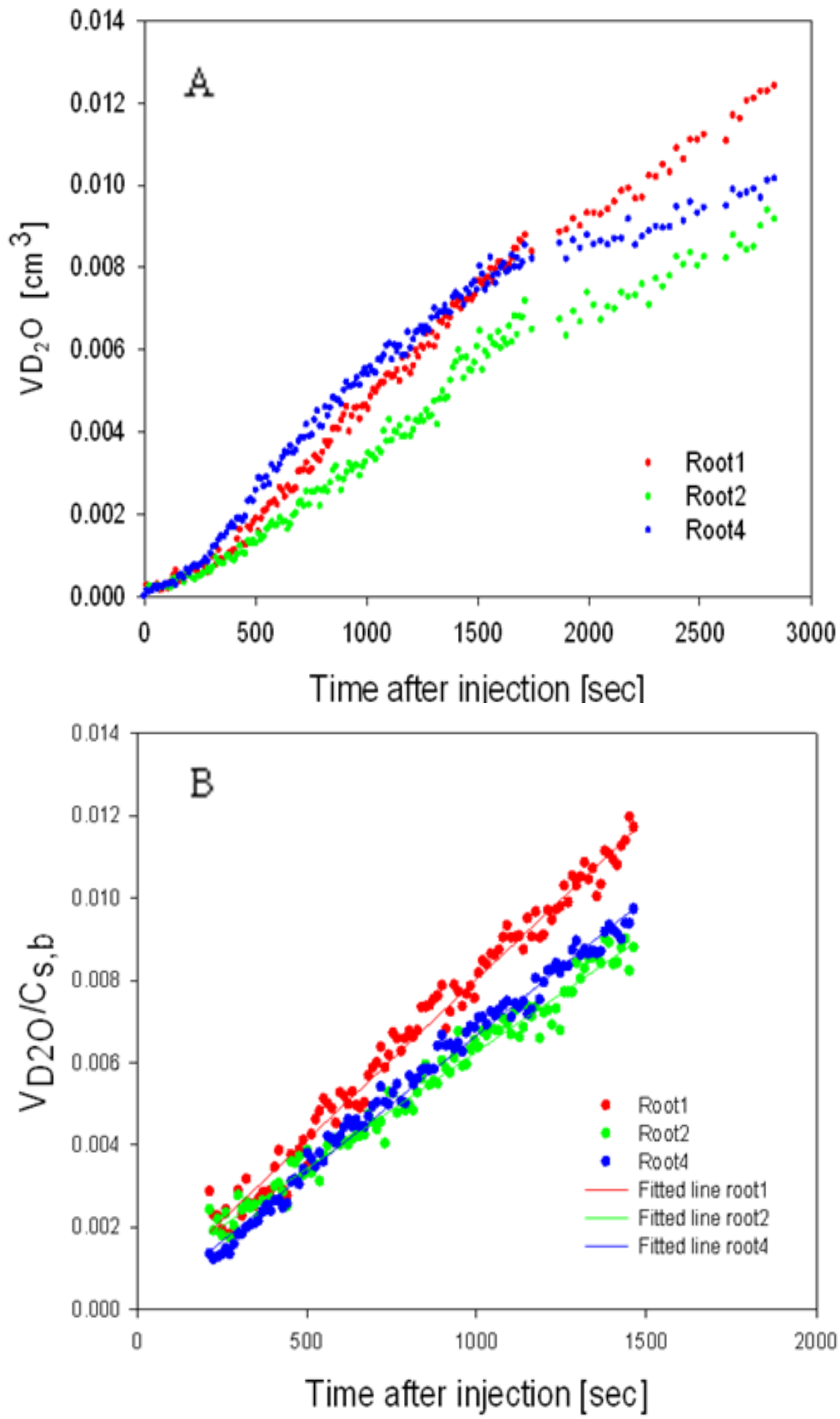

Figure 6: Total volume of $\mathrm{D}_{2} \mathrm{O}$ passing the barrier as a function of time after $\mathrm{D}_{2} \mathrm{O}$ injection (A) and total volume of $\mathrm{D}_{2} \mathrm{O}$ passing the barrier divided by the concentration in the root at the barrier (B). Linear regression of the data in the right figure yielded the axial water flow rate. 


\section{Discussion}

For the first time, local water uptake by individual roots in soil was quantified using deuterated water and neutron radiography. Deuterated water was injected into the soil near the roots and its transport in soil and roots was monitored during the day (transpiring plant) and night (non-transpiring plant) using time-series neutron radiography. The goal was to determine the radial transport of $\mathrm{D}_{2} \mathrm{O}$ into the roots as representative of radial water flux $\left(j_{\mathrm{r}}\right)$ which is one of the key parameters in understanding and modeling local root water uptake.

We developed a simple model to describe the local transport of $\mathrm{D}_{2} \mathrm{O}$ into root and the model suggested valuable hydraulic properties of the root. The model predicted the average diffusional permeability of cortical cell membrane to be $P_{D, C}=3.3 \times 10^{-6} \pm 1.19 \times 10^{-8} \mathrm{~cm} \mathrm{~s}^{-1}$ and the average diffusional permeability of the endodermis to be $P_{D}=9.42 \times 10^{-6} \pm 8.70 \times 10^{-7} \mathrm{~cm} \mathrm{~s}^{-}$ 1. Permeability coefficient of endodermis was greater than that of the cortical cell membrane. This suggests the contribution of apoplastic flow across the endodermis. If there were no apoplastic pathway in endodermis and cell-to-cell pathway was the only pathway, diffusional permeability coefficient of endodermis could have been lower than that of cortical cells. Note that in cell-to-cell transport across the endodermis, $\mathrm{D}_{2} \mathrm{O}$ passes two membranes. Further experiments are needed to confirm this hypothesis.

As the first attempt, the model was tested by comparing the axial flow rate $\left(J_{x, b}\right)$ calculated using our model (Eq. (2.24)) with independent calculation of $J_{x, b}$ (Eq. (2.25)). We obtained a good agreement between the calculated $J_{x, b}$ from the two approaches (Table 2) that may support the modeling approach. However, there are limitations in the current model because of assumptions made. To calculate the radial flow rate of water across root, we assumed the diffusional permeability of endodermis to $\mathrm{D}_{2} \mathrm{O}$ transport will be similar during the day and night. This may not be true. The diffusional permeability of endodermis may vary during the day when cell-to-cell pathway is regulated by aquaporins. Such variability should be verified in further experiments and eventually included in the calculations. Another assumption of the model is the quick transport of $\mathrm{D}_{2} \mathrm{O}$ in the apoplast. Consequence of this assumption is that cortical cells and endodermis were simultaneously imposed to an identical $\mathrm{D}_{2} \mathrm{O}$ concentration to that of the soil at the root surface. In reality, it takes some time for $\mathrm{D}_{2} \mathrm{O}$ molecules to diffuse from the root surface to the endodermis. The typical diffusion time is given by $t=l^{2} /$ $\left(2 D_{e}\right)$, where $l$ is diffusional length and $D_{e}$ is the diffusion coefficient of $\mathrm{D}_{2} \mathrm{O}$ in $\mathrm{H}_{2} \mathrm{O}$. Using the value of diffusion coefficient of $\mathrm{D}_{2} \mathrm{O}$ in water $\left(2.272 \times 10^{-5} \mathrm{~cm}^{2} \mathrm{~s}^{-1}\right.$, Longsworth, 1960), 
and $l$ equal to the cortex thickness $(0.015 \mathrm{~cm})$, we obtain the $\mathrm{D}_{2} \mathrm{O}$ diffusion time to reach to the endodermis to be 5 seconds. Although the actual pathway could be longer due to tortuosity, diffusion in the apoplast seems quick enough to meet our assumption (if diffusional length was 1.5 times longer, the time would have been $11 \mathrm{sec}$ ). It is important to mention that if this assumption was not valid, the actual $\mathrm{D}_{2} \mathrm{O}$ concentration imposed to endodermis would have been overestimated and the diffusional permeability of endodermis would have been underestimated. Consequently, the values of $j_{r}$ calculated from the model would have been overestimated. However, similar value of $J_{x, b}$ calculated by our model and by the independent calculation may support this assumption. Additionally, immediate presence of $\mathrm{D}_{2} \mathrm{O}$ beyond the barrier in day sample (Fig. 6A) suggests that $\mathrm{D}_{2} \mathrm{O}$ arrived to endodermis shortly after $\mathrm{D}_{2} \mathrm{O}$ injection.

The diffusional permeability of the cortical cells was calculated to be $P_{D, C}=3.3 \times 10^{-6} \mathrm{~cm} \mathrm{~s}^{-1}$ and this value was comparable to other literature values. Henzler and Steudle (1995) measured permeability coefficient of deuterated water for intermodal cells of Chara corallina using a cell pressure probe. Their values ranged from $4 \times 10^{-4}$ to $8 \times 10^{-4} \mathrm{~cm} \mathrm{~s}^{-1}$. The water permeability in this type of cell is known to be higher than in cortical cells of higher plants, and values could be variable depending on open/closed status of water channels within the cell membranes. Bacic and Ratkovic (1987) reported the diffusional permeability of $\mathrm{D}_{2} \mathrm{O}$ in cortical cell for roots grown in hydroponic cultures to be in the range of $10^{-6}-10^{-3} \mathrm{~cm} \mathrm{~s}^{-1}$. The estimation of this value depended on the model used for describing $\mathrm{D}_{2} \mathrm{O}$ transport. The average value of diffusional permeability of cortical cell membrane in our study $\left(3.3 \times 10^{-6} \mathrm{~cm}\right.$ $\mathrm{s}^{-1}$ ) falls within the reported range.

Using the total water uptake divided by the total root cross section divided by the radial flux, we estimated that $63 \%$ of the total root length would be needed to fulfill the water demand by the plant. This estimation is larger than the values of 30\% reported by Passioura (1980), Doussan et al. (2003), and Zwieniecki et al. (2003). The difference between our estimation and the literature could be explained by the errors in the assumption of uniform radial flux of water along the active parts of the root system. This uncertainty in the measurements of local water fluxes into and along roots is an important source of error in existing methods.

The significance of this study is the description of a new method to locally quantify water flow into individual roots of living plants. Quantification of the radial flux $\left(j_{r}\right)$ requires a model of water and $\mathrm{D}_{2} \mathrm{O}$ transport inside the roots. The model results were tested by comparing them with an independent measurement of the axial flow rate $\left(J_{x, b}\right)$. This method 
makes it possible to quantitatively address the question of where roots take up water in soils. The answer to this question would open wide ranges of agronomy applications aimed at understanding root development and root functioning in response to various environmental conditions. Additionally, the data can be used to calibrate and test the existing models of root water uptake. Future experiments with $\mathrm{D}_{2} \mathrm{O}$ injected at different locations will give information on the variation of root properties and root water uptake along the root systems.

\section{Acknowledgments}

The corresponding author is financially supported by "IPSWaT" scholarship (under stipendium IPS 11/Q04) from the Germany Federal Ministry of Education and Research (BMBF). Dr. Yangmin Kim is financially supported by the Alexander von Humboldt Foundation, Germany. We thank the late Prof. Ernst Steudle from Bayreuth University, Germany for discussions. Dr. Kosala Ranathunge from Guelph University, Canada is acknowledged for helping with the cross sections of roots. We appreciate the support from Mr. Abbas Dara, University of Potsdam, Germany during the experiments. We thank on the anonymous reviewer for the detailed comments that significantly improved the understandability and the quality of this smanuscript. 


\section{References}

Bacic,G., and S.Ratkovic. 1987. NMR-Studies of Radial Exchange and Distribution of Water in Maize Roots - the Relevance of Modeling of Exchange Kinetics. Journal of Experimental Botany. 38:1284-1297.

Barrowclough,D.E., C.A.Peterson, and E. Steudle. 2000. Radial hydraulic conductivity along developing onion roots. Journal of Experimental Botany. 51:547-557.

Carminati,A., A.B.Moradi, D.Vetterlein, P.Vontobel, E.Lehmann, U.Weller, H.J.Vogel, and S.E.Oswald. 2010. Dynamics of soil water content in the rhizosphere. Plant and Soil. 332:163-176.

Coners,H., and C.Leuschner. 2002. In situ water absorption by tree fine roots measured in real time using miniature sap-flow gauges. Functional Ecology. 16:696-703.

Dainty, J. and Ginzburg, B. Z. 1964.The reflection coefficient of plant cell membranes for certain solutes. Biochim.Biophys.Acta. 79:129:137.

De Jong Van Lier,Q., K.Metselaar, and J.C.Van Dam. 2006. Root water extraction and limiting soil hydraulic conditions estimated by numerical simulation. Vadose Zone Journal. 5:1264-1277.

Doussan,C., L.Pages, and A.Pierret. 2003. Soil exploration and resource acquisition by plant roots: an architectural and modelling point of view. Agronomie. 23:419-431.

Doussan,C., A.Pierret, E.Garrigues, and L.Pages. 2006. Water uptake by plant roots: II Modelling of water transfer in the soil root-system with explicit account of flow within the root system - Comparison with experiments. Plant and Soil. 283:99-117.

Draye,X., Y.Kim, G.Lobet, and M.Javaux. 2010. Model-assisted integration of physiological and environmental constraints affecting the dynamic and spatial patterns of root water uptake from soils. Journal of Experimental Botany. 61:2145-2155.

Enstone, D.E, C.A. Peterson and F.S. Ma. 2002 Root endodermis and exodermis: structure, function, and responses to the environment. Journal of Plant Growth Regulation. 21:335-351. 
Frensch,J., and E.Steudle. 1989. Axial and Radial Hydraulic Resistance to Roots of Maize (Zea-Mays-L). Plant Physiology. 91:719-726.

Frensch, J., T.C.Hsiao, and E.Steudle. 1996. Water and solute transport along developing maize roots. Planta. 198:348-355.

Garrigues,E., C.Doussan, and A.Pierret. 2006. Water uptake by plant roots: I - Formation and propagation of a water extraction front in mature root systems as evidenced by $2 \mathrm{D}$ light transmission imaging. Plant and Soil. 283:83-98.

Henzler,T., and E.Steudle. 1995. Reversible closing of water channels in Chara internodes provides evidence for a composite transport model of the plasma-membrane. Journal of Experimental Botany. 46:199-209.

House,C.R. 1974. Water transport in cells and tissues. Edward Arnold, London.

Huang,B., and P.S.Nobel. 1993. Hydraulic conductivity and anatomy along lateral roots of cacti - changes with soil-water status. New Phytologist. 123:499-507.

Javaux,M., T.Schroder, J.Vanderborght, and H.Vereecken. 2008. Use of a three-dimensional detailed modeling approach for predicting root water uptake. Vadose Zone Journal. 7:1079-1088.

Kaestner, A.P., S.Hartmann, G.Kuehne, G.Frei, C.Gruenzweig, L.Josic, F.Schmid, E.H.Lehmann. 2011. The ICON beamline - A facility for cold neutron imaging at SINQ. Nuclear Instruments and Methods in Physics Research Section A: Accelerators, Spectrometers, Detectors and Associated Equipment. 659:387-393.

Landsberg,J.J., and N.D.Fowkes. 1978. Water-movement through plant roots. Journal of the Science of Food and Agriculture .29:831-832.

Longsworth,L. 1960. The Mutual diffusion of light and heavy water. Journal of Physical Chemistry 64:1914-1917.

McLean,E.H., M.Ludwig, and P.F.Grierson. 2011. Root hydraulic conductance and aquaporin abundance respond rapidly to partial root-zone drying events in a riparian Melaleuca species. New Phytologist .192:664-675. 
Matsushima,U., N.Kardjilov, A.Hilger, W.Graf, and W.B.Herppich. 2008. Application potential of cold neutron radiography in plant science research. Journal of Applied Botany and Food Quality-Angewandte Botanik. 82:90-98.

Meyer,C.J., J.L.Seago, and C.A.Peterson. 2009. Environmental effects on the maturation of the endodermis and multiseriate exodermis of Iris germanica roots. Annals of Botany. 103:687-702.

Menon, B., M. Menon, B. Robinson, S.E. Oswald, A. Kaestner, K.C. Abbaspour, E. Lehmann, and R. Schulin, 2007. Visualization of root growth in heterogeneously contaminated soil using neutron radiography. European Journal of Soil Science. 58: 802-810.

Moradi,A.B., H.M.Conesa, B.Robinson, E.Lehmann, G.Kuehne, A.Kaestner, S.Oswald, and R.Schulin. 2009. Neutron radiography as a tool for revealing root development in soil: capabilities and limitations. Plant and Soil. 318:243-255.

Moradi,A.B., A.Carminati, D.Vetterlein, P.Vontobel, E.Lehmann, U.Weller, J.W.Hopmans, H.J.Vogel, and S.E.Oswald. 2011. Three-dimensional visualization and quantification of water content in the rhizosphere. The New phytologist. 192:653-663.

Passioura,J.B. 1980. The Transport of water from soil to shoot in wheat seedlings. Journal of Experimental Botany. 31:333-345.

Peterson, C. A., M. Murrmann and E. Steudle. 1993. Location of major barriers to water and ion movement in young roots of Zea mays L. Planta. 190:127-136.

Pierret,A., M.Kirby, and C.Moran. 2003. Simultaneous X-ray imaging of plant root growth and water uptake in thin-slab systems. Plant and Soil. 255:361-373.

Pohlmeier,A., A.Oros-Peusquens, M.Javaux, M.I.Menzel, J.Vanderborght, J.Kaffanke, S.Romanzetti, J.Lindenmair, H.Vereecken, and N.J.Shah. 2008. Changes in soil water content resulting from Ricinus root uptake monitored by magnetic resonance Imaging. Vadose Zone Journal. 7:1010-1017.

Roose,T., and A.C.Fowler. 2004. A model for water uptake by plant roots. Journal of Theoretical Biology. 228:155-171. 
Somma,F., J.W.Hopmans, and V.Clausnitzer. 1998. Transient three-dimensional modeling of soil water and solute transport with simultaneous root growth, root water and nutrient uptake. Plant and Soil. 202:281-293.

Steudle,E. 2000. Water uptake by plant roots: an integration of views. Plant and Soil. 226:4556.

Zwieniecki,M.A., M.V.Thompson, and N.M.Holbrook. 2003. Understanding the hydraulics of porous pipes: Tradeoffs between water uptake and root length utilization. Journal of Plant Growth Regulation. 21:315-323. 



\section{Where do roots take up water? Neutron radiography of water flow into roots of transpiring plants growing in soil}

Mohsen Zarebanadkouki, Yangmin X. Kim, Andrea Carminati

New Phytologisit Journal (2013), doi: 10.1111/nph.12330 


\section{Summary}

- Where and how fast does water flow from soil into roots? Answer to this question requires direct and in-situ measurement of local flow of water into roots of transpiring plants growing in soil.

- We used neutron radiography to trace the transport of deuterated water $\left(\mathrm{D}_{2} \mathrm{O}\right)$ in Lupine roots. Lupines were grown in aluminum containers $(30 \times 25 \times 1 \mathrm{~cm})$ filled with sandy soil. $\mathrm{D}_{2} \mathrm{O}$ was injected in different soil regions and its transport in soil and roots was monitored by neutron radiography. The transport of water into roots was then quantified using a convection-diffusion model of $\mathrm{D}_{2} \mathrm{O}$ transport into roots.

- The results showed that water uptake was not uniform along root. Water uptake was higher in the upper soil layers than in the lower ones. Along an individual roots, the radial flux was higher into the proximal segments than into the distal segments.

- In Lupines most of the water uptake occurred in lateral roots. The function of the taproot was to collect water from laterals and transport it to the shoot. This function is ensured by a low radial conductivity and a high axial conductivity. Lupine root architecture seems favorable to take up water from deep soil layers. 


\section{Introduction}

Where and how fast do roots take up water? Despite its importance in plant and soil sciences, there is limited experimental information on the location of water uptake along roots of transpiring plants growing in soil. Root water uptake is a dynamic process that involves complex interactions between atmosphere, plants and soil. Location of water flow into roots depends on the relative importance of the hydraulic conductivities of the root-soil interface, of the radial path across roots, and of the axial path along the xylem (Landsberg \& Fowkes, 1978; Steudle \& Peterson, 1998; Draye et al., 2010).

Due to the porous nature of the roots, the relative importance of radial and axial conductances determines the profile of water uptake along roots (Landsberg \& Fowkes, 1978; Frensch et al., 1996; Hsiao \& Xu, 2000; Zwieniecki et al., 2003). During transpiration, the initiating low water potential at the proximal end of a root dissipates along the root and a lower tension transmittes to the distal parts. A combination of high radial conductivity and low axial conductivity results in a big pressure dissipation along xylem, and in a reduced uptake from the distal parts. Conversely, low radial conductivity and high axial conductivity result in uniform water uptake along the root.

Root hydraulic conductivities vary along the root system during root maturation as well as in response to external conditions. As roots mature, their radial hydraulic conductivities decrease as a consequence of anatomical modification of the root tissue (Steudle \& Peterson, 1998; Enstone et al., 2003; Bramley et al., 2009; Knipfer \& Fricke, 2010). Decrease of the radial hydraulic conductivity with age shifts the water uptake zone to the distal root segments. The axial conductivity varies along root length as a consequence of the differentiation of early metaxylem vessels during the developmental stage of plants and the formation of secondary xylem during secondary growth (Varney \& Canny, 1993; McCully, 1995; Vercambre et al., 2002; Bramley et al., 2009). Increase of axial hydraulic conductivity through root maturation helps to redistribute the water uptake zone more evenly along roots. As the soil dries, the soil hydraulic conductivity may further limit root water uptake. As the soil typically dries up quicker in the upper layers (due to evaporation, gravity and higher root length density), the water uptake zone is expected to move downwards along the soil profile. 
To date, it has been difficult to directly measure where roots take up water in soil. Thanks to recent advances in imaging methods, it is now possible to monitor the spatiotemporal distribution of roots and water content in soil (Pierret et al., 2003; Garrigues et al., 2006; Pohlmeier et al., 2008; Moradi et al., 2011). In these studies, root water uptake was indirectly estimated from the decrease in soil water content near the roots. However, simulations of water flow in soil demonstrated that water uptake is not equal to the change in water content because of soil water redistribution. Therefore, observations of water content change must be coupled with models of water flow in roots and soil (Javaux et al., 2008). Such methods require accurate knowledge of root and soil hydraulic properties and cannot differentiate between uptake rates of neighboring roots.

In this study, we tested a new method to measure the local fluxes of water into and along the root system of transpiring plant growing in soil. The method consists of monitoring the transport of deuterated water $\left(\mathrm{D}_{2} \mathrm{O}\right)$ into roots by means of time-series neutron radiography. Neutron radiography is an imaging technique that has high sensitivity to normal water $\left(\mathrm{H}_{2} \mathrm{O}\right)$. Compared to normal water, $\mathrm{D}_{2} \mathrm{O}$ is almost transparent in neutron radiography and its transport into roots can be monitored at high temporal and spatial resolution. The method was introduced by Zarebanadkouki et al.( 2012), who applied it to lateral roots of Lupines at a specific location of the root system. The objective of the present study was to apply the technique to different locations along the roots of lupins. The model introduced by Zarebanadkouki et al.( 2012) has been extended to the case of roots partly immersed in $\mathrm{H}_{2} \mathrm{O}$ and partly in $\mathrm{D}_{2} \mathrm{O}$. Additionally, the description of the radial pathway of water into roots has been generalized to allow a varying importance of apoplastic and cell-to-cell flow. The questions we addressed are: where does water enter the roots of lupins? Is the water uptake higher in the taproot or in the laterals, and in the proximal or in the distal segments? In these experiments, the soil was kept wet. In further studies, we will investigate how the uptake patterns change as the soil dries. 


\section{Materials and methods}

\section{Plant and soil preparation}

Lupines (Lupinus albus L.cv. Feodora) were grown in aluminum containers ( $25 \mathrm{~cm}$ wide, 30 $\mathrm{cm}$ high and $1 \mathrm{~cm}$ thick) filled with sandy soil. The soil was collected from the artificial catchment of Chicken Creek located near Cottbus, Germany. The soil (sieved to a particle size smaller than $2 \mathrm{~mm}$ ) consisted of $92 \%$ sand, $5 \%$ silt and $3 \%$ clay. The aluminum faces of the containers were detachable to allow filling of the soil. Three vertical sticks $(1 \times 30 \times 1 \mathrm{~cm})$ and three horizontal ones $(1 \times 25 \times 1 \mathrm{~cm})$ made of plastic were placed inside the containers dividing the internal space of the containers into sixteen compartments ( 4 rows $\times 4$ columns). The sandy soil was poured into each compartment through a $2 \mathrm{~mm}$ sieve to favor a homogeneous soil deposition and to reduce soil layering while the containers were laid horizontally. Dry weight of the soil was approximately $1 \mathrm{~kg}$ in each container. The soil was wetted and the sticks were removed from the containers. The space between the compartments was filled with coarse sand (grain diameter of 1.2-1.7 $\mathrm{mm}$ ). The layers of coarse sand acted as capillary barriers to hydraulically disconnect the adjacent compartments without hindering root penetration. We refer to these layers as capillary barriers. The detachable faces of the containers were then closed, and the samples were gently turned vertically. This procedure resulted in an average bulk density of $1.4 \mathrm{~g} \mathrm{~cm}^{-3}$. The detachable face of the containers had holes of $1 \mathrm{~mm}$ in diameter at intervals of $3 \mathrm{~cm}$. A fine-needle syringe was used for injecting D2O through the holes into the soil. The top of the samples was covered with $1 \mathrm{~cm}$ layer of quartz gravel with grain size of $3 \mathrm{~mm}$ to minimize evaporation.

Lupines (Lupinus albus L.cv. Feodora) were grown in aluminum containers ( $25 \mathrm{~cm}$ wide, 30 $\mathrm{cm}$ high and $1 \mathrm{~cm}$ thick) filled with sandy soil. The soil was collected from the artificial catchment of Chicken Creek located near Cottbus, Germany. The soil (sieved to a particle size smaller than $2 \mathrm{~mm}$ ) consisted of $92 \%$ sand, $5 \%$ silt and $3 \%$ clay. The aluminum faces of the containers were detachable to allow filling of the soil. Three vertical sticks $(1 \times 30 \times 1 \mathrm{~cm})$ and three horizontal ones $(1 \times 25 \times 1 \mathrm{~cm})$ made of plastic were placed inside the containers dividing the internal space of the containers into sixteen compartments ( 4 rows $\times 4$ columns). The sandy soil was poured into each compartment through a $2 \mathrm{~mm}$ sieve to favor a 
homogeneous soil deposition and to reduce soil layering while the containers were laid horizontally. Dry weight of the soil was approximately $1 \mathrm{~kg}$ in each container. The soil was wetted and the sticks were removed from the containers. The space between the compartments was filled with coarse sand (grain diameter of 1.2-1.7 mm). The layers of coarse sand acted as capillary barriers to hydraulically disconnect the adjacent compartments without hindering root penetration. We refer to these layers as capillary barriers. The detachable faces of the containers were then closed, and the samples were gently turned vertically. This procedure resulted in an average bulk density of $1.4 \mathrm{~g} \mathrm{~cm}^{-3}$. The detachable face of the containers had holes of $1 \mathrm{~mm}$ in diameter at intervals of $3 \mathrm{~cm}$. A fine-needle syringe was used for injecting $\mathrm{D}_{2} \mathrm{O}$ through the holes into the soil. The top of the samples was covered with $1 \mathrm{~cm}$ layer of quartz gravel with grain size of $3 \mathrm{~mm}$ to minimize evaporation.

Lupine seeds were germinated on moist filter paper in the dark for 24 hours. The seedlings were then planted in the containers at $1 \mathrm{~cm}$ depth. The plants were grown for 18 to 21 days with photoperiod of 14 hours, light intensity of $300 \mu \mathrm{mol} \mathrm{m} \mathrm{m}^{-1}$, day/night temperature of $24^{\circ} \mathrm{C} / 19^{\circ} \mathrm{C}$, and relative humidity of $60 \%$. Plants were irrigated every third day by slowly immersing the samples in a nutrient solution until the water table reached the bottom of the upper compartments. The bottom of containers had holes to allow infiltration from the bottom. The samples were then slowly lifted letting each compartment to drain freely. This resulted in an average water content of $0.20 \mathrm{~cm}^{3} \mathrm{~cm}^{-3}$ in each compartment. The nutrient solution was composed of (in $\mathrm{mM}$ ): $\mathrm{K}_{2} \mathrm{SO}_{4}, 3.5 ; \mathrm{KCl}, 1 ; \mathrm{KH}_{2} \mathrm{PO}_{4}, 1 ; \mathrm{Ca}\left(\mathrm{NO}_{3}\right)_{2}, 1 ; \mathrm{MgSO}_{4}, 5$; and (in $\mu \mathrm{M}) \mathrm{H}_{3} \mathrm{BO}_{3}, 100 ; \mathrm{MnSO}_{4}, 5 ; \mathrm{ZnSO}_{4}, 5 ; \mathrm{CuSO}_{4}, 2 ;\left(\mathrm{NH}_{4}\right) \mathrm{Mo}_{7} \mathrm{O}_{24}, 0.1 ;$ Fe-EDTA, 200. The plants were 18 to 21day-old when the neutron radiography experiment started. Transpiration rates were calculated by weighing samples at intervals of six hours during day and night. The average of daytime transpiration of 18 to 21 -day-old plants was $1.23 \pm 0.18 \mathrm{~g} \mathrm{~h}^{-}$ ${ }^{1}(\mathrm{n}=10)$ and it was negligible at night. At this stage, plants had six leaves with a total leaf area of approximately $63 \pm 5 \mathrm{~cm}^{2}(\mathrm{n}=3)$. After the measurement, we opened the containers and washed the roots. We did not observe any evidence of arbuscular mycorrhizas and rhizobial nodules. 


\section{Neutron radiography}

Neutron radiography is an imaging technique that, due to its high sensitivity to hydrous materials, has been widely used to image water and root distribution in soil (Tumlinson et al., 2007; Oswald et al., 2008; Moradi et al., 2008; Carminati et al., 2010). Neutron radiography consists in guiding a neutron beam across the sample. The transmitted beam carries the information about sample composition and thickness. The Beer-Lambert law describes the attenuation of the neutron beam through a sample

$$
\frac{I}{I_{0}}=\exp ^{-\sum_{i=1}^{i=n}\left(\mu_{i} d_{i}\right)}
$$

where $I$ is the intensity of the attenuated neutron beam [number of neutrons $\mathrm{m}^{-2} \mathrm{~s}^{-1}$ ], $I_{0}$ is the intensity of the incident neutron beam [number of neutrons $\mathrm{m}^{-2} \mathrm{~s}^{-1}$ ], $\mathrm{d}_{\mathrm{i}}(\mathrm{m})$ is the thickness of the $i$-material composing the sample, and $\mu_{i}\left[\mathrm{~m}^{-1}\right]$ is the macroscopic neutron attenuation coefficient, which describes the probability of neutron interactions with the materials per unit of thickness.

Our experiments were carried out at the ICON beam-line of the Paul Scherrer Institute (PSI), Switzerland. We used a CCD camera detector with an array of $1260 \times 1260$ pixels, resulting in a field of view of $15.75 \times 15.75 \mathrm{~cm}$ and an effective spatial resolution of $0.125 \mathrm{~mm}$. Four radiographs with marginal overlaps were needed to scan a whole sample. For the measurements during daytime, a lamp that was identical to those in the growth chamber was installed in the imaging station above the plants. Plants were kept in the imaging station for one hour before starting the measurement. The measurements lasted approximately two hours. Transpiration rate was measured from the weight of samples before and after neutron radiography. During daytime measurements, the average transpiration was $1.43 \pm 0.25 \mathrm{~g} \mathrm{~h}^{-1}$ $(n=4)$.

\section{Deuterated water}

Deuterated water $\left(\mathrm{D}_{2} \mathrm{O}\right)$ was used as a contrast agent to trace the flow of water into the roots. In contrast to normal water, $\mathrm{D}_{2} \mathrm{O}$ has a much lower neutron attenuation coefficient, which makes it well distinguishable in neutron radiographs. Because of its similarity to water, $\mathrm{D}_{2} \mathrm{O}$ has been used since long time to study water flow in plants (Ordin \& Kramer, 1956; 
Matsushima et al., 2008; Da-Ines et al., 2010). We locally injected 3-4 $\mathrm{ml}$ of $\mathrm{D}_{2} \mathrm{O}$ (purity of $99.97 \%$ ) in selected soil compartments using a syringe. Spatiotemporal distribution of $\mathrm{D}_{2} \mathrm{O}$ in soil and its transport into and along roots were monitored by time-series neutron radiography at time intervals of 10 seconds for a period of two hours. The measurements were performed during daytime and nighttime at different locations of 10 samples.

\section{Image processing}

Neutron radiographs were referenced to flat field (radiography without sample) and dark current (signal recorded by the camera when there was no beam). The neutron attenuations of aluminum and dry soil were determined by the neutron radiographs of a slab filled with dry soil. After subtraction of the contribution of aluminum and dry soil, the remaining values gave the water content in the sample. Due to their high water content, roots could be clearly distinguished from the soil. Roots were segmented from soil using the roottracker2D algorithm developed by Anders Kaestner (Menon et al., 2007). Root segmentation was performed on the radiographs obtained before the injection of $\mathrm{D}_{2} \mathrm{O}$. The segmented roots were skeletonized and their length and diameter were calculated using the Euclidean distance. In $2 \mathrm{D}$ radiographs, the signal in the pixels containing the roots was composed of attenuation coefficients of the root and of the soil in front of and behind of the root in the beam direction (across soil thickness). The actual contributions of $\mathrm{H}_{2} \mathrm{O}$ and $\mathrm{D}_{2} \mathrm{O}$ in the root were calculated assuming that the amount of $\mathrm{H}_{2} \mathrm{O}$ and $\mathrm{D}_{2} \mathrm{O}$ in soil in front of and behind of the root was equal to that of the soil at the sides of the root (i.e. it we assumed a radial symmetry around the roots). We calculate the volumetric concentration of $\mathrm{D}_{2} \mathrm{O}$ in root $\left(\mathrm{C}_{\mathrm{r}}\right)$ and soil $\left(\mathrm{C}_{0}\right)$ as the thickness of $\mathrm{D}_{2} \mathrm{O}$ divided by the total liquid thickness in root and soil, respectively. $\mathrm{C}_{\mathrm{r}}$ and $\mathrm{C}_{0}$ were averaged along the segment of roots immersed in $\mathrm{D}_{2} \mathrm{O}$.

The volume of $\mathrm{D}_{2} \mathrm{O}$ transported beyond the capillary barrier was calculated by subtracting the radiographs at time $t$ from the radiograph before $\mathrm{D}_{2} \mathrm{O}$ injection. This image processing is described in details in the supplementary information (Method S1) and Zarebanadkouki et al. (2012). 


\section{Model of $\mathrm{D}_{2} \mathrm{O}$ transport in roots}

To quantify the radial flux of water into roots, Zarebanadkouki et al. ( 2012) introduced a simple model of $\mathrm{D}_{2} \mathrm{O}$ transport into and along roots. The transport of $\mathrm{D}_{2} \mathrm{O}$ into roots was described by a diffusion-convection model, where the transport rate of $\mathrm{D}_{2} \mathrm{O}$ into the roots depended on the convective transport (net root water uptake) and on the diffusion of $\mathrm{D}_{2} \mathrm{O}$ (Fig. 1). Zarebanadkouki et al. (2012) assumed that the entire root segment, including the root tip, was immersed in $\mathrm{D}_{2} \mathrm{O}$ and the radial flow of water across the cortex was primarily apoplastic. In the present paper, the model is extended to the case when a portion of the root is immersed in $\mathrm{D}_{2} \mathrm{O}$, while the rest is immersed in normal water. Additionally, the description of the water flow across the cortex has been generalized to allow a variable importance of the apoplast and cell-to-cell pathways. The model is explained in the next sections. Derivation of the equations is given in the Appendix A.

L: root lenght immersed in $\mathrm{D}_{2} \mathrm{O}$

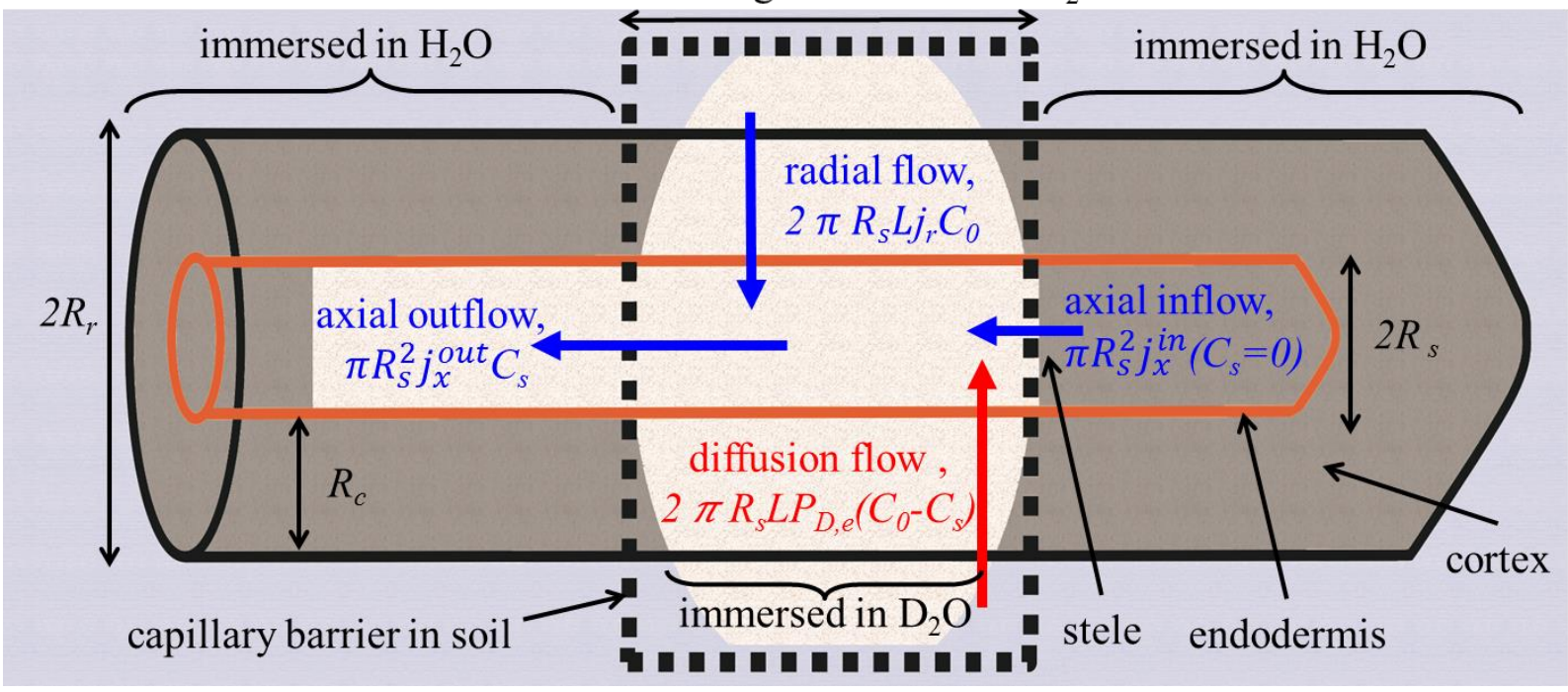

Figure 1: Illustration of $\mathrm{D}_{2} \mathrm{O}$ transport into a root that is partially immersed in $\mathrm{D}_{2} \mathrm{O}$. The radial transport of $\mathrm{D}_{2} \mathrm{O}$ into the root is driven by the concentration gradients between soil and root (diffusion, red arrows) and by convection following the transpiration stream (blue arrows). As $\mathrm{D}_{2} \mathrm{O}$ reaches the xylem, it mixes with the incoming water flow and it flows axially along the root. The capillary barriers were used to limit $\mathrm{D}_{2} \mathrm{O}$ diffusion in soil. 
The model is based on the observation that the increase of $\mathrm{D}_{2} \mathrm{O}$ was well fitted with the sum of two exponential curves. Statistical justification of the use of a two exponential equation instead of single exponential is given as Appendix B, Fig S1. The two exponential rates were explained by the different dynamics of $\mathrm{D}_{2} \mathrm{O}$ transport into cortex and stele. Dynamics of $\mathrm{D}_{2} \mathrm{O}$ into cortex and stele depends not only on the diffusional permeability of the two compartments separated by the endodermis, but also on the axial flow along the roots. Imagine that a root segment is immersed in $\mathrm{D}_{2} \mathrm{O}$, while its proximal and distal segments are immersed in normal water. As normal water flows into the distal segment, $\mathrm{D}_{2} \mathrm{O}$ and normal water will mix depending on the relative magnitudes of the radial and axial flow. The final concentration in the xylem of the segment immersed into $\mathrm{D}_{2} \mathrm{O}$ will converge to a lower value than the $\mathrm{D}_{2} \mathrm{O}$ concentration in soil and the rate of increase will be affected by the axial flow of apical segment. Instead, the concentration in the cortex will converge to that of the soil, as the axial flow into the cortex is typically neglected. For this reason, the $\mathrm{D}_{2} \mathrm{O}$ dynamics in stele and cortex are treated separately.

The average $\mathrm{D}_{2} \mathrm{O}$ concentration in the root, $C_{r}$, is calculated as the sum of the $\mathrm{D}_{2} \mathrm{O}$ concentration in the cortex, $C_{c}$, and the stele, $C_{s}$

$$
C_{r}=\frac{\left(R_{r}-R_{s}\right) C_{c}+R_{s} C_{s}}{R_{r}}
$$

where $R_{r}$ and $R_{s}$ are the root and the stele radius.

We first consider the experiments at nighttime, when convection is assumed to be negligible. As mentioned above, our observations showed that the concentration of $\mathrm{D}_{2} \mathrm{O}$ in root could be described by a two exponential model. Increase of $\mathrm{C}_{\mathrm{D} 2 \mathrm{O}}$ in roots at nighttime is described as

$$
C_{r}=\frac{R_{r}-R_{s}}{R_{r}} C_{0}\left(1-\exp ^{-k_{c}^{n} t}\right)+\frac{R_{s}}{R_{r}} C_{0}\left(1-\exp ^{-k_{s}^{n} t}\right)
$$

where $C_{0}$ is the $\mathrm{D}_{2} \mathrm{O}$ concentration in soil, and $k_{c}^{n}$ and $k_{s}^{n}$ are the rate constants of $\mathrm{D}_{2} \mathrm{O}$ concentration increase in the root cortex and the root stele at nighttime. Under the following assumptions, Eq. (3.3) can be demonstrated and the two rate constants have a physical 
meaning. The assumptions are: (i) reflection coefficient of $\mathrm{D}_{2} \mathrm{O}$ across root membranes is approximated as zero, as measured by Henzler \& Steudle (1995); (ii) $\mathrm{D}_{2} \mathrm{O}$ rapidly diffuses through the apoplast of the root cortex; and (iii) the endodermis is the main resistance to transport of $\mathrm{D}_{2} \mathrm{O}$ from the inner part of the cortex to the xylem vessels, with a consequient uniform $\mathrm{D}_{2} \mathrm{O}$ concentration inside the root stele. Note that the assumption (ii) does not necessarily mean that there is a significant $\mathrm{D}_{2} \mathrm{O}$ transport $\left[\mathrm{m}^{3} \mathrm{~s}^{-1}\right]$ across the apoplast. Under these assumptions, the parameters in Eq. (3.3) are

$$
\begin{aligned}
k_{c}^{n} & =\frac{2 P_{D, c}}{r_{c}} \\
k_{s}^{n} & =\frac{2 P_{D, e}}{R_{s}}
\end{aligned}
$$

where $P_{D, c}\left[\mathrm{~m} \mathrm{~s}^{-1}\right]$ is the diffusional permeability of the cortical cells, $r_{\mathrm{c}}$ is the radius of the cortical cells, and $P_{D, e}\left[\mathrm{~m} \mathrm{~s}^{-1}\right]$ is the diffusional permeability of the endodermis. The diffusional permebility is defined as the diffusion ceoffiecent of $\mathrm{D}_{2} \mathrm{O}$ across the membrane divided by the thinckness of the membrane. In circumstances when the assumptions are not valid, Eq. (3.3) has to be considered as an empirical equation and the rate constants as effective diffusional parameters of cortex and stele.

During the daytime, transpiration results in a convective flow of water from soil to roots. Convective transport of $\mathrm{D}_{2} \mathrm{O}$ across the root (radial flow) and along the root (axial flow) need to be included in the model. Increase of $\mathrm{D}_{2} \mathrm{O}$ concentration in the roots at daytime is described as

$$
C_{r}=\frac{R_{r}-R_{s}}{R_{r}} C_{0}\left(1-\exp ^{-k_{c}^{d} t}\right)+\frac{R_{s}}{R_{r}} \beta C_{0}\left(1-\exp ^{-k_{s}^{d} t}\right)
$$

where $k_{c}^{d}$ and $k_{s}^{d}$ are rate constants of the root cortex and the root stele at daytime, and $\beta$ is a coefficient that describes the fact that when a root is only partly immersed in $\mathrm{D}_{2} \mathrm{O}$ its concentration does not converge to $C_{0}(\beta \leq 1)$ Under the assumptions (i)-(iii), Eq. (3.5) can be explicitly derived and its parameters have the following physical meaing 


$$
\begin{gathered}
k_{c}^{d}=\frac{2 P_{D, c}+\lambda \frac{j_{r}}{2}}{r_{c}} \\
k_{s}^{d}=\frac{2 P_{D, e}}{R_{s}}+\frac{j_{x}^{\text {out }}}{L} \\
\beta=\frac{\frac{2 P_{D, e}+2 j_{r}}{R_{s}}}{\frac{2 P_{D, e}}{R_{s}}+\frac{j_{x}^{\text {out }}}{L}}
\end{gathered}
$$

where $j_{r}\left[\mathrm{~m} \mathrm{~s}^{-1}\right]$ is the radial flux of water into the root endodermis, $j_{x}^{\text {out }}\left[\mathrm{m} \mathrm{s}^{-1}\right]$ is the axial flux of water through the root stele from the root segment immersed in $\mathrm{D}_{2} \mathrm{O}, L$ is the length of the root segment immersed in $\mathrm{D}_{2} \mathrm{O}$, and $\lambda$ is a coefficient vairing between zero and unity and describing the relative importance of the apoplastic and cell-to-cell flow across the cortex. If the flow through the cortex is purely apoplectic, $\lambda=0$ and the model corrensponds to that of Zarebanadkouki et al. (2102). If the flow though the cortex is purely cell-to-cell, $\lambda=1$.

If the root segment including the root tip is entirely immersed in $\mathrm{D}_{2} \mathrm{O}$, the outflow of liquid from the root segment is equal to the radial flow into the segment $\left(\pi R_{S}^{2} j_{x}^{\text {out }}=2 \pi R_{S} L j_{r}\right)$. From Eq. (3.6) it follows that $\beta=1$ and $k_{s}^{d}=2\left(P_{D, e}+j_{r}\right) / R_{s}$. This case corresponds to the model of Zarebanadkouki et al . (2012). For the roots that are partly immersed in $\mathrm{D}_{2} \mathrm{O}$, the outflow of liquid from the root segment is equal to the radial convective flow into the segment plus the axial inflow of liquid into the root segment $\left(\pi R_{s}^{2} j_{x}^{\text {out }}=2 \pi R_{s} L j_{r}+\right.$ $\left.\pi R_{S}^{2} j_{x}^{i n}\right)$. In this case, $\beta<1$.

Eq. (3.3) and Eq. (3.5) were fitted to the data of the $\mathrm{D}_{2} \mathrm{O}$ concentration increase in roots during nighttime and daytime that were obtained from neutron radiographs. From the nighttime measurements, we calculated the diffusional permeabilities, $P_{D, c}$ and $P_{D, e}$. To calculate the net transport of $\mathrm{D}_{2} \mathrm{O}$ into roots, we assumed that the diffusional permeability coefficients were identical at daytime and nighttime. The validity of this assumption is discussed later in the text. 


\section{Quantification of axial flux along the root}

The axial fluxes, $j_{x}^{\text {out }}$, were directly calculated from the volume of $\mathrm{D}_{2} \mathrm{O}$ that passed the capillary barrier, $V_{\mathrm{D} 2 \mathrm{O}}\left[\mathrm{m}^{3}\right] . V_{\mathrm{D} 2 \mathrm{O}}$ is related to the axial flow according to

$$
\frac{d V_{D_{2} O}}{d t}=\pi R_{s}^{2} j_{x}^{\text {out }} C_{s, b}(t)
$$

where $C_{s, b}$ is the $\mathrm{D}_{2} \mathrm{O}$ concentration in the root stele at the place of capillary barrier . $V_{\mathrm{D} 2 \mathrm{O}}$ was quantified from the time-series neutron images. Note that the values obtained with Eq. (3.7) are independent from our modeling approach.

\section{Results}

We measured the transport of $\mathrm{D}_{2} \mathrm{O}$ into the roots of ten plants. $\mathrm{D}_{2} \mathrm{O}$ was injected into selected compartments of each sample during daytime and nighttime. To illustrate the results, we show the radiographs of one sample in which $\mathrm{D}_{2} \mathrm{O}$ was injected during the daytime in two compartments (Figure 2). Figure 2a shows radiography of the sample before injection of $4 \mathrm{ml}$ of $\mathrm{D}_{2} \mathrm{O}$ into each compartment. The image was obtained by overlapping four radiographs taken at different locations. A close-up of the regions where $\mathrm{D}_{2} \mathrm{O}$ was injected is shown in Figure $2 \mathrm{~b}$. In Figure $2 \mathrm{a}$ and $2 \mathrm{~b}$ the gray values are proportional to water content: the darker was the image the higher was the soil water content. Before $\mathrm{D}_{2} \mathrm{O}$ injection, the average soil water content in all compartments of the 10 sampels was between 0.08 and $0.15\left[\mathrm{~cm}^{3} \mathrm{~cm}^{-3}\right]$, which in our soil corresponds to soil matric potentials of $-70 \mathrm{hPa}$ and $-20 \mathrm{hPa}$, respectively (Carminati et al., 2010). After injection of $\mathrm{D}_{2} \mathrm{O}$, the water content increased from 0.08-0.15 to $0.18-0.25$. The corresponding change in pressure is expected to be of approximately $50 \mathrm{hPa}$, which is small compared to the difference in water potential between soil and root.

The sharp contrast between roots and the surrounding soil resulting from the higher volumetric water content in roots allowed us to segment roots from soil. The average root length of the ten plants was $470 \pm 36 \mathrm{~cm}(\mathrm{n}=10)$. The marked rectangles in Figure $2 \mathrm{a}$ show the compartments where $\mathrm{D}_{2} \mathrm{O}$ was injected. The roots that were selected for the analysis of $\mathrm{D}_{2} \mathrm{O}$ transport are marked as roots 1-7 (Figure 2b). Root 1, 2 and 4 had a length of 12-14 cm, and roots 3 and 7 had a length of $8-10 \mathrm{~cm}$. 

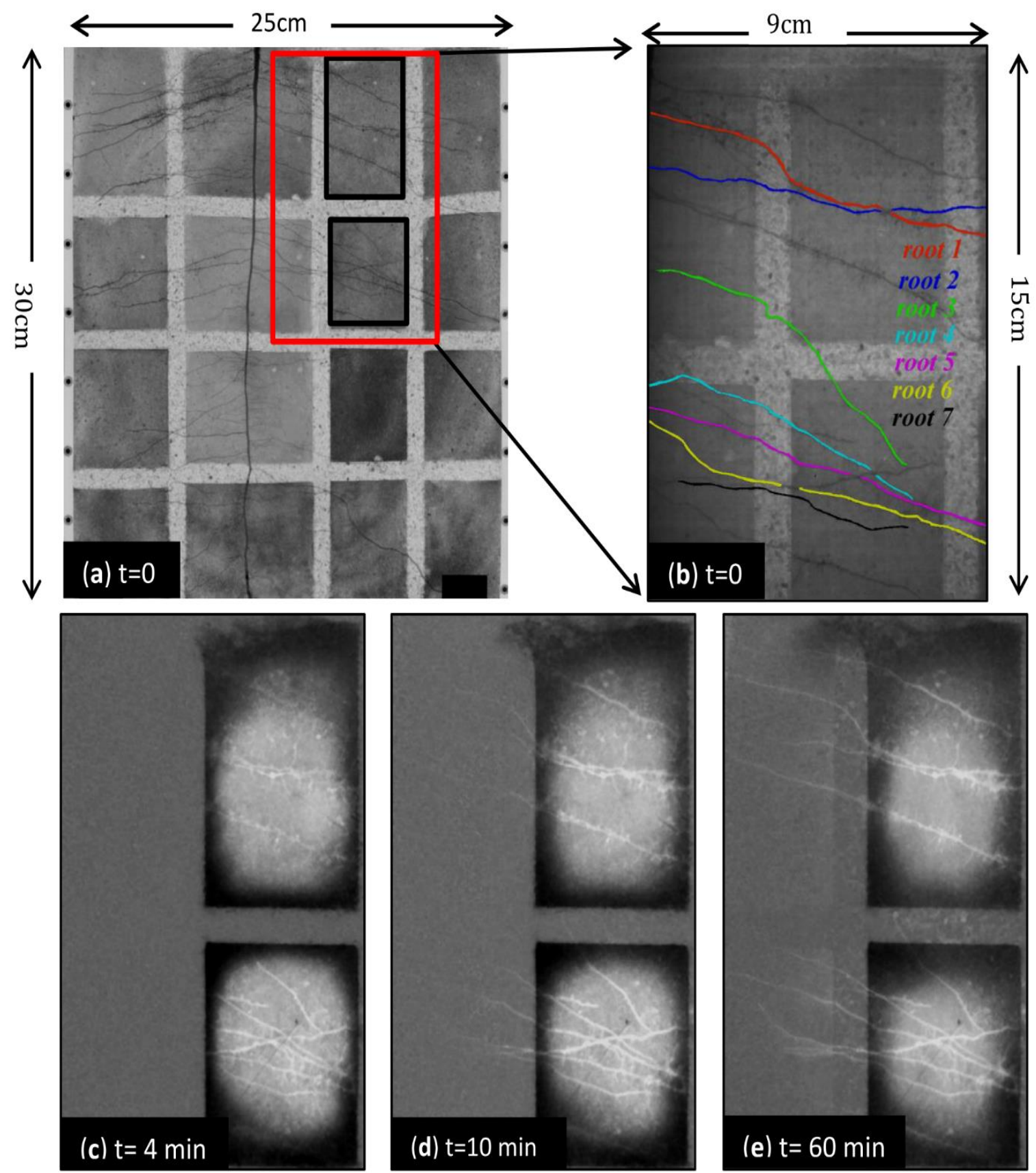

Figure 2: Neutron radiographs of one sample before (2a and $2 \mathrm{~b}$ ) and after injection of $4 \mathrm{ml} \mathrm{D}_{2} \mathrm{O}(2 \mathrm{c}, 2 \mathrm{~d}$, and 2e) during daytime. Image 2a shows roots and soil water distribution. This image was obtained from stitching together four radiographs with original with field of view of $15.75 \times 15.75 \mathrm{~cm}$. The marked rectangles show the two compartments in which we injected $\mathrm{D}_{2} \mathrm{O}$ and monitored its transport into roots and soil. Image $2 \mathrm{~b}$ is a close-up of the original field of view showing the roots selected for the flow analysis. In image $2 \mathrm{a}$ and $2 \mathrm{~b}$ the darker the image, the wetter is the soil. Images $2 \mathrm{c}$, 2d, and $2 \mathrm{e}$ show the difference between the actual radiographs at time $t$ and the radiograph before $\mathrm{D}_{2} \mathrm{O}$ injection $(t=0)$. Here, brighter colors indicate lower neutron attenuation and higher $\mathrm{D}_{2} \mathrm{O} / \mathrm{H}_{2} \mathrm{O}$ ratio. 
Figure $2 \mathrm{c}, 2 \mathrm{~d}$, and $2 \mathrm{e}$ show the difference between the actual radiographs at time $t$ and the radiograph before $\mathrm{D}_{2} \mathrm{O}$ injection $(t=0)$. Brighter gray values indicate reduced neutron attenuation due to increased $\mathrm{D}_{2} \mathrm{O} / \mathrm{H}_{2} \mathrm{O}$ ratio. Conversely, the dark areas show accumulation of $\mathrm{H}_{2} \mathrm{O}$ after $\mathrm{D}_{2} \mathrm{O}$ injection. Figure $2 \mathrm{c}$ to $2 \mathrm{e}$ show that $\mathrm{D}_{2} \mathrm{O}$ quickly redistributed in the soil due to the rapid dissipation of pressure (bulk flow of $\mathrm{H}_{2} \mathrm{O}+\mathrm{D}_{2} \mathrm{O}$ ). The diffusive mixing of $\mathrm{D}_{2} \mathrm{O}$ and $\mathrm{H}_{2} \mathrm{O}$ appeared to be relatively slow. After injection, roots turned bright, which indicates that $\mathrm{D}_{2} \mathrm{O}$ entered into roots. As $\mathrm{D}_{2} \mathrm{O}$ entered the roots, it started to move along the root beyond the capillary barrier. During the nighttime, by contrast, $\mathrm{D}_{2} \mathrm{O}$ entered the roots more slowly and there was no $\mathrm{D}_{2} \mathrm{O}$ transport beyond the capillary barrier.

Figure 3a shows the transport of $\mathrm{D}_{2} \mathrm{O}$ into taproot and laterals in the upper root zone $(2-9 \mathrm{~cm}$ in depth from soil surface) at nighttime. We injected $7 \mathrm{ml} \mathrm{D}_{2} \mathrm{O}$ into the middle compartment of the sample. Taproot turned bright slower than the lateral roots, indicating that the radial diffusive flow of $\mathrm{D}_{2} \mathrm{O}$ into taproot was significantly slower than into the lateral roots. Figure $3 \mathrm{~b}$ shows the increase of $\mathrm{D}_{2} \mathrm{O}$ concentration in the taproot (averaged in the segments at a distance of $24-25 \mathrm{~cm}$ from the root tip) and in the lateral roots (averaged in the segments at a distance of $10-12 \mathrm{~cm}$ from the root tip). These data are averaged for three roots and demonstrate that the taproot was less permeable than lateral roots. For this reason we expect that the role of the taproot in the absorption of water should be small and we focused our analysis on lateral roots.

For the quantification of $\mathrm{D}_{2} \mathrm{O}$ transport into roots, we selected the roots with minimum second order laterals and cluster roots. We averaged the concentration of $\mathrm{D}_{2} \mathrm{O}$ in the centermost pixel of the root segment immersed in $\mathrm{D}_{2} \mathrm{O}$. At nighttime, $\mathrm{D}_{2} \mathrm{O}$ concentration in roots increased to a maximum value identical to that of the soil at the root surface (data not shown). At daytime, $\mathrm{D}_{2} \mathrm{O}$ concentration in roots rapidly increased to a maximum that varied among roots. Figure $4 \mathrm{a}$ shows the average $\mathrm{D}_{2} \mathrm{O}$ concentration in the roots markeded in Figure 2.

We calculated the diffusional permeability of the cortical cells, $P_{D, c}$, and the endodermis, $P_{D, e}$, by fitting the nighttime measurements with Eq. (3.3). The radius of the root stele $\left(R_{s}=150 \pm 0.1 \mu \mathrm{m}, \mathrm{n}=5\right)$ and of the cortical cell $\left(r_{c}=23 \pm 0.05 \mu \mathrm{m}, \mathrm{n}=20\right)$ were obtained from microscopic observation of the root cross sections (Zarebanadkouki et al., 2012). $P_{D, c}$, and $P_{D, e}$ at three locations along laterals are reported in Table 1. 

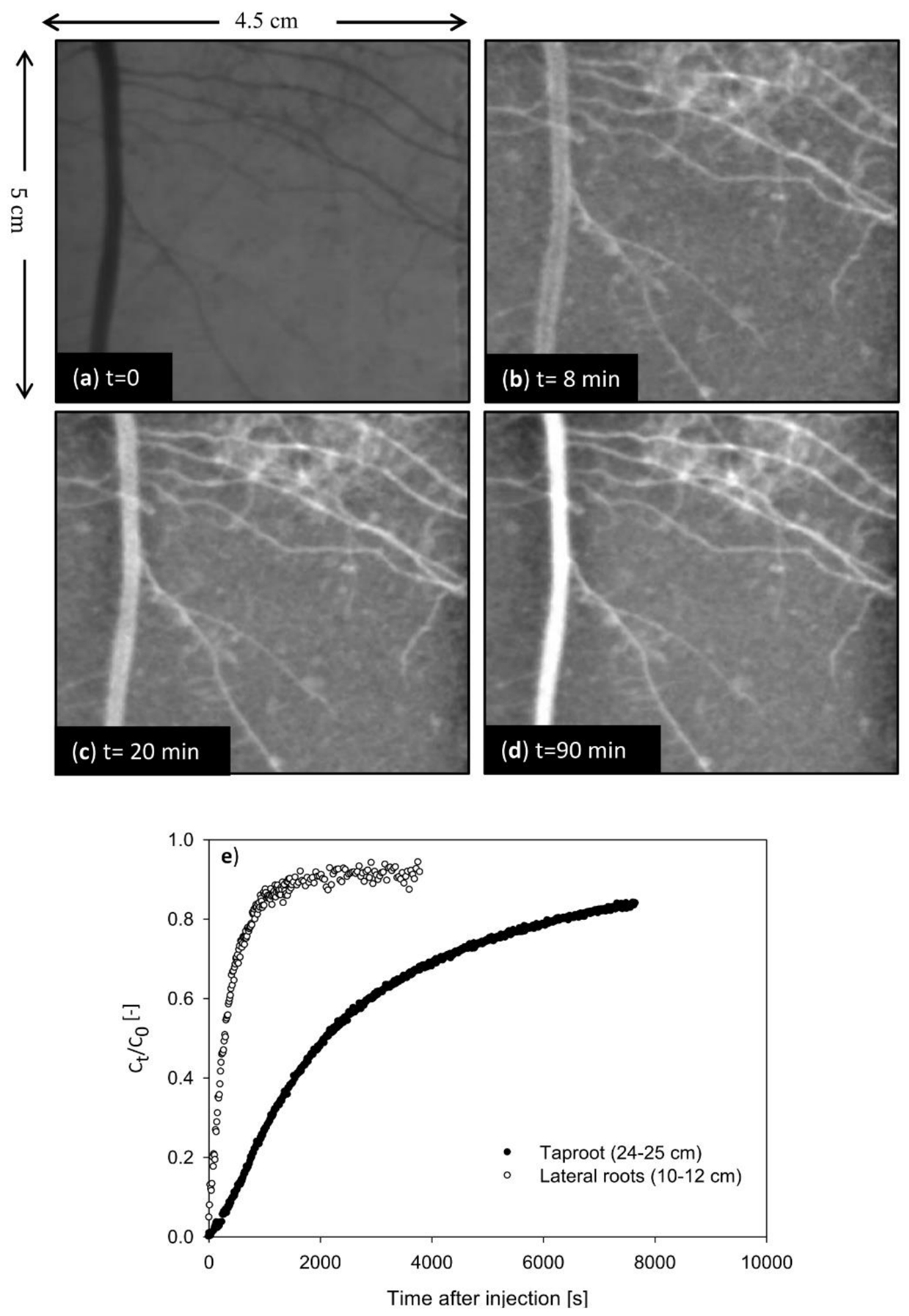

Figure 3: Neutron radiographs of one sample before $\mathrm{D}_{2} \mathrm{O}$ injection (3a) and after injection (3b-d) at nighttime. Images 3b-dare the difference between the actual radiograph at various times and the one before injection (at $\mathrm{t}=\mathbf{0}$ ). Images 3a-d show radial transport of $\mathrm{D}_{2} \mathrm{O}$ into the proximal parts of the taproot (3-8 cm depth) and the lateral roots. Brighter colors in images $3 \mathrm{~b}-3 d$ indicate higher $\mathrm{D}_{2} \mathrm{O} / \mathrm{H}_{2} \mathrm{O}$ ratio. Figure 3e shows the average concentration of $\mathrm{D}_{2} \mathrm{O}$ in the taproot and in the laterals. The data are 
averaged for three plants. These results show that the taproot of Lupines is less permeable than the laterals.

The diffusional permeability of cortical cells showed no variation along roots and had an average value of $4.8 \pm 0.3 \times 10^{-8} \mathrm{~m} \mathrm{~s}^{-1}$. In contrast, the diffusional permeability of the endodermis decreased from $1.4 \pm 0.2 \times 0.210^{-7} \mathrm{~m} \mathrm{~s}^{-1}$ in the most distal parts of roots $(2-3 \mathrm{~cm}$ from the root tip) to $5.6 \pm 0.3 \times 10^{-8} \mathrm{~m} \mathrm{~s}^{-1}$ in the most proximal parts $(10-12 \mathrm{~cm}$ from the root tip).

Table 1: Diffusional permeability of cortical cells, $P_{\mathrm{D}, \mathrm{c}},\left[\mathrm{m} \mathrm{s}^{-1}\right]$, and endodermis, $P_{\mathrm{D}, \mathrm{e}},\left[\mathrm{m} \mathrm{s}^{-1}\right]$, along lateral roots. Diffusional permeabilities were measured at various distances from the root tip using the data of $\mathrm{D}_{2} \mathrm{O}$ transport into the roots at nighttime, when transpiration was nearly zero. The values are average of six roots.

\begin{tabular}{ccc}
\hline Distance & Diffusional permeability & Diffusional permeability \\
from tip & of cortical cells, $P_{D, C}\left[\mathrm{~m} \mathrm{~s}^{-1}\right]$ & of endodermis, $P_{D, e}\left[\mathrm{~m} \mathrm{~s}^{-1}\right]$ \\
\hline $2-3 \mathrm{~cm}$ & $5.0 \pm 0.4 \times 10^{-8}$ & $1.4 \pm 0.2 \times 10^{-7}$ \\
$7-8 \mathrm{~cm}$ & $4.6 \pm 0.2 \times 10^{-8}$ & $1.0 \pm 0.1 \times 10^{-7}$ \\
$10-12 \mathrm{~cm}$ & $4.6 \pm 0.3 \times 10^{-8}$ & $5.6 \pm 0.3 \times 10^{-8}$ \\
\hline
\end{tabular}

By fitting the increase of $\mathrm{D}_{2} \mathrm{O}$ concentration in roots using Eq. (3.5), we obtained the radial flux, $j_{r}$, the axial flux, $j_{x}^{\text {out }}$, and the parameter $\lambda$. To summarize the results, we grouped the roots of ten plants into an upper zone (roots at $2-9 \mathrm{~cm}$ in depth from soil surface) and into a lower zone (18-27 cm in depth). Additionally we grouped the roots according to their length: (i) long roots with length of $12-14 \mathrm{~cm}$, (ii) medium roots with length of $8-10 \mathrm{~cm}$, (iii) and short roots with length of 3-4 cm. These groups yield a picture of the distribution of root water uptake along the root system as presented in Figure 5. 

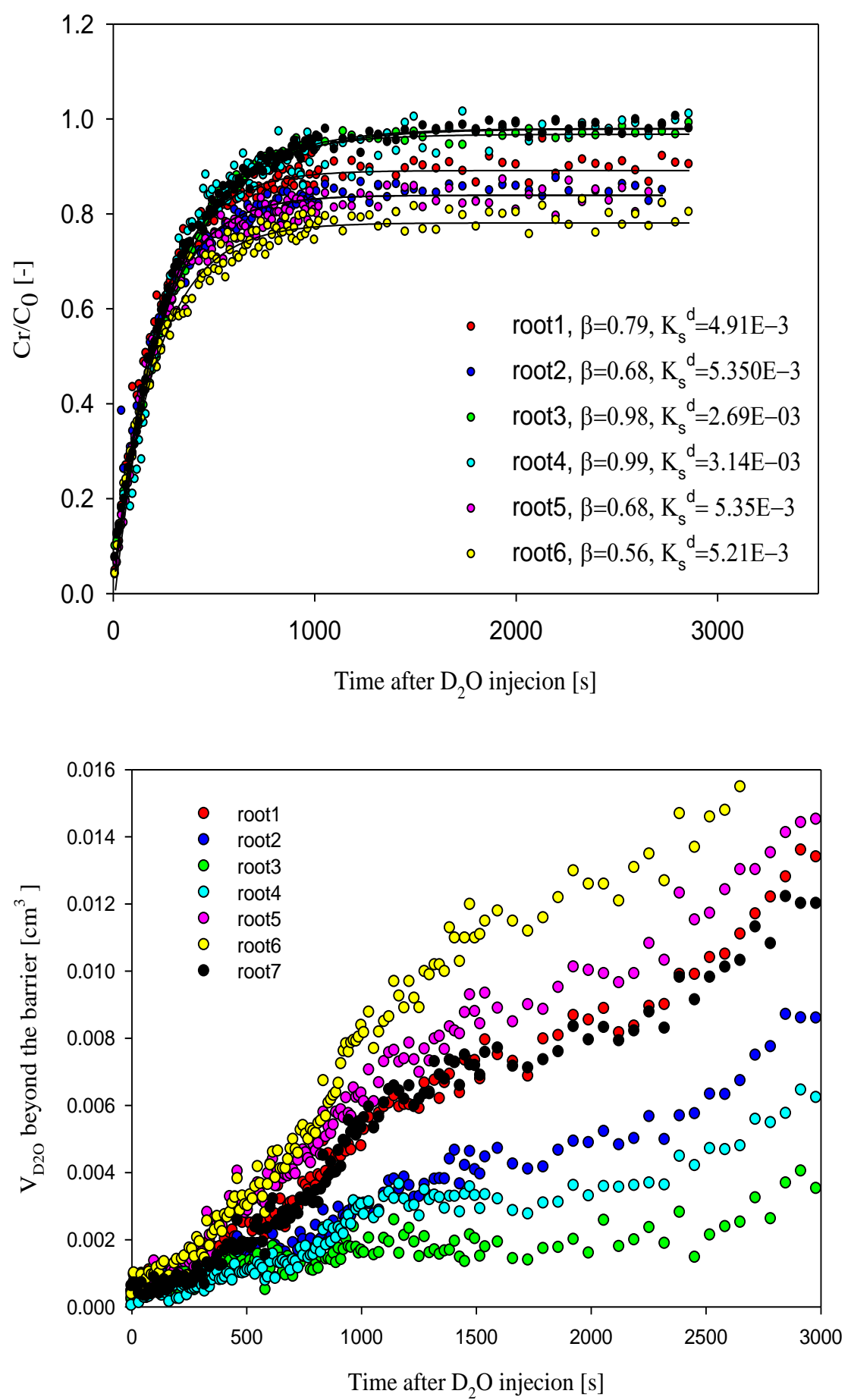

Figure 4: Increase of $\mathrm{D}_{2} \mathrm{O}$ concentration inside roots (a), and volume of $\mathrm{D}_{2} \mathrm{O}$ passing beyond the barrier (b). The lines refere to the roots marked in Figure 2. The experiment was performed during daytime. The 
concentrations were averaged along the segment of roots that were immersed in $\mathrm{D}_{2} \mathrm{O}$. $\mathrm{D}_{2} \mathrm{O}$ concentrations in roots were fitted with Eq. (5). The fitted parameters are presented in the legend for each root.

To quantify the results, we first started with the middle segments (distance of 6-9 $\mathrm{cm}$ from the root tip) of long roots (length of $12-14 \mathrm{~cm}$ ). For these root segments the axial fluxes, $j_{x}^{\text {out }}$, were calculated from Eq. (3.7) using the volume of $\mathrm{D}_{2} \mathrm{O}$ passing beyond the capillary barrier. Figure $4 \mathrm{~b}$ shows the volume of $\mathrm{D}_{2} \mathrm{O}$ passing the capillary barrier in different roots of the sample presented in Figure 2. A few seconds after $\mathrm{D}_{2} \mathrm{O}$ injection, we observed transport of $\mathrm{D}_{2} \mathrm{O}$ beyond the capillary barrier. The volume of $\mathrm{D}_{2} \mathrm{O}$ passing the capillary barrier increased gradually in the beginning because the $\mathrm{D}_{2} \mathrm{O}$ concentration in the root xylem was increasing. After approximately $200 \mathrm{~s}$, when the $\mathrm{D}_{2} \mathrm{O}$ concentration in the root at the capillary barrier reached a constant value, $\mathrm{V}_{\mathrm{D} 2 \mathrm{O}}$ started to increase linearly with time. The linear behavior was observed until $1200 \mathrm{~s}$, when the $\mathrm{D}_{2} \mathrm{O}$ front reached the taproot and exited the field of view. The values of $j_{x}^{\text {out }}$ were calculated according to Eq. (3.7) using the linear phase of the curves. The remaining parameters $j_{r}$ and $\lambda$ were derived from fitting the data from daytime measurement using Eq. (3.5). The best fitt was obtained with $\lambda=0.14 \pm 0.1(n=10)$. The results of curve fittings for the sample presented in Figure 2 are given in Figure 4a. For the remaining roots we set $\lambda=0.14$ and we calculated $j_{r}$ and $j_{x}^{\text {out }}$. This fitting procedure was chosen because the independent estimation of $j_{x}^{\text {out }}$ from Eq. (3.7) was not possible for the root segments near the taproot.

The results of the radial flux calculations at different locations of ten plants are summarized in Figure 5. The calculated radial fluxes showed a significant variation along roots. The radial fluxes into lateral roots were higher in the upper zone than in the lower zone. The radial fluxes into the most proximal segments of long and short roots were approximately 3-4 times higher in the upper zone than in the lower one. The radial fluxes in the more distal parts were 6 times higher in the upper than in the lower zone.

Looking at individual laterals, the highest radial fluxes observed in the most proximal segments, and they declined towards the distal segments (near the root tip). For the long roots in the upper zone, the radial flux into the most proximal segments $(11-14 \mathrm{~cm}$ from the root tip) was 2 times higher than into the middle segments $(6-9 \mathrm{~cm}$ from the root tip), and 9 times higher than into the distal segments $(2-3 \mathrm{~cm}$ from the root tip). For the medium roots in the upper zone, the radial flux into the most proximal segments $(8-10 \mathrm{~cm}$ from the root tip) was 6 
times higher than into the distal segments $(2-3 \mathrm{~cm}$ from the root tip). For the medium roots in the lower region, the flux into the proximal segments was 9 times higher than into the distal segments.

The radial flux into the root endodermis predicted by the model agree well with independent measurements of average root water uptake. Taking the average total root length $(470 \mathrm{~cm})$, the average water consumption $(1.43 \mathrm{~g} / \mathrm{h})$ and the radius of endodermis $(150 \mu \mathrm{m})$, one obtain an average radial flux into the endodermis equal to $8.910^{-8} \mathrm{~m} \mathrm{~s}^{-1}$, which falls well in the values predicted by the model (Figure 5).

The axial flux at different locations of long and medium lateral roots calculated from the model (Eq. 3.5) and those directly obtained from Eq. (3.7) are shown in figure 6. The highest axial fluxes were found in the more proximal parts of roots to be $2.9 \pm 0.2 \times 10^{-4} \mathrm{~m} \mathrm{~s}^{-1}$ for long root, and $2.1 \pm 0.2 \times 10^{-4} \mathrm{~m} \mathrm{~s}^{-1}$ for medium root.

\section{Discussion}

The transport of $\mathrm{D}_{2} \mathrm{O}$ into the roots showed a two exponential growth over time. This was explained with: (i) different rate of $\mathrm{D}_{2} \mathrm{O}$ transport into the cortical cells and the root stele, and (ii) dilution of $\mathrm{D}_{2} \mathrm{O}$ concentration in the root stele due to inflow of normal water in the xylem during transpiration (when distal parts of roots were not immersed in $\mathrm{D}_{2} \mathrm{O}$ ). We developed a simple diffusion-convection model to describe the local transport of $\mathrm{D}_{2} \mathrm{O}$ into roots. The radial transport through the cortex included both an apoplastic and a cell-to-cell pathway. The relative importance of the two pathways varied with the parameter $\lambda$. The best fitting was obtained with $\lambda=0.14$, which suggests a dominant apoplastic flow through the cortex. Note, that the model says nothing about the relative importance of the two pathways across the whole root: i.e. it may be that the apoplast at the endodermis is completely interrupted and that the overall root conductivity is controlled by the cell-to-cell pathway. By fitting the neutron radiograph data, the model calculated the diffusional permeability of the cortical cells and of the endodermis and the radial and axial flux of water in different root segments. The results demonstrated significant variations of water uptake rate along the root system. The radial fluxes were higher in the upper zone than in the lower zone. In each root, the radial fluxes were higher in the more proximal segments and decreased towards the distal segments. 


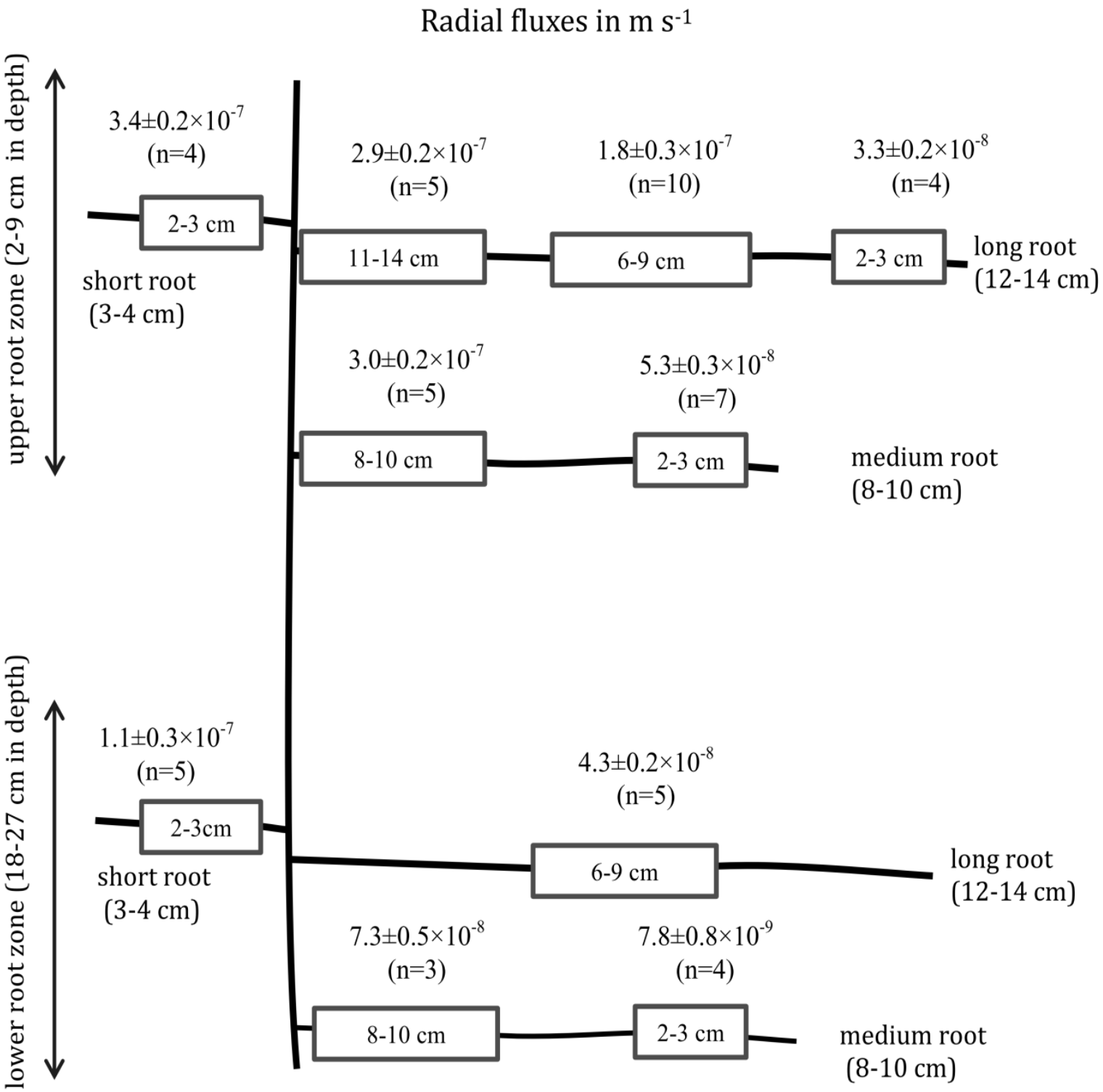

Figure 5: Scheme of the root system showing the distribution of the radial fluxes, $\mathrm{jr}_{\mathrm{r}},\left[\mathrm{m} \mathrm{s}^{-1}\right]$ calculated with Eq. (3.5). Roots are grouped in upper zone and lower root zone according to their depth. Additionally roots were grouped in long, medium and short roots. The numbers inside the boxes indicate the distance from the root tip. The value of radial flux for each position is averaged for $\mathbf{n}$ replications and is given above the boxes in meter per second. The results are averaged among 10 samples. 


\section{Axial fluxes in $\mathrm{m} \mathrm{s}^{-1}$}
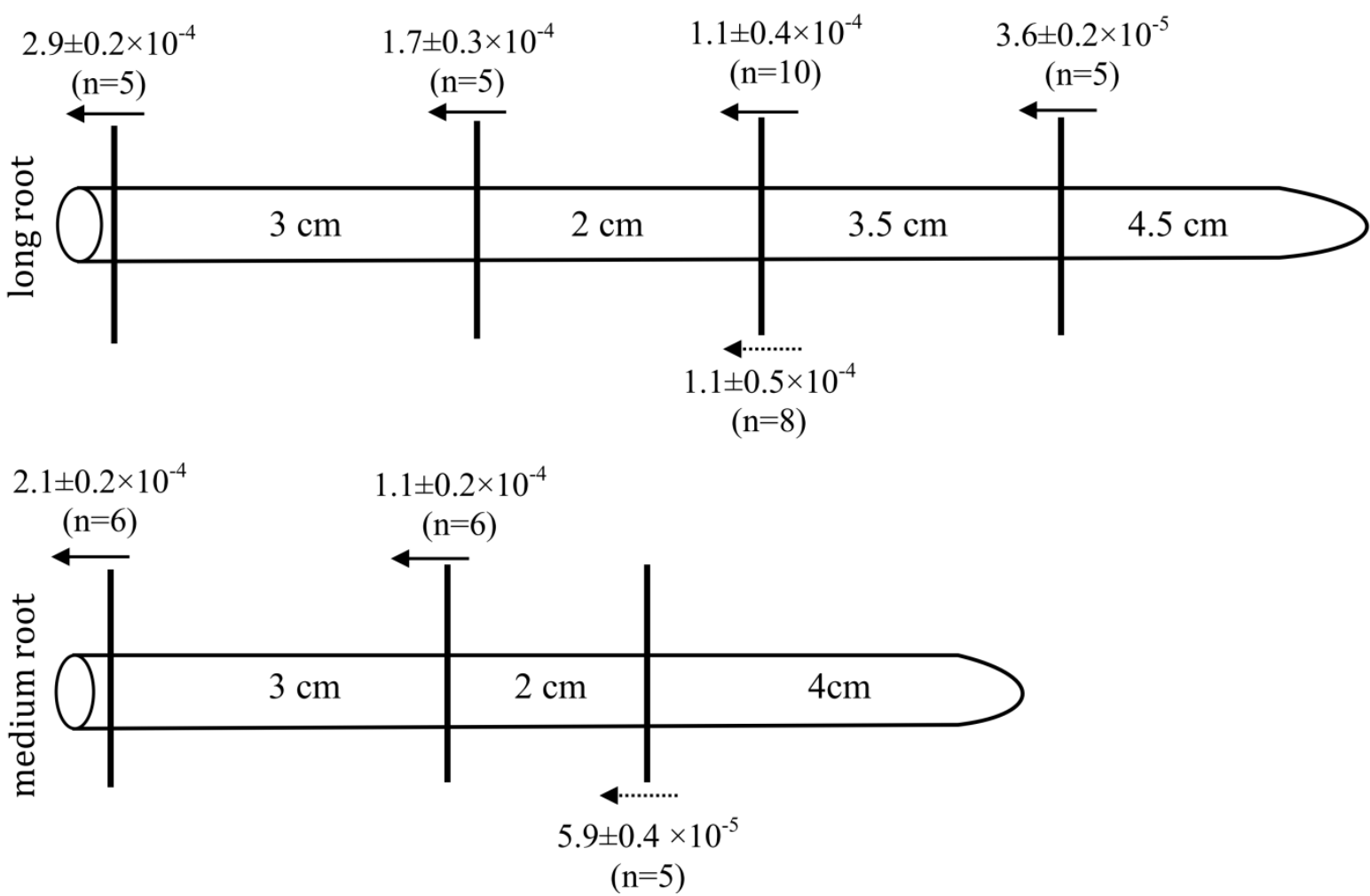

Figure 6: Axial fluxes, $j_{x}^{\text {out }}\left[\mathrm{m} \mathrm{s}^{-1}\right]$, in long and medium roots calculated from the model (Eq. 3.5, solid arrows above roots) and directly obtained from radiographs (Eq. 3.7, dashed thin arrows below roots). The numbers inside the roots indicate the distance between each root segment. Note that the axial fluxes are calculated for the cross-section of the root stele.

Lower water uptake in the distal segments of lateral roots could be explained by (i) lower radial conductivity of the distal segments and/or (ii) significant dissipation of the water potential along the root system (driving force). The experiments at nighttime showed that $\mathrm{D}_{2} \mathrm{O}$ entered more quickly into the distal segments than in the proximal ones. This indicates that the radial permeability of roots was higher in the distal segments than in the proximal ones. A more likely explanation of the lower water uptake in the distal segments is that there was a significant dissipation of water potential along the xylem of lateral roots. Due to the porous nature of roots, the relative importance of radial and axial conductivity determines the distribution of water potential and water uptake along the root (Landsberg \& Fowkes, 1978; Frensch et al., 1996; Hsiao \& Xu, 2000; Zwieniecki et al., 2003). High ratio of radial to axial conductivity results in a higher dissipation of water potential along roots and in consequent hydraulic "isolation" of the distal segments. In the lateral roots, incomplete development of 
the xylem vessels towards distal segments would produce lower axial conductivity and may have further decreased the water uptake in the most apical parts (McCully \& Canny, 1988; Huang \& Nobel, 1993; McCully, 1995; Bramley et al., 2009).

The decrease in water uptake with distance in depth was smaller than with distance in laterals. In laterals, water uptake decreased 9 times over a distance of $10 \mathrm{~cm}$ from the proximal segments to the distal ones $(2-3 \mathrm{~cm}$ from the tips). Instead, water uptake into the proximal segments of roots decreased of 3 to 4 times over a depth of $15 \mathrm{~cm}$ (Fig. 5). This indicates that the dissipation of water potential for the same unit of the root length along the taproot is less significant than along lateral roots. The low dissipation of water potential along the taproot is explained by the low ratio of radial to axial conductivity. Indeed, the microscopic observation of the root cross sections revealed that xylem vessels were larger and more abundant in the taproot compare to the lateral roots (data not shown). Additionally, experiments at nighttime showed the radial transport of $\mathrm{D}_{2} \mathrm{O}$ into the taproot was significantly slower than into the lateral roots (Fig. 3). This indicates that in comparison to lateral roots, the taproot is significantly more resistant to radial flow of water into roots. The function of the taproot is to collect water from laterals and transport to shoot. The combination of high axial conductivity and low radial conductivity is beneficial for collecting water from deep soil and increasing the portion of roots involved in water uptake. The tap-rooted architecture seems optimal for plant survival in soils where water is mainly stored in the deep profiles.

Our observations of higher radial fluxes at the more proximal segment of roots are in agreement with modeling studies (Landsberg \& Fowkes, 1978; and Doussan et al., 1998), experiment studies with excised roots (Frensch \& Steudle, 1989; Zwieniecki et al,. 2003), and those with roots in soils (Doussan et al., 2006). Location of root water uptake is expected to change with root maturation. Decrease of radial hydraulic conductivity and increase of axial conductivity due to root maturation might move the location of water uptake to more distal zones. Sanderson, (1983) measured the profile of water uptake along roots of barley grown in hydroponics culture using a potometer apparatus. He found that the peak of water uptake was at a distance of 4-5 cm from the tip. Varney \& Canny, (1993) measured water uptake of lateral and axile roots for aeroponically grown maize. They observed that maximum uptake from laterals occurred at $30-60 \mathrm{~cm}$ from the root tip of the main axes, and it decreased towards the tip and the proximal parts. The axile roots were approximately $100 \mathrm{~cm}$ long. Variations in root architecture, maturation of xylem vessels, changes of root 
permeability by root maturation, and different growth condition account for the discrepancy in the proximal parts.

As discussed above, the ratio of axial to radial conductivities determines the profile of water uptake along a root. In order to maintain large area of roots involved in water uptake, root elongation needs to be coupled with a decrease of radial conductivity and an increase of axial conductivity. In addition to irreversible modification of roots during maturation, the ratio of radial to axial resistance might be regulated by aquaporins and also by the resistance of the root-soil interface. Recent studies on water dynamics in the rhizosphere showed that when the soil dries, the rhizosphere becomes temporarily hydrophobic (Carminati et al., 2010). Such a temporary hydrophobicity may help plants to isolate the roots from the top dry soil and favor the uptake from the deep wet soil (Carminati, 2012). A similar mechanism will happen when roots shrink and lose contact with the soil (Nobel \& Cui, 1992; Nye, 1994; North \& Nobel, 1997; Carminati et al., 2012). Carminati et al. (2012) used X-ray CT to monitor the formation of air-filled gaps between soil and roots of lupins. They found that gap occurred mainly around the taproot. As we showed that the taproot is not so important for water uptake, gaps seem not to represent a limit for water uptake. Such rhizosphere dynamics and gaps formation are reversible and their role on plant adaptation to drought needs further investigation.

Some assumptions of the model of $\mathrm{D}_{2} \mathrm{O}$ transport in soil and root need to be further investigated, with consequent improvement of the model. We assumed that after $\mathrm{D}_{2} \mathrm{O}$ injection, $\mathrm{D}_{2} \mathrm{O}$ rapidly moved by diffusion and convection in the apoplast of the root cortex. With this assumption, our model can be explicitely derived and the parameters have a physical meaning. Diffusion time of $\mathrm{D}_{2} \mathrm{O}$ in the apoplast of the cortex is given by $t=l^{2} /(2 D)$, where 1 is the diffusional length and $\mathrm{D}$ is the diffusion coefficient of $\mathrm{D}_{2} \mathrm{O}$ in $\mathrm{H}_{2} \mathrm{O}$ through the apoplast of the cortex. The diffusional length is given by the thickness of the cortex, $1=1.5 \times 10^{-4} \mathrm{~m}$. The diffusion coefficient of $\mathrm{D}_{2} \mathrm{O}$ in pure water is $\mathrm{D}=2.27 \times 10^{-9} \mathrm{~m}^{2} \mathrm{~s}^{-1}$ (Longsworth, 1960). This value would give a diffusional time $\mathrm{t}=5 \mathrm{~s}$, which is consistent with our hypothesis. However, the diffusion of $\mathrm{D}_{2} \mathrm{O}$ is slower in the apoplast than in pure water. Richter \& Ehwald, (1983) observed that diffusivity of sucrose (molecular weight of $342 \mathrm{gr}$ $\mathrm{mol}^{-1}$ ) in extracellular space of sugar beet was 5-10 times lower than in water. Aikman et $a l .$, (1980) reported a decrease of 10 times for $\mathrm{Rb}^{+}$diffusion. The diffusivity of charged and large molecules is expected to be reduced more significantly than that of a neutral and low 
molecular weight molecule like $\mathrm{D}_{2} \mathrm{O}$ (Aikman et al., 1980; Richter \& Ehwald, 1983; Fleischer \& Ehwald, 1995; Fritz \& Ehwald, 2011). A reduction of 10 times in D seems therefore a safe assumption and would give a diffusional time of 50 seconds. This value is still smaller than the half time measured at nighttime, which was around 300 seconds (Zarebanadkouki et al., 2012). A second assumption that needs further investigation is whether or not diffusional permeability of cortical cells and endodermis is constant during daytime and nighttime. It is known that aquaporin activity is function of transpiration and therefore it would affect the diffusional permeabilities (Maurel et al., 2008). Bramley et al. (2009) showed that the radial flow of water in Lupine roots occurred primarily through the apoplast, with a negligible involvement of aquaporins, while in wheat the water flow mainly occurred in the cell-to-cell. Our assumption of constant diffusional permeability of the endodermis during daytime and nighttime may therefore be justified for Lupine roots, but it should be improved before application to other plant species. Future improvements of the model should include: the diffusion of $\mathrm{D}_{2} \mathrm{O}$ though the apoplast of the cortex, which is now assumed to be instantaneous, and a variable $\mathrm{P}_{\mathrm{d}}$ during daytime and nighttime. Further experiments with plant species that are known to have a dominant cell-to-cell pathway would be greatly beneficial to test the model.

\section{Appendix A: Derivation of the model of $\mathrm{D}_{2} \mathrm{O}$ transport into roots}

We assume that when roots are immersed in $\mathrm{D}_{2} \mathrm{O}$, the apoplastic free space of the root cortex rapidly saturates with $\mathrm{D}_{2} \mathrm{O}$ diffusion. This results in an identical $\mathrm{D}_{2} \mathrm{O}$ concentration in the apoplast of the root cortex to that of the soil at the root surface, $\mathrm{C}_{0}$. The reflection coefficient of membrane to $\mathrm{D}_{2} \mathrm{O}$ transport is assumed to be zero (Henzler \& Steudle 1995). During night, under these assumptions, the total flow of $\mathrm{D}_{2} \mathrm{O}$ into the cortical cells, $J_{r, c}^{n}\left[\mathrm{~m}^{3} \mathrm{~s}^{-1}\right]$, is described by a diffusion equation as

$$
J_{r, c}^{n}=2 \pi r_{c} L P_{D, c}\left(C_{0}-C_{c}\right)
$$

where $r_{c}[\mathrm{~m}]$ is radius of the cortical cells, $L[\mathrm{~m}]$ is the length of the root immersed in $\mathrm{D}_{2} \mathrm{O}$, $P_{D, c}\left[\mathrm{~m} \mathrm{~s}^{-1}\right]$ is diffusional permeability of the cortical cell and $C_{c}[-]$ is the $\mathrm{D}_{2} \mathrm{O}$ concentration inside the cortical cell. From mass conservation it follows that

$$
\pi r_{c}^{2} L \frac{\partial C_{c}}{\partial t}=2 \pi r_{c} L P_{D, c}\left(C_{0}-C_{c}\right)
$$


Under the boundary conditions

$$
\begin{array}{cc}
C_{r}=0 & t=0 \\
C_{0}(t)=C_{0} & t>0
\end{array}
$$

the solution of Eq.(AP.3) is

$$
C_{c}=C_{0}\left(1-\exp ^{-k_{c}^{n} t}\right)
$$

where

$$
k_{c}^{n}=\frac{2 P_{D, c}}{r_{c}}
$$

Similarly, during the night, the total flow of $\mathrm{D}_{2} \mathrm{O}$ into the root stele, $J_{r, s}^{n}\left[\mathrm{~m}^{3} \mathrm{~s}^{-1}\right]$, is described by a diffusion equation as

$$
J_{r, s}^{n}=2 \pi R_{s} L P_{D, e}\left(C_{0}-C_{s}\right)
$$

where $R_{S}[\mathrm{~m}]$ is the root radius, $P_{D, e}\left[\mathrm{~m} \mathrm{~s}^{-1}\right]$ is the diffusional permeability of the endodermis, and $C_{s}[-]$ is the $\mathrm{D}_{2} \mathrm{O}$ concentration inside the root stele. From the mass conservation it follows that

$$
\pi R_{s}^{2} L \frac{\partial C_{s}}{\partial t}=2 \pi R_{s} L P_{D, e}\left(C_{0}-C_{s}\right)
$$

Under the boundary conditions of Eq.(AP.3), the solution of Eq.(AP.7) is

$$
C_{s}=C_{0}\left(1-\exp ^{-k_{s}^{n} t}\right)
$$

where

$$
k_{s}^{n}=\frac{2 P_{D, e}}{R_{s}}
$$

The average $\mathrm{D}_{2} \mathrm{O}$ concentration in the root, $C_{r}[-]$ is the sum of $\mathrm{D}_{2} \mathrm{O}$ concentration in the cortex and stele:

$$
C_{r}=\frac{\left(R_{r}-R_{s}\right) C_{c}+R_{s} C_{s}}{R_{r}}
$$

where $R_{r}[\mathrm{~m}]$ is the roots radius. By substituting Eq.(AP.4) and Eq.(AP.8) in Eq.(AP.10) it follows that the increase of $C_{r}$ at night is 


$$
C_{r}=\frac{R_{r}-R_{s}}{R_{r}} C_{0}\left(1-\exp ^{-k_{c}^{n} t}\right)+\frac{R_{s}}{R_{r}} C_{0}\left(1-\exp ^{-k_{s}^{n} t}\right)
$$

During the day, leaf transpiration induces a net flow of water into the roots. The convective transport of $\mathrm{D}_{2} \mathrm{O}$ into the cortical cells depends on the ratio between the cell-to-cell water flow and the total flow. We call $\lambda[-]$ the ratio of the cell-to-cell to total water flow. The net flow of $\mathrm{D}_{2} \mathrm{O}$ into the cortical roots during day, $J_{r, c}^{d}\left(\mathrm{~m}^{3} \mathrm{~s}^{-1}\right)$, is described as

$$
J_{r, c}^{d}=2 \pi r_{c} L P_{D, c}\left(C_{0}-C_{c}\right)+\lambda \frac{2 \pi r_{c}}{4} L j_{r}\left(C_{0}-C_{c}\right)
$$

where $j_{r}\left[\mathrm{~m} \mathrm{~s}^{-1}\right]$ is radial flux of water into the root, and $\lambda[-]$ is the ratio between the cell-tocell water flow and the total water flow across the cortex. By geometrical consideration, the convective flow of water crosses approximately one fourth of the cortical cell perimeter. From the mass balance it follows that

$$
\pi r_{c}^{2} L \frac{\partial C_{c}}{\partial t}=2 \pi r_{c} L P_{D, c}\left(C_{0}-C_{c}\right)+\lambda \frac{2 \pi r_{c}}{4} L j_{r}\left(C_{0}-C_{c}\right)
$$

under boundary conditions Eq.(AP.3) the solution of Eq.(AP.13) is

$$
C_{c}=C_{0}\left(1-\exp ^{-k_{c}^{d} t}\right)
$$

where

$$
k_{c}^{d}=\frac{2 P_{D, c}+\lambda \frac{j_{r}}{2}}{r c}
$$

The net flow of $\mathrm{D}_{2} \mathrm{O}$ into the root stele during day, $J_{r, s}^{d}\left[\mathrm{~m}^{3} \mathrm{~s}^{-1}\right]$, is described by

$$
J_{r, s}^{d}=2 \pi R_{s} L P_{D, e}\left(C_{0}-C_{s}\right)+2 \pi R_{s} L j_{r} C_{0}-\pi R_{s}^{2} j_{x}^{\text {out }} C_{s}
$$

where $j_{x}^{\text {out }}$ is the axial flux [ $\mathrm{m} \mathrm{s}^{-1}$ ] calculated for the stele cross-section. In Eq.(AP.16) it is assumed that the only the root segment of length $\mathrm{L}$ is immersed in $\mathrm{D}_{2} \mathrm{O}$, while the other root segments are immersed in normal water. From the mass conservation for $\mathrm{C}_{\mathrm{D} 2 \mathrm{O}}$ it follows that

$$
\pi R_{s}^{2} L \frac{\partial C_{s}}{\partial t}=2 \pi R_{s} L P_{D, e}\left(C_{0}-C_{s}\right)+2 \pi R_{s} L j_{r} C_{0}-\pi R_{s}^{2} j_{x}^{\text {out }} C_{s}
$$

Under the boundary conditions of Eq.(AP.3), the solution of Eq.(AP.17) is

$$
C_{s}=\beta C_{0}\left(1-\exp ^{-k_{s}^{d} t}\right)
$$


where

$$
\begin{array}{r}
k_{s}^{d}=\frac{2 P_{D, e}}{R_{s}}+\frac{j_{x}^{\text {out }}}{L} \\
\beta=\frac{\frac{2 P_{D, e}+2 j_{r}}{R_{s}}}{\frac{2 P_{D, e}}{R_{s}}+\frac{j_{x}^{\text {out }}}{L}}
\end{array}
$$

By substituting Eq.(AP.14 and AP.18) in Eq.(AP.10) it follows that the increase of $C_{r}$ at the day

$$
C_{r}=\frac{R_{r}-R_{s}}{R_{r}} C_{0}\left(1-\exp ^{-k_{c}^{d} t}\right)+\frac{R_{s}}{R_{r}} \beta C_{0}\left(1-\exp ^{-k_{s}^{d} t}\right)
$$

Appendix B: $\mathrm{D}_{2} \mathrm{O}$ concentration in the roots: experimental results and best fits with single and double exponential curves

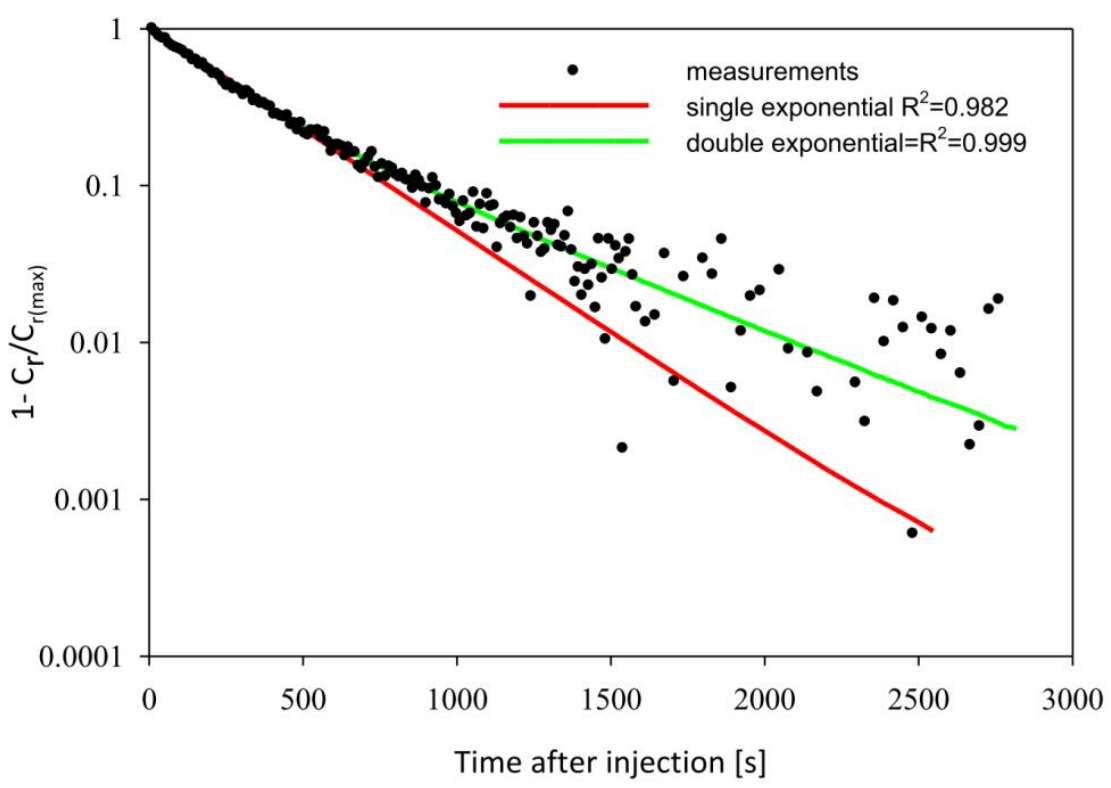

Figure 7: Measured $\mathrm{D}_{2} \mathrm{O}$ concentration inside the roots and the best-fit lines using a single and double exponential equation. The experimental points are obtained from $\mathrm{D}_{2} \mathrm{O}$ injection at nighttime and are averaged along a lateral root segment that was 9-12 cm distant from the root tip. 


\section{References}

Aikman, D.P., Harmer, R., \& Rust, T.S.O. 1980. Electrical resistance and ion movement through excised discs of sugar beet root tissue. Physiol. Plant. 48, 395-402.

Bramley, H., Turner, N.C., Turner, D.W., \& Tyerman, S.D. 2009. Roles of morphology, anatomy, and aquaporins in determining contrasting hydraulic behavior of roots. Plant Physiol. 150, 348-364.

Carminati, A. 2012. A Model of Root Water Uptake Coupled with Rhizosphere Dynamics. Vadose Zone J.

Carminati, A., Moradi, A.B., Vetterlein, D., Vontobel, P., Lehmann, E., Weller, U., Vogel, H.-J., \& Oswald, S.E. 2010. Dynamics of soil water content in the rhizosphere. Plant Soil 332, 163-176.

Carminati, A., Vetterlein, D., Koebernick, N., Blaser, S., Weller, U., \& Vogel, H.-J. 2012. Do roots mind the gap? Plant Soil doi:10.1007/s11104-012-1496-

Da-Ines, O., Graf, W., Franck, K.I., Albert, A., Winkler, J.B., Scherb, H., Stichler, W., \& Schäffner, A.R. 2010. Kinetic analyses of plant water relocation using deuterium as tracer-reduced water flux of Arabidopsis pip2 aquaporin knockout mutants. Plant Biology 12, 129-139.

Doussan, C., Pierret, A., Garrigues, E., \& Pagès, L. 2006. Water Uptake by Plant Roots: II Modelling of Water Transfer in the Soil Root-system with Explicit Account of Flow within the Root System - Comparison with Experiments. Plant Soil 283, 99-117.

Doussan, C., Page, L.., Vercambre, G. 1998. Modelling of the Hydraulic Architecture of Root Systems: An Integrated Approach to Water AbsorptionĐModel Description. Annal. Bot. $\operatorname{Vol}(81): 213-223$

Draye, X., Kim, Y., Lobet, G., \& Javaux, M. 2010. Model-assisted integration of physiological and environmental constraints affecting the dynamic and spatial patterns of root water uptake from soils. J. Exp. Bot. 61, 2145-2155. 
Enstone, D.E., Peterson, C.A., \& Ma, F. 2003. Root Endodermis and Exodermis: Structure, Function, and Responses to the Environment. J. Plant Growth Regul. 21, 335-351.

Fleischer, A., \& Ehwald, R. 1995. The free space of sugars in plant tissues6. J. Exp. Bot. 46, 647-654.

Frensch, J., \& Steudle, E. 1989. Axial and radial hydraulic resistance to roots of maize (Zea mays L.). Plant Physiol. 91, 719-726.

Frensch, J., T.C. Hsiao, and E. Steudle. 1996. Water and solute transport along developing maize roots. Planta. 198:348-355. doi:10.1007/BF0062005

Fritz, M., \& Ehwald, R. 2011. Mannitol permeation and radial flow of water in maize roots. New Phytol. 189, 210-217.

Garrigues, E., Doussan, C., \& Pierret, A. 2006. Water Uptake by Plant Roots: I - Formation and Propagation of a Water Extraction Front in Mature Root Systems as Evidenced by 2D Light Transmission Imaging. Plant Soil 283, 83-98.

Henzler, T., and E. Steudle. 1995. Reversible closing of water channels in Chara internodes provides evidence for a composite transport model of the plasma membrane. J. Exp. Bot. 46:199-209.

Hsiao TC, Xu LK (2000) Sensitivity of growth of roots versus leaves to water stress: biophysical analysis and relation to water transport. J Exp. Bot, 51: 1595-1616

Huang, B., \& Nobel, P.S. 1993. Hydraulic conductivity and anatomy along lateral roots of cacti: changes with soil water status. New Phytol. 123, 499-507.

Javaux, M., Schröder, T., Vanderborght, J., \& Vereecken, H. 2008. Use of a threedimensional detailed modeling approach for predicting root water uptake. Vadose Zone J. 7, 1079-1088.

Knipfer, T., \& Fricke, W. 2010. Water uptake by seminal and adventitious roots in relation to whole-plant water flow in barley (Hordeum vulgare L.). J. Exp. Bot. 62, 717-733.

Landsberg, J.J., \& Fowkes, N.D. 1978. Water movement through plant roots. Ann. BotLondon 42, 493-508. 
Longsworth, L. 1960. The mutual diffusion of light and heavy water. J. Phys.Chem. 64:19141917.

Matsushima, U., Kardjilov, N., Hilger, A., Graf, W., \& Herppich, W.B. 2008. Application potential of cold neutron radiography in plant science research. J. Appl. Bot. Food Qual. 82, 90-98.

Maurel, C., Verdoucq, L., Luu, D.-T., \& Santoni, V. 2008. Plant aquaporins: membrane channels with multiple integrated functions. Annu. Rev. Plant Biol. 59, 595-624.

McCully, M. 1995. How Do Real Roots Work?(Some New Views of Root Structure). Plant Physiol. 109, 1-6.

McCully, M.E., \& Canny, M.J. 1988. Pathways and processes of water and nutrient movement in roots. Plant Soil 111, 159-170.

Menon, M., Robinson, B., Oswald, S.E., Kaestner, A., Abbaspour, K.C., Lehmann, E., \& Schulin, R. 2007. Visualization of root growth in heterogeneously contaminated soil using neutron radiography. Eur. J. Soil. Sci. 58, 802-810.

Moradi, A.B., Carminati, A., Vetterlein, D., Vontobel, P., Lehmann, E., Weller, U., Hopmans, J.W., Vogel, H.-J., \& Oswald, S.E. 2011. Three-dimensional visualization and quantification of water content in the rhizosphere. New Phytol. 192, 653-663.

Moradi, A.B., Conesa, H.M., Robinson, B., Lehmann, E., Kuehne, G., Kaestner, A., Oswald, S., \& Schulin, R. 2008. Neutron radiography as a tool for revealing root development in soil: capabilities and limitations. Plant Soil 318, 243-255.

Ordin, L., \& Kramer, P.J. 1956. Permeability of Vicia Faba Root Segments to Water as Measured by Diffusion of Deuterium Hydroxide. Plant Physiol. 31, 468-471.

Oswald, S.E., Menon, M., Carminati, A., Vontobel, P., Lehmann, E., \& Schulin, R. 2008. Quantitative imaging of infiltration, root growth, and root water uptake via neutron radiography. Vadose Zone J. 7, 1035-1047.

Pierret, A., Kirby, M., \& Moran, C. 2003. Simultaneous X-ray imaging of plant root growth and water uptake in thin-slab systems. Plant Soil 255, 361-373. 
Pohlmeier, A., Oros-Peusquens, A., Javaux, M., Menzel, M.I., Vanderborght, J., Kaffanke, J., Romanzetti, S., Lindenmair, J., Vereecken, H., \& Shah, N.J. 2008. Changes in soil water content resulting from Ricinus root uptake monitored by magnetic resonance imaging. Vadose Zone J. 7, 1010-1017.

Richter, E., \& Ehwald, R. 1983. Apoplastic mobility of sucrose in storage parenchyma of sugar beet. Physiologia Plantarum 58, 263-268.

Sanderson, J. 1983. Water uptake by different regions of the barley root. Pathways of radial flow in relation to development of the endodermis. J. Exp. Bot. 34, 240-253.

Steudle, E., \& Peterson, C.A. 1998. How does water get through roots? J. Exp. Bot. 49, 775788.

Tumlinson, L.G., Liu, H., Silk, W.K., \& Hopmans, J.W. 2007. Thermal Neutron Computed Tomography of Soil Water and Plant Roots. Soil Sci. Soc. Am. J. 72, 1234-1242. 


\section{Reduced root water uptake after drying and rewetting}

Mohsen Zarebanadkouki and Andrea Carminati

Published in J. Plant Nutr. Soil Sci. (2013) 


\begin{abstract}
The ability of plants to extract water from soil is limited by the hydraulic conductivity of roots and, as the soil dries, by that of the soil near the roots, the so called rhizosphere. Recent experiments showed that the rhizosphere turned hydrophobic after drying and it remained dry after rewetting. Our objective was to investigate whether rhizosphere hydrophobicity is associated with a reduction in root water uptake after drying and rewetting. We used neutron radiography to trace the transport of deuterated water $\left(\mathrm{D}_{2} \mathrm{O}\right)$ in the roots of lupines growing in a sandy soil. The plants were initially grown in relatively moist conditions $(0.1<\theta<0.2)$. Three weeks after planting, we let one soil region dry for two-three days. Then, we injected $\mathrm{D}_{2} \mathrm{O}$ in this soil region and in a symmetric region that was kept wet. We monitored $\mathrm{D}_{2} \mathrm{O}$ transport in soil and roots with time-series neutron radiography. From the $\mathrm{D}_{2} \mathrm{O}$ transport into roots we calculated the root water uptake. We found that root water uptake in the soil region that was let dry and rewetted was 4-8 times smaller than that in the region that was kept moist. The reduced uptake persisted for more than 2 hours. We conclude that a reduction in hydraulic conductivity occurred after drying and rewetting. We expect that this reduction was caused by the rhizosphere hydrophobicity.
\end{abstract}




\section{Introduction}

Root water uptake depends on the hydraulic conductivities of roots and soil. In wet soil, the hydraulic conductivity of roots typically controls the water uptake. As the soil dries, its conductivity decreases by several orders of magnitude and may limit the flow of water into the roots (Passioura, 1980; Draye et al., 2010). Model calculations showed that as the soil dries, a critical drop in water potential may occur in the immediate vicinity of the soil, the so called rhizosphere. The drop occurs because of the radial geometry of the flow to the roots and the nonlinearity of the unsaturated soil conductivity (Gardner, 1960; Carminati et al., 2011). As large gradients in water potential occur in the rhizosphere, plants typically decrease the transpiration rate by closing leaf stomata with a consequent reduction in photosynthesis (Dodd, 2003).

To adapt to water shortage, plants can alter their own properties: as example, they can tune the root permeability by aquaporin regulation (North and Nobel, 1997; Meyer et al., 2008; Knipfer et al., 2011), increase the root to leaf area ratio (Sperry et al., 1998), and vary the xylem resistance by ion concentration in the sap flow (Zwieniecki et al., 2003; Lee et al., 2012). An additional, complementary strategy consists in altering the hydraulic properties of the soil in the vicinity of roots, the so called rhizosphere, in order to optimize the acquisition of water and nutrients.

Effects of rhizosphere on root water uptake and drought tolerance are still matter of controversy. Young (1995) measured larger water contents in the rhizosphere than in the bulk soil, and he explained this observation with mucilage exuded by roots. Mucilage is primarily composed of polysaccharides and it can hold big volumes of water (McCully and Boyer, 1997); this can justify the observations of Young (1995) of a wetter rhizosphere compared to the bulk soil. However, other studies suggest that the rhizosphere is drier than the bulk soil. Read et al. (2003) showed that mucilage contains lipids that reduce the surface tension of the soil solution and that likely decrease the water holding capacity of the soil. Hallett et al. (2003) showed a low wettability of the rhizosphere compared to the bulk soil. Moradi et al. (2012) measured a high water repellency of the rhizosphere of lupines in dry sandy soils.

These opposite results on the water distribution in bulk soil and rhizosphere are not a contradiction, but are rather an expression of the rhizosphere plasticity (Carminati and Vetterlein, 2012). Carminati et al. (2010) found that the rhizosphere was wetter than the bulk soil during drying and it stayed temporarily dry upon rewetting. Based on this observation, 
they concluded that the hydraulic properties of the rhizosphere are hysteretic and timedependent. The authors interpreted their observations as the effect of mucilage. When mucilage is in equilibrium with the water potential in the bulk soil, it is expected to increase the rhizosphere water holding capacity. However, as roots take up water and the soil dries, mucilage shrinks and it becomes hydrophobic. Mucilage drying and its slow rewetting upon irrigation is shown in Figure 1.

Carminati et al. (2011) showed that a rhizosphere with higher water holding capacity than the bulk soil attenuated the drop in water potential towards the roots and facilitated the water uptake from dry soils. Keeping the rhizosphere wet, for instance by mucilage exudation, would be a strategy to improve the water extraction when water is scarce. However, this strategy seems to have a drawback: when mucilage dries it turns hydrophobic (Moradi et al. 2012). Therefore, the positive effect during the drying phase could be counteracted by the dryness of the rhizosphere after rewetting.

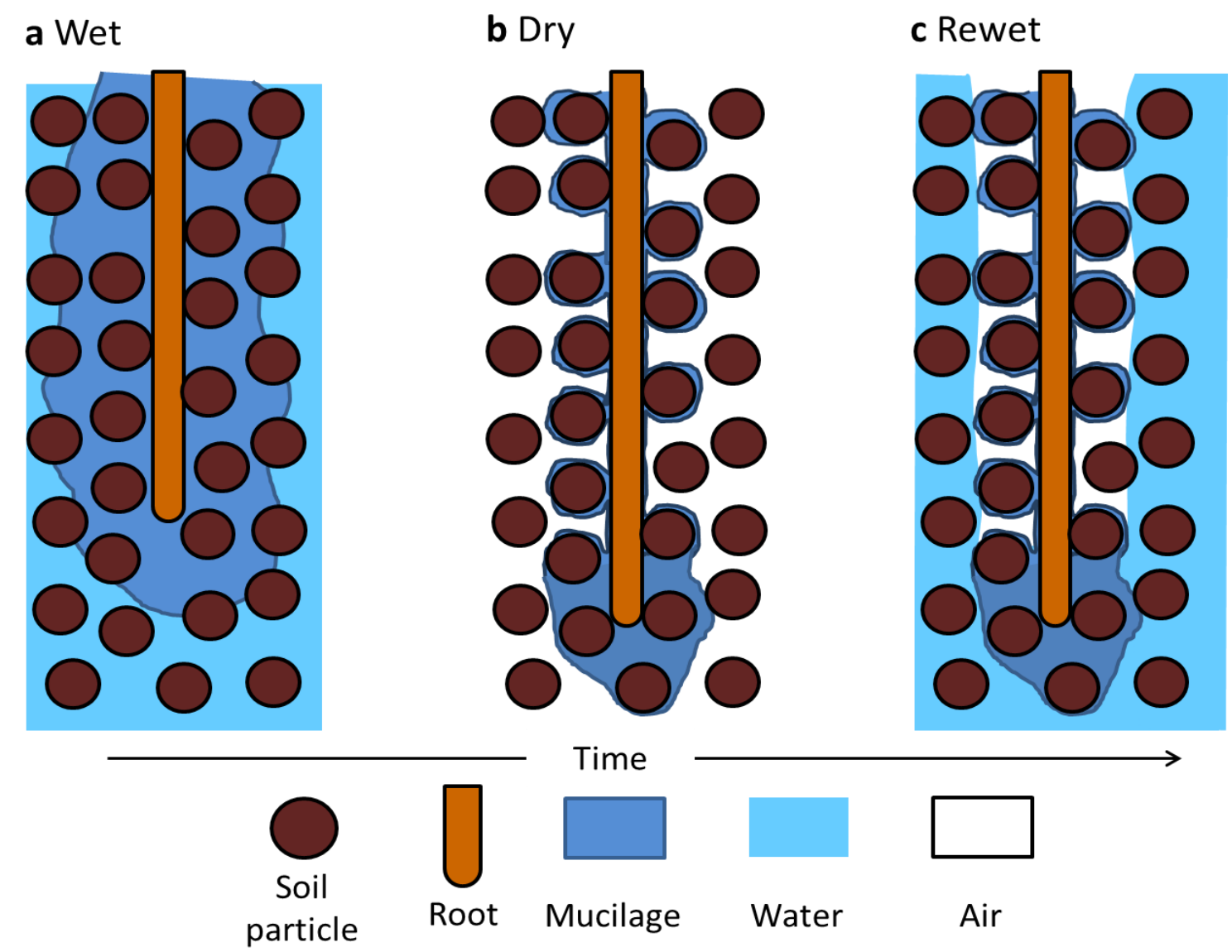

Figure 1: Hypothetical water distribution in the rhizosphere during drying and wetting including mucilage dynamics 
The low wettability of the rhizosphere after drying and subsequent rewetting is shown in Figure 2. The image was obtained with neutron radiography and it shows the spatial distribution of water content and roots of a 25-day-old lupine 30 minutes after irrigation. The initial water content of the soil was 0.02 and it was irrigated from the top with constant infiltration at a rate of $1 \mathrm{ml} \mathrm{min}{ }^{-1}$. In this radiograph, dark values correspond to high water contents, bright values to low water contents. After irrigation, water content in the bulk soil increased significantly, but a thin layer around the roots remained markedly drier. The white regions around the roots show that the rhizosphere rewetted much less than the bulk soil.

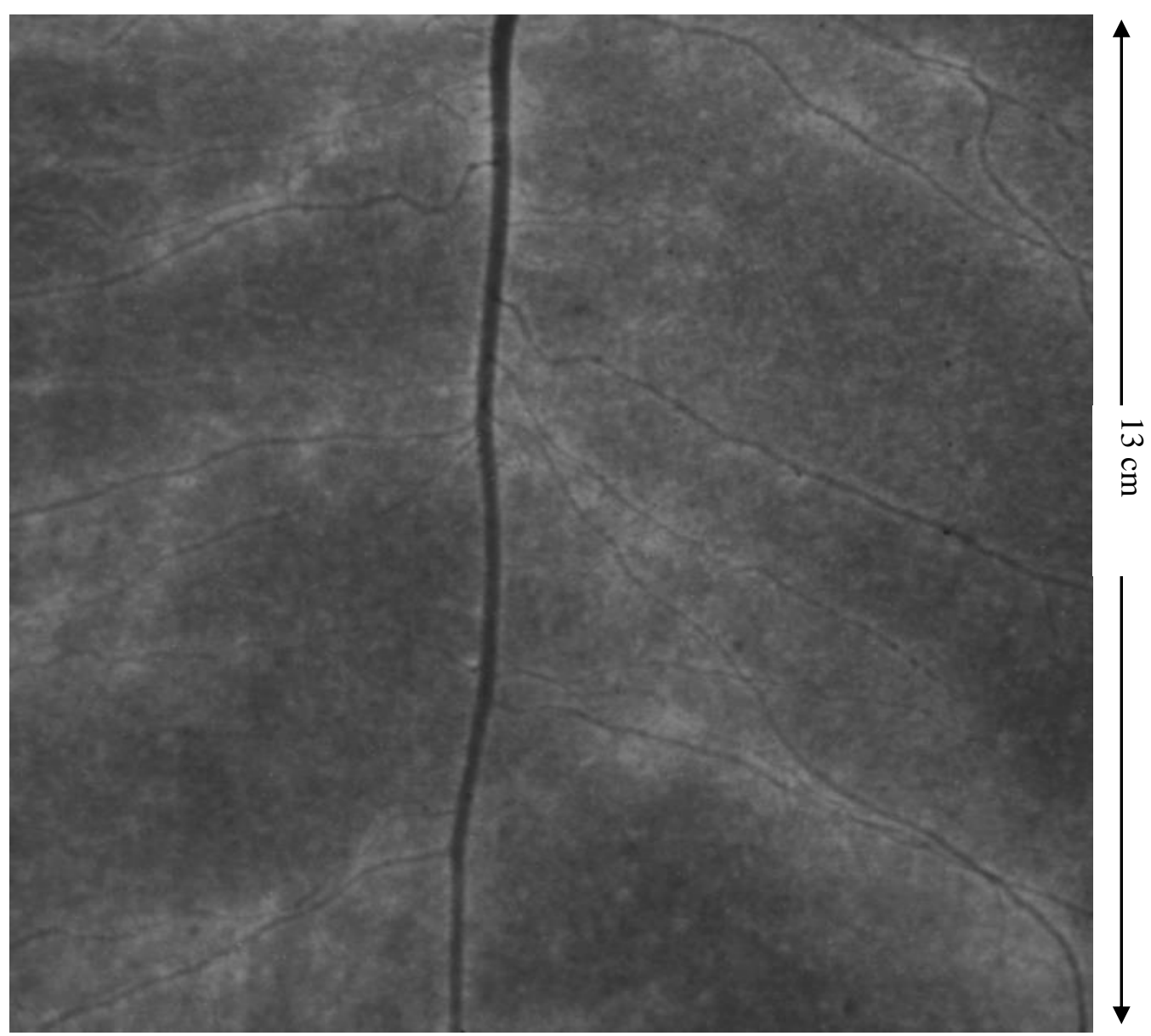

Figure 2: Neutron radiograph of a sample one hour after irrigation with normal water. Initial water content in the bulk soil was 0.02 and increased to 0.20 after irrigation. The darker gray value corresponds to big change in water content after irrigation. The brighter layers around roots indicate that the rhizosphere did not rewet. Note that neutron attenuation is averaged across the soil thickness (1 cm). Assuming that the rhizosphere has a thickness of $1.5 \mathrm{~mm}$ around roots the actual neutron attenuation in the rhizosphere would be at least 6 times bigger is seen on the radiographs. 
This observation was consistent in six samples and confirms the previous studies of Carminati et al. (2010) and Moradi et al. (2012). In the present study, we focus on a new aspect. Given that the rhizosphere becomes hydrophobic after drying, what are the effects on root water uptake? Does it prevent roots from taking up water? Does it impede the recovery of plants after drought? Or does water easily flow across the rhizosphere, with no consequences for root water uptake.

Answering these questions has been so far impeded by the lack of experimental methods to in-situ measure local flux of water into the roots. Recently, Zarebanadkouki et al. (2012; 2013) developed a new method to visualize the local water flow into roots by using deuterated water $\left(\mathrm{D}_{2} \mathrm{O}\right)$ and neutron radiography. In this study we applied this method to roots growing in soil regions that were let dry and subsequently rewetted. Our hypothesis was that after drying and subsequent rewetting, the rhizosphere became hydrophobic and root water uptake was limited.

\section{Materials and methods}

\section{Plants and soil}

We grew ten lupines (Lupinus albus) in aluminum slabs $(28 \mathrm{~cm}$ wide, $28 \mathrm{~cm}$ high and $1 \mathrm{~cm}$ thick) filled with sandy soil. The soil consisted of $92 \%$ sand, 5\% silt, 3\% clay. Before the filling procedure, we placed a grid of $1 \mathrm{~cm}$ thickness into the containers to partition the soil medium in nine compartments, 3 rows $\times 3$ columns (Figure 3 ). We poured the sandy soil into each compartment through one sieve to favor a homogeneous soil deposition and to reduce soil layering. During the filling procedure, the containers laid horizontally. We wetted the soil and removed the grids. After removing the grid, we filled the space between the compartments with coarse sand (grain diameter of 1.2-1.7 mm). The layers of coarse sand acted as capillary barriers to hydraulically disconnect the adjacent compartments without hindering root penetration. One face of each container had holes of $1 \mathrm{~mm}$ at a distance of 2 cm to allow injection of $\mathrm{H}_{2} \mathrm{O}$ and $\mathrm{D}_{2} \mathrm{O}$ in selected positions. We filled the upper one centimeter of the samples with quartz gravel to minimize evaporation.

Lupine seeds were germinated on moist filter paper for a period of 24 hours. The seeds were gently placed into the soil at $1 \mathrm{~cm}$ depth. The plants were grown with a photoperiod of 14 hours, light intensity of $300 \mu \mathrm{mol} \mathrm{m} \mathrm{m}^{-1}$, day/night temperature of $25^{\circ} \mathrm{C} / 19^{\circ} \mathrm{C}$, and relative humidity of $60 \%$. We irrigated the plants every fourth day to maintain the soil water content 
in each compartment between 0.1 and 0.2. Three weeks after planting, we stopped irrigating one of the two upper lateral compartments of each sample. We measured the transpiration rate of plant gravimetrically by weighing the samples every eight hours. Daily transpiration was $2.20 \pm 0.23(\mathrm{n}=10) \mathrm{g} \mathrm{h}^{-1}$ per plant. The plants were 28 day-old when the neutron radiography experiment started. At this stage plants had eight leaves with a total leaf area of approximately $170 \pm 6.31 \mathrm{~cm}^{2}(\mathrm{n}=10)$.

\section{Neutron radiography}

Neutron radiography is an imaging technique with high sensitivity to water and high temporal and spatial resolution. We used neutron radiography to monitor spatial and temporal distribution of $\mathrm{H}_{2} \mathrm{O}$ and $\mathrm{D}_{2} \mathrm{O}$ in soil. Neutron radiography was carried out at the cold neutron imaging beam-line ICON at the Paul Scherrer Institut (PSI), Switzerland. We used a CCD camera detector with an array of $1024 \times 1024$ pixels, resulting in a field of view of $14.5 \mathrm{~cm} \times$ $14.5 \mathrm{~cm}$, which corresponds to a pixel size of $0.0125 \mathrm{~cm}$. Nine radiographs with marginal overlaps were needed to scan the entire sample. For the measurements at daytime, a lamp identical to those in the growth chamber was installed in the imaging station above the plant, providing a light intensity of $300 \mu \mathrm{mol} \mathrm{m} \mathrm{m}^{2}$.

\section{$\mathrm{D}_{2} \mathrm{O}$ injection experiments}

Deuterated water $\left(\mathrm{D}_{2} \mathrm{O}\right)$ was used as a contrast agent to trace the flow of water into the roots. In contrast to normal water, $\mathrm{D}_{2} \mathrm{O}$ has a much lower neutron attenuation coefficient, which makes it well distinguishable in neutron radiographs.

After maintaining the plants well irrigated for 25 days, we stopped irrigating one of the upper lateral compartments while we continued to irrigate the other compartments. When the notirrigated compartment reached a water content of 0.02 (this took approximately 2-3 days), we injected 8-10 $\mathrm{ml}$ of $\mathrm{D}_{2} \mathrm{O}$ into each of the two top lateral compartments of eight sample. We refer to these two compartments as compartments with dry and wet rhizosphere. The compartment with wet rhizosphere was the control treatment and gave the root water uptake when the rhizosphere was hydrated. After injection of $\mathrm{D}_{2} \mathrm{O}$, both compartments had a water content $0.10<\theta<0.20$. In our sandy soil, this water contents correspond to soil matric potentials of $-50 \mathrm{hPa}<h<-20 \mathrm{hPa}$ (Carminati et al., 2010). This difference is smaller than typical differences in water potential between soil and roots during transpiration. 
The water potential in the roots of the two compartments was expected to be similar because all roots were connected to the same tap root. Therefore, the difference in water fluxes into the roots of the two compartments mostly depended on the hydraulic conductivity of the rhizosphere-root continuum.

Redistribution of $\mathrm{D}_{2} \mathrm{O}$ in soil and roots was monitored with time series neutron radiography with time interval of 10 seconds for a period of three hours. In four samples, $\mathrm{D}_{2} \mathrm{O}$ was injected at daytime, when a lamp identical to that of the growth chamber was mounted inside the imaging station. Transpiration was measured gravimetrically by weighing the samples before and after measurements. In other four samples, $\mathrm{D}_{2} \mathrm{O}$ was injected at nighttime when transpiration was negligible. The experiments at nighttime were made to determine the effect of convection (net water transport) and diffusion on the $\mathrm{D}_{2} \mathrm{O}$ transport along roots (axial transport) and from soil to roots (radial transport).

\section{Image processing}

The individual radiographs were referenced using a flat field (radiography without sample) and dark current (image recorded by the camera when there was no beam). The sharp contrast between roots and surrounding soil facilitated the visual separation (segmentation) of the roots from the surrounding soil. The segmented roots were skeletonized and their length and diameter were calculated. In the pixels containing roots, the signal was the sum of the attenuation coefficients of the root and the soil in front of and behind the root in the beam direction. The actual contributions of $\mathrm{H}_{2} \mathrm{O}$ and $\mathrm{D}_{2} \mathrm{O}$ in the root were calculated assuming that the contribution of $\mathrm{H}_{2} \mathrm{O}$ and $\mathrm{D}_{2} \mathrm{O}$ in soil in front of and behind the root was equal to those of the soil at the sides of the roots. We calculated the pixel-wise $\mathrm{D}_{2} \mathrm{O}$ content in the centermost pixels of the roots from the measured neutron attenuation coefficients in the radiographs. The volumetric concentration of $\mathrm{D}_{2} \mathrm{O}$ in the roots was calculated as the thickness of $\mathrm{D}_{2} \mathrm{O}$ divided by the total liquid thickness in roots. The image processing is described in details in Zarebanadkouki et al. (2012).

\section{Quantification of the water fluxes}

Transport of $\mathrm{D}_{2} \mathrm{O}$ in roots is driven by two processes: 1) diffusion following the gradient of $\mathrm{D}_{2} \mathrm{O}$ concentration, and 2) net volume of water driven by the transpiration stream (convection). Zarebanadkouki et al. (2012) showed that diffusion and convection are equally 
important in the transport of $\mathrm{D}_{2} \mathrm{O}$ from soil to roots across the root-soil interface and root tissue (radial transport). In contrast, $\mathrm{D}_{2} \mathrm{O}$ transport in the xylem along the root (axial transport) is primarily driven by convection. Comparison of experiments at nighttime, when convection is negligible, with experiments at daytime, when both convection and diffusion take place, gives information on the convective fluxes and, consequently on root water uptake.

Quantitative estimation of root water uptake by comparing daytime and nighttime radiographs is not straightforward and requires a modeling approach. Crucial is how the pathway of water across cortex, endodermis and stele, as well as the relative importance of the apoplastic and cell-to-cell pathways, are modeled (Zarebanadkouki et al. 2013). The results are therefore affected by the validity of the model and its assumptions.

Conversely, estimation of root water uptake from the axial transport in the roots does not need a modeling approach. Since $\mathrm{D}_{2} \mathrm{O}$ diffusion along the xylem is negligible compared to the convective transport, the volume of $\mathrm{D}_{2} \mathrm{O}$ passing the barrier, $\mathrm{V}_{\mathrm{D} 2 \mathrm{O}}$, is related to the axial flux according to:

$\frac{d V_{D 2 O}}{d t}=\pi r^{2} j_{x} C(t)$

where $C[-]$ is the $\mathrm{D}_{2} \mathrm{O}$ concentration in the root stele at the place of the barrier, $\mathrm{t}$ is time, $\mathrm{r}$ is the radius of the root stele and $j_{x}\left[\mathrm{~cm} \mathrm{~s}^{-1}\right]$ is the axial flux of water across the stele at the place of the barrier. Eq. (4.1) is valid until the $\mathrm{D}_{2} \mathrm{O}$ front reaches the taproot and then moves out from the field of view. When concentration of $\mathrm{D}_{2} \mathrm{O}$ reaches a constant value, the slope of $V_{D 2 O}(t)$ is a straight line and is used to calculate $j_{x}$. The relation between $j_{x}$ and the radial flow into the root, $j_{r}\left[\mathrm{~cm} \mathrm{~s}^{-1}\right]$ is given by:

$\pi r^{2} j_{x}=2 \pi \mathrm{r} L j_{r}$

where $L[\mathrm{~cm}]$ is the length of the root and $j_{r}$ is the flux into the endodermis averaged along $\mathrm{L}$. In this study, we used the axial transport of $\mathrm{D}_{2} \mathrm{O}$ to calculate the water uptake of the roots immersed in $\mathrm{D}_{2} \mathrm{O}$.

\section{Results}

Neutron radiography of one sample before injection of $\mathrm{D}_{2} \mathrm{O}$ is shown in Figure 3. The radiograph is obtained from stitching nine radiographs with marginal overlaps. It shows the distribution of water and roots. The gray values are proportional to the water contents (darker=wetter). The two compartments selected for the $\mathrm{D}_{2} \mathrm{O}$ injection are marked with a 
white and a black rectangle. We refer to these compartments as compartments with dry rhizosphere (white) and wet rhizosphere (black). The average water content before injection was equal to 0.02 in the dry compartment 0.10 in the wet compartment.

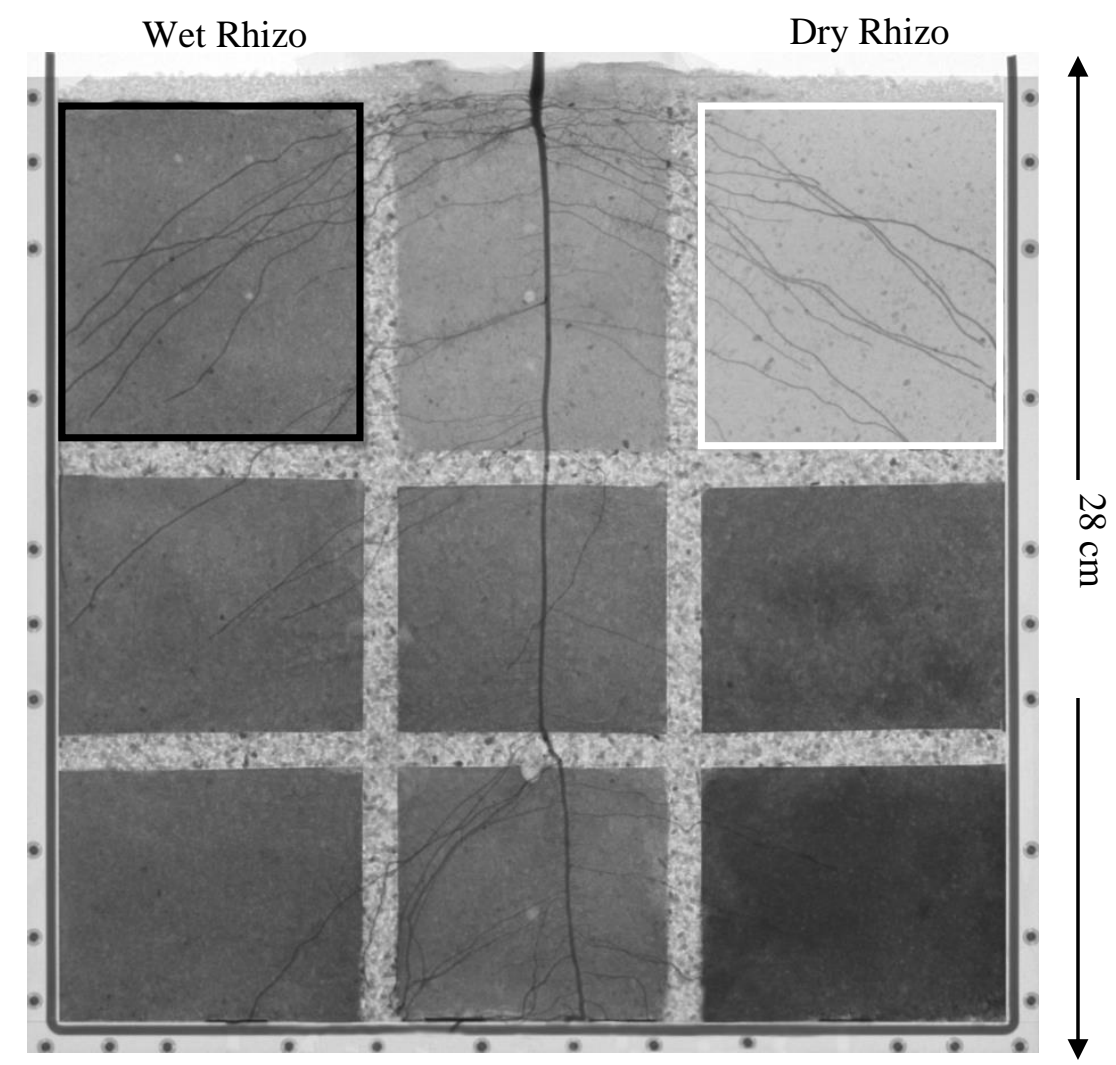

Figure 3: Neutron radiography of a sample that was used for $\mathrm{D}_{2} \mathrm{O}$ injection. Gray values are proportional to water contents (dark=wet). Roots appeared dark because of their high water content. The two compartments selected for $\mathrm{D}_{2} \mathrm{O}$ injection are marked in white (compartment with day rhizosphere) and black (compartment with wet rhizosphere).

We injected 8-10 $\mathrm{ml}$ of $\mathrm{D}_{2} \mathrm{O}$ into the two compartments at daytime. Neutron radiographs of the sample after injection of $\mathrm{D}_{2} \mathrm{O}$ are shown in Figure 4. The images show the ratio between the actual radiographs at time $t$ and the radiograph before injection $(t=0)$. Bright gray values indicate increased $\mathrm{D}_{2} \mathrm{O} / \mathrm{H}_{2} \mathrm{O}$ ratio. Dark gray values indicate accumulation of $\mathrm{H}_{2} \mathrm{O}$. Shortly after injection, $\mathrm{D}_{2} \mathrm{O}$ pushed away the $\mathrm{H}_{2} \mathrm{O}$ presented in the soil until the sum of $\theta_{\mathrm{H} 2 \mathrm{O}}=$ $\mathrm{V}_{\mathrm{H} 2 \mathrm{O}} / \mathrm{V}_{\text {tot }}$ and $\theta_{\mathrm{D} 2 \mathrm{O}}=\mathrm{V}_{\mathrm{D} 2 \mathrm{O}} / \mathrm{V}_{\text {tot }}$ was constant throughout the compartment. This process was driven by water potential gradients inside the compartment and was relatively fast (around one minute). The successive mixing of $\mathrm{D}_{2} \mathrm{O}$ and $\mathrm{H}_{2} \mathrm{O}$ was driven by diffusion and was relatively slower. 
After $\mathrm{D}_{2} \mathrm{O}$ injection, the roots inside the compartment turned bright indicating transport of $\mathrm{D}_{2} \mathrm{O}$ into roots. Subsequently, $\mathrm{D}_{2} \mathrm{O}$ moved along roots and passed the capillary barriers. This axial transport was faster in the roots with wet rhizosphere than in the roots with dry rhizosphere. Fast transport in the roots with wet rhizosphere was observed in all samples (Figure 5).

The measurements at nighttime showed that the axial transport along roots was negligible (Figure 6). This observation is consistent with our previous work (Zarebanadkouki et al., 2012; Zarebanadkouki et al., 2013) and it demonstrates that the axial transport of $\mathrm{D}_{2} \mathrm{O}$ beyond the barrier depends mainly on the convective fluxes.

To extract the quantitative information about the transport of $\mathrm{D}_{2} \mathrm{O}$ into roots with dry and wet rhizosphere, we calculated the volume of $\mathrm{D}_{2} \mathrm{O}$ passing the barrier, $V_{\mathrm{D} 2 \mathrm{O}}\left[\mathrm{cm}^{3}\right] . V_{\mathrm{D} 2 \mathrm{O}}$ is related to the axial flux $j_{x}\left[\mathrm{~cm} \mathrm{~s}^{-1}\right]$ according to Eq. (4.1). In Figure 7 we plotted the cumulative fluxes for the roots of the sample shown in Figure 4. The cumulative fluxes were calculated from the increase of $V_{\mathrm{D} 2 \mathrm{O}} /\left(\pi r^{2} C\right)$ [cm] over time in the time interval when $\mathrm{C}$ was constant. The slopes of the lines in Figure 7A are equal to the axial fluxes $j_{x}$. Figure 7A shows that the water fluxes were much higher in the compartments with wet rhizosphere than in those with dry

rhizosphere. 

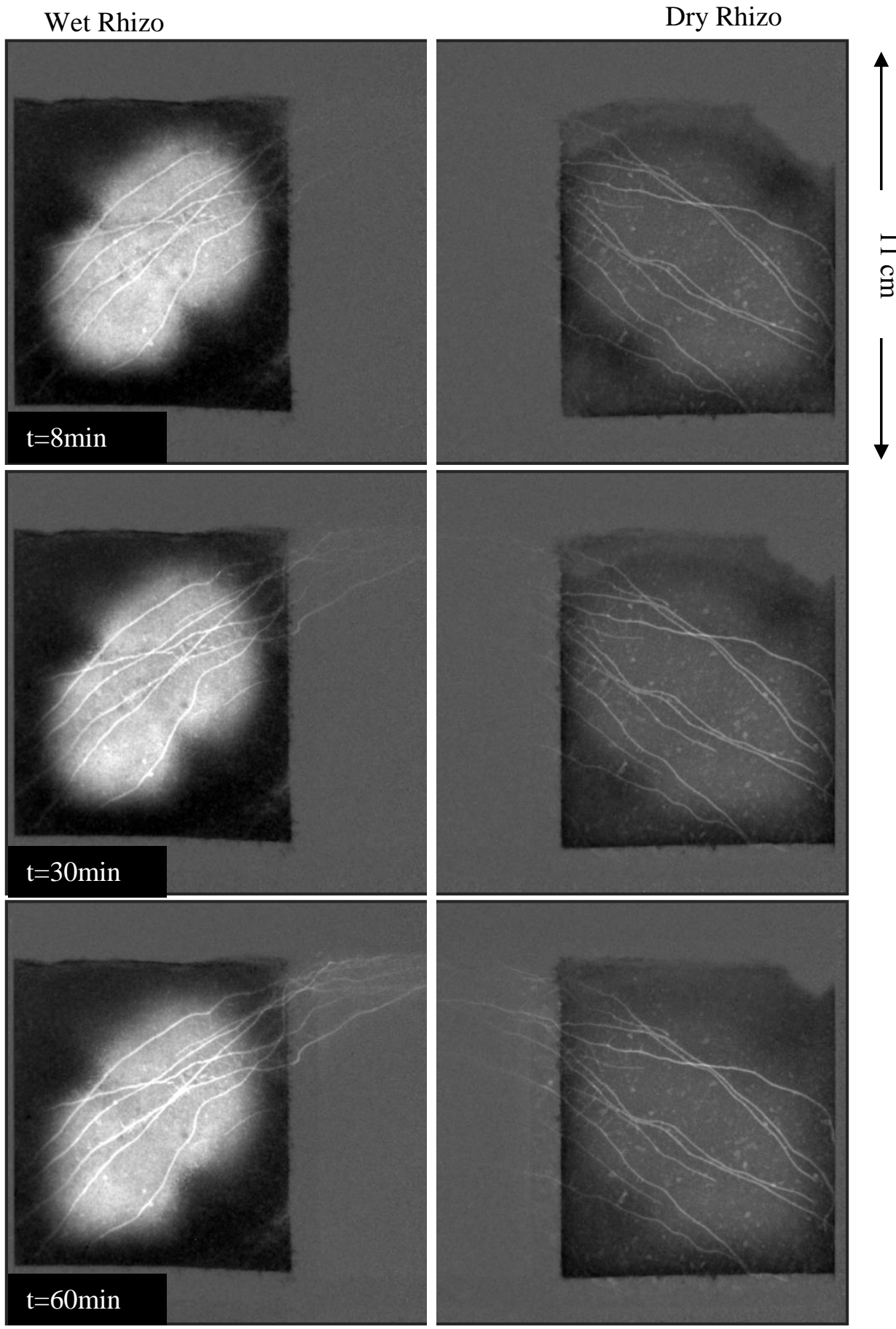

Figure 4: Neutron radiographs of the sample presented in Figure 3 after $\mathrm{D}_{2} \mathrm{O}$ injection. Radiographs show the ratio between the actual radiographs and the one at $\mathbf{t}=\mathbf{0}$. Bright values indicate less neutron attenuation and high values of $\mathrm{D}_{2} \mathrm{O} / \mathrm{H}_{2} \mathrm{O}$. Roots appeared bright indicating the transport of $\mathrm{D}_{2} \mathrm{O}$ into roots. The axial transport of $\mathrm{D}_{2} \mathrm{O}$ into roots was faster for the roots with wet rhizosphere than the roots with dry rhizosphere. 
Wet Rhizo
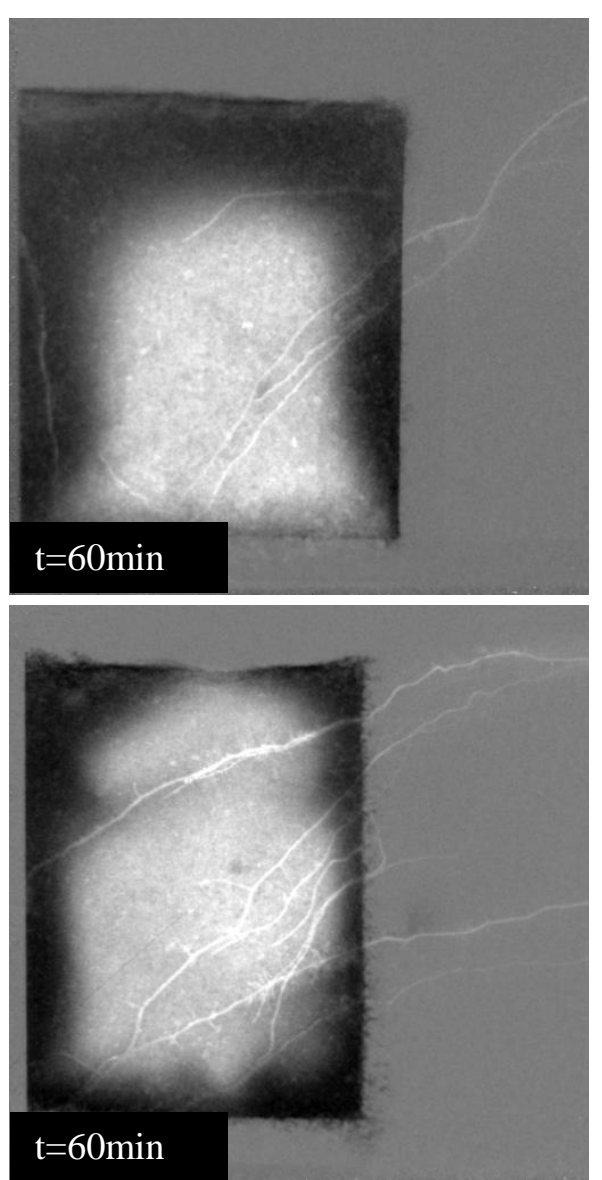

Dry Rhizo
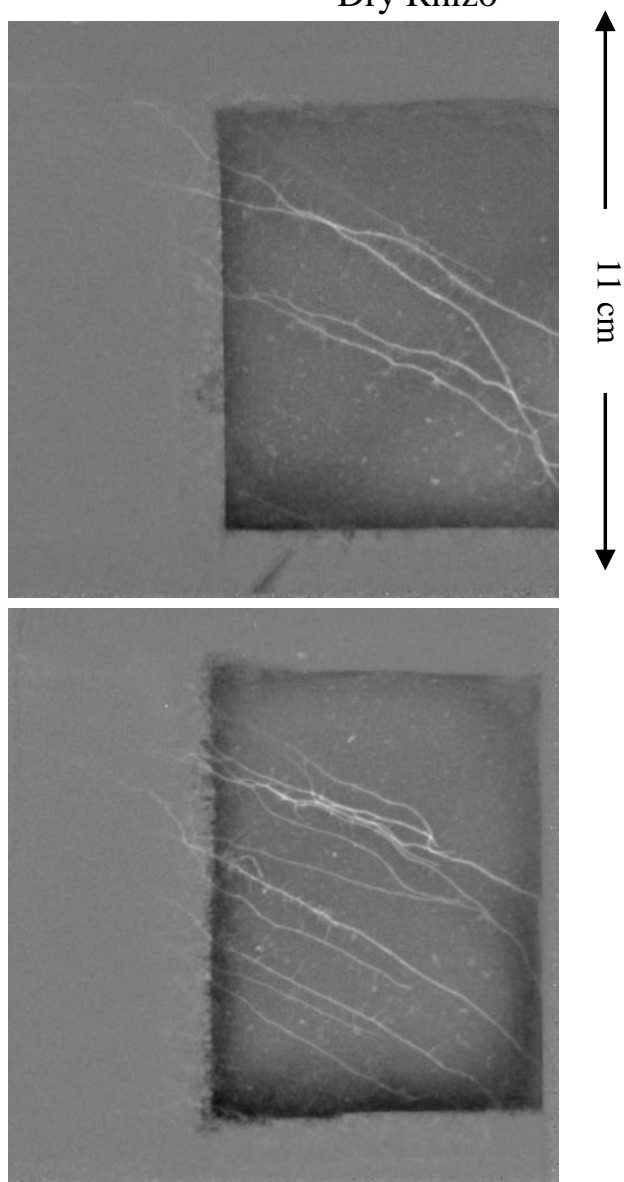

Figure 5: Neutron radiographs of two additional samples one hour after $\mathrm{D}_{2} \mathrm{O}$ injection. Radiographs show the ratio between the actual radiographs and the one at $t=0$. Bright values indicate less neutron attenuation and high values of $\mathrm{D}_{2} \mathrm{O} / \mathrm{H}_{2} \mathrm{O}$. $\mathrm{D}_{2} \mathrm{O}$ was injected into each compartment separately. 
A Dry Rhizo-Nighttime

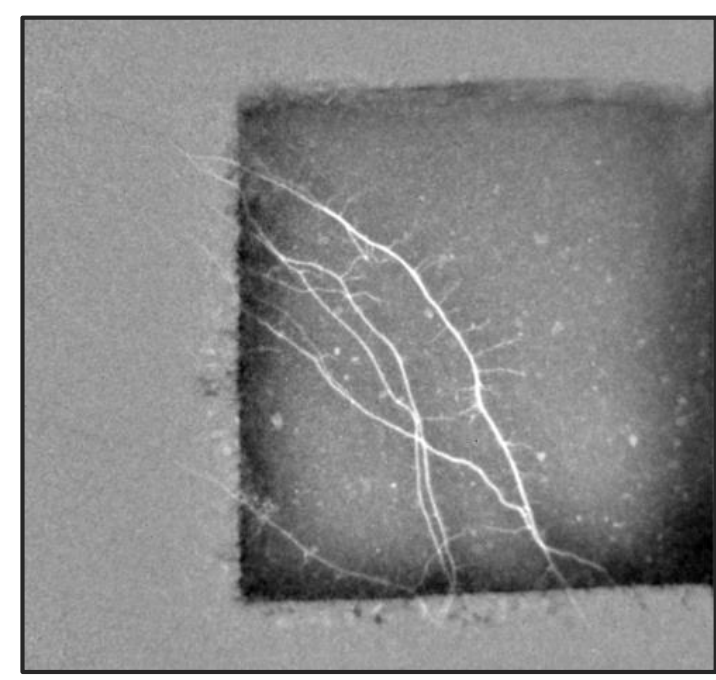

B Dry Rhizo-Daytime

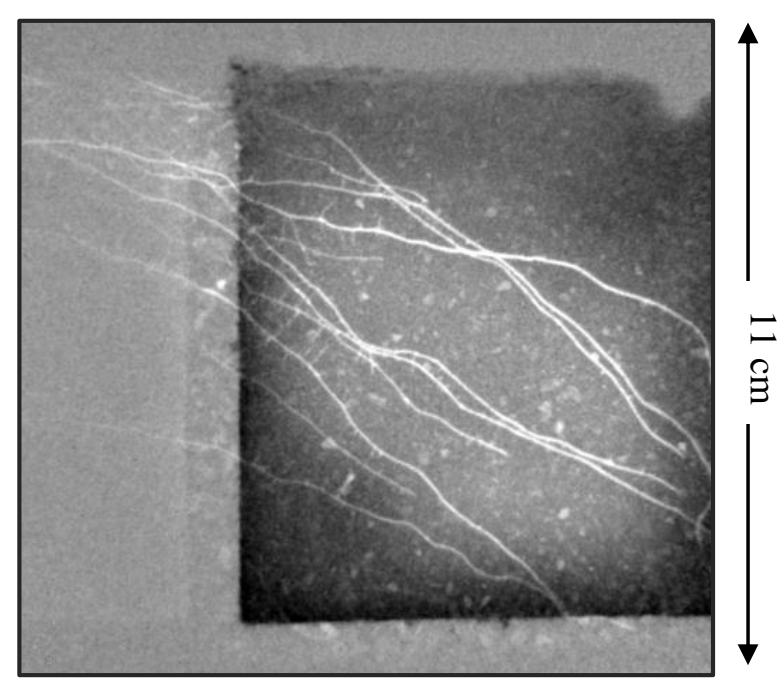

Figure 6: Comparison between axial transport of $\mathrm{D}_{2} \mathrm{O}$ beyond the barrier for the roots with dry compartment at night (A) and day (B). Radiographs show the ratio between the actual radiographs 90 minutes after injection and the one at $t=0$. Bright values indicate less neutron attenuation and high value of $\mathrm{D}_{2} \mathrm{O} / \mathrm{H}_{2} \mathrm{O}$. These radiographs show that axial transport of $\mathrm{D}_{2} \mathrm{O}$ beyond the barrier is negligible at night.

As $j_{x}$ increases with root length (Eq.4.1), we grouped roots in long (length of $16-17 \mathrm{~cm}$, $\mathrm{n}=14$ ), medium (length of 12-13 cm, $\mathrm{n}=9$ ), and short roots (length of 9-10 cm, n=6), with $\mathrm{n}$ being the number of roots. The mean axial fluxes for all samples are plotted in Figure 7B. In long roots the fluxes in the compartments with dry rhizosphere decreased of 7.6 times. In medium and short roots, the fluxes decreased of 6.8 and 4.2 times, respectively. The higher reduction in long roots compared to that in short roots suggests that water repellency and rewetting times increased with root age.

The higher water uptake of the roots with wet rhizosphere is also visible in the increase of $\mathrm{D}_{2} \mathrm{O}$ concentration inside the root. The rate of the $\mathrm{D}_{2} \mathrm{O}$ increase inside the root depends on diffusion and convection. Under the assumption that diffusion into roots is equal at nighttime and daytime, the difference between nighttime and daytime measurements contains the information about the convective flux. Therefore, we expect a larger day/night variation in the roots with wet rhizosphere. The average concentration of $\mathrm{D}_{2} \mathrm{O}$ in the roots with wet and dry rhizosphere is plotted in Figure 8. As expected, the larger day/night variations occurred in the roots with wet rhizosphere, while for the roots with dry rhizosphere the curves at daytime and nighttime were more similar. This observation confirms the measurements of $j_{x}$ shown in Figure 7 - i.e. higher uptake in roots with wet rhizosphere. 

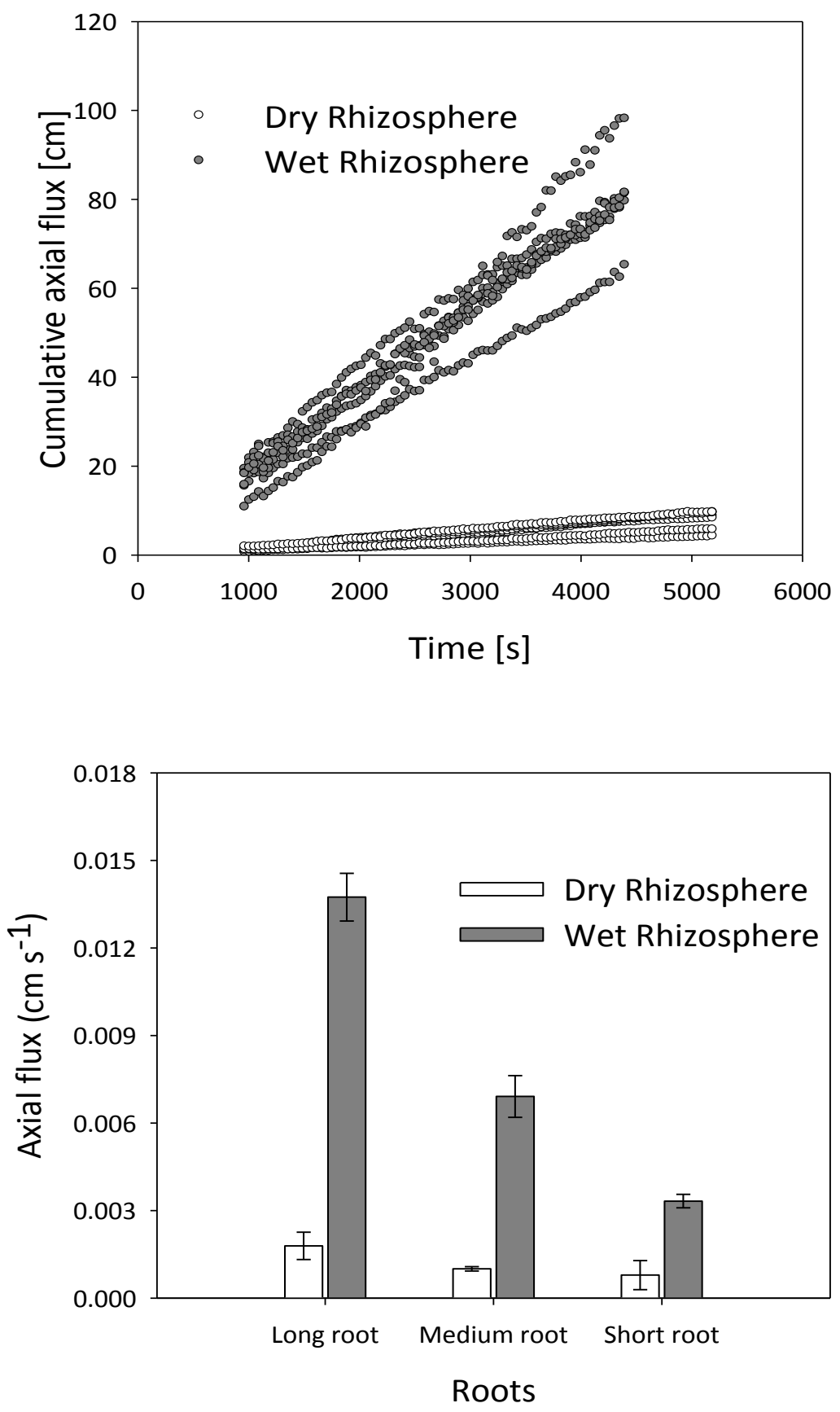

Figure 7: Water uptake of roots with dry and wet rhizosphere. (A) Cumulative axial fluxes into roots with dry and wet rhizosphere. The values refer to the sample shown in Figure 3. (B) Axial fluxes within the roots of all samples. Roots are grouped in long $(16-17 \mathrm{~cm}, \mathrm{n}=14)$, medium $(12-13 \mathrm{~cm}, \mathrm{n}=9)$ and short roots $(9-10 \mathrm{~cm}, \mathrm{n}=6)$. The axial fluxes are calculated at the capillary barriers $(5-6 \mathrm{~cm}$ from taproot). 


\section{Discussion}

The axial $\mathrm{D}_{2} \mathrm{O}$ transport into roots (Figure 7) and the radial one (Figure 8) show a lower root water uptake in the soil compartments that were let dry and subsequently rewetted. Root water uptake in these compartments was reduced of 4-8 times. This reduction persisted for at least one-two hours after rewetting. Such observations are in line with former observations of high water repellency in the rhizosphere (Moradi et al. 2012; Carminati et al. 2010).

Figure $8 \mathrm{~B}$ shows also an unexpected result. During daytime, the increase of $\mathrm{D}_{2} \mathrm{O}$ into the roots with dry rhizosphere is as fast as in the roots with wet rhizosphere; and during nighttime, the increase of $\mathrm{D}_{2} \mathrm{O}$ into root with dry rhizosphere is even faster than in the roots with wet rhizosphere. How can we explain these observations? Is there a contradiction with our hypothesis that after drying the rhizosphere becomes a limiting factor for water transport into roots?

One explanation is that in the roots with dry rhizosphere there is an additional force that drives water into the root after $\mathrm{D}_{2} \mathrm{O}$ injection. This force originates from the sudden increase of water potential in the soil compartment that was let dry. Based on the water retention curve of our sandy soil, we expect an increase of water potential up to $1 \mathrm{MPa}$. Let us consider the experiment at nighttime. Let us assume that when transpiration was null roots and soil were in equilibrium. After irrigation, the soil water potential suddenly increased and initiated a water flow into the roots. As water entered the roots, the roots swoll, their tissue rehydrated and their water potential increased until it equaled that of the soil. During $\mathrm{D}_{2} \mathrm{O}$ injection, this initial flow into the root increased the rate of $\mathrm{D}_{2} \mathrm{O}$ transport into the root and could explain our observations. Obviously, hydraulic equilibration between soil and roots is more complex and depends on the hydraulic redistribution between roots. However, this simple picture illustrates the effect of the abrupt change of water potential in the dry compartment. A similar process will occur at day.

A second explanation is that the increase of $\mathrm{D}_{2} \mathrm{O}$ that we attribute to the roots with dry rhizosphere did not come only from the roots themselves, but it partly came from the rhizosphere. The reason is illustrated in Figure 9. Before $\mathrm{D}_{2} \mathrm{O}$ injection, according to Carminati et al. (2010) and Moradi et al. (2011), we expect that the water content increased towards the roots. Let us assume that the initial water content of the bulk soil was 0.02 and the water content in the rhizosphere was 0.06 (Figure 9A). Taking a neutron attenuation coefficient of normal water $\Sigma_{\mathrm{H} 2 \mathrm{O}}=4 \mathrm{~cm}^{-1}$, we obtain a neutron attenuation of 0.24 [-] for the rhizosphere and of 0.08 [-] for the bulk soil. After injection of $9 \mathrm{ml} \mathrm{D}_{2} \mathrm{O}$, the liquid content $\left(\mathrm{H}_{2} \mathrm{O}+\mathrm{D}_{2} \mathrm{O}\right)$ in the bulk soil increased to 0.12 . If we entirely replaced the $\mathrm{H}_{2} \mathrm{O}$ present in the 
bulk soil with $\mathrm{D}_{2} \mathrm{O}$ and we assume $\Sigma_{\mathrm{D} 2 \mathrm{O}}=0.6 \mathrm{~cm}^{-1}$, the neutron attenuation in the radiographs for the bulk soil would be 0.07 [-]. Since the liquid content $\left(\mathrm{H}_{2} \mathrm{O}+\mathrm{D}_{2} \mathrm{O}\right)$ in the rhizosphere did not change instantaneously after injection (Carminati et al. 2010), the neutron attenuation in the rhizosphere remained constant (Figure 9B). If we take the difference between the radiograph before and immediately after $\mathrm{D}_{2} \mathrm{O}$ injection, we cannot expect to see any effect of rhizosphere water repellency. Indeed, we did not see it in the experiments with $\mathrm{D}_{2} \mathrm{O}$. However, after some time, $\mathrm{H}_{2} \mathrm{O}$ initially presents in the rhizosphere mixed with $\mathrm{D}_{2} \mathrm{O}$ of the bulk soil until the concentration of $\mathrm{D}_{2} \mathrm{O}$ in the soil solution was uniform. We expect that $\mathrm{H}_{2} \mathrm{O} / \mathrm{D}_{2} \mathrm{O}$ mixing was slower in the rhizosphere than in the bulk soil, due to the presence of mucilage around the roots. After complete $\mathrm{H}_{2} \mathrm{O} / \mathrm{D}_{2} \mathrm{O}$ mixing in the rhizosphere (Figure 9C), the neutron attenuation in the rhizosphere decreased down to 0.07 (based on the total volumes of $\mathrm{D}_{2} \mathrm{O}$ and $\mathrm{H}_{2} \mathrm{O}$ in the compartment, at equilibrium we can expect $\mathrm{H}_{2} \mathrm{O} / \mathrm{D}_{2} \mathrm{O}=1 / 5$ ). Compared to the initial radiograph, this means that the decrease in the neutron attenuation after $\mathrm{D}_{2} \mathrm{O}$ injection was much bigger in the rhizosphere than in the bulk soil. Since our analysis is based on the two-dimensional picture, we cannot be sure that the signal in the root was not affected by the signal of the rhizosphere. On the contrary, it is very likely that part of the increase of $\mathrm{D}_{2} \mathrm{O}$ in Figure $8 \mathrm{~B}$ came from the rhizosphere, rather than exclusively from the root. 

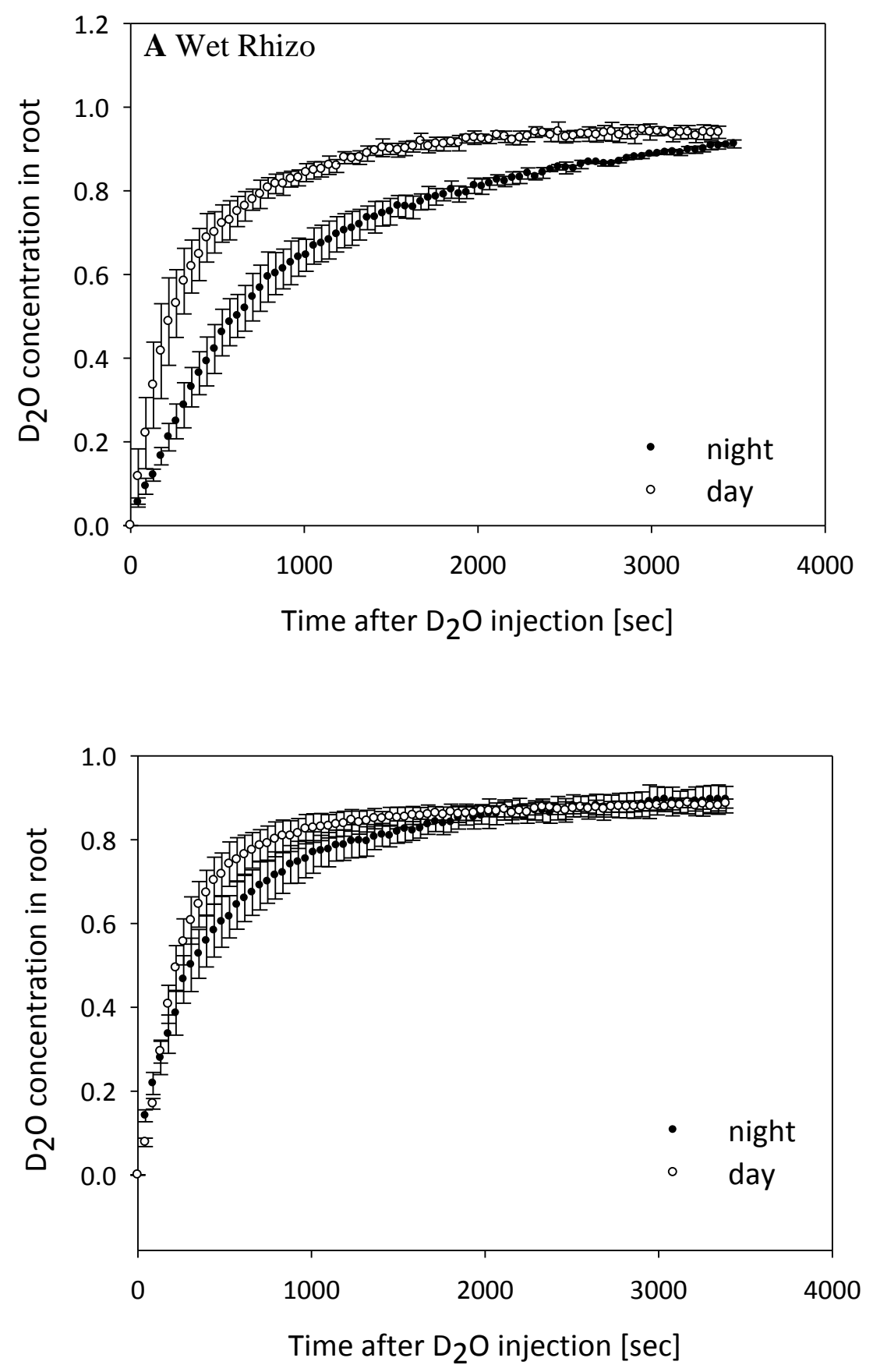

Figure 8: Concentration of $\mathrm{D}_{2} \mathrm{O}$ in roots crossing dry and wet rhizosphere at daytime (A) and nighttime (B). Error bars show the standard deviation. 

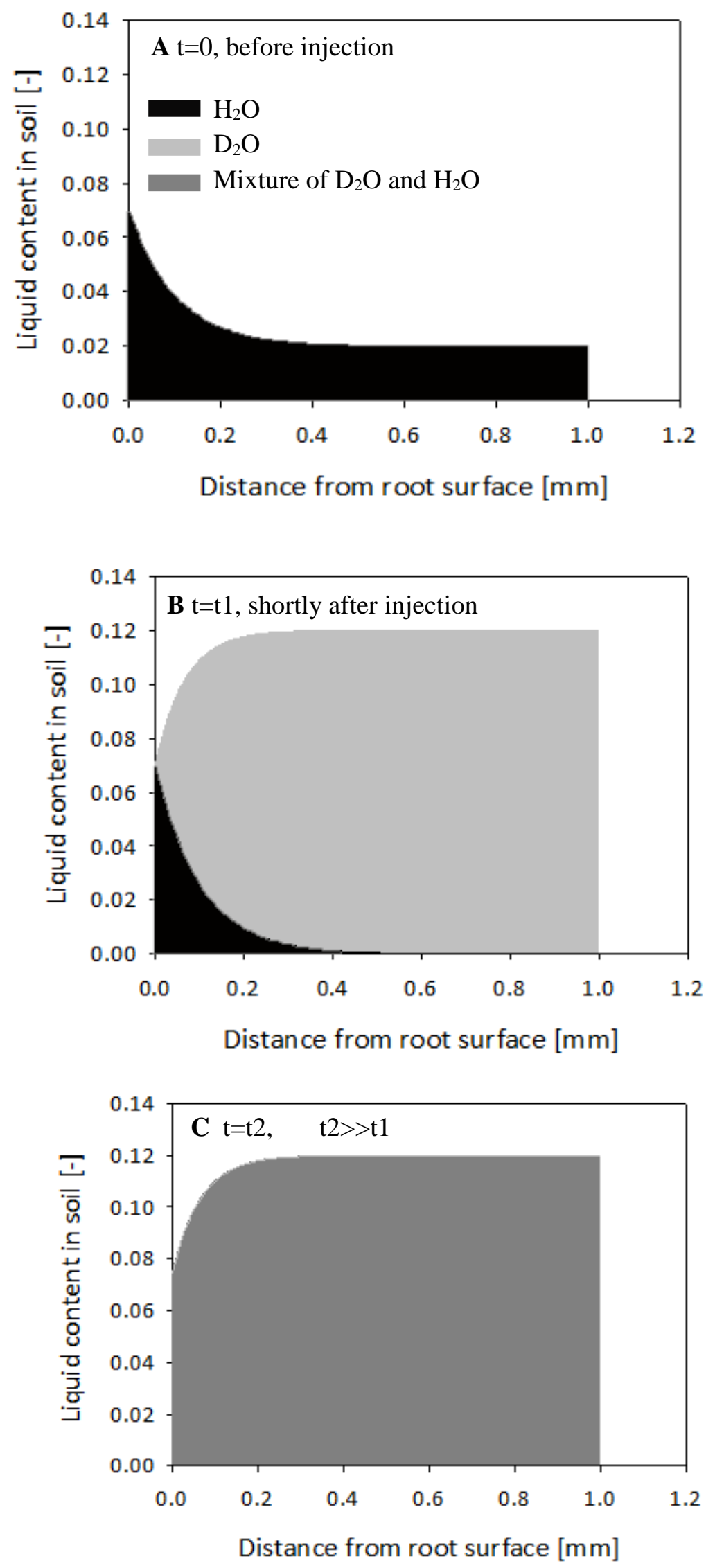

Figure 9: Putative $\mathrm{H}_{2} \mathrm{O}$ and $\mathrm{D}_{2} \mathrm{O}$ distribution as a function of distance from the root surface at different times after $\mathrm{D}_{2} \mathrm{O}$ injection. 
The interpretation of Figure $8 \mathrm{~B}$ in terms of radial transport into the root is therefore not trivial and the effect of $\mathrm{H}_{2} \mathrm{O} / \mathrm{D}_{2} \mathrm{O}$ mixing in the rhizosphere should be better understood and interpreted.

Beside this unexpected increase of $\mathrm{D}_{2} \mathrm{O}$ into the root of the dry compartment, our experiments clearly demonstrated two points:

1) Although the rhizosphere became hydrophobic after drying and rewetting (Figure 2), water could flow from soil to roots across the rhizosphere.

2) Root water uptake in the compartment with dry rhizosphere was reduced of 4-8 times compared to the well watered compartment.

The first point confirms the model of Carminati (2012), in which water content, water potential and hydraulic conductivity of the rhizosphere are not related by a unique function, but their relation varies over time. In fact, rhizosphere rewetting and transport across the rhizosphere show different dynamics: rhizosphere rewetting takes one-two days (Carminati et al. 2010), whilst the transport of $\mathrm{D}_{2} \mathrm{O}$ across the dry rhizosphere is relatively fast. This point alone, however, does not allow a conclusion on the effects of the rhizosphere on root water uptake.

The second point shows that the hydrophobicity of the rhizosphere is associated with a reduction of root water uptake. As the driving forces in the compartments with dry and wet rhizosphere are expected to be similar and the bulk soil was wet, the low root water uptake must result from a decrease in the hydraulic conductivity of the system. The decrease in hydraulic conductivity may have occurred in the rhizosphere or in the root.

The reduced hydraulic conductivity of the rhizosphere may have resulted from the rhizosphere hydrophobicity discussed above or from the shrinkage of roots and the consequent formation of air-filled gaps (Nobel and Cui, 1992; North and Nobel, 1997; Carminati et al., 2012).

Decrease of root hydraulic conductivity may have occurred at different levels. One possibility is that the radial conductivity decreased in response to aquaporine closure during drying. However, Bramley et al. (2009) found that aquaporine closure did not affect significantly the conductivity of Lupine roots and concluded that the pathway of water flow in Lupine roots was predominantly apoplastic. Another possibility is that during the 2-3 days of soil drying, the endodermis of the roots became tighter blocking the apoplastic flow (Henzler and Steudle, 1995; Knipfer et al., 2011; Hu et al., 2011; McLean et al., 2011). Beside a decrease in radial conductivity, also a decrease in the axial conductivity may have occurred due to 
cavitation of some vessels in the xylem (Tyree and Sperry, 1989; Tyree and Zimmermann, 2002). Note that such hypothesis would explain both the low net water uptake and the relatively quick $\mathrm{D}_{2} \mathrm{O}$ diffusion into the roots with dry rhizosphere, whereas a decrease in the radial conductivity would not explain the latter observation.

However, the growing condition of the roots in the dry compartment were varied only for 2-3 days after 25 days of wet growing conditions. Additionally, having only a small portion of the soil relatively dry may have limited the risk of cavitation and root dehydration, due to partial hydraulic redistribution during night. Note that the plants were well turgid throughout all the measurement time and did not show any symptoms of water shortage. Therefore, we think that this experimental set-up minimized the risk of cavitation and alteration of the root properties in the dry compartment in the short time interval of our measurements.

The main result of this study is that after a drying/wetting cycle the local root water uptake was 4-8 times lower than in well watered regions, and it stayed low for at least 1-2 hour. Such reduction in water uptake is in line with our observations of water repellency in the rhizosphere. However, we cannot exclude that cavitation or reduced root permeability may have contributed to the reduced root water uptake. The apparently quick $\mathrm{D}_{2} \mathrm{O}$ transport across the dry rhizosphere needs further investigation. 


\section{Acknowledgements}

We thank Yangmin Kim for support in the interpretation of the data and for comments to a previous version of the manuscript. We acknowledge Anders Kaestner and the staff at the ICON imaging station of the Paul scherrer Institut (PSI) for technical support during the measurements with neutron radiography. The position of $\mathrm{M}$. Zarebanadkouki was funded by IPSWaT, BMBF, grant IPS 11/Q04.

\section{References}

Bramley, H., N.C. Turner, D.W. Turner, and S.D. Tyerman. (2009). Roles of morphology, anatomy, and aquaporins in determining contrasting hydraulic behavior of roots. Plant Physiol 150(1): 348-364.

Carminati, A. (2012). A Model of Root Water Uptake Coupled with Rhizosphere Dynamics. Vadose Zone J 11(3).

Carminati, A., A.B. Moradi, D. Vetterlein, P. Vontobel, E. Lehmann, U. Weller, H.-J. Vogel, and S.E. Oswald. (2010) Dynamics of soil water content in the rhizosphere. Plant Soil 332(1-2): 163-176.

Carminati, A., C.L. Schneider, A.B. Moradi, M. Zarebanadkouki, D. Vetterlein, H.J. Vogel, A. Hildebrandt, U. Weller, L. Schüler, and S.E. Oswald. (2011). How the Rhizosphere May Favor Water Availability to Roots. Vadose Zone J 10(3): 988-998.

Carminati, A., and D. Vetterlein. (2012). Plasticity of rhizosphere hydraulic properties as a key for efficient utilization of scarce resources. Ann. Bot.

Carminati, A., D. Vetterlein, N. Koebernick, S. Blaser, U. Weller, and H.-J. Vogel. (2012). Do roots mind the gap? Plant Soil doi:10.1007/s11104-012-1496-9.

Dodd, I.C. (2003). Hormonal interactions and stomatal responses. J Plant Growth Regul 22(1): 32-46.

Draye, X., Y. Kim, G. Lobet, and M. Javaux. (2010). Model-assisted integration of physiological and environmental constraints affecting the dynamic and spatial patterns of root water uptake from soils. J Exp Bot 61(8): 2145-2155.

Gardner, W.R. (1960). Dynamic aspects of water availability to plants. Soil Sci 89(2): 63-73. 
Hallett, P.D., D.C. Gordon, and A.G. Bengough. (2003). Plant influence on rhizosphere hydraulic properties: direct measurements using a miniaturized infiltrometer. New Phytol 157(3): 597-603.

Henzler, T., and E. Steudle. (1995). Reversible closing of water channels in Chara internodes provides evidence for a composite transport model of the plasma membrane. J Exp Bot 46(2): 199-209.

Hu, T., S. Kang, F. Li, and J. Zhang. (2011). Effects of partial root-zone irrigation on hydraulic conductivity in the soil-root system of maize plants. J Exp Bot 62(12): $4163-4172$.

Knipfer, T., M. Besse, J.-L. Verdeil, and W. Fricke. (2011). Aquaporin-facilitated water uptake in barley (Hordeum vulgare L.) roots. J Exp Bot 62(12): 4115-4126.

Lee, J. N.M. Holbrook, and M.A. Zwieniecki. (2012). Ion induced changes in the structure of bordered pit membranes. Front Plant Sci.

McCully, M.E., and J.S. Boyer. (1997). The expansion of maize root-cap mucilage during hydration. 3. Changes in water potential and water content. Physiol Plant. 99(1): 169177.

McLean, E.H., M. Ludwig, and P.F. Grierson. (2011). Root hydraulic conductance and aquaporin abundance respond rapidly to partial root-zone drying events in a riparian Melaleuca species. New Phytol 192(3): 664-675.

Meyer, C.J., J.L. Seago, and C.A. Peterson. (2008). Environmental effects on the maturation of the endodermis and multiseriate exodermis of Iris germanica roots. Ann Bot-Lond. 103(5): 687-702.

Moradi, A.B., A. Carminati, A. Lamparter, S.K. Woche, J. Bachmann, D. Vetterlein, H.J. Vogel, and S.E. Oswald. (2012). Is the rhizosphere temporarily water repellent? Vadose Zone J 11(3).

Moradi, A.B., A. Carminati, D. Vetterlein, P. Vontobel, E. Lehmann, U. Weller, J.W. Hopmans, H.-J. Vogel, and S.E. Oswald. (2011). Three-dimensional visualization and quantification of water content in the rhizosphere. New Phytol 192(3): 653-663. 
Nobel, P.S., and M. Cui. (1992). Hydraulic conductances of the soil, the root-soil air gap, and the root: changes for desert succulents in drying soil. J Exp Bot 43(3): 319-326.

North, G.B., and P.S. Nobel. (1997). Drought-induced changes in soil contact and hydraulic conductivity for roots of Opuntia ficus-indica with and without rhizosheaths. Plant Soil 191(2): 249-258.

Passioura, J.B. (1980). The Transport of Water from Soil to Shoot in Wheat Seedlings. J Exp Bot 31(1): 333-345.

Read, D.B., A.G. Bengough, P.J. Gregory, J.W. Crawford, D. Robinson, C.M. Scrimgeour, I.M. Young, K. Zhang, and X. Zhang. (2003). Plant roots release phospholipid surfactants that modify the physical and chemical properties of soil. New Phytol 157(2): 315-326.

Sperry, J.S., F.R. Adler, G.S. Campbell, and J.P. Comstock. (1998). Limitation of plant water use by rhizosphere and xylem conductance: results from a model. Plant Cell Env. 21(4): $347-359$.

Tyree, M.T., and J.S. Sperry. (1989). Vulnerability of Xylem to Cavitation and Embolism. Annu Rev Plant Physiol Plant Mol Biol 40(1): 19-36.

Tyree, M.T., and M.H. Zimmermann. (2002). Xylem Structure and the Ascent of Sap. Springer.

Young, I.M. (1995). Variation in moisture contents between bulk soil and the rhizosheath of wheat (Triticum aestivum L. cv. Wembley). New Phytol 130(1): 135-139.

Zarebanadkouki, M., Y.X. Kim, A.B. Moradi, H.-J. Vogel, A. Kaestner, and A. Carminati. (2012). Quantification and Modeling of Local Root Water Uptake Using Neutron Radiography and Deuterated Water. Vadose Zone J 11(3).

Zarebanadkouki M, Kim YX, A, Carminati A. (2013). Where do roots take up water? Neutron radiography of water flow into the roots of transpiring plants growing in soil. New Phytol. DOI: $10.1111 /$ nph.12330.

Zwieniecki, M.A., M.V. Thompson, and N.M. Holbrook. (2003). Understanding the Hydraulics of Porous Pipes: Tradeoffs Between Water Uptake and Root Length Utilization. J Plant Growth Regul 21(4): 315-323. 


\section{A method to measure hydraulic conductivity of the rhizosphere after drying}

Mohsen Zarebanadkouki and Andrea Carminati, (In preparation) 


\section{Abstract}

The ability of plants to take up water from the soil is influenced by the hydraulic behavior of the soil in the immediate vicinity of the roots, the so called rhizosphere. Hydraulic properties of the rhizosphere are actively altered by roots and associated microorganisms. In previous works (Carminati et al 2010; Moradi et al. 2011; Moradi et al. 2012), it has been shown that the water retention curve of the rhizosphere differs from that of the bulk soil. However, the hydraulic property that is expected to have a higher impact on soil-plant water relations is the hydraulic conductivity of the rhizosphere. To data, there is very little experimental information on the hydraulic conductivity of the rhizosphere.

In this study we attempted to measure the hydraulic conductivity of the rhizosphere after drying. To this end, we monitored the redistribution of water in the soil and root during a drying and wetting cycle using time-series neutron radiography.

Lupines were grown in aluminium containers filled with sandy soil. Plants were irrigated every fourth day for a period of two weeks and then irrigation was stopped. Six days after stopping irrigation, we rewatered the samples from the top (60 ml water) and simultaneously monitored redistribution of water in the soil and roots by mean of neutron radiography. The radiographs showed that the rhizosphere stayed temporarily dry and it slowly rewetted with time. Over time, we observed that roots swelled.

We used the swelling rate of roots to estimate the effective hydraulic conductivity of the rhizosphere. To calculate effective hydraulic conductivity of the rhizosphere, we assumed that roots and soil were at the same water potential before and the end of infiltration. We used a Darcy type of equation where the flux of water into roots was obtained from the swelling rate of roots and gradient in water potential between roots and soil was estimated from the pressure volume curve of the roots. We found that the effective hydraulic conductivity of the rhizosphere was initially $1 \times 10^{-11} \mathrm{~cm} \mathrm{~s}^{-1}$ and it increased to $2 \times 10^{-9} \mathrm{~cm} \mathrm{~s}^{-1}$ in four hours. 


\section{Introduction}

The rhizosphere is defined as the soil in the immediate vicinity of roots that is actively modified by roots and microorganisms living in symbiosis with the roots (Gregory, 2006). Many studies reported that the rhizosphere has specific and distinct properties that differ from those of the bulk soil. How these properties may affect the balance of water between plants and soil has been subject of many investigations (Young, 1995; Read \& Gregory, 1997; Read et al., 1999; Hallett et al., 2003; Whalley et al., 2004, 2005; Carminati et al., 2010; Moradi et al., 2012).

Due to the small size of the rhizosphere, its importance as water capacitor is negligible compared to the big transpiration demand of the plants. However, the hydraulic conductivity of the rhizosphere may affect the flux of water into the roots. Typically, the ability of plants to take up water from the soil is controlled by the resistance of roots. But, as the soil dries, the soil hydraulic conductivity decreases of several orders of magnitudes and may become dominant (Gardner, 1960; Passioura, 1980; Nobel \& Cui, 1992; Doussan et al., 2006; Carminati et al., 2011). Modelling calculations showed that under dry condition, the flow of water into roots is limited by the hydraulic properties of the soil in the immediate vicinity of the roots due to a big drop in water potential and hydraulic conductivity around the roots in the soil ( Carminati et al., 2011).

It has been known that by exuding mucilage, roots modify the relation between water content and water potential in the rhizosphere (McCully \& Boyer, 1997; Czarnes et al., 2000; Hallett et al., 2003; Whalley et al., 2004). Carminati et al. (2010) and Moradi et al. (2011) observed unexpectedly higher water contents in the rhizosphere than in the bulk soil during a drying cycle. They explained this observation with the presence of mucilage in the rhizosphere. Mucilage is expected to increase the water-holding capacity of the soil by improving the absorbing capacity of soil and the soil structure (Chenu, 1993; Watt et al., 1994; McCully \& Boyer, 1997; Or et al., 2007). Higher water content in the rhizosphere has been also reported by others (Young, 1995; Nakashi, 2005).

Carminati et al. (2010) observed that immediately after rewetting, the rhizosphere remained markedly dry and it slowly rewatered until it became again wetter than the bulk soil. They explained this observation with a temporarily hydrophobicity of the rhizosphere caused by the presence of surfactants in the mucilage. Mucilage contains surfactants that reduce the surface tension of water in soil. Coating the soil particles in the rhizosphere with surfactants, in 
particular lipid components, reduces the wettability of the rhizosphere (Read \& Gregory, 1997; Read et al., 1999; Czarnes et al., 2000; Hallett et al., 2003; Moradi et al., 2012). Other authors have also reported low water content in the rhizosphere (MacFall et al., 1990; Segal et al., 2008). Carminati et (2012) suggests that different observations of a wet and dry rhizosphere are not in contradiction, but they rather reflect the dynamic and hysteretic hydraulic behavior of the rhizosphere. These studies show that the rhizosphere has hydraulic properties than cannot be explained by classical models. According to the classical models, the hydraulic conductivity of soil is a unique function of water content. Carminati (2012) proposed a new model in which the rewetting of the rhizosphere does not follow the changes in water potential in the rhizosphere and it depends on wettability and swelling rate of the mucilage. This model could simulate the unexpected water distribution around the roots during drying and rewetting cycles. In the present study, we aimed to measure the hydraulic conductivity of the rhizosphere during the rewetting cycle. To this end, we used neutron radiography technique to monitor redistribution of water in the soil and roots of lupines. We used the swelling rate of roots to estimate the effective hydraulic conductivity of the rhizosphere. This study will introduce a capable technique to measure the hydraulic conductivity of the dry rhizopsphere. It will also provide experimental data needed for understanding and modelling root water uptake in dry condition.

\section{Material and methods}

\section{Preparation of the soil and plants}

Lupine seeds (Lupine Albus) were grown in aluminium containers $(15 \mathrm{~cm}$ wide, $30 \mathrm{~cm}$ high and $1 \mathrm{~cm}$ thick) filled with a sandy soil. The sandy soil was collected from the artificial catchment Chicken Creek located near Cottbus, Germany. The soil (sieved to $<2 \mathrm{~mm}$ ) consisted of approximately $92 \%$ sand, 5\% silt and 3\% clay. The soil hydraulic properties are given in Table. The containers were filled with soil while they were laid horizontally. The sandy soil was poured into the containers through two sieves to favor a homogenous sand deposition and limit soil layering. The open faces of the containers were then closed, turned vertically, and gently shaken to achieve a stable packing. The average bulk density of the soil was $1.4 \mathrm{~g} \mathrm{~cm}^{-3}$. The top of the samples was covered with a $1 \mathrm{~cm}$-thick layer of quartz gravel (size of $5 \mathrm{~mm}$ grain) to minimize evaporation. 
Lupine seeds were germinated on moist filter paper for a period of 24 hours. Then, we placed the seedling into the soil at $1 \mathrm{~cm}$ deptsh. We grew the plants with a photoperiod of 14 hours, light intensity of $300 \mu \mathrm{mol} \mathrm{m} \mathrm{s}^{-1}$, day/night temperature of $25^{\circ} \mathrm{C} / 19^{\circ} \mathrm{C}$, and relative humidity of $60 \%$. We irrigated the plants every fourth day to maintain the soil water content between 0.10 and 0.20 . Two weeks after planting, we stopped irrigation. Transpiration was monitored gravimetrically by weighing the samples every 8 hours. The average daily transpiration rate was $1.04 \pm 0.13(\mathrm{n}=6) \mathrm{g} \mathrm{h}^{-1}$ per plant. After stopping irrigation, transpiration was rather constant for four days and then it reduced to $0.4 \pm 0.21(\mathrm{n}=6) \mathrm{g} \mathrm{h}^{-1}$ per plant at the day when we started the neutron radiography experiments (plants were 20 days old).

\section{Neutron radiography}

Neutron radiography is an imaging technique with high sensitivity to water and high temporal and spatial resolution. Neutron radiography was carried out at the cold neutron imaging beamline ICON at Paul Scherrer Institut (PSI), Switzerland. We used a CCD camera detector with an array of $1260 \times 1260$ pixels, resulting in a field of view of $15.75 \mathrm{~cm} \times 15.75 \mathrm{~cm}$, and effective spatial resolution of $0.2 \mathrm{~mm}$. Two radiographs with marginal overlaps were needed to scan the entire sample. The neutron radiography experiments were performed at nighttime when transpiration was negligible.

\section{Infiltration experiments}

Six days after stopping the irrigation, we started neutron radiography experiment. Plants were three weeks old when we started the experiments. At nighttime when plants were not transpiring, we infiltrated the samples from top using three syringes. Samples were infiltrated with $60 \mathrm{ml}$ water for a period of three minutes. Spatiotemporal distribution of water in soil and the roots were monitored using time series neutron radiography for a period of four hours. During the rewetting phase only the upper part has been scanned

Table 1: Mualem-van Genuchten parameters for the bulk soil.

\begin{tabular}{lllll}
\hline$\theta_{\text {res }}[-]$ & $\theta_{\text {sat }}[-]$ & $\mathrm{n}[-]$ & $\alpha\left[\mathrm{cm}^{-1}\right]$ & $\mathrm{k}_{\mathrm{s}}\left[\mathrm{cm} \mathrm{s}^{-1}\right]$ \\
0.02 & 0.36 & 2.21 & 0.03 & $3 \times 10^{-3}$ \\
\hline
\end{tabular}




\section{Root segmentation}

The sharp contrast between roots and surrounding soil, due to the marked difference in their water contents, allowed us to easily segment roots from the soil. Root thickness calculation and root segmentation were carried out by image processing using the algorithm roottracker2D (Menon et al., 2007). We calculated root radius and root length using the Euclidean distance map and the skeleton of the segmented roots.

\section{Quantification of water content in the bulk soil}

The individual radiographs were referenced using a flat field (radiography without sample) and dark current (image recorded by the camera when there was no beam). The Beer-Lambert law for our samples can be rewritten as

$$
-\log I_{\text {norm }}(x, y)=+\mu_{A l} d_{A l}+\mu_{s}(1-\phi) d_{t o t}+\mu_{H 2 O} d_{H 2 O}
$$

where the subscripts $\mathrm{Al}, \mathrm{S}$, and $\mathrm{H}_{2} \mathrm{O}$ refer to aluminium container, solid phase of the soil, and normal water, respectively, $I_{n o r m}(x, y)$ is the corrected image, $\mu\left(\mathrm{cm}^{-1}\right)$ is the macroscopic neutron attenuation coefficient, $\emptyset$ is the soil porosity $\left(\mathrm{cm}^{3} \mathrm{~cm}^{-3}\right)$, and $d_{t o t}$ is the inner thickness of the container $(1 \mathrm{~cm})$. The contribution of container and soil were derived from the radiograph of a dry sample, $I_{d r y}(x, y)$. The attenuation coefficients of water $\left(\mu_{\mathrm{H} 2 \mathrm{O}}=3.65 \mathrm{~cm}^{-1}\right)$ were measured using control samples with known normal water content. Assuming that the contribution of the container and soil was uniform across the sample, the contribution of $\mathrm{H}_{2} \mathrm{O}$ in the sample can be written as

$$
-\log \left(\frac{I_{n o r m}(x, y)}{I_{d r y}(x, y)}\right)=\mu_{H 2 O} d_{H 2 O}
$$

The average water content, $\bar{\theta}[-]$, across the thickness of the sample can be written as

$$
\frac{d_{H 2 O}}{d_{t o t}}=\bar{\theta}
$$

where $d_{t o t}$ is the total thickness of the inner space of the container $(1 \mathrm{~cm})$. This equation can be used to calculate water content in the bulk soil, but not in the roots and their rhizosphere. 


\section{Quantification of water content in the rhizosphere}

Since the radiographs are 2D images resulting from neutron transmission across the sample thickness, the radiographs give the average water content in the rhizosphere and in the portion of the soil in front and behind the rhizosphere. Consider the example illustrated in Figure 1: If water content in the rhizosphere is two time bigger than the bulk soil, the attenuated neutron projected in the pixel A of the radiograph will yield a water content of only 1.18 times bigger than the one of the bulk soil, because the attenuated neutron is an averaged across 45 pixels, while only 9 pixels had a high water content (rhizosphere). Additionally, the pixels containing the rhizosphere also have different distance from the roots. Assuming a radial symmetry around the root, the relation between the actual water content as a function of distance from root, $\theta(r)$, and the average water content calculated from the radiographs, $\theta(x)$, can be written as:

$\bar{\theta}(x)=\frac{1}{d_{t o t}} \int_{x}^{\sqrt{x^{2}+d_{\text {tot }}^{2}}} \theta(r) \sqrt{\frac{r^{2}}{r^{r}-x^{2}}} d r$

where $d_{t o t}$ is the thickness of soil, $r$ is the radial distance from the root surface and $x$ is the apparent distance from the root surface in the radiograph.

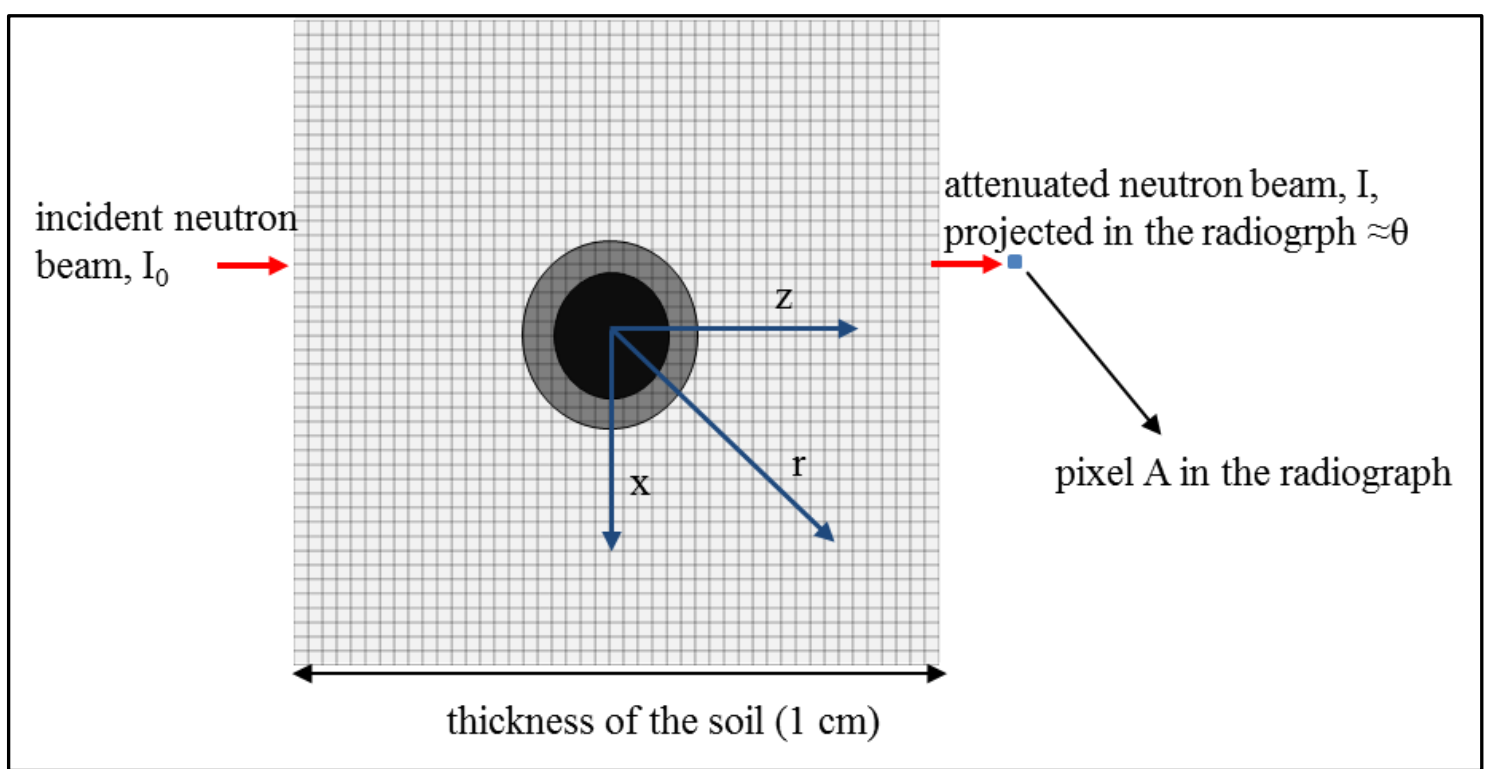

Figure 1: Schematic cross-section of root (black), rhizosphere (dark gray) and bulk soil (light gray). Neutron radiography yielded the water content averaged along the $1 \mathrm{~cm}$ sample thickness. In the pixels next to the root, $\theta$ is the average of the water content in the bulk soil and the rhizosphere. 


\section{Quantification of water content in roots}

In the pixels containing roots, the signals are the average of the attenuation coefficient of the root and the soil in front and behind the root. The actual contributions of $\mathrm{H}_{2} \mathrm{O}$ in roots can be calculated assuming that the contributions of $\mathrm{H}_{2} \mathrm{O}$ in front and behind the root are equal to those of soil beside the roots quantified by Eq.(5.3). The pixel-wise water content in the roots was calculated as

$$
\mu_{\text {root }}=\frac{-\log \left(\frac{I_{\text {root }}}{I_{\text {soil }}}\right)+\mu_{s}(1-\phi) d_{\text {root }}-\mu_{\text {soil }} d_{\text {root }}}{d_{\text {root }}}
$$

where $I_{\text {root }}$ is the value of $I_{\text {norm }}$ in the centermost pixel in the roots, $I_{\text {soil }}$ is the average value of $I_{\text {norm }}$ in soil near to the roots and $d_{\text {root }}$ is the root diameter. The attenuation coefficient of root $\left(\mu_{\text {root }}\right)$ depends on the volumetric water content in the root.

\section{Effective hydraulic conductivity of the rhizosphere}

To calculate hydraulic conductivity of the rhizosphere, we assumed that the rhizosphere is a region with $1.5 \mathrm{~mm}$ distance from the root surface. Then we calculated effective hydraulic conductivity of the rhizosphere, which determines how easily water flows from the soil into roots crossing the rhizosphere. According to Darcy law, the hydraulic conductivity can be calculated as

$$
j=k(\theta) \frac{h_{b}-h_{r}}{d}
$$

where $j$ is the flux of water into root $\left[\mathrm{cm} \mathrm{s}^{-1}\right], k$ is the hydraulic conductivity of the rhizosphere $\left[\mathrm{cm} \mathrm{s}^{-1}\right], h_{b}$ is the water potential in the bulk soil $[\mathrm{cm}], h_{r}$ is the water potential in root $[\mathrm{cm}], d$ is the thickness of the rhizosphere in direction of flow [cm]. To be correct, $k$ is the hydraulic conductivity of the rhizosphere-root continuum, and only when the conductivity of the rhizosphere is much smaller than that of the root, $k$ is equal to the rhizosphere conductivity. We will come back to this point later on in the discussion.

We assumed an equal water potential in roots and soil at nighttime, when plants were not transpiring. Then we used swelling rate of the roots obtained from neutron radiographs to calculate the flux of water into the roots - ie. the changes in the root water content over time was equal to the net flow of water into the roots, and the axial flow along root was negligible. 
The water potential in soil during infiltration was derived from the water content based on the measured water retention curve. The relation between water potential, $\Psi_{p},[\mathrm{~cm}]$, and root volume was parameterized according to (Stadelmann, 1984)

$\Psi_{p}=\Psi_{p(\max )} e^{\beta \cdot\left(R W C^{-1}-1\right)}$

where $\Psi_{\mathrm{p}(\max )}$ is the maximum water potential in the roots $[\mathrm{cm}], \beta$ is the exponential factor related to sensitivity the elasticity change with degree of water saturation [-] and $R W C$ is the relative water content in roots [-]. From this equation it follows that

$\ln \Psi_{p}-\ln \Psi_{p(\max )}=\beta \cdot\left(R W C^{-1}-1\right)$

To find the value of $\beta$ for our roots, we assumed that the roots were in equilibrium with the soil at the beginning and at the end of infiltration experiment. The relative water content of roots was calculated from the water content of roots divided by the final water content at the end of the experiment.

\section{Results}

We monitored the distribution of water in soil and roots in five samples following a rewetting cycle. Figure 2 shows the radiographs of one sample in which we infiltrated the sample from the top with injection of $60 \mathrm{ml} \mathrm{H}_{2} \mathrm{O}$. We also presented the results of radiography of one more samples in the appendix. The radiographs are a close-up of the original field of view of $15.5 \mathrm{~cm} \times 15.5 \mathrm{~cm}$. Images $2 \mathrm{a}$ in Figure 2 shows water and roots distribution in the sample before infiltration. Images $2 \mathrm{~b}-\mathrm{f}$ show the ratio between the actual radiographs at time $t$ and the radiograph before injection, indicating the changes in water content in both roots and soil after infiltration. In these images, the dark values correspond to big changes in water content and bright values to small changes. After infiltration, water content in the bulk soil increased, but a tiny region in the vicinity of the roots appeared slightly drier (brighter color). This indicates that the bulk soil was conductive enough to be rewatered quickly while the rewetting of the rhizosphere was restricted. The slow rewetting of the rhizosphere can be explained by hydrophobicity of the rhizosphere (Moradi et al., 2012) or formation of air gaps due to shrinkage of roots (Nobel \& Cui, 1992; Nye, 1994; North \& Nobel, 1997; Carminati et al., 2009). 


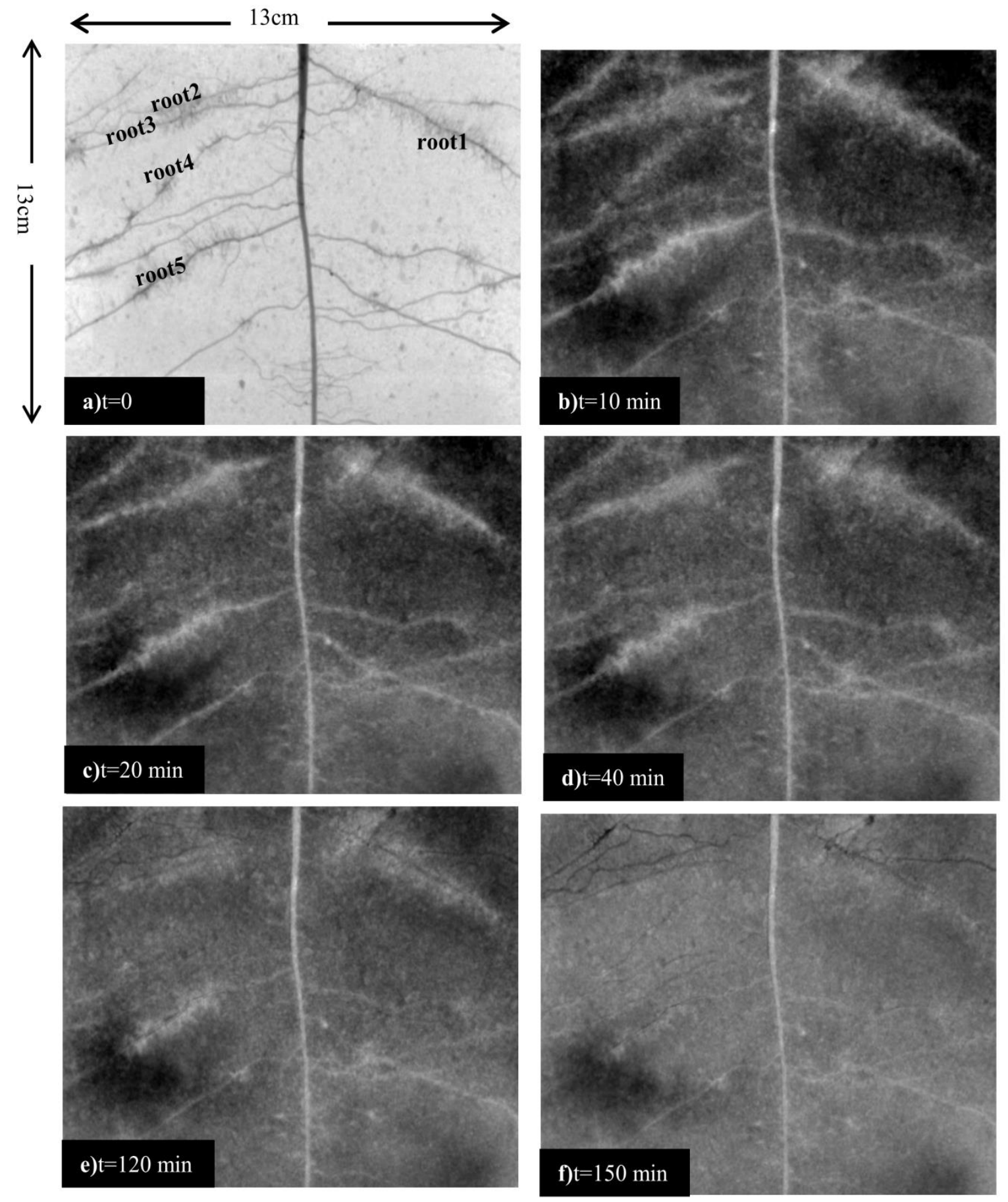

Figure 2: Neutron radiographs of sample after a drying period (a) and after rewetting at time $\mathbf{t}(\mathbf{b}-\mathbf{f})$ during nighttime. The soil was infiltrated from the top with $60 \mathrm{ml}$ of water. Images $2 \mathrm{~b}$-f are differences between the actual radiographs at time $t$ and the one before infiltration $(t=0)$. In these images the darker is the image, the wetter is the soil. The bright region around roots indicates a slow rewetting of the rhizosphere. The images are a close up of the original field of view of $(15.5 \times 15.5 \mathrm{~cm})$. 
This observation was consistent in all our samples and confirmed the previous results of Carminati et al. (2010). The intensity of dark colors in the bulk soil decreased over time due to drainage of water from the top of the sample to the bottom (Images 2b-f). Despite of drainage of water in the bulk soil, the rhizosphere turned dark, indicating that water content in the rhizosphere slowly increased. The images $2 \mathrm{~d}-\mathrm{f}$ show that roots slowly turned dark after infiltration, which indicates the root swelling.

After root segmentation, we quantified the water content in soil and roots. We selected five roots with rather similar length for detailed analysis (Fig. 2a). The quantified water content near the roots in the soil was average of water content across the soil thickness. We reconstructed the actual profile of water content as a function of distance from roots according to Eq. (5.4). The data are shown in Figure 3. Note here and elsewhere in our text the time zero for each root is referenced to the time that water front arrived in the vicinity of the roots. The results showed a higher initial water content in the rhizosphere of all roots than the bulk soil. The 3D profiles showed that water content increased at a distance of 1.5-2 mm toward the root surface and in average it was 3 times higher in the rhizosphere than in the bulk soil. This observation was consistent with the results from (Carminati et al., 2010; Moradi et al., 2011). After infiltration, water content in the bulk soil quickly increased but not in the rhizosphere. Following infiltration, water content in the bulk soil decreased due to gravity drainage but in the rhizosphere it slowly increased and finally exceeded the one in the bulk soil. We averaged the water content in the immediate vicinity of the roots (a distance of $1.5 \mathrm{~mm}$ from the root surface) and along the roots as representative of water content in the rhizosphere (Carminati et al., 2010; Moradi et al., 2011). We also averaged water content in a distance of 10 to $12 \mathrm{~mm}$ from the root surface of the selected roots as the water content in the bulk soil. Figure 4 shows the change in water content of the rhizosphere and the bulk soil following infiltration. These results show that after infiltration, the rhizosphere of each roots stayed dry at the beginning, it rewetted slowly, and finally exceeded the water content of the bulk soil. 

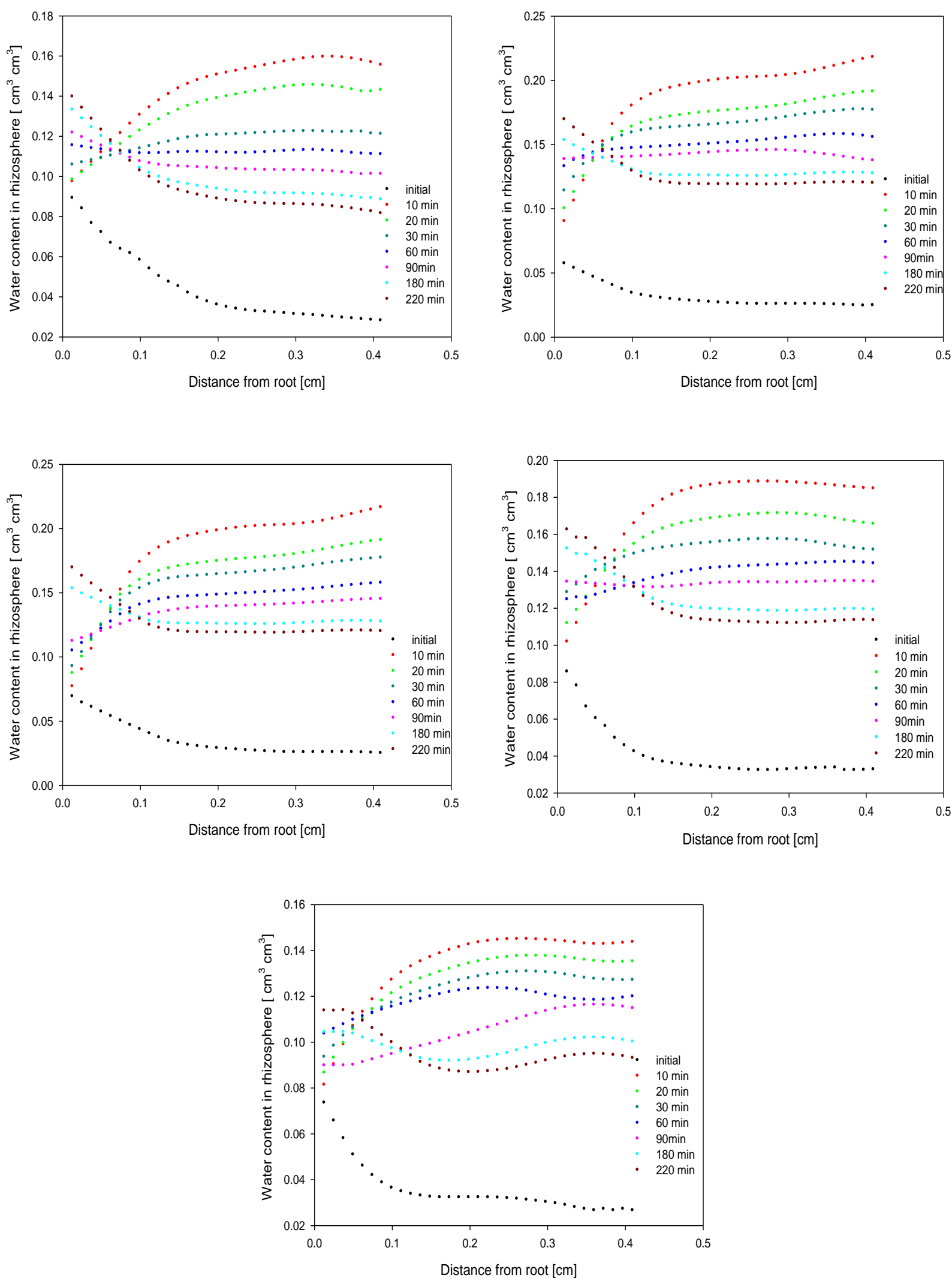

Figure 3: The profile of water content as a function of distance to roots after irrigation in different roots (a-e). 


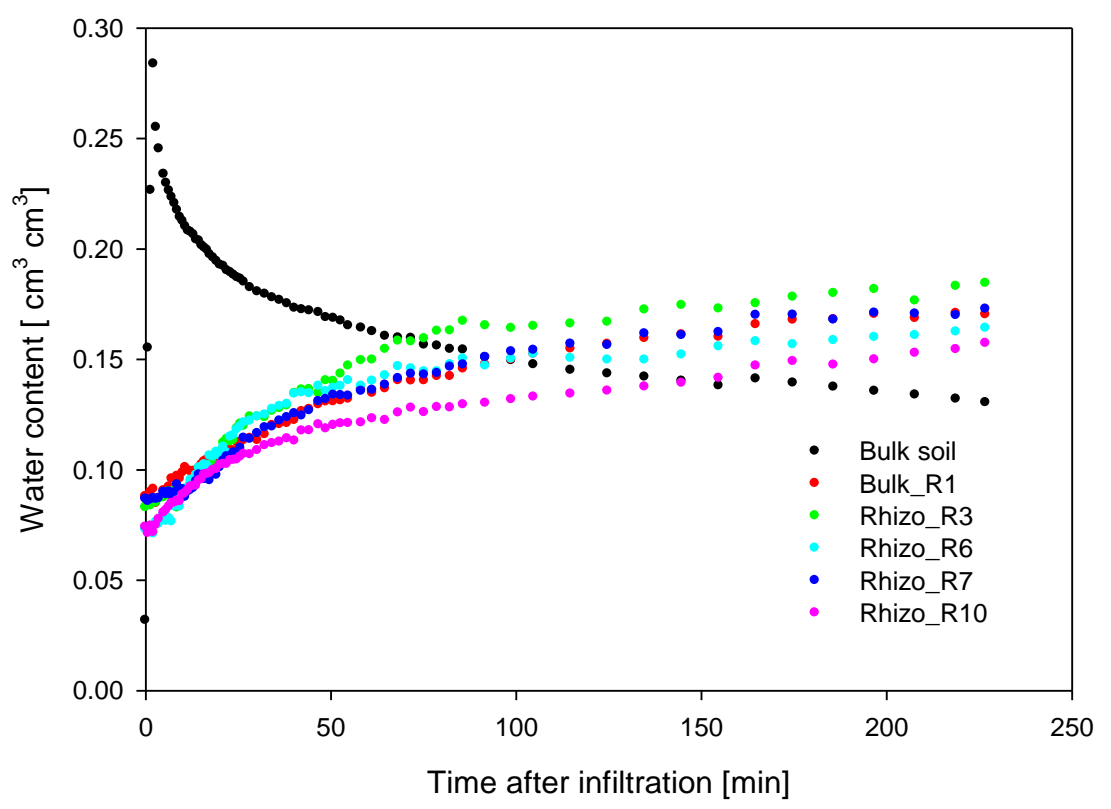

Figure 4: Average water content in the rhizosphere and in the bulk soil after infiltration. Water content in the rhizosphere was initially higher than in the bulk soil. After rewetting, the rhizosphere remained markedly drier than the bulk soil and re-watered slowly with time and finally the water content exceeded that of the bulk soil.

The changes in root volumes after infiltration are shown in Figure 5a. The changes in volume of roots were taken as an indication of water flux into roots. The results showed that the volume of roots stayed rather constant for 10-15 min after infiltration, indicating that there was not significant water flux into the roots. Following infiltration, the swelling rate was initially slow and it became faster until it reached a constant value. We used these volumes to estimate the flux of water into the roots and the pressure in the roots. The pressure volume curve that we estimated from our data using (5.7) is shown in Figure 5b. This curve suggested that the change in the root volume as a function of change in root pressure was big at more negative potentials and became smaller at less negative water potentials. We calculated the hydraulic conductivities according to Eq. (5.6), using swelling rate of the roots. Figures 6a and $6 \mathrm{~b}$ show the effective hydraulic conductivity of the rhizosphere as a function of time after infiltration and water content in the rhizpshere, respectively. The effective hydraulic conductivity of the rhizosphere ranged between $1.5 \times 10^{-11}$ and $2.5 \times 10^{-9} \mathrm{~cm} \mathrm{~s}^{-1}$. Following rewetting of the rhizosphere, the effective hydraulic conductivity increased. The hydraulic conductivity of the bulk soil was calculated using retention curve of the soil and van Genechten-Mualem equation. At the same water content, the effective hydraulic conductivity of the rhizosphere was 4 to 5 orders of magnitude smaller than the one of the bulk soil. 

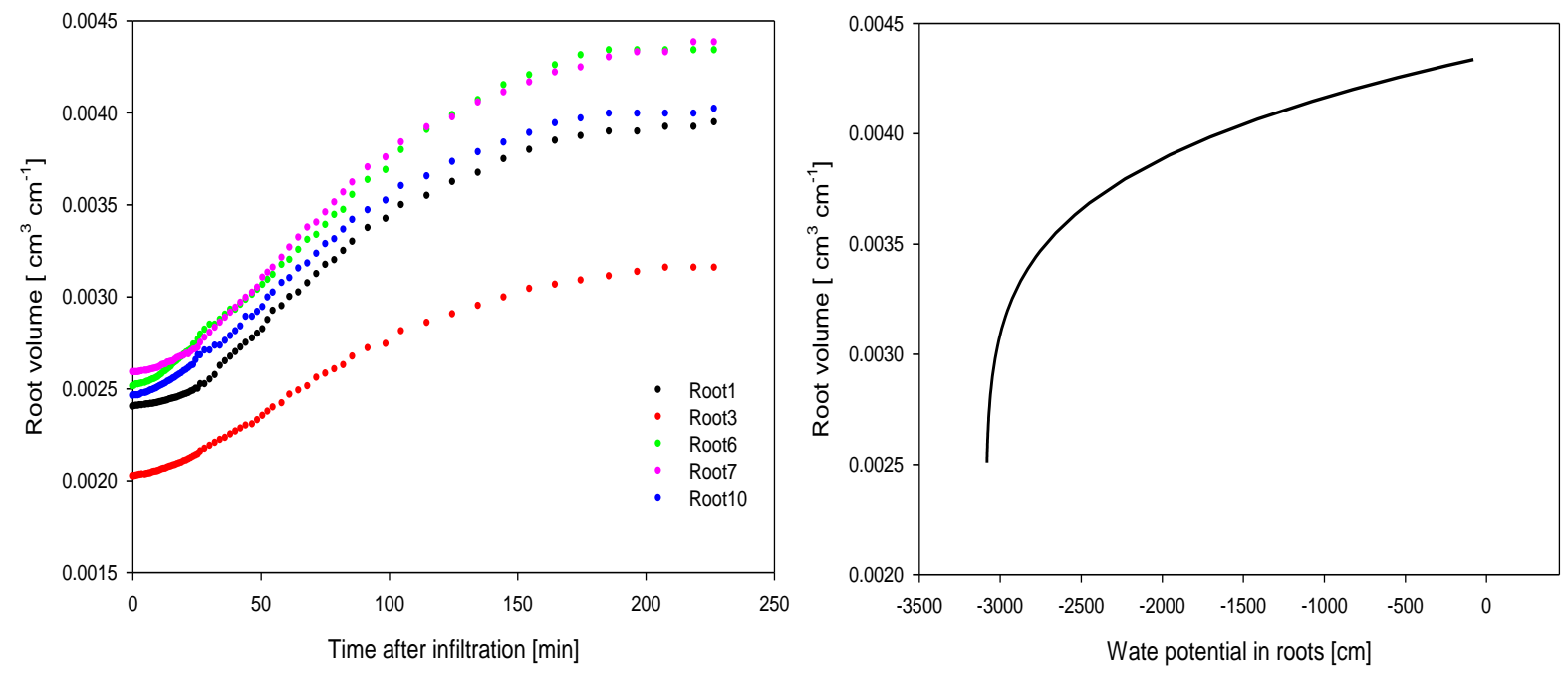

Figure 5: (a) Change in volume of roots after irrigation. (b) Volume-pressure curve of the Lupine roots parameterized according to Eq. (5.7).
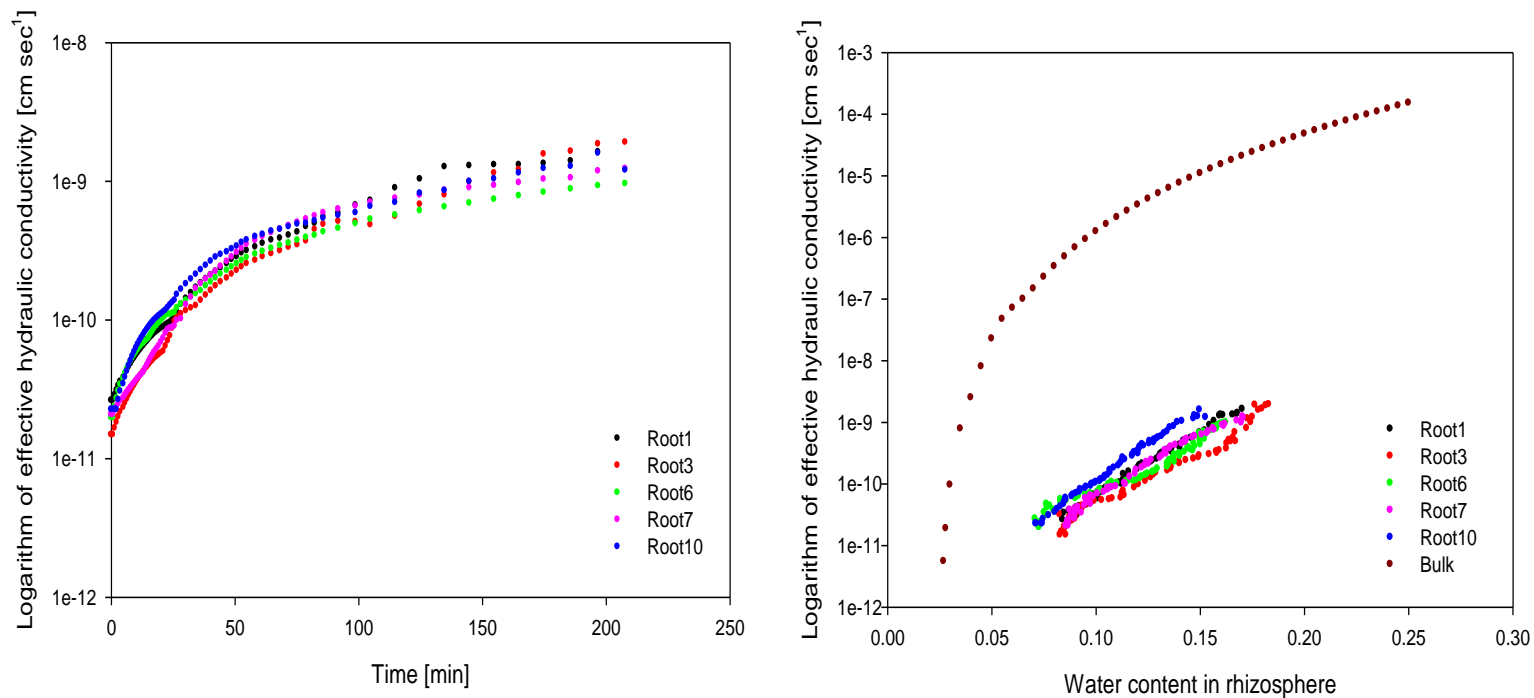

Figure 6: Effective hydraulic conductivity of the rhizosphere as a function of time after irrigation (a), and as a function of water content in the rhizosphere (b). 


\section{Discussion}

Although the ability of plants to take up water from the soil is influenced by the hydraulic properties of the soil in the immediate vicinity of the root. To date, it has been technically difficult to quantify the effect of hydrophobicity of the rhizosphere on hydraulic properties of the soil. This information is urgently required for a better understanding and modelling of water flow from soil to roots. We previously showed that flux of water into roots was reduced as the rhizosphere bocame hydrophobic. We explained the reduction of flux by low hydraulic conductivity of the rhizosphere following a rewetting cycle. To test our hypothesis, we introduced a technique to estimate effective hydraulic conductivity of the rhizosphere following a rewetting cycle. To this end, we monitored the distribution of water in soil and root following a rewetting cycle. Consistent with previous observations (Carminati et al., 2010; Moradi et al., 2011, 2012), we found that the rhizosphere held more water than the bulk soil during drying cycle and it stayed temporarily drier than the bulk soil during rewetting cycle. The hydrophobicity reported by Carminati et al. (2010) and Moradi et al. (2012) stayed for more than a day following rewetting cycle while in our case the recovery seemed to be faster. The difference can be due to the different energy state of water in soil. They infiltrated the samples by capillary rise from bottom while we infiltrated our samples from the top by applying a positive pressure.

We estimated the effective hydraulic conductivity of the rhizosphere from the swelling rate of roots. The results showed that the effective hydraulic conductivity of the rhizosphere was 4-5 order of magnitude smaller than one of the bulk soil and it recovered slowly with time. We explained the low effective hydraulic of rhizosphere due to the temporal hydrophobicity of the rhizosphere based on the literature evidences which showed a low wettability of the rhizosphere (Hallett et al., 2003; Read et al., 2003; Moradi et al., 2012). However, one may also explain this low hydraulic partly by formation of air gaps due to shrinkage of roots in dry soil (Nobel \& Cui, 1992; Nye, 1994; North \& Nobel, 1997; Carminati et al., 2009). Degree of hydrophobicity of the rhizosphere depends on the chemical component of the mucilage, soil texture, water content, and drying/wetting cycles. Plants exudate vast ranges of chemicals in soil. There has not been any evidences in the literatures if the quantity and quality of the root exudate changes in response to environmental conditions such as water stress. We expect a higher degree of hydrophobicity in the rhizosphere of sandy soil than clay soil, because the surface area of sand particles for a given volume is smaller and therefore less volume of the mucilage is needed to cover the soil particles (Ritsema \& Dekker, 2003). It is also known that 
the degree of water repellency of organic matter in particular lipid component is a function of water content (Ritsema \& Dekker, 2003), but it is not known to us if there is a critical water content that the rhizosphere turns hydrophobic resulting in low hydraulic conductivity, or its hydraulic conductivity is continuously lower than the bulk soil.

The consequences of the temporarily low hydraulic conductivity of the rhizosphere for plants, at the first glance, seem to be negative, as it may limit the flow of water into the roots that were under prolonged water stress (see previous chapter). However, this phenomenon can be interpreted differently: a hydrophobic rhizosphere with a low hydraulic conductivity may build up an additional resistance to prevent back flow of water from the roots into the soil. Let us imagine a deep rooted plant growing in soil. Our finding on distribution of water uptake zone along roots showed that the basal segments of roots near the soil surface are initially more involved in root water uptake. These regions become dry quicker while deeper roots are still in contact with water. Hydraulic isolation of roots in contact with dry soil will shift the uptake zone to distal roots in deep soil and may improve the overall hydraulic performance of the plant.

Eq. 5.6 gives the hydraulic conductivity of the rhizosphere at the condition that the hydraulic conductivity of the roots is much bigger than the one of the rhizosphere. Otherwise the hydraulic conductivity will be effective hydraulic conductivity of the soil-root continuum, The flow of water into roots has to overcome two resistances in series: the rhizosphere and the root tissue. The flow of water into roots will be controlled by the bigger resistance. We did not measure the resistance of roots but we have arguments to believe that the resistance across the hydrophobic rhizosphere was controlling the flow during the rewetting phase. We found that the effective hydraulic conductivity increased two orders of magnitude with time. This rather big recovery is difficult to explain with changes in root resistance and aquaporins. The literature indicates that even after complete blockage of aquaporines, root permeability reduced up to 80\% (Martre et al., 2001; Bramley et al., 2009; Knipfer et al., 2011). However, root hydraulic conductivity reduces in response to dry condition (Huang \& Nobel, 1993; McLean future, 2011). In the future, the resistance of roots and the pressure volume curve of roots can be independently measured which will improve the calculations. 


\section{Appendix}

To reduce the complexity of the measurement, we repeated the same experiment when we infiltrated the sample from the top with a constant infiltration rate. This helped us to keep the water content in the bulk soil constant over time. Neutron radiographs of one sample following of a repeating cycle are shown in Figure 7.

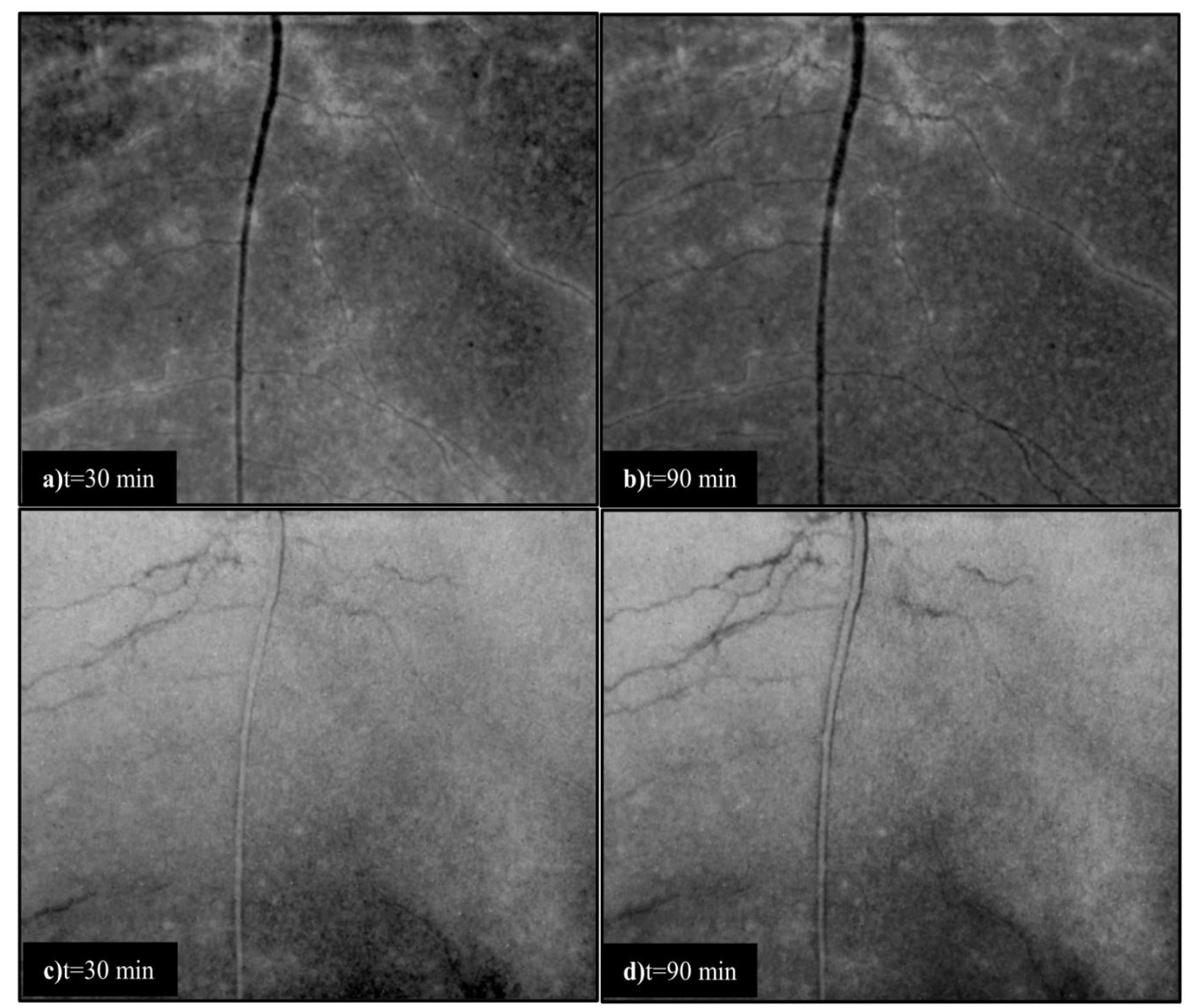

Figure 7: Neutron radiographs of a sample after rewetting at time $t$ (7a and $7 b)$. Images $7 b$ and $7 b$ are a close up of the original neutron radiographs. In these images the darker color corresponds to a high water content in the soil. The bright region around roots indicates a slow rewetting of the rhizosphere. Images $7 \mathrm{c}$ and $7 \mathrm{~d}$ are the differences between actual radiographs at time $t$ and the one 15 minutes after infiltration when the bulk soil reached to a constant water content. Images $7 \mathrm{c}$ and $7 \mathrm{~d}$ show the changes in water content in both soil and roots over time. The darker is the image, the bigger is the change in water content over time. The images are a close up of the original field of view of $(15.5 \times 15.5 \mathrm{~cm})$ 


\section{References}

Bramley, H., Turner, N.C., Turner, D.W., \& Tyerman, S.D. 2009. Roles of morphology, anatomy, and aquaporins in determining contrasting hydraulic behavior of roots. Plant Physiol. 150, 348-364.

Carminati, A. 2012. A Model of Root Water Uptake Coupled with Rhizosphere Dynamics. Vadose Zone J. 11Available

Carminati, A., Moradi, A.B., Vetterlein, D., Vontobel, P., Lehmann, E., Weller, U., Vogel, H.-J., \& Oswald, S.E. 2010. Dynamics of soil water content in the rhizosphere. Plant Soil 332, 163-176.

Carminati, A., Schneider, C.L., Moradi, A.B., Zarebanadkouki, M., Vetterlein, D., Vogel, H.J., Hildebrandt, A., Weller, U., Schüler, L., \& Oswald, S.E. 2011. How the Rhizosphere May Favor Water Availability to Roots. Vadose Zone J. 10, 988-998.

Carminati, A., Vetterlein, D., Weller, U., Vogel, H.-J., \& Oswald, S.E. 2009. When Roots Lose Contact. Vadose Zone J. 8, 805.

Chenu, C. 1993. Clay-or sand-polysaccharide associations as models for the interface between micro-organisms and soil: water related properties and microstructure. Geoderma 56, $143-156$.

Czarnes, S., Hallett, P.D., Bengough, A.G., \& Young, I.M. 2000. Root-and microbial-derived mucilages affect soil structure and water transport. Eur. J. Soil. Sci. 51, 435-443.

Gardner, W.R. 1960. Dynamic aspects of water availability to plants. Soil Sci. 89, 63-73.

Gregory, P.J. 2006. Roots, rhizosphere and soil: the route to a better understanding of soil science? Eur. J. Soil. Sci. 57, 2-12.

Hallett, P.D., Gordon, D.C., \& Bengough, A.G. 2003. Plant influence on rhizosphere hydraulic properties: direct measurements using a miniaturized infiltrometer. New Phytol. 157, 597-603.

Knipfer, T., Besse, M., Verdeil, J.-L., \& Fricke, W. 2011. Aquaporin-facilitated water uptake in barley (Hordeum vulgare L.) roots. J. Exp. Bot. 62, 4115-4126.

MacFall, J.S., Johnson, G.A., \& Kramer, P.J. 1990. Observation of a water-depletion region surrounding loblolly pine roots by magnetic resonance imaging. Proc. Natl. Acad. Sci. USA 87, 1203. 
Martre, P., North, G.B., \& Nobel, P.S. 2001. Hydraulic conductance and mercury-sensitive water transport for roots of Opuntia acanthocarpa in relation to soil drying and rewetting. Plant Physiol. 126, 352-362.

McCully, M.E., \& Boyer, J.S. 1997. The expansion of maize root-cap mucilage during hydration. 3. Changes in water potential and water content. Physiol. Plantarum 99, 169-177.

Menon, M., Robinson, B., Oswald, S.E., Kaestner, A., Abbaspour, K.C., Lehmann, E., \& Schulin, R. 2007. Visualization of root growth in heterogeneously contaminated soil using neutron radiography. Eur. J. Soil. Sci. 58, 802-810.

Moradi, A.B., Carminati, A., Lamparter, A., Woche, S.K., Bachmann, J., Vetterlein, D., Vogel, H.J., \& Oswald, S.E. 2012. Is the rhizosphere temporarily water repellent? Vadose Zone J. 11.

Moradi, A.B., Carminati, A., Vetterlein, D., Vontobel, P., Lehmann, E., Weller, U., Hopmans, J.W., Vogel, H.-J., \& Oswald, S.E. 2011. Three-dimensional visualization and quantification of water content in the rhizosphere. New Phytol. 192, 653-663.

Nakashi, T.M. 2005. Water gradient profiles at bean plant roots determined by neutron beam analysis. J. Radioanal. Nucl. Chem. 264, 313-317.

Nobel, P.S., \& Cui, M. 1992. Hydraulic conductances of the soil, the root-soil air gap, and the root: changes for desert succulents in drying soil. J. Exp. Bot. 43, 319-326.

North, G.B., \& Nobel, P.S. 1997. Drought-induced changes in soil contact and hydraulic conductivity for roots of Opuntia ficus-indica with and without rhizosheaths. Plant and soil 191, 249-258.

Nye, P.H. 1994. The effect of root shrinkage on soil water inflow. Philos. T. Roy. Soc. B. 345, 395-402.

Or, D., Phutane, S., \& Dechesne, A. 2007. Extracellular polymeric substances affecting porescale hydrologic conditions for bacterial activity in unsaturated soils. Vadose Zone J. 6, 298-305.

Read, D.B., Bengough, A.G., Gregory, P.J., Crawford, J.W., Robinson, D., Scrimgeour, C.M., Young, I.M., Zhang, K., \& Zhang, X. 2003. Plant roots release phospholipid surfactants that modify the physical and chemical properties of soil. New Phytol. 157, $315-326$.

Read, D.B., \& Gregory, P.J. 1997. Surface tension and viscosity of axenic maize and Lupine root mucilages. New Phytol., 623-628.

Read, D.B., Gregory, P.J., \& Bell, A.E. 1999. Physical properties of axenic maize root mucilage. Plant Soil 211, 87-91.

Ritsema, C.J., \& Dekker, L.W. 2003. Soil water repellency: Occurrence, consequences, and amelioration. Elsevier Science.

Segal, E., Kushnir, T., Mualem, Y., \& Shani, U. 2008. Microsensing of water dynamics and root distributions in sandy soils. Vadose Zone J. 7, 1018-1026. 
Stadelmann, E.J. 1984. The derivation of the cell wall elasticity function from the cell turgor potential. J. Exp. Bot. 35, 859-868.

Watt, M., McCully, M.E., \& Canny, M.J. 1994. Formation and stabilization of rhizosheaths of Zea mays L.(Effect of soil water content). Plant Physiol. 106, 179-186.

Whalley, W.R., Leeds-Harrison, P.B., Leech, P.K., Riseley, B., \& Bird, N.R.A. 2004. The Hydraulic Properties of Soil At Root-Soil Interface. Soil Sci. 169, 90-99.

Whalley, W.R., Riseley, B., Leeds-Harrison, P.B., Bird, N.R.A., Leech, P.K., \& Adderley, W.P. 2005. Structural differences between bulk and rhizosphere soil. Eur. J. Soil. Sci. 56, 353-360.

Young, I.M. 1995. Variation in moisture contents between bulk soil and the rhizosheath of wheat (Triticum aestivum L. cv. Wembley). New Phytol. 130, 135-139. 


\section{Final conclusions}





\section{Summary}

In this thesis, a new method was developed and applied to measure the local flux of water into the roots of plants growing in soil. The method consists of injecting deuterated water $\left(\mathrm{D}_{2} \mathrm{O}\right)$ in the soil and tracing its transport into the roots by a time-series neutron radiography. The experiments were performed at different locations of lupine roots during daytime (transpiring plants) and nighttime (non-transpiring plants). The objective of the thesis was to derive the net flow of water into the roots (radial flux). A simple diffusion-convection model was developed to describe the transport of $\mathrm{D}_{2} \mathrm{O}$ into the roots. In the model, the increase rate of $\mathrm{D}_{2} \mathrm{O}$ concentration in the roots depends on convective (net root water uptake) and diffusive transport of $\mathrm{D}_{2} \mathrm{O}$. The model predicted that the concentration of $\mathrm{D}_{2} \mathrm{O}$ in roots increases as the sum of two exponentials. The exponential rates depended on the radial flux of water into the roots, the axial flux of water along the roots, and the permeability of the root tissue. The technique was applied to map the fluxes of water into the different locations of roots to answer the long-standing questions: (i) where roots take up water from soil; and (ii) how the rhizosphere affects root water uptake.

The measurements showed that root water uptake was not uniform along the root system. Uptake rate was higher in the upper root zone near the soil surface and it decreased towards the deep root segments. Along individual roots, water uptake was higher in the proximal parts and it decreased towards the distal parts. The changes in water uptake with distance along lateral roots were higher than the changes along the taproot in depth. This suggests a functional role of the taproot in collecting water from deep root segments and transporting it to the shoots. Due to the porous nature of roots, the relative importance of radial and axial resistances determines the profile of water uptake along the roots. A high ratio of the radial to the axial resistance of the proximal parts of roots, as it was observed along the taproot, will distribute water uptake zone towards the distal parts. This ratio is expected to change with root maturation and boundary conditions, such as soil moisture.

The method was applied to assess the effect of the rhizosphere on root water uptake after drying and consequent rewetting. This experiment rooted from unexpected observations of water dynamics in the rhizosphere during a drying/wetting cycle. Our results confirmed that the rhizosphere of roots stayed temporarily dry upon rewetting which was explained with hydrophobicity of the rhizosphere. The next question was: does such hydrophobicity affect the rhizosphere conductivity and the fluxes of water into the root? As a first step, a new 
method was introduced to estimate the effective hydraulic conductivity of the roots from the swelling rate of the roots during a rewetting period, which followed a severe drying. The swelling rates of the roots and rewetting of the rhizosphere were monitored by means of neutron radiography. After rewetting, the hydraulic conductivity of the rhizosphere remained markedly lower than that of the bulk soil, and it partly increased as the rhizosphere rewetted. To answer the question about the effects of hydrophobicity on root water uptake, the transport of $\mathrm{D}_{2} \mathrm{O}$ into roots crossing a dry and a wet rhizosphere was monitored. The experiments showed that flux of water across a hydrophobic rhizosphere were reduced by a factor of 4 and 8 in short roots (length of 16-17 cm ) and long roots (length of 9-10 cm), respectively. These results demonstrate for the first time that the rhizosphere affects water availability to plants. Hydrophobicity of the rhizosphere may have positive or negative effects on root water uptake. At first glance, the reduction of water into the roots after rewetting should have a negative impact on the plant water balance. However, it may have positive effect for plants growing in deep soil with water stored in the subsoil by temporarily shifting water uptake zone down towards the distal parts of the roots in depth and preventing the back flow of water from the upper roots in contact with the dry top soil.

\section{Limitations of the method}

Calculation of root water uptake based on $\mathrm{D}_{2} \mathrm{O}$ transport into roots is not trivial and needs the support of convection-diffusion models. We found that there is no way to interpret this data without taking into account the structure of the roots. Our model is generalized to the composite transport of water in the radial direction and it allows a varying importance of the apoplastic and cell-to-cell pathways. The model was initially thought for roots in which the apoplastic pathway was the dominant flow path. The model needs to be validated for the case in which transport of $\mathrm{D}_{2} \mathrm{O}$ into roots is purely cell-to-cell.

Application of this technique is limited to relatively wet soils. This is due to the increase of soil water content after injection of $\mathrm{D}_{2} \mathrm{O}$. The increase of soil water content after injection will induce a significant gradient in water potential between soil and roots. In this case, the flux of water into root will be overestimated. Here, we selected a sandy soil in which the change in water potential following $\mathrm{D}_{2} \mathrm{O}$ injection was negligible compared to typical water potentials in the xylem. 
To quantify transport of $\mathrm{D}_{2} \mathrm{O}$ into roots we introduced a simple diffusion-convection model that assumes: (i) quick diffusion of $\mathrm{D}_{2} \mathrm{O}$ in the apoplastic pathways of the root cortex; (ii) the diffusional permeability of cell membranes is constant at the daytime and the nighttime (independent from transpiration rate). We discussed the validity of these assumptions for lupine roots in details in chapters 2 and 3. Application of this technique to roots with a dominant cell-to-cell pathway will probably need an adaptation of the model.

\section{Outlooks}

In this study, we developed a new technique to measure the local flux of water into the roots. The technique was applied to answer the question about where roots take up water from soil and how rhizosphere affects water uptake.

This technique has a high potential to solve long-standing questions about water relations of soil and plants under varying and more complex environmental conditions. Future applications include:

1- Application to other plants than lupines. Comparison between taprooted and fibrous root systems will reveal the hydraulic functions of different root system.

2- Architectural models of root water uptake are typically lacking of experimental information on the properties of individual roots. Using the fluxes of water into roots that are measured with neutron radiography and $\mathrm{D}_{2} \mathrm{O}$, is possible to inversely calculate the distribution of resistances (radial and axial) along the roots.

3- Here, as a first attempt, we averaged transport of $\mathrm{D}_{2} \mathrm{O}$ along the root length that was immersed in $\mathrm{D}_{2} \mathrm{O}$. In future, it will be possible to numerically solve the diffusionconvection equations along the root length. The concentration of $\mathrm{D}_{2} \mathrm{O}$ in the roots will be fitted locally. This procedure will give information not only about the distribution of fluxes along the root length immersed in $\mathrm{D}_{2} \mathrm{O}$ but also the root length beyond that segment. In this way, the capillary barriers may not be used anymore, as the boundary conditions do not need to be constant in time.

4- The technique can be applied to the roots growing in soils with heterogeneous water content. It would be interesting to see how the water uptake zone moves as parts of the soil become dry. Does water uptake move towards the more distal parts along laterals or along depth? 
5- It was found that water uptake by roots was restricted as the rhizosphere became dry. Application of the technique to roots grown at different water contents may reveal whether or not the hydrophobicity can be an adaptive strategy of plants. This would be possible by comparing the flux of water into roots imposed to different drying cycle during their growth period. If modifying the rhizosphere is an adaptive strategy of plants responding to drought stress it should be more pronounced in the samples with more drying cycle.

6- This technique can be used to investigate the effect of nutrients, salinity, root maturation, and other external condition on root permeability and root water uptake. 


\section{Curriculum Vitae}

Surname : Zarebanadkouki

First name : Mohsen

Date of birth : 07 Sep 1983

Citizen of : Iran

\section{Education}

2002 - 2006 Bachelor's degree in Soil Science, Department of Soil Science, College of Agriculture, Vali-e-Asr University of Rafsanjan, Iran

2006 - 2009 Master's degree in Soil Science with specialization in Soil Physics, Soil

Science Department, College of Agriculture, Isfahan University of Technology, Isfahan, Iran

2009-2013 Doctoral students in the Soil Hydrology Division of George August University of Göttigen, Germany 